\title{
Die Krise des demokratischen Rechtsstaats im 21. Jahrhundert
}

Tagung des Jungen Forums Rechtsphilosophie (JFR) in der Internationalen Vereinigung für Rechtsund Sozialphilosophie (IVR) im April 2019 in Salzburg

Herausgegeben von Kristin Y. Albrecht, Lando Kirchmair und Valerie Schwarzer 
8 
Archiv für Rechts- und Sozialphilosophie Archives for Philosophy of Law and Social Philosophy Archives de Philosophie du Droit et de Philosophie Sociale Archivo de Filosofía Jurídica y Social

Herausgegeben von der Internationalen Vereinigung für Rechtsund Sozialphilosophie (IVR)

Redaktion: DR. ANNETTE BROCKMÖLLER, LL.M.

Beiheft 164 


\section{DIE KRISE DES}

DEMOKRATISCHEN RECHTSSTAATS

IM 21. JAHRHUNDERT

oder

\section{WIE SICH DIE GESCHICHTE GEGEN IHR ENDE WEHRT}

Tagung des Jungen Forums Rechtsphilosophie (JFR) in der Internationalen Vereinigung für Rechts- und Sozialphilosophie (IVR) im April 2019 in Salzburg

Herausgegeben von Kristin Y. Albrecht, Lando Kirchmair und Valerie Schwarzer

Franz Steiner Verlag 
Mit Unterstützung des Open Access-Publikationsfonds der Universität Salzburg veröffentlicht.

Dieses Buch ist eine Open-Access-Publikation.

\section{(c) $\frac{1}{\mathrm{BY}}(\mathrm{NC})$}

Dieses Werk ist lizenziert unter einer Creative Commons Namensnennung Nicht kommerziell - Keine Bearbeitungen 4.o International Lizenz.

https://creativecommons.org/licenses/by-nc-nd/4.o/deed.de

Umschlagbild: Justitia, Landgericht Ulm

Quelle: shutterstock.com / Georg_89

Bibliografische Information der Deutschen Nationalbibliothek:

Die Deutsche Nationalbibliothek verzeichnet diese Publikation in der Deutschen Nationalbibliografie; detaillierte bibliografische Daten sind im Internet über $<$ http://dnb.d-nb.de> abrufbar.

Dieses Werk einschließlich aller seiner Teile ist urheberrechtlich geschützt.

Jede Verwertung außerhalb der engen Grenzen des Urheberrechtsgesetzes ist unzulässig und strafbar.

(C) Franz Steiner Verlag, Stuttgart 2020

Layout und Herstellung durch den Verlag

Satz: DTP + TEXT Eva Burri, Stuttgart

Druck: Beltz Grafische Betriebe, Bad Langensalza

Gedruckt auf säurefreiem, alterungsbeständigem Papier.

Printed in Germany.

ISBN 978-3-515-12670-o (Print)

ISBN 978-3-515-12674-8 (E-Book)

https://doi.org/10.25162/9783515126748 


\section{Inhaltsverzeichnis}

\section{Einleitung}

KRISTIN Y. ALBRECHT / LANDO KIRCHMAIR / VALERIE SCHWARZER

Die Krise des demokratischen Rechtsstaats im 21. Jahrhundert

Oder: wie sich die Geschichte gegen ihr Ende wehrt..................... 11

\section{Prolog}

FRANCIS FUKUYAMA

Warum hält die Demokratie nicht, was sie verspricht? ................ 23

III. Die Grundlagen des demokratischen Rechtsstaates und dessen Krise

HOLGER GREFRATH / CLARA MAIER

Demokratie als Attribut

Zur Theorie des demokratischen Rechtsstaates als Verfassungsprinzip...

JAKOB GAIGG

Transnationale verfassungsgebende Gewalt

Verfassungslyrik oder destituierende Gewalt

TIMO GREGER

Radikale Freiheit oder Leitkultur?

Individuelle Freiheit, kollektive Selbstbestimmung und normativer Grundkonsens.....

BENJAMIN SCHMID

Zeit und Raum als basale Problemfelder der Krise der Demokratie 101 
IV. Demokratische Teilhabe und Weltanschauung als Problem und Lösungsansatz

BERIT VÖLZMANN

Partizipation durch Mobilisierung

Gerichte als Teil demokratischer Deliberation.

NULA FREI

Die direkte Demokratie zwischen Populismus und Rechtsstaat

Demokratietheoretische Wege aus der "Populismuskrise“.

SEBASTIAN ENGHOFER

Demokratie und Weltanschauung

Zur Krise des demokratischen Charakters... 151

\section{Antagonisten des demokratischen Rechtsstaats}

KARSTEN SCHUBERT

„Political Correctness" als Kern der Politik

Mit Nietzsche gegen die neue Rechte. . 167

DÓRA FREY

Eine illiberale Demokratie und ihre Vorbilder?

Die ungarische historische Verfassung in Theorie und Praxis 177

\section{Internationale Aspekte}

MELISSA MULLER

Polarisierung als potentielle Herausforderung für den Verfassungspatriotismus Eine vergleichende Analyse zwischen Deutschland und den USA

BRUNO TADEU BUONICORE

Formaler vs. konkreter Staatsbürger

Die Problematik des sub-citizen und der Legitimation der Staatsgewalt im Rahmen der sogenannten Latin American peripheral modernity................. 211

MARIA BERTEL

Demokratie, Korruption und Populismus

Oder: Weshalb Montesquieu Recht behält... 
VII. Epilog

HEINZ FISCHER

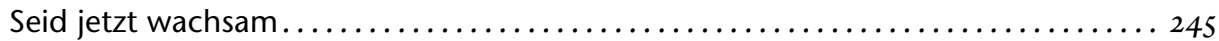

Herausgeber*innen und Autor*innen $\ldots \ldots \ldots \ldots \ldots \ldots \ldots \ldots \ldots \ldots \ldots \ldots \ldots \ldots \ldots \ldots$ 

I. Einleitung 



\title{
Die Krise des demokratischen Rechtsstaats im 21. Jahrhundert \\ Oder: wie sich die Geschichte gegen ihr Ende wehrt
}

\author{
KRISTIN Y. ALBRECHT / LANDO KIRCHMAIR / \\ VALERIE SCHWARZER
}

\section{Einleitung}

Noch vor über 15 Jahren erschien es als Selbstverständlichkeit, dass die Welt sich zum „gemeinsame[n] Humane[n]“ entwickeln „und damit Friede und Sicherheit, diese

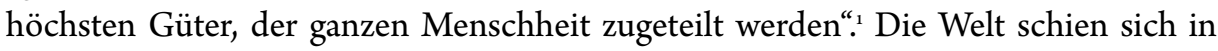
einem „geraden und unfehlbaren Weg zur ,besten aller Welten“ “ zu befinden. . Ganz in diesem Sinn fragte Francis Fukuyama 1989, ob dies bereits das Ende der Geschichte sei ${ }^{3}$ und bejahte dies postwendend: „Was wir erleben ist nicht nur das Ende des kalten Krieges, oder das Ende einer bestimmten Nachkriegshistorie, sondern das Ende der Geschichte als solcher" ${ }^{4}$. Mit dieser These, die weltweit für großes Aufsehen sorgte und bis heute kontrovers diskutiert wird, meinte Fukuyama nicht, dass es keine undemokratischen Ereignisse oder Rückschläge mehr geben werde, sondern vielmehr,

1 Stefan Zweig, Die Welt von Gestern. Erinnerungen eines Europäers, 4. Aufl. 2015, 18.

2 Ibid, 17.

3 Francis Fukuyama, The End of History?, National Interest 16 (1989), 3 (4) „What we may be witnessing is not just the end of the Cold War, or the passing of a particular period of postwar history, but the end of history as such: that is, the end point of mankind's ideological evolution and the universalization of Western liberal democracy as the final form of human government. This is not to say that there will no longer be events to fill the pages of Foreign Affairs's yearly sum maries of international relations, for the vic tory of liberalism has occurred primarily in the realm of ideas or consciousness and is as yet incomplete in the real or material world. But there are powerful reasons for believing that it is the ideal that will govern the material world in the long run." [Hervorhebung im Original]."

4 Ibid. 
dass die parlamentarische Demokratie konkurrenzlos und sohin „das Ende der ideologischen menschlichen Entwicklung und die Universalisierung westlicher liberaler Demokratien als die finale Form der menschlichen Regierungsform“ erreicht sei. ${ }^{5}$ Die letzte Synthese, durch die „alle wirklich großen Fragen endgültig geklärt“ seien, war proklamiert. ${ }^{6}$ Der Gang der Geschichte schien diese Einschätzung zu bestätigen: Von 1970 bis 2000, speziell nach dem Zusammenbruch der UdSSR und des Kommunismus 1989, stieg die Zahl der repräsentativen Demokratien von 35 auf fast $120 .^{7}$

$\mathrm{Zu}$ Beginn des 21. Jahrhunderts ist dieser Optimismus verblasst. ${ }^{8}$ Vielfach wird das, was wir zurzeit erleben, als eine veritable Krise der Demokratie und des Rechtsstaats gedeutet. ${ }^{9}$ Diese Krise zu diagnostizieren bzw. an bestimmten einschlägigen Entwicklungen festzumachen, ist allerdings ein äußerst schwieriges Unterfangen. ${ }^{10}$

Man stelle sich folgendes Szenario vor: Die AfD ist seit einem guten Jahr in Regierungsverantwortung; die Bundesministerin des Auswärtigen ist Frauke Petry. Zu ihrer Hochzeit lädt sie Wladimir Putin ein, tanzt mit ihm und bedankt sich hierfür mit einem tiefen Knicks; der Bundesminister des Inneren, Alexander Gauland, gibt eine interne Devise aus, die an die Öffentlichkeit gerät: Den so genannten „kritischen Medien“ sollen nicht mehr alle Informationen zugespielt werden und der Informationsfluss aus dem Innenministerium solcherart klar zu Gunsten „regierungsfreundlicher“ Medien gesteuert werden.

Ist man mit solch einem dystopischen Gedankenspiel zu schwarzmalerisch? Einige sind sich sicher, dass sich eine derartige Situation glücklicherweise wohl nie zutragen werde. Sollte man dementsprechend auch den Titel dieses Bandes ändern und den ihm innewohnenden, die Krise bereits feststellende Charakter, abschwächen? Sofern die genannten Parteien und Personen als Platzhalter verstanden werden, wird schlag-

5 Ibid.

6 Francis Fukuyama, Das Ende der Geschichte. Wo stehen wir?, 1992, 13.

7 Francis Fukuyama, Identität - Wie der Verlust der Würde unsere Demokratie gefährdet, 2019, 11.

8 Siehe dazu den Bericht von Freedomhouse, Democracy in Retreat - Freedom in the World 2019 (2019), abrufbar unter https://freedomhouse.org/sites/default/files/Feb2019_FH_FITW_2019_Report_ForWeb -compressed.pdf [zuletzt abgerufen am 22. September 2019]; vgl. dazu auch Fukuyama, (Fn. 7) 2019, 11; sowie Mark A Graber, Sanford Levinson und Mark Tushnet (Hrsg), Constitutional Democracy in Crisis?, 2018.

9 Vgl. aus der rapide anwachsenden Literatur nur Philipp Blom, Was auf dem Spiel steht, 2017; Aziz Z Huy und Tom Ginsburg, How to Save a Constitutional Democracy, How to Lose a Constitutional Democracy, California Law Review (2018), 78; Steven Levitsky und Daniel Ziblatt, How Democracies Die, 2018; Yascha Mounk, The People vs Democracy. Why Our Freedom is in Danger and How to Save It, 2018; David Runciman, How Democracy Ends, 2018; Nancy Fraser, Die Krise der Demokratie: Über politische Widersprüche des Finanzmarktkapitalismus jenseits des Politizismus, in: Was stimmt nicht mit der Demokratie?, hrsg. v. Hanna Ketterer/Karina Becker, 2019, 77-99 (77).

10 Vgl. für eine kritische Analyse des Begriffs der Krise, insbesondere mit Fokus auf die Demokratie, bspw Wolfgang Merkl (Hrsg.), Demokratie und Krise. Zum schwierigen Verhältnis von Theorie und Empirie, 2015. Vgl. für Stimmen, welche sich um adäquate Gegenmittel zu dieser Entwicklung bemühen, bspw Tom Ginsburg und Aziz Z Huy, How to Save a Constitutional Democracy?, 2018; oder András Jakab, Was kann Verfassungsrecht gegen die Erosion von Demokratie und Rechtsstaatlichkeit tun?, Zeitschrift für Öffentliches Recht 74 (3) (2019), 369-397. 
artig klar, welche Entwicklung mit dem Gedankenexperiment veranschaulicht werden sollte: Das im Rahmen der XVII. JFR-Tagung 2019 behandelte Thema der Krise des demokratischen Rechtsstaates wird zunehmend als schleichendes Phänomen begriffen. Nicht ein einziger Putsch bringt den demokratischen Rechtsstaat im 21. Jahrhundert ins Wanken. Trotz nach demokratischen Standards abgehaltenen Wahlen schreitet die langsame Erosion von rechtsstaatlichen und demokratischen Grundprinzipien voran." Ein Nachteil dieser (teilweise) langsam voranschreitenden Entwicklung ist ein gradueller Anpassungsprozess an die damit einhergehenden destruktiven Begleiterscheinungen. Man gewöhnt sich an die neue politische Sprache, an ein Klima der Verrohung sowie an die ein oder andere - mitunter empfindliche - Einschränkung von Verfassungstraditionen. Das eingangs erwähnte Gedankenspiel will aufzeigen, dass wir vielleicht gut daran tun, einzelne Entwicklungen nicht für sich, sondern in einem größeren Kontext zu betrachten und zu beurteilen. So können wir ein Verständnis dafür gewinnen, was Kim Lane Scheppele gemeint hat, als sie den Begriff des Frankenstate eingeführt hat: ${ }^{12}$ Die Aneinanderreihung von scheinbar hinnehmbaren Entwicklungen, welche für sich genommen manchmal sogar einer (mehr oder weniger überzeugenden) Rechtfertigung zugänglich sind, wie etwa eine politisch motivierte Besetzung von Verfassungsrichter*innen, eine Verschränkung der Gewalten, eine $\mathrm{Zu}$ spitzung politischer Kampagnen und eine besondere Hervorhebung oder gar Stigmatisierung bestimmter Gruppen, schafft in der Gesamtschau ein Monster.

Die zu Beginn aufgezählten Ereignisse waren leider keine Einzelfälle, sondern haben sich beispielsweise in Österreich 2019 monatlich ereignet. Unmittelbar vor der Tagung im April 2019 wurde in Braunau am Inn, dem Standort des vieldiskutierten Geburtshauses Hitlers, vom nun zurückgetretenen Vizebürgermeister ein unsägliches Gedicht veröffentlicht, in welchem Migrant*innen mit Ratten gleichgesetzt wurde. Während der Tagung hat ein österreichischer Spitzenpolitiker einem Journalisten in den Abendnachrichten für dessen kritische Nachfragen mit „Konsequenzen“ gedroht. Kurz nach der Tagung folgte das sog. „Ibiza-Video“, in welchem der ehemalige österreichische Vizekanzler die Beschneidung der Medien als Handelsgut dar- und seine Allmachtsphantasien und Korruptionsbereitschaft zur Schau stellte. Die davon ausgelösten Folgeerscheinungen, welche ua zum ersten Mal in Österreichs Geschichte zu einem Misstrauensvotum des Parlaments gegenüber der aktuellen Regierung führte, setzen diese Serie von Einzelfällen beispiellos fort.

11 Siehe zu eben dieser Erosion klar Jakab (Fn. 10). Vgl. ebenso Wojciech Sadurski, Poland's Constitutional Breakdown, 2019, welcher detailgetreu die Vorkommnisse in Polen schildert. Diese bezeichnet er allerdings als , anti-constitutionalist backsliding", da u. a. der Terminus Erosion zu passiv sei, und eben die verantwortlichen Akteure nicht ausreichend einbeziehe.

12 Kim Lane Scheppele, The Rule of Law and the Frankenstate: Why Governance Checklists Do Not Work, Governance 26 (2013), 559-562 (560). 
Eben dieser demokratische Rechtsstaat ist eine prägende zivilisatorische Errungenschaft. Während das freiheitlich-liberale, „westliche“ politische System vor knapp 30 Jahren noch als „das Ende der Geschichte“ ausgerufen und als End- und Höhepunkt der menschlichen Entwicklung gedeutet wurde, ${ }^{13}$ weist uns das junge 21. Jahrhundert auf die Fragilität dieser Errungenschaft hin. Wir erleben, wie sich demokratische Rechtsstaaten zu illiberalen Staaten rückentwickeln, demokratische Grundprinzipien in Frage gestellt und rechtsstaatliche Grundpfeiler angesägt werden. Mitten in Europa zeigen Ungarn und Polen, aber auch Rumänien und die Slowakei, dass der demokratische Rechtsstaat vorschnell als selbstverständlich vorausgesetzt wurde. Exemplarisch zeigen sich bei dem Aufstieg antidemokratischer Strömungen eine politisch motivierte Personalpolitik, ausufernde Korruption und die Aushebelung der verfassungsmäßig garantierten Unabhängigkeit der Gerichte sowie von Grund- und Menschenrechten angeführt werden. ${ }^{14}$ Als Krisenursachen werden u.a. Angst, fehlende Identität und ökonomische Ungleichheit diskutiert. Ist es letztendlich die fehlende ökonomische Gleichheit, die angesichts der sich immer weiter öffnenden Schere zwischen Arm und Reich als Krise ausdrückt? ${ }^{15}$ Oder ist die Ursache fehlende Anerkennung, welche nationalistische Parteien durch das scheinbare Angebot einer gemeinsamen Identität vermitteln? Der identitätsstiftende Kern des rechtsstaatlichen Prinzips, namentlich die Bindung der Politik an das Recht, sieht sich fortdauernder Belastung ausgesetzt. ${ }^{16}$

Auf Grund der Vielzahl dieser besorgniserregenden Ereignisse ist es von eminenter Bedeutung, diese Krise des demokratischen Rechtsstaates im 21. Jahrhundert zu analysieren und potentielle Antworten zu finden. Diese Entwicklungen sind auch keineswegs auf Europa beschränkt. Entwicklungen, wie beispielsweise in den USA, aber auch in Brasilien, zeugen von der globalen Tragweite dieses Phänomens. Wie kann diesen Angriffen auf den demokratischen Rechtsstaat begegnet werden? Stehen uns internationale oder supranationale Mittel zur Bewältigung dieser Krisensituation zur Verfügung? Wie können Antworten aussehen, wenn doch der freiheitliche Rechtsstaat von Voraussetzungen lebt, die er um seiner Freiheitlichkeit willen nicht (mehr) selbst garantieren kann? Das sind Fragen, welche die Autor*innen in diesem Beiheft beschäftigen. Die Beiträge setzen sich mit der historischen Dimension der Thematik auseinander und nehmen Gegenwartsanalysen vor, die auf konkrete Auswirkungen und zeitnah drohende Konsequenzen des angeführten Phänomens eingehen. In methodischer

13 Zunächst vor genau 30 Jahren Francis Fukuyama, The End of History? (Summer 1989) No 16 The National Interest 3-18; sowie anschließend monographisch Francis Fukuyama, The End of History and the Last Man (Free Press 1992).

14 Vergleiche für eine Enummeration von Krisenanzeichen Jakab (Fn. 10) sowie Sadurski (Fn. 10).

15 Zu den ökonomischen Auswirkungen hierzu eindringlich Joseph E. Stiglitz, The Great Divide, 2015.

16 Hierfür ist leider wiederum Österreich ein äußerst treffendes Beispiel, als der amtierende Innenminister meinte, dass sich immer noch das Recht der Politik und nicht die Politik dem Recht beugen müsse. Hierzu äußerst klar in seiner in diesem Beiheft als Epilog abgedruckten Festrede Heinz Fischer: dies ist schlicht falsch. Was der Innenminister hier beschrieben habe, sei einfach ein Rechtsbruch. 
Hinsicht ist es gelungen, das Tagungsthema in interdisziplinärer Weise zu analysieren. Insbesondere wird die (vermeintliche) Krise vor dem Hintergrund der Verbindung von Rechtsstaat und Demokratie und der Gleichursprünglichkeit von Volkssouveränität und Menschenrechten beleuchtet, wobei nicht davor zurückgescheut wird, zu untersuchen, ob es Demokratie ohne Rechtsstaat oder den Rechtsstaat ohne Demokratie geben kann. Gleichermaßen wird kritisch gefragt, weshalb von der Demokratie nur als Attribut des Rechtsstaats gesprochen wird.

Aktuelle Zeitungsberichte und TV-Beiträge unterstreichen die Brisanz des Tagungsthemas und seine Bedeutung im gesellschaftspolitischen Diskurs - weit über die rechtsphilosophischen Fachkreise hinaus. Es zeigt aber auch deutlich, dass die zu diesem Beiheft vereinigten und aus zahlreichen Einreichungen ausgewählten Beiträge die akademische und indirekt auch die gesellschaftliche Debatte hinsichtlich des Zustandes des demokratischen Rechtsstaats erheblich bereichern können. Es ist gelungen dafür sprechen zumindest die äußerst konstruktiven und lebhaften Diskussionen während der Tagung - in interdisziplinärer Weise Historiker*innen, Philosoph*innen, Politikwissenschaftler*innen und Rechtswissenschaftler*innen zum gemeinsamen Nachdenken über den demokratischen Rechtsstaat zu vereinen. Die Nachwuchswissenschaftler*innen haben sich aus Brasilien, Deutschland, Österreich, Ungarn, den USA und der Schweiz in Österreich eingefunden, um eben diese Krisenursachen und Lösungsansätze zu diskutieren.

\section{Prolog: Warum hält die Demokratie nicht, was sie verspricht?}

Eröffnet wird dieses Beiheft mit einem Prolog, in welchem Francis Fukuyama erläutert, warum die Demokratie aus seiner Sicht nicht hält, was sie verspricht. Seiner Diagnose zufolge ist die schwache Performance der Demokratie in den letzten Jahren vor allem auf ein Scheitern einer Institutionalisierung zurückzuführen. Fukuyama argumentiert, dass staatliche Kapazitäten in vielen neuen und existierenden Demokratien nicht ausreichend vorhanden sind bzw funktionieren und so die Forderung nach demokratischer Rechenschaftspflicht ins Leere geht. Dementsprechend bietet er Hinweise dafür, wie man einen modernen Staat etabliert und betont dabei, dass der Fokus auf die staatliche Handlungsfähigkeit sowie auf die Organisation von gesellschaftlichen Bewegungen und deren Übergang in politische Parteien gelegt werden sollte. Bewegungen zur Förderung der Demokratie müssen somit Hand in Hand mit der Förderung moderner Staatlichkeit gehen. 


\section{Die Grundlagen des demokratischen Rechtsstaates und dessen Krise}

Clara Maier und Holger Grefrath schließen an diese Überlegungen nahtlos an. Sie werfen die Frage auf, warum wir vom „demokratischen Rechtstaat“ und nicht von der „rechtsstaatlichen Demokratie“ oder von „Demokratie und Rechtsstaat“ sprechen? In ihrem Beitrag geben sie einen Einblick in die „geistige Welt des demokratischen Rechtsstaats“ und kritisieren die „Demokratie als Attribut“. Sie rekonstruieren die Spannung in der Konzeption des demokratischen Rechtsstaats, wie sie zunächst von Hermann Heller vorgelegt wurde. Schließlich schlagen sie ein neues Verständnis des demokratischen Rechtsstaats im Rahmen der Verfassungsprinzipien des deutschen Grundgesetzes als gegenseitig beschränkend, definierend und ändernd vor.

Jakob Gaigg beschäftigt sich in seinem Beitrag mit der transnationalen verfassungsgebenden Gewalt und der Möglichkeit von Recht ohne Demokratie und untersucht so die Antipode zum Beitrag von Clara Maier und Holger Grefrath auf der transnationalen Ebene. Er diagnostiziert in seinem Beitrag, dass Nationalstaaten durch die postnationale Konstellation zunehmend unter Druck geraten und fragt, ob die verfassunggebende Gewalt auf der transnationalen Ebene eher Verfassungslyrik oder destituierende Gewalt ist. Ihm zufolge bringt der Begriff der verfassungsgebenden Gewalt die legitimatorische Klammer zum Ausdruck, die Verfassung und politische Gemeinschaft zusammenhält. Dementsprechend fragt er, ob, wenn von Verfassung jenseits des Nationalstaats die Rede ist, auch von einer transnationalen oder gar globalen verfassungsgebenden Gewalt gesprochen werden kann. In Auseinandersetzung mit dem Ansatz von Bardo Fassbender, die UN-Charter als Verfassung der internationalen Gemeinschaft zu interpretieren, entwickelt er ein relationales Verständnis verfassungsgebender Gewalt und kommt zu dem Schluss, dass es jenseits des Nationalstaates keine verfassungsgebende Gewalt im Sinne des relationalen Verständnisses mehr geben kann.

Timo Greger widmet sich den Fragen nach einer individuellen Freiheit, der kollektiven Selbstbestimmung und einem normativen Grundkonsens. Benötigen wir radikale Freiheit oder doch eine Leitkultur? Für Ihn ist Demokratie mehr als nur die Aggregation von individuellen Präferenzen. Damit stellt er sich klar gegen populäre liberale Positionen. Demokratie ist nicht nur konstituiert durch einen Allgemeinwillen, der sich aus einem prozeduralen modus vivendi aller Bürgerinteressen generiert. Vielmehr beruht Demokratie auf einem umfassenden vorpolitischen normativen Konsensus. Diese Konsensus-Normativität stammt ihm gemäß aus drei Quellen: Einer rationalen, einer pragmatischen und einer identitätsbasierenden Quelle. Demokratie hängt von einer positiv entwickelten liberalen, Kollektive inkludierenden Identität ab, wenn sie gegenüber konkurrierenden Identitätsangeboten die Oberhand behalten will.

Benjamin Schmid identifiziert und beleuchtet Zeit und Raum als basale Problemfelder der Krise der Demokratie. Ihm zufolge ist die gegenwärtige Krise der Demokratie das Resultat einer gestörten Wahrnehmung von Zeit und Raum. Das Fundament der 
demokratischen Form und politischer Ordnung zerfallen auf Grund der Beschleunigung seit der industriellen und der französischen Revolution. Als Reaktion auf diesen Zerfallsprozess ist es nach Benjamin Schmid notwendig, dieser Beschleunigung Einhalt zu gebieten. Ein Verzögerer soll es ermöglichen, Zeit und Raum für die Demokratie zurückzugewinnen.

\section{Demokratische Teilhabe und Weltanschauung als Problem und Lösungsansatz}

Berit Völzmann beleuchtet die Judikative als Teil der Demokratie. Sie argumentiert mit Jürgen Habermas, dass Demokratie nicht allein als Herrschaftsform, sondern auch als Modus der Beteiligung von Bürger*innen verstanden werden sollte. Diese Beteiligung unterscheidet sich damit von den klassischen Beteiligungsformen der Wahl dadurch, dass nicht das Kollektiv, sondern der bzw. die einzelne Bürger*in im Fokus steht. Jede bzw. jeder kann in einen gesellschaftlichen Diskurs eintreten, indem sie oder er ihre Rechte vor Gericht wahrnimmt. Der Gerichtsprozess wird dadurch, und das ist Völzmanns zentrales Anliegen, zum deliberativen demokratischen Prozess. Eine lebendige Demokratie ist eine, an der sich Bürger*innen beteiligen können.

Nula Frei sieht die direkte Demokratie vor einer Instrumentalisierung durch den Rechtspopulismus gefährdet. Den scheinbar einfachsten Weg, die Schwächen einer direkten Demokratie am besten dadurch zu umgehen, indem man direktdemokratische Elemente an sich ablehnt, will die Autorin dabei aber nicht gehen. Eine Bevormundung des Volkes durch Expert*innen lehnt sie ebenfalls ab. Stattdessen erörtert sie Wege, wie die direkte Demokratie selbst mit ihren Missbrauchspotentialen umgehen kann. Sie sieht dabei eine selbstbewusste, aufgeklärte direkte Demokratie als Lösung.

Dass eine Demokratiekrise derzeit vorliegt, ist ein Allgemeinplatz. Aber wann begann sie bzw. noch abstrakter gefragt: Was ist das erste Zeichen, an dem man erkennen kann, dass eine Demokratie ins Wanken gerät? Sebastian Enghofer argumentiert, dass die Wurzel allen Übels in der Abwendung von einer demokratischen Weltanschauung liegt. Diese These stützt er einerseits auf demokratietheoretische Überlegungen von Hans Kelsen und andererseits auf Erkenntnisse der Moralpsychologie. Er kommt zu dem Schluss, dass man bereits für eine demokratische Weltanschauung aktiv eintreten muss, um die Demokratie zu erhalten. Dabei versucht er Erkenntnisse aus der Psychologie auf die Staatstheorie zu übertragen und kommt zum Schluss, dass, auch wenn eine entscheidende Stärke der Demokratie ihre Offenheit gegenüber vielen Überzeugungen ist, man immer wieder um sie kämpfen müsse, um sie zu erhalten. 


\section{Antagonisten des demokratischen Rechtsstaats}

Karsten Schubert stellt das Phänomen der „Political Correctness“ ins Zentrum seiner Überlegungen. Nach ihm ist dies der Kern der Politik und so entwickelt er ein positiv besetztes Verständnis von „Political Correctness“ mit Nietzsche, welches sich gegen die Interpretation der neuen Rechten wendet. Er nimmt die Behauptung der Rechten, „Political Correctness“ würde Nietzsches Sklavenmoral entsprechen, ernst und skizziert eine systematische Lesart als Gegenpol zu dieser rechts-nietzscheanischen Position. Diese Verbindung von „Political Correctness“-Kritik und Nietzsche ermöglicht ihm zufolge ein tieferes Verständnis rechter Rationalität sowie der affektiven Energie, welche dieser Kritik zu Grunde liegt. Dieser Kontrast ermöglicht die Einsicht, dass die Essenz von Politik in der Neukonzeption von Normen liegt, die Privilegien verteilen. Deswegen spricht er schlussendlich nicht mehr von „Political Correctness“, sondern von „politischen Urteilen“. Das trifft den Prozess unverdiente Privilegien einzuschränken, seines Erachtens besser.

Dóra Frey analysiert in ihrem Beitrag die theoretischen und praktischen Fragen, die sich im Zusammenhang mit der Anwendung der ungarischen historischen Verfassung in der heutigen Zeit ergeben. Der im Jahr 2011 neu beschlossenen ungarischen Verfassung (genannt Grundgesetz) zufolge sind die Errungenschaften der historischen Verfassung Teil der Auslegungsregeln des Grundgesetzes, weshalb die Thematik in den letzten Jahren in den Mittelpunkt gerückt ist. Die Hauptfragen des Beitrags zielen darauf $a b$, zu prüfen, inwieweit die ungarische historische Verfassung bzw deren Errungenschaften heute überhaupt noch anwendbar sind (zumal im politischen Diskus regelmäßig auf sie Bezug genommen wird), ob ihr Inhalt - sofern überhaupt ermittelbar - in der Praxis des ungarischen Verfassungsgerichts relevant ist und ob diese historische Verfassung als Vorbild für die heutige ungarische Demokratie und den Rechtsstaat dienen kann.

\section{Internationale Aspekte}

Melissa Muller diskutiert ebenso eine psychologische Komponente und fragt, ob die Demokratie durch einen Verfassungspatriotismus gestärkt werden kann. Dieser Verfassungspatriotismus drücke sich vor allem darin aus, wie über die Verfassung im gesellschaftlichen Diskurs gesprochen wird. Er kann in seiner besten Form das einheitsstiftende Element einer Demokratie sein. Bei der derzeitigen Verschärfung der Debatte und der weitergehenden Polarisierung auch innerhalb der Parteien in den USA sieht Muller die Verfassung aus verschiedenen Perspektiven instrumentalisiert und dadurch in ihrer Symbolkraft geschwächt. Der Verfassungspatriotismus vermag laut Muller daher sogar, bei einer stark polarisierten politischen Debatte, die Verfassung als einheitsstiftendes Symbol der Demokratie zu schwächen. 
Bruno Buonicore setzt sich in seinem Beitrag schwerpunktmäßig mit der Frage auseinander, inwiefern der (demokratische und soziale Rechts-)Staat im Kontext der sog. „Latin American peripheral modernity" berechtigt ist, sein Gewaltmonopol gegenüber bestimmten Staatsbürger*innen aufgrund einer tatbestandsmäßig-rechtswidrigen Handlung anzuwenden, wenn die betreffenden Staatsbürger keinen materiellen Zugang zu den fundamental-sozialen und in der Verfassung verankerten Staatsleistungen wie z.B. Gesundheit, Bildung, Arbeit und Qualitätslebensmitteln haben und insofern sozial exkludiert sind (Diskrepanz zwischen bloß formalem und konkretem Staatsbürger). Insbesondere im lateinamerikanischen Kontext diagnostiziert Bruno Buonicore eine evidente Asymmetrie zwischen den staatlichen Normen, die von allen Staatsbürgern befolgt werden müssen und dem Zugang zu materiellen Rechten, der für einen Großteil der Bevölkerung eingeschränkt ist (defizitäre materielle Anerkennung). Wenn ein formaler, aber keineswegs konkreter Staatsbürger eine tatbestandsmäßig-rechtswidrige Handlung setzt, dann sei der Staat aufgrund seiner defizitären materiellen Anerkennung mitverantwortlich für das Verbrechen, da ein bloß formaler Staatsbürger nicht legitimer Weise als konkreter Staatsbürger behandelt werden darf. Im Kern schlägt Bruno Buonicore als Konsequenz vor, materielle Freiheit statt bloß formaler Freiheit zur Voraussetzung strafrechtlicher Verantwortung bzw. Zurechnung zu erheben.

Maria Bertel beleuchtet in ihrem Beitrag die vielschichtigen und komplexen Zusammenhänge zwischen (repräsentativer) Demokratie, Korruption und Populismus. Zur exemplarischen Veranschaulichung dieser vielfältigen Verbindungen führt sie drei (lateinamerikanische) Fallbeispiele an. Besonderes Augenmerk legt sie auf die Verbindung zwischen Demokratie und Populismus, da Populismus in vielen Fällen demokratischen Rückbaus eine zentrale Rolle spielt. Auch Korruption stellt einen entscheidenden Katalysator für das Erodieren von Demokratien dar, wenngleich die Einordnung dessen, was als Korruption betrachtet wird, variieren kann und von diversen Faktoren abhängig ist. Zwar vermag Demokratie ein gewisses Maß an Korruption und Populismus auszuhalten, für ihr grundsätzliches Funktionieren und die Erhaltung des Vertrauens des Wahlvolkes sind jedoch überzeugende legislative Maßnahmen gegen die Korruption und eine entsprechende Durchsetzung erforderlich. Gleichzeitig gibt sie zu bedenken, dass Demokratie ebenso vom Misstrauen lebt; lediglich Nichtvertrauen im Sinne einer Abwesenheit von Vertrauen schadet einer Demokratie langfristig. Misstrauen vermag nämlich eine wichtige Korrektivfunktion zu haben, und zwar solcherart, dass es als eine Form der kritischen Auseinandersetzung des Wahlvolkes mit seinen gewählten Vertretern betrachtet werden kann. Demgegenüber ist Nichtvertrauen insofern der Demokratie abträglich, als diese darauf angewiesen ist, dass die Bürger zum einen daran glauben, dass ihre Vertreter im Interesse der Allgemeinheit handeln, zum anderen sich aber auch darauf verlassen, dass der andere Bürger ebenso die Normen freiwillig befolgt. 


\section{Epilog: Seid jetzt wachsam}

Dem Ziel der Tagung, dieses nur schwer konturierbare Thema in seiner aktuellen Dynamik aus interdisziplinärer Sicht zu skizzieren, wurde bereits mit dem Eröffnungsvortrag, der von Heinz Fischer, österreichischer Bundespräsident a. D. und studierter Rechts- und habilitierter Politikwissenschaftler, gehalten wurde, gerecht. Heinz Fischer ging zunächst auf die historische Dimension des Tagungsthemas ein. Sein Befund, wonach die Lehren aus der Geschichte nicht zeitlich unbegrenzt anhalten würden, kann zur Erklärung des Phänomens, dass rückwärtsgewandte nationalistische Ideologien sowie rechtsstaatsfeindliche und antidemokratische Positionen wieder an Einfluss gewinnen, einen wichtigen Beitrag leisten. Heinz Fischer stellte in weiterer Folge fundierte Überlegungen hinsichtlich der Frage an, ob der demokratische Rechtsstaat gegenwärtig bereits verwirklicht sei oder ein unerreichbares, an vielerlei Realitäten scheiterndes Ideal darstelle. Im Bewusstsein, dass sich die Ursachen für die im Tagungstitel diagnostizierte Krise des demokratischen Rechtsstaats monokausaler Erklärungsmuster entziehen, identifizierte der Festredner die systematischen Schwächen des demokratischen Rechtsstaats. Nationale Egoismen und das Verfolgen von Partikularinteressen bedrohen die Zukunft des europäischen Friedensprojekts. Mit Blick auf die zahlreichen Risse, die sich durch die Europäische Union ziehen, warnte Heinz Fischer vor einem Wiedererstarken nationalistischer Tendenzen und den Risiken, die damit einhergehen. In diesem Zusammenhang rief er eindringlich in Erinnerung, dass der demokratische Rechtsstaat wesensmäßig mit einem Bekenntnis zu Menschenrechten und Menschenwürde verbunden sei.

Wachsamkeit in Krisenzeiten ist folglich geboten. Das Wort Krise ist abgeleitet vom

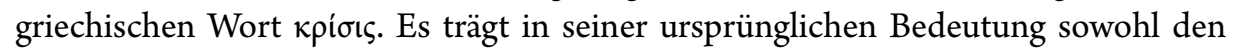
Streit als auch dessen Lösung, Schlichtung bzw Entscheidung in sich. ${ }^{17}$ Ganz in diesem janusköpfigen Sinne widmen sich die Autor*innen dieses Bandes der Ursachenforschung der Krise, versuchen aber auch mögliche Lösungsvorschläge zu finden. Die Ambivalenz und Fragilität der heutigen Situation schwingt dabei immer mit: Manche Staaten werden in autoritäre Systeme zurückfallen, manche werden noch bewusster für Demokratie und Rechtsstaatlichkeit einstehen. ${ }^{18}$ Die Verteidigung von Demokratie und Rechtsstaatlichkeit ist es, was alle Autor*innen in ihren interdisziplinären und facettenreichen Beiträgen in diesem Beiheft eint.

17 Reinhart Koselleck, Krise, Historisches Wörterbuch der Philosophie, Band 4, Sp. 1235 f.

18 Vgl. hierzu Franklin D. Roosevelt, Acceptance Speech at the Democratic Convention, Chicago am 2. Juli 1932: „Out of every crisis (...) mankind rises with some share of greater knowledge, higher decency, purer purpose." 
II. Prolog 



\title{
Warum hält die Demokratie nicht, was sie verspricht?
}

\author{
Why is Democracy Performing so Poorly?*
}

FRANCIS FUKUYAMA

Das Journal of Democracy publizierte seine erste Ausgabe kurz nach dem Höhepunkt der von Samuel P. Huntington bezeichneten „dritten Welle“ der Demokratisierung; gleich nach dem Fall der Berliner Mauer und unmittelbar vor dem Zusammenbruch der Sowjetunion. ${ }^{1}$ Der Übergang in Südeuropa und in den meisten lateinamerikanischen Ländern war schon geschehen und Osteuropa entfernte sich mit schwindelerregend hohem Tempo vom Kommunismus, während der demokratische Umschwung in Subsahara-Afrika und der ehemaligen Sowjetunion gerade erst seinen Anfang nahm. Insgesamt gab es weltweit über einen Zeitraum von beinahe 45 Jahren einen bemerkenswerten Demokratisierungs-Fortschritt, in dessen Rahmen die Zahl der Wahldemokratien von ungefähr 35 im Jahre 1970 auf über $110 \mathrm{im} \mathrm{Jahr} 2014$ anstieg.

Wie aber Larry Diamond aufgezeigt hat, gibt es seit 2006 eine demokratische Rezession, die sich - nach der Zählung von Freedom House - in jährlich sinkenden Demokratiewerten niederschlägt. ${ }^{2}$ Das Jahr 2014, mit zwei sich am jeweiligen Ende von Eurasien befindenden und bewegenden autoritären Supermächten - Russland und China -, war kein gutes für die Demokratie. Der „Arabische Frühling“ von 2011, welcher die Erwartung weckte, dass die bislang von der Dritten Welle der Demokratisierung weitgehend unberührte Arabische Welt ebenfalls einen Demokratisierungsprozess erleben würde, artete in einer erneuerten Diktatur im Falle Ägyptens, und in Anarchie im Falle Libyens,

* Übersetzung des Beitrages Francis Fukuyama, Why is Democracy Performing so Poorly?, Journal of Democracy 26 (1) (2015) 11-20, von Lando Kirchmair und Valerie Schwarzer.

1 Samuel P. Huntington, The Third Wave: Democratization in the Late Twentieth Century, Oklahoma City, University of Oklahoma Press, 1991.

2 Larry Diamond, Facing Up to the Democratic Recession, Journal of Democracy 26 (1) (2015) 141-155. 
des Jemens und auch Syriens aus, wobei Syrien gemeinsam mit dem Irak die Geburtsstätte einer neuen radikalen islamistischen Bewegung, des Islamischen Staates im Irak und Syrien (ISIS), war. Es ist schwer, vorauszusagen, ob wir einen bloß vorübergehenden Rückschlag in einer allgemeinen weltweiten Demokratiebewegung - vergleichbar mit Börsenkorrekturen - erleben, oder ob die Ereignisse des Jahres 2014 tiefgreifendere Veränderungen der Weltpolitik und den Aufstieg von ernstzunehmenden Alternativen zur Demokratie bedeuten. In beiden Fällen kann leicht der Eindruck gewonnen werden, dass die Performance der Demokratien in der ganzen Welt in den letzten Jahren unzulänglich war. Dies beginnt schon mit den am stärksten entwickelten und erfolgreichsten Demokratien, den Vereinigten Staaten und den Ländern der Europäischen Union, die sich in den späten 200oern in einer massiven Wirtschaftskrise befunden haben, und weiterhin mit einem langsamen Wachstum und stagnierendem Einkommen zu kämpfen haben. Aber auch die Performance einer Reihe neuerer Demokratien, von Brasilien über die Türkei bis nach Indien, war in vielerlei Hinsicht enttäuschend. Auch diese Demokratien hatten mit ihren eigenen Protestbewegungen zu kämpfen. Spontane aus der Zivilgesellschaft hervorgehende demokratische Bewegungen gegen autoritäre Regime entstehen weiterhin - von der Ukraine und Georgien über Tunesien und Ägypten bis nach Hong Kong. Nur wenige dieser Bewegungen waren jedoch erfolgreich in ihrem Bestreben, stabile und gut funktionierende Demokratien zu etablieren. Es erhebt sich die Frage, warum Demokratie weltweit eine Rezession erleidet.

Meines Erachtens gibt es einen Hauptgrund für die vielen demokratischen Rückschläge, die sich in der Vergangenheit zugetragen haben. Es betrifft dies das Misslingen einer Institutionalisierung - namentlich konnten die staatlichen Kapazitäten in vielen neuen und existierenden Demokratien nicht mit den allgemeinen Forderungen nach demokratischer Rechenschaftspflicht Schritt halten. Der Wandel von einem patrimonialen oder neopatrimonialen Staat zu einem modernen, unpersönlichen Staat ist wesentlich schwieriger als der Übergang von einem autoritären Regime zu einem auf regulären, freien und fairen Wahlen beruhenden System. Mit dieser sich gleichsam als Achillesferse jüngerer demokratischer Übergangsprozesse erweisenden Problematik geht das Unvermögen einher, moderne, gut geführte Staaten zu etablieren.

\section{Einige Definitionen}

Moderne liberale Demokratien vereinigen drei grundlegende Institutionen in sich: den Staat, die Rechtsstaatlichkeit („rule of law“) und die demokratische Rechenschaftspflicht.

Die erste dieser Institutionen, der Staat, ist der Träger des legitimen Gewaltmonopols, wobei er seine Autorität über ein begrenztes Gebiet ausübt. Staaten konzentrieren Macht und wenden diese an, um Frieden zu erhalten, Gemeinschaften vor äußeren Feinden zu verteidigen, Recht durchzusetzen, und grundlegende öffentliche Güter zur Verfügung zu stellen. 
Die Rechtsstaatlichkeit („rule of law“) stellt sich als ein Regelwerk dar, das gemeinschaftliche Werte widerspiegelt, die nicht nur für Bürger, sondern auch für die Eliten, welche Zwangsbefugnis ausüben, verbindlich sind. Wenn das Recht den Mächtigen keine Schranken auferlegt, so wäre es lediglich als Bündel von Exekutivbefehlen zu begreifen, womit die Voraussetzung für eine bloße Herrschaft durch Recht („,rule by law") geschaffen wäre.

Die demokratische Rechenschaftspflicht zielt schlussendlich darauf ab, dass die Regierung im Interesse der gesamten Gemeinschaft und nicht im Eigeninteresse der Regierenden agiert. Sie wird üblicherweise über Prozesse wie freie und faire Mehrparteienwahlen erreicht, wenngleich prozedurale Rechenschaftspflicht nicht immer gleichbedeutend mit politischer Rechenschaftspflicht ist.

Eine liberale Demokratie schafft einen Ausgleich zwischen diesen potentiell miteinander in Widerspruch stehenden Institutionen. Dem Staat kommt die Schaffung und Ausübung von Macht zu, während die Rechtsstaatlichkeit und die demokratische Rechenschaftspflicht darauf abzielen, diese Machtausübung einzuschränken und sicherzustellen, dass sie im öffentlichen Interesse ausgeübt wird. Ein Staat ohne die ihn einschränkenden Institutionen ist eine Diktatur. Ein Gemeinwesen ohne Einschränkungen und jegliche Machtausübung ist anarchisch.

Wie Samuel Huntington zu behaupten pflegte, muss ein Gemeinwesen zunächst selbst die Macht ausüben, bevor es die Machtausübung einschränken kann. In den Worten von Alexander Hamilton: „[e]ine schwache Exekutive bedeutet eine schwache Ausübung der Regierungsgewalt. Eine schwache Ausübung ist nur ein anderer Begriff für eine schlechte Ausübung; und eine schlecht ausgeübte Regierung wird, was immer sie in der Theorie sein mag, in der Praxis eine schlechte Regierung sein. ${ }^{{ }^{3}}$

Darüber hinaus bedarf es noch einer weiteren wesentlichen Unterscheidung zwischen einem patrimonialen und einem modernen Staat. Ein moderner Staat strebt die Unpersönlichkeit an und behandelt alle Staatsangehörigen gleich - unabhängig davon, ob sie in einer persönlichen Beziehung zum Regierenden stehen. Im Gegensatz dazu wird in patrimonialen Staaten das Gemeinwesen als eine Art persönliches Eigentum angesehen und nicht zwischen öffentlichem Interesse und dem Eigeninteresse der Regierenden differenziert. Heutzutage gibt es keine rein patrimonialen Gesellschaften mehr, da es niemand mehr wagt, Eigentum an einem ganzen Land zu behaupten, wie dies Könige und Königinnen in der Vergangenheit taten. Es gibt allerdings viele neopatrimoniale Staaten, die vorgeben, moderne Gemeinschaften zu sein, in Wahrheit aber Kleptokratien darstellen, die die ökonomischen Gewinne zum privaten Vorteil einiger weniger aufteilen („rent-sharing kleptocracies"). Neopatrimonialismus und Demokratie können nebeneinander bestehen, wobei dieses Nebeneinander freilich in

3 Alexander Hamilton, Federalist 70, 1788, übersetzt von Barbara Zehnpfennig, Darmstadt, Wiss. Buchges., 1993, 415. 
weit verbreitetem Protektionismus und Klientelismus resultiert, in dessen Rahmen die Politiker staatliche Ressourcen mit einem ganzen Netzwerk an politischen Unterstützern teilen. In derartigen Gesellschaften geht der Einzelne nicht in die Politik, um eine Vision für das Gemeinwohl zu verfolgen, sondern vielmehr mit dem Ziel, sich selbst zu bereichern.

Zwang ist nach wie vor ein zentrales Element für das Funktionieren des Staates. Das ist auch der Grund dafür, dass staatliche Machtausübung oftmals Angst und Hass hervorruft. Michael Mann hat bekanntlich zwischen „despotischer“ und „infrastruktureller" Macht unterschieden. Erstere bezieht sich auf Zwang; für letztere ist die Fähigkeit, öffentliche Güter zur Verfügung zu stellen und das Gemeinwohl zu fördern, ausschlaggebend. ${ }^{4}$ Diese Unterscheidung könnte uns zu der Annahme verleiten, dass "gute" Staaten infrastrukturelle Macht hätten, während „schlechte“ Staaten Macht in despotischer Weise ausüben würden. Tatsächlich aber ist Zwang für alle Staaten von zentraler Bedeutung. Erfolgreichen Staaten gelingt es, Macht in Autorität umzuwandeln und auf diese Weise sicherzustellen, dass die Bürger die Gesetze freiwillig und in der Überzeugung befolgen, dass das staatliche Handeln rechtmäßig ist. Nicht alle Bürger sind jedoch zur Gesetzestreue bereit und sogar die am stärksten legitimierten Demokratien sind zur Rechtsdurchsetzung auf Polizeigewalt angewiesen. So ist es beispielsweise unmöglich, Korruption einzudämmen oder Steuern einzuziehen, wenn Gesetzesverstöße nicht mit der Sanktion eines Gefängnisaufenthaltes bedroht sind. Staatliche Durchsetzungsfähigkeiten entstehen nicht einfach durch das Verabschieden von Gesetzen; vielmehr bedarf es einer Investition in Aus- und Weiterbildungen geeigneter Kräfte und der Schaffung institutioneller Regeln, welche die Gesetzesausübung determinieren.

Wenn wir etwas aus der Erfahrung der letzten 25 Jahre gelernt haben, dann ist es das, dass das demokratische Bein dieses Dreifußes viel leichter zu errichten ist, als die Rechtsstaatlichkeit oder der moderne Staat. Oder um es ein wenig anders zu formulieren: Die Entwicklung moderner Staatlichkeit hat nicht Schritt gehalten mit der Entwicklung demokratischer Institutionen, was zu unausgewogenen Situationen geführt hat, in welchen neue (und manchmal sogar gut etablierte) Demokratien nicht in der Lage waren, die Erwartungen ihrer Bürger an hochqualitative staatliche Dienstleistungen zu erfüllen. Das wiederum hat zur Delegitimierung der Demokratie als solcher geführt. Hingegen hat die Tatsache, dass autoritäre Staaten wie China und Singapur im Stande waren, diese Dienstleistungen zu erbringen, ihr Ansehen im Vergleich zu jenem von Demokratien in vielen Teilen der Welt erhöht.

Die jüngsten Erfahrungen mit Afghanistan und dem Irak verdeutlichen das Problem. Nach dem US-Einmarsch und der Besatzung dieser beiden Länder 2001 bezie-

4 Michael Mann, The Sources of Social Power, Bd. 1: A History of Power from the Beginning to AD 1760, Cambridge, Cambridge University Press, 1986. 
hungsweise 2003 haben die Vereinigten Staaten mit internationaler Hilfe demokratische Wahlen organisiert, die in beiden Ländern neue Regierungen hervorgebracht haben. Die Qualität der Demokratie in beiden Ländern - insbesondere in Afghanistan, wo die Präsidentschaftswahlen 2009 und 2014 von schwerwiegenden Betrugsvorwürfen begleitet waren ${ }^{5}$ - wurde von vielen in Frage gestellt, zumindest aber wurde ein demokratischer Prozess in Gang gesetzt, welcher eine Staatsführung mit demokratischem Anstrich hervorgebracht hat.

In keinem der beiden Länder gelang es, einen modernen Staat einzurichten, der zur Verteidigung des Territoriums vor inneren und externen Feinden und zu einer fairen und unparteilichen Verteilung öffentlicher Güter in der Lage gewesen wäre. Beide Länder hatten mit inneren Aufständen zu kämpfen und 2014 brach die vom US-Militär trainierte irakische Armee im Norden unter dem Ansturm des IS zusammen. In beiden Ländern grassierte die Korruption, was wiederum deren Fähigkeit einschränkte, staatliche Dienstleistungen zur Verfügung zu stellen; ein Legitimitätsverlust war die Folge. Die von den Vereinigten Staaten und deren Koalitionspartnern in beiden Ländern getätigten hohen Investitionen in den Aufbau von Staatlichkeit scheinen nur begrenzte Wirkung gehabt zu haben.

Misserfolge im Aufbau von Staatlichkeit waren auch ein Katalysator für die Ereignisse in der Ukraine. Westliche Demokratien jubelten, als die Orange Revolution im Jahr 2004 zu neuen Präsidentschaftswahlen führte, welche zur Niederlage des Amtsinhabers und Premierministers Viktor Janukowitsch und dem Sieg Viktor Juschtschenkos führten. Die neue Orange Koalition erwies sich jedoch als schwach und korrupt und trug nichts zur Verbesserung der Regierungsqualität in der Ukraine bei. Dies führte dazu, dass Janukowitsch Juschtschenko bei den Wahlen 2010, die von den meisten Beobachtern als frei und fair bezeichnet wurden, besiegte. Die Rücksichtslosigkeit, die Präsident Janukowitsch bei Ausübung seines Amtes an den Tag legte, provozierte jedoch erneute Proteste in Kiew, wobei die gegen Ende des Jahres 2013 von Janukowitsch getätigte Ankündigung, eher eine Assoziierung mit Wladimir Putins Eurasischer Union als mit der Europäischen Union anzustreben, eine zentrale Rolle spielte. In der Zwischenzeit hatte Putin seine zunehmend illiberale Regentschaft in Russland gefestigt und die Position Russlands in der Welt(ordnung) gestärkt; dies wiederum ermöglichte die offene Annexion der Krim in Folge von Janukowitschs Amtsenthebung im Februar 2014.

Ich würde behaupten, dass der gegenwärtige Konflikt zwischen Russland und der neuen ukrainischen Regierung und ihrer westlichen Unterstützer weniger ein Konflikt über Demokratie per se als über die Entscheidung zwischen einer modernen und einer neopatrimonialen politischen Ordnung ist. Es bestehen wenig Zweifel, dass die Popularitätswerte Wladimir Putins in Russland infolge der Annexion der Krim erheblich

5 Sarah Chayes, Thieves of State: Why Corruption Threatens Global Security, New York, W. W. Norton, 2015. 
gestiegen sind und er mit großer Wahrscheinlichkeit mit überwältigender Mehrheit (vorgezogene) Wahlen gewinnen würde. Die wahre Herausforderung der Menschen in dieser Region ist eine andere - nämlich, ob ihre Gesellschaften von Regierungen geführt werden, die das Gemeinwohl in einer unpersönlichen Weise verfolgen, oder ob sie von einer korrupten Koalition von Eliten regiert werden, die den Staat als Mittel zur Erreichung persönlicher Vorteile betrachten.

Die Legitimität vieler Demokratien weltweit hängt weniger von der Vertiefung ihrer demokratischen Institutionen als von ihrer Fähigkeit ab, qualitativ hochwertige staatliche Dienstleistungen zur Verfügung zu stellen. Der neue ukrainische Staat wird nicht überleben, wenn es ihm nicht gelingt, die grassierende Korruption in den Griff zu bekommen, die bereits die Orange Vorgängerkoalition zu Fall gebracht hat. Die Demokratie hat sich in den letzten Jahrzehnten in weiten Teilen Lateinamerikas tief verwurzelt; was heute vielmehr in Ländern wie Brasilien, Kolumbien und Mexiko fehlt, ist die Fähigkeit, der Bevölkerung grundlegende öffentliche Güter, wie Bildung, Infrastruktur und Sicherheit zu gewährleisten. Dasselbe kann von der weltweit größten Demokratie - Indien - gesagt werden, welche mit allgegenwärtigem Klientelismus und Korruption zu kämpfen hat. Der Wahlerfolg der Bharatiya Janata Partei unter Narendra Modi im Jahr 2014 war von der Hoffnung begleitet, dass Modi entschlossene Führungsqualitäten zeigen und eine starke Regierung stellen könnte, ganz im Gegensatz zu der schwachen und korrupten Kongresspartei, welche in den vergangenen Jahrzehnten die Regierungsmacht innehatte.

\section{Wie etabliert man einen modernen Staat}

Es gibt mittlerweile immens viel Literatur zu demokratischem Übergang, viel davon publiziert im Journal of Democracy. Vergleichsweise wenig Literatur gibt es hinsichtlich der Frage, wie der Übergang von einem neopatrimonialen zu einem modernen Staat gelingen kann, wenngleich sich in den letzten 15 Jahren auch auf diesem Gebiet einiges getan hat. Darin spiegelt sich ein konzeptuelles Defizit wider, das in Fehlvorstellungen bezüglich der Natur des zu Grunde liegenden Problems wurzelt.

So besteht zum Beispiel die Tendenz, staatliche Modernität mit fehlender Korruption zu assoziieren. Korruption ist freilich ein großes Problem in vielen Gesellschaften und dies wurde auch zahlreich in einschlägiger Literatur behandelt. Zwar gibt es einen hohen Korrelationsgrad zwischen Korruption und schlechter staatlicher Performance, sie gleichzusetzen wäre jedoch verfehlt. Ein Staat kann verhältnismäßig wenig korrupt und zugleich aber nicht in der Lage sein, elementare Dienstleistungen auf Grund von Unvermögen zu gewährleisten. Niemand hat beispielsweise behauptet, dass Guinea, Sierra Leone oder Liberia auf Grund von Korruption in ihrem jeweiligen Gesundheitssystem unfähig waren, die jüngste Ebola-Epidemie in den Griff zu bekommen; das Problem besteht vielmehr in unzureichenden personellen und materiellen Res- 
sourcen - Ärzten, Krankenschwestern, Krankenhäusern mit Elektrizität, sauberem Wasser und Ähnlichem.

Wenn es darum geht, den Kern moderner Staatlichkeit zu beschreiben, ist daher der Fokus viel eher auf die staatliche Handlungsfähigkeit zu legen als auf die Frage, wie korrupt der jeweilige Staat ist. Moderne Staaten stellen eine fast unüberschaubare Anzahl an Dienstleistungen zur Verfügung - von der Erstellung von Wirtschafts- und Sozialstatistiken über die Katastrophenhilfe bis zur Wettervorhersage und der Luftverkehrskontrolle. Diese Aktivitäten erfordern allesamt hohe Investitionen in personelle und materielle Ressourcen, die es den Staaten ermöglichen, erfolgreich tätig zu werden; die bloße Tatsache, dass ein Staat wenig korrupt ist, bedeutet nicht notwendigerweise, dass die zuvor beschriebenen Dienstleistungen auch tatsächlich erbracht werden. Doch auch mit dem Begriff der staatlichen Handlungsfähigkeit können die Ziele, deren Erreichung diese Fähigkeit dient und der Grad an Unpersönlichkeit, mit welchem diese ausgeübt wird, nicht richtig erfasst werden.

Darüber hinaus besteht erhebliche Unklarheit darüber, wie starke staatliche Handlungsfähigkeit in der Vergangenheit erreicht werden konnte. Derzeit gibt es zumindest einen gewissen Konsens innerhalb der Gebergemeinschaft hinsichtlich der Frage, wie gute Regierungsführung verfolgt werden kann - eingebettet ist dieser Konsens in diverse Programme, wie partizipatives Budgetieren, offene Regierungspartnerschaften und die Initiativen der zahlreichen Organisationen zur Förderung der staatlichen Transparenz auf der ganzen Welt. Diesen Ansätzen ist die Theorie gemein, dass gute Regierungsführung das Ergebnis größerer Transparenz und Rechenschaftspflicht ist. Diesen Ansätzen liegt der Gedanke zugrunde, dass mehr Informationen über Korruption innerhalb der Regierung oder sonstige Amtsvergehen Bürger verärgern und Auslöser für Forderungen nach besseren staatlichen Leistungen sind, was wiederum Regierungen zur Selbstreformierung veranlassen wird. Eine qualitativ höherwertige Demokratie, wird - mit anderen Worten - als Lösung des Korruptionsproblems und schwacher staatlicher Handlungsfähigkeit angesehen.

Das einzige Problem dieser Strategie besteht darin, dass es erstaunlich wenig empirische Nachweise gibt, die nahelegen würden, dass existierende besonders leistungsfähige Regierungen nach einem derartigen Ansatz geschaffen worden sind; weder historische Hinweise noch gegenwärtige Umstände legen dies nahe. Viele Staaten mit relativ leistungsfähigen Regierungen - beispielsweise China, Japan, Deutschland, Frankreich und Dänemark - haben moderne „Webersche“ Bürokratien unter autoritären Bedingungen geschaffen; diejenigen Staaten, welche anschließend zu Demokratien wurden, haben jeweils einen leistungsorientierten Staatsapparat geerbt, der einfach die Übergangsphase überlebt hat. Die Motivation zur Schaffung moderner Regierungen ging nicht auf Druck von mobilisierten und informierten Bürgern zurück, sondern vielmehr auf jenen Druck, der von der Führungsschicht ausgeübt und oftmals mit nationalen Sicherheitsbedenken begründet wurde. Charles Tillys berühmter Aphorismus, „Staaten machen Kriege und Kriege machen Staaten“, fasst nicht nur die 
Erfahrung, die im Europa der frühen Neuzeit gemacht wurden, sondern auch jene von China während der „Frühlings- und Herbstperiode“ sowie der „Periode der streitenden Reiche“, die ihrerseits zur Entstehung eines unpersönlichen Staates während der Qin-Vereinigung im 3. Jahrhundert vor Christus führten, zusammen. ${ }^{6}$

Gleichermaßen gibt es auffallend wenig Nachweise dafür, dass Bemühungen von NGOs und anderen Gebern zur Förderung einer verantwortungsvollen Regierungsführung mittels erhöhter Transparenz- und Rechenschaftspflichten einen messbaren Einfluss auf die staatliche Performance gehabt hätten. ${ }^{7}$ Die Theorie, dass es eine Korrelation zwischen der zunehmenden Verfügbarkeit von Informationen über die Regierungsleistung und der Qualität der tatsächlichen Regierungsleistung gibt, beruht auf einer Reihe heroischer Annahmen - dass Bürger sich über eine schlechte Regierungsleistung Gedanken machen würden (anstatt sich mit auf ethnisch motivierte Vetternwirtschaft zurückzuführenden Vorteilen zu begnügen); dass sie dazu in der Lage wären, sich politisch zu organisieren, um Druck auf die Regierung auszuüben; dass die politischen Institutionen eines Landes so ausgestaltet wären, dass sie den tatsächlichen Willen des Volkes den Politikern übermitteln könnten und zwar in einer Weise, die letztere rechenschaftspflichtig machen würden; und schlussendlich, dass die Regierung tatsächlich in der Lage ist, den Anforderungen der Bürger gerecht zu werden.

Die tatsächliche Beziehungsgeschichte zwischen staatlicher Modernität und Demokratie ist weitaus komplizierter, als gegenwärtige Theorien nahelegen. Dem erstmals von Martin Shefter entwickelten Rahmenkonzept folgend, habe ich an anderer Stelle argumentiert, dass die Abfolge, in welcher Demokratie (gemessen am Grad des allgemeinen Wahlrechts) und moderne Staatlichkeit entstanden sind, die langfristige Qualität von Regierungen bestimmt hat. ${ }^{8}$ Dort, wo ein moderner Staat konsolidiert wurde, noch bevor es zu einer Ausdehnung des Wahlrechts kam, hat dieser oft bis in die Moderne überlebt; eine der Staatsreform vorangegangene demokratische Öffnung resultierte jedoch in zahlreichen Fällen in weitverbreitetem Klientelismus. Das gilt vor allem für jenes Land, das das Wahlrecht zunächst nur allen weißen Männern zuerkannte, nämlich die Vereinigten Staaten. Hier entstand sodann das weltweit erste tief verzweigte klientelbestimmte politische System (in den Vereinigten Staaten bekannt als das System der Ämterpatronage („spoils system“ oder „patronage system“)).

6 Diesen Punkte mache ich in meinem Buch The Origins of Political Order: From Prehuman Times to the French Revolution, New York, Farrar, Straus and Giroux, 2011.

7 Siehe, zum Beispiel, Ivar Kolstad / Arne Wiig, Is Transparency the Key to Reducing Corruption in Resource-Rich Countries?, World Development 37 (2009) 521-532; Mehmet Bac, Corruption, Connections and Transparency: Does a Better Screen Imply a Better Scene?, Public Choice 107 (2001) 87-96; Susan Rose-Ackerman / Rory Truex, Corruption and Policy Reform, working paper prepared for the Copenhagen Consensus Project, 27. Februar 2012; und Luca Etter, Can Transparency Reduce Corruption?, paper vorgestellt auf der Doing Business Conference, Georgetown University, Washington, D. C., Februar 2014.

8 Martin Shefter, Political Parties and the State: The American Historical Experience, Princeton, Princeton University Press, 1994. 
In diesem Land standen sich während des 19. Jahrhunderts die Demokratie und die Qualität der Staatlichkeit klar als Gegensätze gegenüber. Der Grund dafür liegt darin, dass in Demokratien mit niedrigem Einkommens- und Bildungsniveau die Wähler eher durch individuelle Anreizwirkungen (der Kern des Klientelismus) mobilisiert und zum Wählen bewegt werden können als durch Versprechungen einer programmatischen staatlichen Politik. ${ }^{9}$

Die Situation verändert sich allerdings bei einem höheren Wohlstandsniveau. Wähler mit höherem Einkommen sind schwieriger durch individuelle Zahlungen zu bestechen, und sie tendieren eher dazu, sich für programmatische Politik zu interessieren. Hinzu kommt, dass ein höheres Entwicklungsniveau in der Regel von marktwirtschaftlichem Wachstum angetrieben ist, womit gewisse Alternativen zur persönlichen Bereicherung außerhalb der Politik eröffnet werden. Die letzte Wahl in Taiwan, die durch ein hohes Maß an Klientelismus gekennzeichnet war, fand in den frühen 1990ern statt; danach waren taiwanesische Wähler schlicht zu wohlhabend, um leicht zu bestechen zu sein. ${ }^{10}$

Obwohl Demokratie bei einem niedrigen Pro-Kopf-Einkommen Klientelismus erheblich begünstigen kann, kann sie den Weg in Richtung einer höheren Regierungsqualität ebnen, wenn Länder wohlhabender werden. Die Vereinigten Staaten bieten sich hier erneut als Beispiel an: In den 1880ern wandelte sich das Land rasch von einer Agrargesellschaft in eine urbane Industriegesellschaft, die über einen gigantischen kontinentalen Markt an neuen Technologien, wie die Eisenbahn, miteinander verbunden war. Wirtschaftliches Wachstum begünstigte das Entstehen neuer ökonomischer Akteure - urbanen Fachkräften, vielschichtigeren unternehmerischen Interessen und der Mittelklasse im Allgemeinen -, die nach einer höheren Regierungsqualität verlangten und im bestehenden Klientelsystem keine Berücksichtigung gefunden haben. Eine Volksbewegung führte 1883 zur Annahme einer Textstelle im Pendleton $A k t$, die das Prinzip eines leistungsorientierten Verfahrens bezüglich Einstellungen in den Beamtenapparat des Bundes verankerte, das von nachfolgenden Präsidenten, wie Theodore Roosevelt (1901-1909) und Woodrow Wilson (1913-1921), stark gefördert wurde. Parteiführer und Klientelpolitik genossen weiterhin eine hohe Stellung bzw florierten auch nach dieser Entwicklung über Jahrzehnte hinweg. Ab der Mitte des 20. Jahrhunderts wurden sie allerdings schrittweise von den meisten U.S.-Städten durch entschlossene politische Kampagnen beseitigt. Wenn heutige Demokratien, wie Indien und Brasilien, Protektionismus und Korruption in den Griff bekommen wollen, werden sie einen ähnlichen Weg beschreiten müssen.

9 Francis Fukuyama, Democracy and the Quality of the State, Journal of Democracy 24 (2013) 5-16.

10 Mushtaq H. Khan, Markets, States, and Democracy: Patron-Client Networks and the Case for Democracy in Developing Countries, Democratization 12 (2005) 704-724; Chin-Shou Wang / Charles Kurzman, The Logistics: How to Buy Votes, in: Elections for Sale: The Causes and Consequences of Vote Buying, hg. v. Frederic Charles Schaffer, Boulder, Colo., Lynne Rienner, 2007, 61-78. 


\section{Die Notwendigkeit der Durchsetzung}

Die Vereinigten Staaten hatten einen gewichtigen Vorteil, den viele neue Demokratien heute nicht haben. Sie konnten sich stets auf eine starke Polizeigewalt stützen, welche in der Lage war, die geltenden Gesetze durchzusetzen. Dieser Vorteil wurzelt im Common Law, einem in den ehemaligen Kolonien Englands bereits vor Erlangung ihrer Unabhängigkeit stark gefestigten Erbe der britischen Kolonialzeit. US-Regierungen konnten sich in jeder Hinsicht immer auf eine vergleichsweise starke Polizeigewalt verlassen, um all jene Personen, die sich auf den unterschiedlichen Regierungsebenen strafbar gemacht hatten, anzuklagen und zu verurteilen. Diese staatliche Zwangsgewalt wurde durch ein tiefes Vertrauen in die Legitimität des Rechts gestützt, weshalb sie sich fast überall als echte Autorität darstellte. In der Fähigkeit zur Rechtsdurchsetzung überlagern sich die staatliche Handlungsfähigkeit und die Rechtsstaatlichkeit; sie ist entscheidend, wenn es darum geht, mit einem Problem wie der Korruption umzugehen. Das Verhalten von Amtsträgern hängt von Anreizen ab, die nicht nur in adäquater Bezahlung bestehen, sondern auch in der Angst, für Rechtsverletzungen bestraft zu werden. In vielen Ländern werden Steuern nicht bezahlt und Bestechungsgelder angenommen, weil die Wahrscheinlichkeit, dass derartige Rechtsverletzungen mit einer Gefängnisstrafe geahndet werden, sehr gering ist.

Die Etablierung einer effektiven Durchsetzung war ein entscheidender Erfolgsfaktor in den georgischen Bemühungen, die Leistung(sfähigkeit) seines öffentlichen Sektors zu verbessern. Im Anschluss an die Rosenrevolution 2003 startete die Regierung unter Präsident Micheil Saakaschwili einen energischen Kampf gegen die Korruption, erfasst war etwa der Bereich der Verkehrspolizei; ebenso wurde gegen Steuerhinterziehung und die allgegenwärtigen Machenschaften von als „Diebe im Gesetz“ („thieves-inlaw") bezeichneten Kriminellen vorgegangen. Während manches davon mittels Transparenzinitiativen und positiven Anreizen (zum Beispiel durch die Veröffentlichung von Regierungsdaten online und der Verzehnfachung der Polizeigehälter) bewerkstelligt wurde, war die Etablierung einer effektiven Durchsetzung von der Schaffung neuer Polizeieinheiten abhängig, welche stark öffentlichkeitswirksame Verhaftungen von (früheren) ranghohen Amtsträgern und Geschäftsmännern vornahmen. Bis zum Ende der Saakaschwili-Regierung war diese verstärkte Polizeigewalt in vielerlei Hinsicht missbraucht worden; politisch hatte dies die Wahl von Bidsina Iwanischwili und seiner Bewegung Georgischer Traum zur Folge. ${ }^{11}$

Korruptionseindämmung erfordert eine grundlegende Verschiebung der normativen Verhaltenserwartungen der Bevölkerung - wenn sich jeder um mich herum be-

11 World Bank, Fighting Corruption in Public Services: Chronicling Georgia's Reforms, Washington, D. C., World Bank, 2012; Peter Pomerantsev et al., Revolutionary Tactics: Insights from Police and Justice Reform in Georgia, Legatum Institute, London, Juni 2014. 
stechen lässt, sähe ich aus wie ein Narr, wenn ich nicht selbst auch mitmachte. Unter derartigen Umständen stellt Angst einen viel wirkungsvolleren Motivator dar als gute Intentionen und wirtschaftliche Anreize. Vor der Rosenrevolution galt Georgien als einer der korruptesten Nachfolgestaaten der ehemaligen Sowjetunion. Die Verabschiedung zahlreicher (Reform)Maßnahmen durch die Regierung hat jedoch dazu geführt, dass Georgien mittlerweile als einer der am wenigsten korrupten Nachfolgestaaten gilt. Es ist nicht leicht, Beispiele effektiv regierter Gemeinwesen zu finden, in denen auf die Ausübung von Zwangsgewalt verzichtet wird. Gegenwärtige Bemühungen, gute Regierungsführung durch verstärkte Transparenz und Rechenschaftspflichten voranzutreiben, sind zum Scheitern verurteilt, wenn nicht gleichzeitig auch Anstrengungen zur Stärkung der Durchsetzungskraft unternommen werden.

In Political Order in Changing Societies führt Samuel Huntington aus, dass die politische Dimension der Entwicklung oftmals nicht mit der gesellschaftlichen Mobilisierung schritthalten kann und folglich zu politischer Unordnung führt. Auch kann es ein korrespondierendes Unvermögen staatlicher Institutionen geben, die nicht mit der Entwicklung demokratischer Institutionen mithalten können.

Diese Erkenntnis hat wichtige Auswirkungen auf die Art und Weise, wie die Vereinigten Staaten und andere Demokratien die Demokratieförderung in anderen Ländern betreiben. In der Vergangenheit bestanden die Schwerpunkte eindeutig darin, in autoritären Ländern die gleichen Voraussetzungen durch die Unterstützung von zivilgesellschaftlichen Organisationen zu schaffen und die Übergangsphase von der Diktatur zur Demokratie zu unterstützen.

Die Schaffung einer lebensfähigen Demokratie erfordert allerdings zwei weitere Schritte, während derer die anfängliche Mobilisierung gegen Tyrannei gefestigt und institutionalisiert und somit in eine dauerhafte Praxis umgewandelt wird. Der erste Schritt besteht in der Organisation von gesellschaftlichen Bewegungen und deren Überführung in politische Parteien, welche an Wahlen teilnehmen können. Zivilgesellschaftliche Organisationen legen ihren Fokus üblicherweise auf ganz spezifische Themen und sind nicht darauf ausgerichtet, Wähler zu mobilisieren - das ist unzweifelhaft die Domäne politischer Parteien. Das Versäumnis, politische Parteien zu gründen, erklärt, warum liberale Kräfte oftmals in Übergangsländern - von Russland über die Ukraine bis nach Ägypten - an der Wahlurne gescheitert sind.

Der zweite notwendige Schritt betrifft sodann die Herausbildung von staatlichen Strukturen und staatlicher Handlungsfähigkeit. Wenn einmal eine demokratische Regierung eingesetzt ist, muss sie tatsächlich regieren - das heißt, sie muss eine legitime Autorität ausüben und die Versorgung der Bevölkerung mit grundlegenden Dienstleistungen sicherstellen. Die Demokratieförderungsbewegung hat den Herausforderungen demokratischen Regierens viel weniger Aufmerksamkeit gewidmet als der ursprünglichen Mobilisierung und dem Übergang. Ohne die Fähigkeit, gut zu regieren, werden neue Demokratien die Erwartungen ihrer Anhänger allerdings enttäuschen und sich selbst delegitimieren. So zeigt die Geschichte der Vereinigten Staaten, dass 
Demokratisierung unter Außerachtlassung staatlicher Modernisierung tatsächlich zu einer Schwächung der Regierungsqualität führen kann.

Das bedeutet hingegen nicht, dass staatliche Modernisierung nur unter autoritären Bedingungen erreicht werden kann. Die Tatsache, dass in vielen seit langem bestehenden Demokratien zuerst die Staatenbildung und erst dann die Demokratisierung was Samuel Huntington als „autoritären Systemwandel“ („authoritarian transition“) bezeichnete - vonstattenging, bedeutet nicht notwendigerweise, dass dies eine tragfähige Strategie für Länder in der heutigen Welt ist, wo die allgemeinen Anforderungen und Erwartungen an die Demokratie ungleich höher sind. Wohl oder übel werden viele Länder weltweit moderne Staatlichkeit zur selben Zeit errichten müssen, zu der sie demokratische Institutionen und Rechtsstaatlichkeit („rule of law“) etablieren. Das bedeutet, dass die Demokratieförderungsbewegung der Errichtung moderner Staatlichkeit viel mehr Beachtung schenken muss und sich nicht zurücklehnen kann, wenn autoritäre Regierungen gestürzt werden. Dementsprechend empfiehlt sich auch ein breiterer intellektueller Themenkatalog für das Journal of Democracy: Neben bedeutenden Beiträgen zum Studium der Entstehung und Konsolidierung von Demokratien besteht die Notwendigkeit, erneute Aufmerksamkeit auf die Frage zu richten, wie moderne staatliche Institutionen entstehen und zerfallen. 
III. Die Grundlagen des demokratischen Rechtsstaates und dessen Krise 



\title{
Demokratie als Attribut Zur Theorie des demokratischen Rechtsstaates als Verfassungsprinzip
}

\author{
HOLGER GREFRATH / CLARA MAIER
}

\section{On Practise and Theory of the Democratic Rechtsstaat as a Constitutional Principle}

Abstract: The democratic Rechtsstaat - as a specific concept apart from the rule of law doctrine - has a long and contradictory history in twentieth century political and constitutional thought as well as in concrete political practise. However, precisely this contradictory history is usually submerged in the contemporary legal historical and theoretical scholarship on this issue. This article seeks to reconstruct the tension inherent in the concept of the democratic Rechtsstaat as first suggested by the constitutional theorist Hermann Heller. It proposes a new understanding of the relationship of the Rechtsstaat and democracy on the basis of the German constitutional principles as mutually restricted, defined and amended in the democratic Rechtsstaat.

Keywords: Rechtsstaat, democracy, constitutional principles, Hermann Heller, Wolfgang Abendroth

\section{Einleitung}

Warum sprechen wir vom „demokratischen Rechtsstaat“? Warum nicht von der „rechtsstaatlichen Demokratie“" ? Und warum nicht schlicht von „Demokratie und Rechtsstaat"? In der politischen Sprache ist der demokratische Rechtsstaat zum Schlagwort für einen legitimen Staat schlechthin geworden. Besonders in der deutschen Öffentlichkeit wird für Länder wie Polen, die Türkei und andere Staaten, in

1 Freilich gibt es prominente Ausnahmen, etwa Ernst-Wolfgang Böckenförde, Demokratie als Verfassungsprinzip, in: Handbuch des Staatsrechts, hg. von Josef Isensee / Paul Kirchhof, Bd. 2, 3. Aufl. $2004, \$ 24$ Rn. 83; Kurt Eichenberger, Gesetzgebung im Rechtsstaat, VVDStRL 40 (1982), 10; Richard Bäumlin, Die rechtsstaatliche Demokratie, 1954. 
denen Verfassungsgerichtsbarkeit und Jurisdiktion geschwächt werden, in denen Bürgerrechte prekär geworden sind, die Wiederherstellung des demokratischen Rechtsstaates gefordert. ${ }^{2}$ So berechtigt solche Aufrufe in der Sache sind, bleibt doch die spezifische Formulierung interessant, da sie auf eine sehr eigene und außerhalb des deutschen Sprachraums nicht immer leicht zu vermittelnde Vorstellung von Politik verweist. Der demokratische Rechtsstaat als zentrale Kategorie im deutschsprachigen politischen Diskurs gibt ein Politikverständnis preis, wonach der Rechtsstaat die primäre Legitimitätsordnung des modernen Staates ist. Innerhalb dieses Politikverständnisses bleibt die Demokratie Attribut.

Auch im wissenschaftlichen Sprachgebrauch begegnen uns Demokratie und Rechtsstaat oft in dieser besonderen Verbindung. Vor allem natürlich im Verfassungsrecht, wo der demokratische Rechtsstaat seine theoretischen Wurzeln hat, treten beide Begriffe zumeist als Amalgam auf. Besonders in der Theoretisierung und juristischen Verarbeitung der sogenannten Verfassungsprinzipien, die mit dem Grundgesetz neu etabliert wurden, spielt der demokratische Rechtsstaat die entscheidende Rolle. Dabei werden jedoch im Verfassungsrecht wie in breiteren Öffentlichkeit mit dem Begriff des demokratischen Rechtsstaates häufig die inneren Spannungen, die zwischen den beiden Prinzipien herrschen, überspielt. Ja, ausgehend von griffigen Kurzdefinitionen der Verfassungsprinzipien der Rechtstaatlichkeit und der Demokratie erscheint der demokratische Rechtsstaat geradezu als die Staatsform der unüberwindlichen Gegensätze, eine Verfassung gewordene contradictio in adiecto: Während der Rechtsstaat die „Staatsform

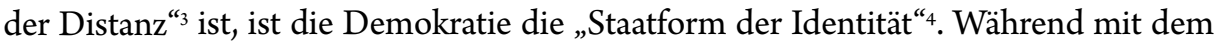
Rechtsstaat der Gegensatz von Staat und Gesellschaft erhalten wird, wird mit der Demokratie der Gegensatz von Beherrschten und Herrschenden endgültig aufgelöst. Wie lassen sich diese widerstrebenden Impulse also vereinen und theoretisch erfassen? Wo liegen die spezifischen Potentiale der demokratischen Rechtsstaatlichkeit?

Im folgenden Beitrag soll sowohl aus politisch theoretischer wie auch verfassungsrechtlicher Perspektive die Form des demokratischen Rechtsstaates genauer untersucht, hinterfragt und historisch eingeordnet werden. Besonderes Augenmerk gilt dabei der Verankerung des demokratischen Rechtsstaates in der deutschen Verfas-

2 Hier sei nur eine kleine Auswahl neuerer Artikel zitiert: Michael Göring, Der Versuch, Europa zu kapern, in: Frankfurter Allgemeine Zeitung, 30.07.2018, Nr. 174, S. 9, Konrad Schuller, Risiko Polen, in: Frankfurter Allgemeine Sonntagszeitung, 08.07.2018, Nr. 27, S. 10, Adrian Lobe, Software frisst die Welt, in: Süddeutsche Zeitung, 05.07.2017, Nr. 152, S. 12, Kai Strittmatter, Hirsch und Pferd, in: Süddeutsche Zeitung, 02.02.2017, Nr. 27, S. 9 .

3 Michael Kloepfer, Gesetzgebung im Rechtsstaat, VVDStRL 40 (1982), 65; vgl. zum „Pathos der Distanz“ im Rechtsstaat zuvor bereits Peter Lerche, Übermaß und Verfassungsrecht, 1961, 57.

4 Trotz aller Unterschiede in der Begründung und in den Konsequenzen in seltener Eintracht Hans Kelsen, Wesen und Wert der Demokratie, 2. Aufl. 1929, 14 und Carl Schmitt, Verfassungslehre, 1928, $234 \mathrm{ff}$.; vgl. dazu Horst Dreier, Kelsens Demokratietheorie: Grundlegung, Strukturelemente, Probleme, in: Kelsens Wege sozialphilosophischer Forschung, hg. von Robert Walter / Clemens Jabloner, 1997, 84 f., 90; Hasso Hofmann, Legitimität gegen Legalität, 4. Aufl. 2002, $139 \mathrm{ff}$. 
sungswirklichkeit durch die Schaffung der Verfassungsprinzipien im Bonner Grundgesetz. Der demokratische Rechtsstaat als Formsprache von Staatlichkeit soll also in seiner spezifischen historischen Entfaltung ernst genommen werden. Von einer Einordnung der juristischen Verankerung des demokratischen Rechtsstaates in der Bundesrepublik, zu seiner dogmatischen Erfassung, seiner theoretischen Begründung und konkreten historischen Gestaltung zeigt dieser Beitrag ein Panorama des demokratischen Rechtsstaates als spezifischer politischer Ordnung nicht als universales Prinzip legitimer Staatlichkeit.

\section{Zur politischen Theorie des demokratischen Rechtsstaats}

Im Gegensatz zur juristischen Literatur, gibt es in der politischen Theorie ein starkes Bewusstsein für die normative und historische Spannung, die zwischen Rechtsstaat und Demokratie potentiell besteht. Diese Spannung findet in der politisch-theoretischen Literatur im Wesentlichen zwei Bearbeitungsformen: Zum einen wird durch eine Gegenüberstellung von Demokratie und Rechtsstaat die Unvereinbarkeit beider Prinzipien behauptet. Eine solche Grundhaltung kommt etwa in dem von Detlef Georgia Schulze geleiteten Forschungsprojekt zu Rechtsstaat und Demokratie in Deutschland und Spanien zum Ausdruck. ${ }^{5}$ Zum anderen gibt es den aktiven Versuch einer normativen Ineinssetzung beider Prinzipien, wie sie Jürgen Habermas mit seinem Konzept der Gleichursprünglichkeit von Rechtsstaat und Demokratie in Die Einbeziehung des Anderen entwickelt hat. ${ }^{6}$

In ihrem Aufsatz Rechtsstaat versus Demokratie durchmisst Detlef Georgia Schulze die Untiefen des Rechtsstaatsdiskurses seit dem 18. Jahrhundert und kommt zu dem Schluss, dass selbst die radikalen Kritiker des Rechtsstaates wie Helmuth Ridder diesen nie - und sei es als politische Rhetorik - ganz aufgeben konnten. Schulze fordert dagegen die Einsicht in den radikal antidemokratischen Charakter des Rechtsstaates. Sie argumentiert, die „Abgrenzung des Rechtsstaats von der Demokratie“ sei für diesen nicht „akzidentiell“, sondern „konstitutiv“?

5 Vgl. die beiden Sammelbände: Rechtsstaat statt Revolution, Verrechtlichung statt Demokratie? Transdisziplinäre Analysen zum deutschen und spanischen Weg in die Moderne, Bd. 1: Historische Voraussetzungen, sowie Bd. 2: Die juristischen Konsequenzen, hg. von Detlef Georgia Schulze / Sabine Berghahn / Frieder Otto Wolf, 2010.

6 Vgl. Jürgen Habermas, Über den internen Zusammenhang von Rechtsstaat und Demokratie, in: Die Einbeziehung des Anderen, 1996, 293-305.

7 Detlef Georgia Schulze, Rechtsstaat versus Demokratie. Ein diskursanalytischer Angriff auf das Heiligste der Staatsrechtslehre, in: Rechtsstaat statt Revolution, Verrechtlichung statt Demokratie? Transdisziplinäre Analysen zum deutschen und spanischen Weg in die Moderne, Bd. 2: Die juristischen Konsequenzen, hg. von Detlef Georgia Schulze / Sabine Berghahn / Frieder Otto Wolf, 2010, 553, 611. 
Dem steht die Theoretisierung des Rechtsstaates bei Habermas gegenüber. Dieser argumentiert, dass Rechtsstaat und Demokratie notwendig aufeinander verwiesen seien. Ja, der Rechtsstaat könne recht im eigentlichen Sinne nur sein, wenn die Rechtssetzung demokratisch legitimiert worden sei. Ein undemokratischer Rechtsstaat erscheint in diesem Sinne als eine contradictio in adiecto. Ähnlich wie die juristischen Autoren sieht Habermas im demokratischen Rechtsstaat ein Ideal von Staatlichkeit verkörpert, das seine Ursprünge in der europäischen Aufklärung hat. Im Gegensatz zu Schulze hält er den Rechtsstaat also nicht für ein spezifisch deutsches Phänomen mit spezifisch deutschen Pathologien.

Dennoch bleibt auch bei Habermas das Ineinandergreifen von Rechtsstaat und Demokratie von spezifischen Vorbedingungen abhängig. Beide Prinzipien ergänzen sich also nicht notwendigerweise. Gerade in der Geschichte der politischen Philosophie, so zeigt Habermas auf, seien beide Prinzipien, als Volkssouveränität und Menschenrechte, oft fälschlich einander gegenübergestellt worden. So habe Rousseau im Sinne eines republikanischen Politikbegriffs den souveränen Willen des Volkes überbetont und Kant im Sinne eines liberalen Verständnisses die Autonomie der Rechtsperson. ${ }^{8}$ Beide, so Habermas, und mit ihnen die von ihnen begründeten Politiktraditionen hätten es so verfehlt die „Gleichursprünglichkeit“ von persönlicher Autonomie und Volkssouveränität auszudrücken:

„[...] die Idee der Menschenrechte, die sich im Recht auf gleiche subjektive Handlungsfreiheiten ausspricht, darf weder dem souveränen Gesetzgeber als äußerste Schranke bloß auferlegt noch als funktionales Requisit für dessen Zweck instrumentalisiert werden.“99

Diesen falschen Konzeptualisierungen des Verhältnisses von Recht und Demokratie setzt Habermas nun seine Vorstellung von einem internen Zusammenhang beider entgegen. Menschenrechte, und damit die Fundierung des modernen Rechtsstaates, dürften dem Souverän nicht, so Habermas, "gleichsam paternalistisch übergestülpt werden“, auch wenn diese „moralisch noch so gut begründet werden können“.10 Vielmehr müssten diese Rechte als das „Medium“ verstanden werden, durch das sich „die Autonomie" der Rechtssubjekte erst Ausdruck zu verleihen im Stande ist. ${ }^{11}$ Rechtsstaat und Demokratie stehen also bei Habermas in einem komplexen Verhältnis. Obwohl ihre Theoretisierungen sie häufig als Gegensätze konstruiert haben, ist die Erkenntnis in ihre „Gleichursprünglichkeit“, ihre dialektische Verwiesenheit aufeinander, entscheidend für das Verständnis legitimer politischer Ordnung. Dennoch bedarf diese Gleichursprünglichkeit bestimmter institutioneller Voraussetzungen, um sich in der

8 Jürgen Habermas, Über den internen Zusammenhang von Rechtsstaat und Demokratie, in: Die Einbeziehung des Anderen, 1996, 299.

9 Ebd.

10 Ebd., 301.

11 Ebd. 
politischen Ordnung richtig auszudrücken. So dürfen nach Habermas die Grundlagen der rechtlichen Ordnung, die Menschenrechte, nicht moralisch begründet und gleichsam in der Politik nur mehr vorgefunden werden. ${ }^{12}$ Dies stellt dann auch Habermas Theoretisierung des demokratischen Rechtsstaats zumindest in ein schwieriges Verhältnis zu der konkreten politischen Verfasstheit zumindest des bundesdeutschen Rechtsstaates, für den der Gegensatz von Volkssouveränität und Menschenrechte schließlich konstitutiv war.

Eine komplexere Deutung der Ideengeschichte von Rechtsstaat und Demokratie vertritt Ingeborg Maus. In ihrer grundlegenden, neuen Theoretisierung der Volkssouveränität aus dem Jahr 2007 argumentiert sie, dass Rechtsstaat und Demokratie erst im 20. Jahrhundert durch eine Verfälschung der Vorstellung von Volkssouveränität zueinander in Konkurrenz getreten seien. Die begriffliche Ordnung, die Schulze diagnostiziert und die Habermas voraussetzt, wonach der demokratische Rechtsstaat in seiner konkreten Institutionalisierung zuerst und zuletzt Rechtsstaat bleibt wird bei Maus neu gedacht. Sie zeigt die ursprüngliche Angewiesenheit von Recht und legitimer Gesetzgebung auf die Volkssouveränität. Der Gegensatz von Rechtsstaat und Demokratie wird so zu einem Produkt der falschen Demokratietheorien des 20. Jahrhunderts. ${ }^{13}$

Insgesamt wird deutlich, dass das Problembewusstsein für die Aporien der demokratischen Rechtsstaatlichkeit in der politischen Theorie und Ideengeschichte durchaus hoch ist. Im Gegensatz zu ihren juristischen Kollegen, sehen Vertreter und Vertreterinnen der politischen Theorie den demokratischen Rechtsstaat als komplexes Phänomen, dessen spezifische politische Bedingungen hergestellt werden müssen. Die konkrete Institutionalisierung von demokratischer Rechtsstaatlichkeit und ihre politischen Implikationen rücken so ins Zentrum des Diskurses. Damit folgen Maus und Schulze, aber auch Habermas, einer Tradition der Rechtsstaatskritik, die gerade für den juristischen Diskurs der Weimarer Zeit prägend war, dessen wesentliche Protagonisten, Franz Neumann, Otto Kirchheimer und Hermann Heller, aber durch die erzwungene Emigration in den 1930er Jahren, in der deutschen Rechtswissenschaft nach dem Krieg kaum eine Rolle spielten. ${ }^{14}$

12 Ebd.

13 Ingeborg Maus, Über Volkssouveränität. Elemente einer Demokratietheorie, 2011.

14 Vgl. zum Wirken der Emigranten Alfons Söllner, Political Scholar. Zur Intellektuellengeschichte des 20. Jahrhunderts, 2018. 


\section{Der demokratische Rechtsstaat in der frühen Bundesrepublik und in der Weimarer Republik}

Im Sinne einer kritischen Theorie demokratischer Rechtsstaatlichkeit darf der Rechtsstaat, wie immer man seine demokratischen Potentiale einschätzt, nicht einfach als „gemeinsames europäisches Substrat" verstanden werden. ${ }^{15}$ Die gemeinsamen Wurzeln etwa mit der rule of law Idee dürfen für eine Begründung des Rechtsstaates nicht einfach vorausgesetzt, sie müssen erwiesen werden. Zusätzlich zur politisch-theoretischen Erfassung des demokratischen Rechtsstaats als politischer Form, sollte aber seine normative Beurteilung auch um eine historische Kontextualisierung ergänzt werden. Denn nur so können die konkreten institutionellen Formen, die der demokratische Rechtsstaat im 20. Jahrhundert angenommen hat, überhaupt in den Blick kommen.

Schon der Begriff des demokratischen und sozialen Rechtsstaates, wie ihn Hermann Heller in seiner 1930 veröffentlichten Schrift Rechtsstaat oder Diktatur? geprägt hat, entstammt ja einer ganz konkreten historischen Situation. Heller drückt mit dem Text das Bedürfnis aus, den Rechtsstaatsbegriff neu zu akzentuieren, den Rechtsstaat durch seine Attribute genauer zu bestimmen. Die Notwendigkeit einer solchen Neubestimmung entsprang der, aus Hellers Sicht, problematischen Entwicklung der Rechtsinstitutionen in der Weimarer Zeit. So beklagte Heller in Rechtsstaat oder Diktatur? die zunehmende Inanspruchnahme von Begriffen materieller Rechtsstaatlichkeit gegen die Legislative. Besonders die radikale Ausdehnung des richterlichen Prüfungsrechts sah Heller als eine gefährliche antidemokratische Verformung des Rechtsstaats in der Weimarer Republik. Es sei bezeichnend, schrieb Heller, dass es „rechtsstehende Juristen“ seien, die wieder materielle Gerechtigkeitsgrundsätze der positiv gesetzten Ordnung entgegen setzen wollten. Diese „eminente politische Bedeutung dieses Standpunktwechsels der konservativen Jurisprudenz" sei aber nur zu verstehen, wenn man den „ungeheuren Machtzuwachs, den sich das Richtertum mit einer juristisch zweifellos falschen Reichsgerichtsentscheidung in Deutschland erobert" habe, berücksichtige. Vorstellungen von materieller Gerechtigkeit und einem materiellen Rechtsstaat können, so zeigt Heller auf, im Zusammenhang mit einem ausgedehnten richterlichen Prüfungsrecht als Waffe gegen die Legislative benutzt werden. ${ }^{16}$ Die „Überwachung der Volkslegislative durch den Richter“" ${ }^{{ }_{17}}$ sei, so Heller, keine „Renaissance des materiellen Rechtsstaatsgedankens“, sondern vielmehr Teil der „alten Entleerung des Rechtsstaatgedankens“.18

In vieler Hinsicht ist der demokratische Rechtsstaat, wie er von seinem Erfinder gedacht wurde also ein radikaler Gegenentwurf zu eben dem Rechtsstaatsdenken, das

15 Helmuth Schulze-Fielitz, Art. 20 (Rechtsstaat), in: Grundgesetz Kommentar, hg. von Horst Dreier, 3. Aufl. 2015, Bd. 2, Rn. 5 .

16 Hermann Heller, Rechtsstaat oder Diktatur, 1930, 9.

17 Ebd., 10.

18 Ebd. 
für die frühe Bundesrepublik prägend wurde. Im Gegensatz zur Vorstellung eines radikalen Bruchs mit einem nur positivistischen Rechtsstaat der Weimarer Zeit, wird so deutlich, wie stark der Rechtsstaatsdiskurs der Nachkriegszeit genau die Impulse konservativen Rechtsdenkens aufgriff, gegen die Heller argumentiert hatte. Nicht nur beruhte er ideologisch auf der Vorstellung einer notwendigen Einschränkung der Macht der Legislative und des Volkes, sondern auch die konkreten Institutionen, in denen er sich ausdrückte, überpositive positive Rechte und eine starke Verfassungsgerichtsbarkeit, stehen in dieser schwierigen Kontinuität.

Der Rechtsstaat wurde nach 1945 zur entscheidenden Ressource für den Wiederaufbau des westdeutschen Staates. Im Gegensatz zur Demokratie, war der Rechtsstaat mit seiner eigentümlichen Verbindung von legaler und legitimer Ordnung - der etymologischen Verknüpfung von Recht und Gerechtigkeit - politisch unverbraucht. Demokratie konnte nach 1945 zum einen als Teil alliierter politischer Erziehung wahrgenommen werden. Zum anderen wurde die Demokratie selbst als Ausgangspunkt des Nationalsozialismus verstanden. Aber nicht nur Historiker wie Friedrich Meinecke sprachen vom Nazi-Regime als von einem "Massenmachiavellismus “ ${ }^{19}$, auch in den Verhandlungen des parlamentarischen Rates drückte sich eine kritische Haltung zu Demokratie und Volkssouveränität aus. Dort wurde der Primat des Rechtsstaats als Verfassungsprinzip betont und die Wichtigkeit der Volkssouveränität als Erstbegründung des neuen Staates heruntergespielt. So argumentierte etwa Theodor Heuss in einer Sitzung des Ausschusses für Grundsatzfragen, dass „in dem Begriff des Rechtsstaats [...] die Legitimität klar zum Ausdruck“ komme und daher der Verweis auf die parlamentarische Regierungsform am Anfang des Grundgesetztextes überflüssig sei. ${ }^{20}$ Und Helene Weber verwies darauf, dass der „Rechtsstaat [...] im Vordergrund stehen“" müsse. Das Volk, so formulierte sie lapidar solle man „nachher bringen“.21

Hier wurde also nicht einfach Rechtsstaatlichkeit wiederhergestellt, sondern eine spezifische und neue Form von Rechtsstaatlichkeit begründet. Diese Rechtsstaatlichkeit beruhte auf einer starken Vorstellung von der Gerechtigkeit als Letztlegitimation der neuen politischen Ordnung. Wie Gustav Radbruch schon 1946 geschrieben hatte:

„Demokratie ist gewiß ein preisenswertes Gut, Rechtsstaat aber ist wie das täglich Brot, wie Wasser zum Trinken und wie Luft zum Atmen, und das Beste an der Demokratie gerade dieses, daß sie geeignet ist, den Rechtsstaat zu sichern“.22

19 Friedrich Meinecke, Die deutsche Katastrophe: Betrachtungen und Erinnerungen [1946], 1965, 84. Siehe dazu auch die Tocqueville Rezeption in konservativen Kreisen der Bundesrepublik, Martina Steber, „The West", Tocqueville and West German Conservatism from the 1950s to the 1970s, in: Germany and "the West". The History of a Modern Concept, hg. von Riccardo Bavaj / Martina Steber, 2015, 230-248.

20 Der Parlamentarische Rat 1948-1949, Akten und Protokolle, Ausschuß für Grundsatzfragen, hg. von Eberhard Pikart / Wolfram Werner, Bd. 5/I, 1981, 11. Sitzung vom 14. Oktober 1948, 289 f.

21 Ebd., 290.

22 Gustav Radbruch, Gesetzliches Unrecht und übergesetzliches Recht, in: SJZ 1 (1946), 108. 
Die eigentliche Rechtsproduktion durch parlamentarische Mehrheiten wurde hier weitgehend ausgeblendet. Zur neuen Konzeption von Rechtsstaatlichkeit trat dann in der frühen Geschichte der Bundesrepublik eine spezifische Institutionalisierung der politischen Ordnung, die die der Gerechtigkeit verpflichtete neue Rechtsstaatlichkeit gestalten sollte. Schon im Text des Grundgesetzes waren die Grundrechte in einer vollkommen neuen Art angelegt worden. Wie Carlo Schmid schon 1948 betonte, sollten die Grundrechte „das Grundgesetz regieren“ und nicht - wie in der Weimarer Republik - bloßes „Anhängsel“ sein. ${ }^{23}$ Hinzu kam, wie seit der Mitte der Weimarer Republik, eine Ausweitung des richterlichen Prüfungsrechts durch die Institutionalisierung des Bundesverfassungsgerichts als dem, wie es selbst sagte, „Hüter der Verfassung“ und als "Garant der objektiven Wertordnung “. 24

\section{Der demokratische Rechtsstaat im Grundgesetz}

Historisch standen Rechtsstaatlichkeit und Demokratie also sicherlich in einem Spannungsverhältnis als die Mütter und Väter des Grundgesetzes den demokratischen Rechtsstaat als Verfassungsprinzip schufen. Wenn aber diese Spannung besteht, ja, wenn sie nicht nur in der Theoretisierung, sondern auch in der konkreten politischen Praxis besteht, wie kann sie dann als Spannung produktiv gemacht werden? Kann aus der dogmatischen Verarbeitung der Verbindung von Demokratie und Rechtsstaatlichkeit zum demokratischen Rechtsstaat ein neues Verständnis beider Prinzipien erwachsen? Mag der Normtext der Verfassungsprinzipien auch noch so vertraut sein, so lohnt doch ein vertiefter Blick auf ihn:

Art. 20 GG

(1) Die Bundesrepublik Deutschland ist ein demokratischer und sozialer Bundesstaat.

(2) Alle Staatsgewalt geht vom Volke aus. Sie wird vom Volke in Wahlen und Abstimmungen und durch besondere Organe der Gesetzgebung, der vollziehenden Gewalt und der Rechtsprechung ausgeübt.

(3) Die Gesetzgebung ist an die verfassungsmäßige Ordnung, die vollziehende Gewalt und die Rechtsprechung sind an Gesetz und Recht gebunden.

23 Carlo Schmid, Was heißt eigentlich: Grundgesetz? [1948], in: Der Parlamentarische Rat 1948-1949, Akten und Protokolle, Plenum, hg. von Wolfram Werner, Bd. 9, 1996, 37.

24 Denkschrift des Bundesverfassungsgerichts vom 27. Juni 1952: Die Stellung des Bundesverfassungsgerichts. Gerichtet an den Bundespräsidenten, die Präsidenten des Bundestags und Bundesrats sowie die Bundesregierung, veröffentlicht am 19. Januar 1953, in: JZ 5 (1953), 157 f. Vgl. zur Formel „Hüter der Verfassung“ Matthias Jestaedt, ,Der Hüter der Verfassung als Frage des Rechtsgewinnungsverständnisses - ein etwas anderer Blick auf die Schriften von Carl Schmitt und Hans Kelsen, in: La controverse sur le guardien de la Constitution et la justice constitutionelle. Kelsen contre Schmitt, hg. von Olivier Beaud / Pasquale Pasquino, 2007, 155-175. 
Die genaue Lektüre des Wortlauts des Art. 20 GG führt zu dem augenfälligen und zunächst erstaunenden Befund, dass das Rechtsstaatsprinzip als einziges Verfassungsprinzip und damit im Gegensatz zum Demokratie-, Sozialstaats-, Bundesstaats- und Republikprinzip nicht ausdrücklich bei seinem Namen genannt, sondern lediglich in seinen Ausprägungen der Gewaltenteilung (Abs. 2) sowie der Verfassungs- und Rechtsbindung aller Staatsgewalt (Abs. 3) umschrieben wird. Diese konkrete Gestalt der Art. 20 GG lässt sich nur teilweise anhand seiner Genese erklären. Nachdem der Herrenchiemseer Entwurf überhaupt keine dem späteren Art. 20 GG entsprechende Norm enthalten hatte, brachte der Abgeordnete v. Mangoldt den Entwurf einer noch als Art. 21 nummerierten Norm in den Grundsatzausschuss ein, die folgenden Wortlaut hatte: „Die Bundesrepublik ist ein demokratischer und sozialer Rechtsstaat mit parlamentarischer Regierungsform und bundesstaatlichem Aufbau. ${ }^{\prime 25}$ Im weiteren Verlauf der Beratungen kommt das Wort „Rechtsstaat“, von dem Helene Weber noch forderte, dass es „im Vordergrund stehen“" ${ }^{26}$ müsse, aus nicht vollständig in den Protokollen dokumentierten und daher letztlich nicht mehr aufzuklärenden Erwägungen abhanden, wahrscheinlich ausgehend von einem Einwurf v. Mangoldts, der den Weg zur Formulierung des späteren Art. 20 Abs. 3 GG ebnete: „Das Wesen des Rechtsstaats besteht in der Herrschaft des Gesetzes, und zwar sowohl des geschriebenen Gesetzes wie des Gewohnheitsrechts. “27

Eine gänzlich andere Sprache spricht dagegen das sogenannte Homogenitätsgebot des Art. 28 Abs. 1 GG, das die für die Bundesländer bindenden Verfassungsgrundsätze normiert und das sich geradezu als eine authentische Interpretation des Art. 20 GG durch den Verfassunggeber selbst begreifen lässt ${ }^{28}$ :

Art. 28 GG

(1) Die verfassungsmäßige Ordnung in den Ländern muß den Grundsätzen des republikanischen, demokratischen und sozialen Rechtsstaates im Sinne dieses Grundgesetzes entsprechen.

Hier rückt das Rechtsstaatsprinzip auf einmal in den Fokus der Regelung, Republik, Demokratie und Sozialstaat werden zu bloßen Attributen des Rechtsstaats.

Wie oben dargestellt, trifft sich diese Unterordnung der anderen Verfassungsprinzipien unter den Rechtsstaat mit dem geistigen Klima, in dem das Grundgesetz verfasst wurde.

25 Der Parlamentarische Rat 1948-1949, Akten und Protokolle, Ausschuß für Grundsatzfragen, hg. von Eberhard Pikart / Wolfram Werner, Bd. 5/I, 1981, 11. Sitzung vom 14. Oktober 1948, 290.

26 Ebd.

27 Ebd., 292.

28 Vgl. etwa Eberhard Schmidt-Aßmann, Der Rechtsstaat, in: Handbuch des Staatsrechts, hg. von Josef Isensee / Paul Kirchhof, Bd. 2, 3. Aufl. 2004, \$26 Rn. 3. 


\section{Der demokratische Rechtsstaat als Verfassungsprinzip}

Für jede Verfassung lassen sich Verfassungsprinzipien beschreiben - in dem Sinne, dass sie ,jene Grundsatzgehalte der Verfassung, die man aufzählen müßte, wenn man mit möglichst wenig Elementen eine Verfassung lückenlos charakterisieren wollte " ${ }^{29}$ enthalten: „Sie erlauben es, einen konkreten Staat mit allgemeinen Begriffen zu charakterisieren“ ${ }^{\text {“ }}$

Das Besondere am Grundgesetz ist jedoch, dass es diese Aufzählung in Art. 20 Abs. 1 bis 3 GG und Art. 28 Abs. 1 GG selbst vorträgt und noch dazu in Art. 79 Abs. 3 GG für unveränderlich erklärt, also mit einer Ewigkeitsgarantie ausstattet. Diese „konzentrierte Zusammenfassung wesentlicher Aussagen über die Strukturprinzipien in einer Schlüsselnorm“ stellt „ein verfassungsrechtliches Novum “ dar. ${ }^{31}$ Durch ihre Positivierung sind die Verfassungsprinzipien nicht länger ein bloß heuristisches, letztlich deskriptives Instrument, sondern voll gültige und daher gleichermaßen subsumtionsfähige wie subsumtionsbedürftige Rechtssätze. Als neuartiger Normtypus und durch ihr konkretes Arrangement im Grundgesetz stellten und stellen die Verfassungsprinzipien die Staatsrechtslehre vor spezifische methodische Herausforderungen.

Seit dem Beginn der wissenschaftlichen Bearbeitung des Grundgesetzes hat sich die methodische Prämisse durchgesetzt, nach der die Auslegung von Verfassungsnormen, und damit auch diejenige der Verfassungsprinzipien im Wesentlichen denselben Regeln folgt wie die übliche Gesetzesauslegung. ${ }^{32}$ Just diesem methodischen Vorgehen fällt die bewusste Zusammensetzung der Verfassungsprinzipien durch die Mütter und Väter des Grundgesetzes anheim. Getreu dem überkommenen methodischen Grundsatz, dass der erste Schritt der Normkonkretisierung, der die folgende Auslegung und syllogistische Anwendung auf einen konkreten Lebenssachverhalt überhaupt erst ermöglicht, in der Zergliederung des Tatbestands der zu konkretisierenden Norm in einzelne Merkmale liegt, also gerade darin, diese Tatbestandsmerkmale möglichst „sauber“"33 vonein-

\footnotetext{
29 Philippe Mastronardi, Strukturprinzipien der Bundesverfassung? Fragen zum Verhältnis von Recht und Macht anhand des Wirtschaftsstaatsprinzips, 1988, 44; vgl. ders., Verfassungslehre. Allgemeines Staatsrecht als Lehre vom guten und gerechten Staat, 2007, 229.

30 Heinrich Koller, Die Aufnahme staatsgestaltender Grundsätze in die neue Bundesverfassung, in: Solothurnische Festgabe zum Schweizerischen Juristentag, 1998, 20.

31 Horst Dreier, Art. 20 (Einführung), in: Grundgesetz Kommentar, hg. von dems., 3. Aufl. 2015, Bd. 2, Rn. 1. 32 Martin Borowski, Subjekte der Verfassungsinterpretation, in: Handbuch des Staatsrechts, hg. von Josef Isensee / Paul Kirchhof, Bd. 12, 3. Aufl. 2004, \$ 274, Rn. 1: „Die Verfassungsinterpretation bildet einen Unter- und Sonderfall der Gesetzesinterpretation."; vgl. teilweise kritisch Ernst-Wolfgang Böckenförde, Die Methoden der Verfassungsinterpretation, in: Staat, Verfassung, Demokratie, 2. Aufl. 1992, $53 \mathrm{ff}$.

33 So wörtlich Bernd Heinrich, Strafrecht Allgemeiner Teil, 5. Aufl. 2016, Rn. 116.
} 
ander zu trennen, werden auch die Verfassungsprinzipien feinsäuberlich voneinander geschieden ${ }^{34}$ und erst dann in den Normanwendungsprozess eingespeist.

Letztlich handelt es sich bei den hier konturierten Vorgang der (Unter-)Scheidung der Verfassungsprinzipien - jenseits aller politischen und gesellschaftlichen Vorverständnisse - um das juristisch-methodische Kernproblem der berühmten Forsthoff-Abendroth-Kontroverse über das Verhältnis von Rechtsstaats- und Sozialstaatsprinzip, die pars pro toto für den methodischen Umgang mit den Verfassungsprinzipien insgesamt steht. Abendroths methodischer Zugang zur Anwendung der Verfassungsprinzipien ging davon aus, dass durch Demokratie, Rechtsstaat und Sozialstaat im Grundgesetz „drei gedankliche Elemente zu einer Einheit“ verbunden sind, die „einander durchdringen und isolierter Interpretation nicht mehr zugänglich sind“"35, das Grundgesetz also eine „unlösbare Zuordnung “ ${ }^{{ }^{36}}$ vorgenommen habe, während nach Forsthoff „Rechtsstaat und Sozialstaat auf der Verfassungsebene nicht vereinbar sind“"37. Freilich verbinden sich sowohl bei Abendroth als auch bei Forsthoff mit den geschilderten methodischen Prämissen ganz handfeste politische Ziele und Interessen, ${ }^{38}$ die einmal mehr die gesellschaftliche Brisanz scheinbar bloß akademischer Methodenfragen im Verfassungsrecht eindrucksvoll unter Beweis stellen.

Angesichts der bewusst im Wortlaut von Art. 20 GG und auch Art. 28 Abs. 1 GG gewählten Zusammenstellungen der Verfassungsprinzipien gut begründete Forderungen nach einer „kombinatorischen Interpretation“" ${ }^{39}$ widerstreben so sehr der juristischen Methode und letztlich dem juristischen Denkstil ${ }^{40}$ an sich, dass sie gar nicht erst entwickelt wurden. Hierbei dürfte nicht zuletzt die Tatsache eine Rolle gespielt haben, dass Abendroth der juristischen Methode und insbesondere deren Hang zum Formalismus die Tendenz zu „illusionären Ideologiesierungen“ attestierte, die es durch eine Verlagerung der Interpretationskompetenz insbesondere des Begriff des Sozialen hin zur „Wissenschaft von der Politik“ zu durchbrechen gelte ${ }^{41}$.

Bedient man sich der herkömmlichen Methode und sind die Verfassungsprinzipien einmal „sauber“ voneinander getrennt und geschieden, entwickelt sich ein ,immanen-

34 Vgl. grundsätzlich zum „Scheiden“ als juristischer Grundtechnik Fabian Steinhauer, Vom Scheiden. Geschichte und Theorie einer juristischen Kulturtechnik, Berlin 2015, passim und insb. $68 \mathrm{ff}$.; zuvor grundlegend Rudolf v. Jhering, Geist des römischen Rechts auf den verschiedenen Stufen seiner Entwicklung, Bd. 2, 1858, 361.

35 Wolfgang Abendroth, Zum Begriff des demokratischen und sozialen Rechtsstaates im Grundgesetz der Bundesrepublik Deutschland, in: Gesammelte Schriften, Bd. 2, 2008, 339.

36 Kurt Eichenberger, Gesetzgebung im Rechtsstaat, VVDStRL 40 (1982), 7, 10.

37 Ernst Forsthoff, Verfassungsprobleme des Sozialstaats, in: Rechtsstaatlichkeit und Sozialstaatlichkeit, 1968,145 .

38 Vgl. zum Überblick Florian Meinel, Der Jurist in der industriellen Gesellschaft, 2. Aufl. 2015, 360 ff.

39 Ulrich Scheuner, Die staatliche Intervention im Bereich der Wirtschaft, VVDStRL 11 (1954), 20.

40 Vgl. zu Begriff des Denkstils Ludwik Fleck, Entstehung und Entwicklung einer wissenschaftlichen Tatsache, 1981, 131.

41 Wolfgang Abendroth, Zum Begriff des demokratischen und sozialen Rechtsstaates im Grundgesetz der Bundesrepublik Deutschland, in: Gesammelte Schriften, Bd. 2, 2008, 356 f. 
te[s] Spannungsverhältnis der Prinzipien (sowohl untereinander als auch im Verhältnis zu anderen Verfassungsbestimmungen), das im Wege verhältnismäßiger Zuordnung bzw. der Herstellung praktischer Konkordanz aufzulösen ist. ${ }^{\text {“42 }}$

Auch bei isolierter, scheidender Interpretation und Anwendung ziehen die Verfassungsprinzipien spezifische methodische Probleme nach sich. Freilich handelt es sich bei den Verfassungsprinzipien nicht um Prinzipien im Sinne der Prinzipientheorie Robert Alexys und seiner Schüler ${ }^{43}$, sondern im Sinne des ,attributiven Charakters" ${ }^{44}$ der Verfassungsprinzipien als „Normen mit grundsätzlicher und besonders hervorgehobener Bedeutung "45 Keines der Verfassungsprinzipien ist jedoch ein Rechtsbegriff wie jeder andere. Kann allenfalls im dogmatischen Detail fraglich sein, was eine „Wegnahme “ im Sinne des $\$ 242$ StGB ist, repräsentieren „Demokratie“, „Rechtsstaat“, „Sozialstaat", „Bundesstaat" und „Republik“" schlagwortartig nichts weniger als die großen Ideen der politischen Menschheitsgeschichte und sind zugleich vage und historisch belastet, zugleich oder unter- und überdeterminiert.

Mit Ernst-Wolfgang Böckenförde lassen sich die Verfassungsprinzipien anschaulich als „Schleusenbegriffe" verstehen, durch die die Geschichte in das Recht einströmt: „[...] zu jenen vom Wortsinn her vagen und nicht ausdeutbaren Schleusenbegriffen, die sich ,objektiv' aus sich heraus, niemals abschließend definieren lassen, vielmehr offen sind für das Einströmen sich wandelnder staats- und verfassungstheoretischer Vorstellungen und damit auch für verschiedenartige Konkretisierungen, ohne sich dabei indessen inhaltlich völlig zu verändern, $d$. h. ihre Kontinuität zu verlieren und zu einer bloßen Leerformel herabzusinken ${ }^{46}$ In ähnlicher Stoßrichtung spricht Susanne Baer von „Schlüsselbegriffen“: „Schlüsselbegriffe sind in erster Linie Termini, die der Verklammerung von Perspektiven dienen. [...] Rechtbegriffe können sich nicht vollständig von einer Schlüsselfunktion abschotten. Die Reduktion auf den Entscheidungszusammenhang ist nie endgültig oder absolut. Rechtsbegriffe können jederzeit wieder ,aufgeschlossen, wieder Schlüsselbegriffe [...] werden. [...] Wir tun methodisch gut daran, das Schlüsselpotenzial der Rechtsbegriffe nicht zu vergessen.“" ${ }^{47}$

42 Horst Dreier, Art. 20 (Einführung), in: Grundgesetz Kommentar, hg. von dems., 3. Aufl. 2015, Bd. 2, Rn. 12.

43 Vgl. zu grundsätzlicher Kritik András Jakab, Re-Defining Principles as ,Important Rules. A Critique of Robert Alexy, in: On the Nature of Legal Principles, hg. von Martin Borowski, ARSP Beiheft 119, 2009, 145-159.

44 Armin von Bogdandy, Prinzipien von Staat, supranationalen und internationalen Organisationen, in: Handbuch des Staatsrechts, hg. von Josef Isensee / Paul Kirchhof, Bd. 11, 3. Aufl. 2013, \$, \$2 232 Rn. 30.

45 Horst Dreier, Art. 20 (Einführung), in: Grundgesetz Kommentar, hg. von dems., 3. Aufl. 2015, Bd. 2, Rn. 12.

46 Ernst-Wolfgang Böckenförde, Entstehung und Wandel des Rechtsstaatsbegriffs, in: Recht, Staat, Freiheit, 1991, $143 \mathrm{f}$.

47 Susanne Baer, Schlüsselbegriffe, Typen und Leitbilder als Erkenntnismittel und ihr Verhältnis zur Rechtsdogmatik, in: Methoden der Verwaltungsrechtswissenschaft, hg. von Eberhard Schmidt-Aßmann / Wolfgang Hoffmann-Riem, 2004, 223. 
Eine Methodenlehre der Verfassungsprinzipien, die deren Schleusen- und Schlüsselpotential vollständig reflektiert und der fallweisen Anwendung zugänglich macht, bleibt indes ein Desiderat, dass seiner interdisziplinären Bearbeitung harrt.

\section{Dogmatik des Rechtsstaatsprinzips und des Demokratieprinzips}

Die eingangs skizzierte Dominanz des Rechtsstaatsprinzips muss aus juristischer Sicht umso mehr verwundern, als es von einer beharrlichen begrifflichen wie inhaltlichen Unschärfe geprägt war und bleibt: „Der Begriff des Rechtsstaats [...] ist aber auch in seinem Ursprungsland [also Deutschland, H. G.] bis heute merkwürdig ungeklärt geblieben. Zwar können wir uns mühelos über einige Phänomene einigen, [...]. Doch ist der Begriff damit nicht eindeutig bestimmt." ${ }^{48}$

Diese „Phänomene“ oder auch „Ausprägungen“, „Elemente“, „Bestandteile“, „Grundpostulate“, „Folgerungen“, „Gebote“, haben zudem die erstaunliche Tendenz, sich mit der Zeit zu vermehren. Zählte man bis in die siebziger Jahre noch eine einstellige $^{49}$ bis allenfalls niedrige zweistellige ${ }^{50} \mathrm{Zahl}$, so sind es in heutzutage gar 25 , wenn nicht inzwischen noch mehr: „Verfassungsstaatlichkeit, Höchstrangigkeit der Verfassung, Verfassungsbindung, Verfassungsgerichtsbarkeit, Freiheitlichkeit, Rechtsgleichheit, Grundrechte, Gewaltenteilung, Gesetzlichkeit, Rechtsbindung, Gerechtigkeit, Gesetzesvorrang, Gesetzesvorbehalt, Ermächtigungsgrenzen nach Art. 8o Abs. 1 GG, Bestimmtheitsgebot, Kompetenzklarheit, Öffentlichkeit des Staatshandeln, funktionsgerechte Organisation der öffentlichen Gewalt, faires Verwaltungsverfahren, rechtes Maß an Staatsaktivität, Rechtssicherheit, allgemeine Justizgewährungspflicht, Gerichtsschutz gegenüber der öffentlichen Gewalt, Staatshaftung, Verhältnismäßigkeit" ${ }^{51}$

Die dogmatische Ver- und Bearbeitung des Demokratieprinzips, jedenfalls nach ganz herrschender Ansicht, ist dagegen von bezeichnender Schärfe und Bündigkeit: „Das demokratische Prinzip ist wesentlich Form, nicht Inhalt, wesentlich Organisations- und Legitimationsprinzip, nicht Ziel- und Legitimitätskategorie. ${ }^{\text {52 }}$ Das Demokratieprinzip kulminiert im Postulat der „ununterbrochenen Legitimationskette vom

\footnotetext{
48 Richard Bäumlin, Der schweizerische Rechtsstaatsgedanke, Zeitschrift des Bernischen Juristenvereins 101 (1965), 82; vgl. bereits Carl Schmitt, Legalität und Legitimität, 1932, 19: „Es gibt einen feudalen, einen ständischen, einen bürgerlichen, einen nationalen, einen sozialen, ferner einen naturrechtlichen, vernunftrechtlichen, historisch-rechtlichen Rechtsstaat.“

49 Vgl. etwa Klaus Stern, Das Staatsrecht der Bundesrepublik Deutschland, Bd. 1, 1. Aufl. 1977, 411 ff.: sieben; Werner Kägi, Zur Entwicklung des schweizerischen Rechtsstaates seit 1848, ZSR 71 (1952) I, S. 174 ff.: neun. 50 Vgl. Ulrich Scheuner, Die neuere Entwicklung des Rechtstaats in Deutschland, in: Staatstheorie und Staatsrecht. Gesammelte Schriften, 1978, 208 ff.: elf.

51 Katharina Sobota, Das Prinzip Rechtsstaat, 1997, $27 \mathrm{ff}$.

52 Vgl. statt aller: Matthias Jestaedt, Demokratieprinzip und Kondominialverwaltung, 1993, 173.
} 
Volk zu den mit staatlichen Aufgaben betrauten Organen und Amtswaltern" ${ }^{53}$, das einerseits sachlich durch den „Bauplan der Ausübung von Staatsgewalt“" ${ }^{54}$, also durch die Wahl der Parlaments, durch die von ihm beschlossenen Gesetze, die strikte Gesetzesbindung von Verwaltung und Rechtsprechung und andererseits durch das „Personalverfassungsrecht "s5, also die Bestimmungen über Auswahl und Verwendung konkreter natürlicher Personen als Amtswalter sowie deren strikte Weisungsgebundenheit bis zum seinerseits dem Parlament verantwortlichen Minister bzw. Bundeskanzler oder Ministerpräsident gewährleistet wird. Nur vor dem Hintergrund dieses hochgradig formalisierten Verständnisses von Demokratie und Volkssouveränität wird verständlich, dass das Bundeverfassungsgericht aus diesen und der sie flankierenden, bisweilen in der Staatsrechtslehre als mysteriös wahrgenommenen, Schlussbestimmung des Grundgesetzes in Art. 146 GG $^{56}$ Maßstab und Schranke des europäischen Integrationsprozesses entnommen hat. ${ }^{57}$

Nach der soeben skizzierten dogmatischen Zurichtung lassen sich Demokratie- und Rechtsstaatsprinzip ohne weiteres einander in praktischer Konkordanz zuordnen, so dass das Demokratieprinzip die Frage nach dem Wer, das Rechtsstaatsprinzip dagegen die Frage nach dem Wie staatlicher Herrschaft stellt: „Die Demokratie antwortet auf die Frage nach dem Träger und Inhaber, nicht nach dem Inhalt der staatlichen Herrschaftsgewalt; sie bezieht sich auf die Bildung, Legitimation und Kontrolle der Organe, welche die organisierte staatliche Herrschaftsmacht ausüben und die staatlichen Aufgaben wahrnehmen. Sie ist insofern ein organisatorisch-formales Formprinzip. [...] Der Rechtsstaat antwortet demgegenüber auf die Frage nach Inhalt, Umfang und Verfahrensweise staatlicher Tätigkeit. Er zielt auf Begrenzung und Bindung staatlicher Herrschaftsgewalt $[\ldots]$, ist insofern ein material-verfahrensmäßiges Formprinzip. ${ }^{{ }_{5} 8}$

\section{Der demokratische Rechtsstaat in produktiver Spannung}

Der demokratische Rechtsstaat muss also gemäß der Vorstellung einer Konkordanz aller Verfassungsprinzipien miteinander, neu und alt gedacht werden. Im Sinne der alten Theorien des demokratischen Rechtsstaates sollte die inhärente Spannung, die

\footnotetext{
53 BVerfGE 47, 253, 275; 77, 1, 40 f.; 93, 37, 66.

54 Utz Schliesky, Souveränität und Legitimität von Herrschaftsgewalt, 2004, $276 \mathrm{f}$.

55 Matthias Rossbach, Das Personal der Republik, im Erscheinen.

56 Vgl. zu Art. 146 GG nun umfassend Konstantin Chatziathanasiou, Verfassungsstabilität - Eine von Artikel 146 Grundgesetz ausgehende juristische und (experimental-)ökonomische Untersuchung, 2019.

57 BVerfGE 89, 155; 123, 267; vgl. zur Bedeutung von Art. 146 GG in diesem Kontext Holger Grefrath, Exposé eines Verfassungsprozessrechts von den Letztfragen? Das Lissabon-Urteil zwischen actio pro socio und negativer Theologie, in: AöR 135 (2010), $221 \mathrm{ff}$.

58 Ernst-Wolfgang Böckenförde, Demokratie als Verfassungsprinzip, in: Handbuch des Staatsrechts, hg. von Josef Isensee / Paul Kirchhof, Bd. 2, 3. Aufl. 2004, \$24, Rn. 83.
} 
dem Begriff innewohnt und die sich auch in seiner politischen Institutionalisierung ausdrückt, ernst genommen werden. Man kann den demokratischen Rechtsstaat als Anspruch kaum verstehen, wenn man Demokratie und Rechtsstaatlichkeit für natürlich aufeinander verweisende Prinzipien hält. Mit Hermann Heller ist der demokratische Rechtsstaat eben einer, der sich von seiner alten Tradition löst und die Herausforderung der Demokratie aktiv aufnimmt. Im Gegensatz zu einer Dogmatik, die den Rechtsstaat theoretisch isoliert und als Letztbegründung moderner Staatlichkeit begreift, muss die spezifische Bestimmung des Rechtsstaates als demokratischer und sozialer Rechtsstaat wieder greifbar gemacht werden. Dazu gehört auch, sich von lieb gewordenen Vorstellungen vom Recht als Hüter ewiger Wertordnungen zu lösen, und Rechtsstaatlichkeit nicht mehr als Schutz vor einer als gefährlich und unberechenbar vorgestellten demokratischen Willensbildung zu denken.

Neu muss auch gedacht werden, was es konkret heißen kann, die innere Spannung des Begriffs des demokratischen Rechtsstaats produktiv zu nutzen. Mit seiner Theoretisierung des sozialen und demokratischen Rechtsstaates entwickelte Wolfgang Abendroth eine neue dynamische Interpretation der Verfassungsprinzipien. Im Gegensatz zu Ernst Forsthoff, der die Bedeutung der einzelnen Prinzipien festschreiben und aus ihren Gegensätzen eine dogmatisch wirksame Rangordnung der Verfassungsprinzipien entwickeln wollte, versuchte Abendroth gerade die Gegensätzlichkeiten und Spannungen der im Grundgesetz festgeschriebenen Verschränkungsbegriffe, produktiv zu nutzen. Wenn das Grundgesetz eben nicht von Rechtsstaat, Sozialstaat und Demokratie, sondern vom demokratischen und sozialen Rechtsstaat spricht, muss das auch Folgen für die Interpretation dieser Prinzipien haben. Verfassungsprinzipien können so nicht nur als Strukturprinzipien verstanden, sondern neu als zu verwirklichende Ansprüche an die verfasste und politische Wirklichkeit betrachtet werden. In diesem Sinne, im Sinne eines politischen und verfassungsrechtlichen Anspruchs lassen sich dann auch konkrete politische Projekte mit der Verwirklichung einer demokratischen und sozialen Rechtsstaatlichkeit verbinden. Der demokratische Rechtsstaat könnte so vom Schlagwort in politischen Debatten über die Fehlentwicklungen in anderen Ländern wieder zu einem produktiven Anspruch, eine Herausforderung, an unsere eigene politische Wirklichkeit werden. 



\title{
Transnationale verfassungsgebende Gewalt Verfassungslyrik oder destituierende Gewalt
}

\author{
JAKOB GAIGG
}

\section{Transnational Constituent Power.}

Constitutional Lyric or Destituent Power

Abstract: Nation states are increasingly coming under pressure due to the postnational constellation. The term constituent power serves as a parenthesis that pulls together constitution and political community. This contribution asks whether there is any possibility for constituent power in transnational or even global contexts, given the fact that there is already a constitutional talk beyond nation states. In dealing with Bardo Fassbenders approach who interprets the UN-Charter as a constitution of the international community, a relational approach to constituent power will be envisaged. It turns out that there can be no constituent power in terms of a relational approach beyond the nation state.

Keywords: transnational/global constituent power, transnational/global constitution, constitutionalism, constitutionalization, political community, global constitutionalism

\section{Einleitung}

In der gegenwärtigen politikwissenschaftlichen, juristischen als auch philosophischen Literatur scheint hinsichtlich der Rolle des Nationalstaats ein mittlerweile gefestigter Common Sense zu bestehen. Mit den Schlagworten einer „global governance“ ${ }^{\text {, }}$, transnationaler/globaler Verfassungsbildung ${ }^{2}$ und postnationaler Konstellation ${ }^{3}$ ist über

1 Siehe etwa James Rosenau / Ernst-Otto Czempiel, Governance without government: order and change in world politics, 1992.

2 Siehe die Literatur, die in Fn. 14, 17, 19 und 20 angeführt wird.

3 Siehe dazu Jürgen Habermas, Die postnationale Konstellation: politische Essays, 1998. 
die letzten drei Jahrzehnte ein disziplinübergreifendes Unisono vernehmbar geworden: Der Nationalstaat westlicher Prägung, mit seinem Versprechen der Institutionalisierung der Gleichursprünglichkeit von öffentlicher und privater Autonomie ${ }^{4}$, von Demokratie und Rechtsstaat, sieht sich vor zwei Herausforderungen gestellt. Einerseits schwinden mit der grenzüberschreitenden Dimension von Problemlagen auch seine Problemlösungskapazitäten, andererseits wird er selbst zum Problem, weil die Entscheidungen, die er trifft, zusehends externe Effekte für Außenstehende nach sich ziehen. Galt der nationalstaatliche Rahmen lange Zeit hindurch als unhinterfragte Voraussetzung, um den Streit über den Inhalt politischer Gemeinschaften und deren $\mathrm{Zu}$ kunft als emanzipatorisches Projekt zu führen, so gerät er zunehmend in Kritik.

Die Verfassungen der Nationalstaaten stehen für die Verknüpfung von individuellem Schutz und kollektiver Ermächtigung, für die Verbindung aus verrechtlichter Politik und politischem Recht. Ihr Anspruch ist schillernd: Sie wollen Herrschaft begrenzen und zugleich ermöglichen. ${ }^{5}$ Die verfassungsgebende Gewalt spielt hierbei die

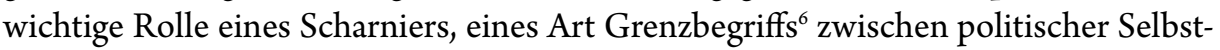
bestimmung und Verfassung, zwischen kollektivem Entscheiden und seiner rechtlich verfassten Form. Doch wie ist es um die verfassungsgebende Gewalt im globalen/ transnationalen Kontext bzw. unter Bedingung der postnationalen Konstellation bestellt? Welche Argumente begegnen uns bei dem Versuch, wenn wir verfassungsgebende Gewalt globalisiert denken wollen? Lässt sich das Modell des Nationalstaats und sein Begriffshaushalt auf eine globale Ebene übertragen und wie wirkt sich das auf die verfassungsgebende Gewalt aus?

Der Beitrag skizziert zu Beginn das Problem der Fragmentierung des internationalen Rechts. Um diesem Problem Herr zu werden, werden seit einiger Zeit Versuche unternommen, den nationalstaatlichen Begriff der Verfassung auf die transnationale bzw. globale Ebene zu transponieren. Hierbei greift der Beitrag unter der Fülle an theoretischen Konzepten dasjenige von Bardo Fassbender heraus, da sich dieser Ansatz aufgrund seiner Methodik eng am nationalstaatlichen Verfassungsmodell orientiert und zudem auch den Begriff der verfassungsgebenden Gewalt bzw. konstituierende Gewalt im Zusammenhang mit der UN-Charter auszuweisen versucht. Bei näherer Betrachtung von Fassbenders Ansatz geraten jedoch verschiedene Argumentationsweisen in den Blick, die den Begriff der verfassungsgebenden Gewalt unterschiedlich fassen. Zum einen scheint Fassbender mit einer etwas verunglückten Auseinanderset-

\footnotetext{
4 Jürgen Habermas, Faktizität und Geltung. Beiträge zur Diskurstheorie des Rechts und des demokratischen Rechtsstaats, 1994, 135.

5 Christoph Möllers, Verfassunggebende Gewalt - Verfassung - Konstitutionalisierung, in: Europäisches Verfassungsrecht. Theoretische und dogmatische Grundzüge, hg. von Armin von Bogdandy / Jürgen Bast, 2009, 231-238.

6 Ernst-Wolfgang Böckenförde, Die verfassungsgebende Gewalt des Volkes - Ein Grenzbegriff des Verfassungsrechts, in: Staat, Verfassung, Demokratie. Studien zur Verfassungstheorie und zum Verfassungsrecht, Ernst-Wolfgang Böckenförde, 1991, 90-112.
} 
zung mit Hans Kelsen eine Unterscheidung zu suggerieren, die für das Denken Carl Schmitts wesentlich war: Präsenz und Repräsentation des Kollektivsubjekts. Dem Ausweis der problematischen Kategorien Schmitts folgt die Einsicht, verfassungsgebende Gewalt nicht zu essentialisieren, indem sie mit vorfindlichen Kollektivsubjekten identifiziert wird. Zum anderen eröffnet sich an diesem Punkt die Sichtweise, dass das Kollektive „Wir“ einer politischen Einheit erst durch eine Verfassung hervorgebracht wird. Doch die repräsentative Perspektive, vor allem bei Hans Kelsen, tendiert dazu, den sozialen Aneignungsprozess von Verfassungen in der Zeit nicht zu berücksichtigen. Zum Schluss wird die verfassungsgebende Gewalt als dynamische Relation zwischen symbolischer Einheit der Verfassung und den sozialen wie politischen Versuchen, dieser Einheit einen konkreten institutionellen Sinn zu geben, verstanden. Dieses dynamische Verständnis droht auf transnationaler/globaler Ebene verloren zu gehen.

\section{Globaler Konstitutionalismus als Analogie}

1. Fragmentierung und Konstitutionalisierung im Völkerrecht

Mit dem Ende des Ost-West-Konflikts beginnt sich eine liberale Hoffnung durchzusetzen. Das anarchisch verfasste Staatensystem ${ }^{7}$ sowie dessen realistisches Deutungsparadigma, das durch die bipolare Konstellation bestätigt zu werden schien, weicht einer zarten Hoffnung auf Realisierung der Grundziele, wie sie in der Charter der Vereinten Nationen bereits nach Ende der wohl schlimmsten Katastrophe der Menschheitsgeschichte niedergelegt wurden. ${ }^{8}$ Doch stellt sich just in dem Moment, der das (liberale) Ende der Geschichte einläuten sollte, ein neues Problem. Die Anarchie des Staatensystems wich einer noch unübersichtlicheren Situation, die durch Fragmentierung geprägt war.

Der Begriff der Fragmentierung ${ }^{9}$ stellt angesichts der alten Probleme des Völkerrechts der fehlenden Zentralisierung des Gewaltmonopols ${ }^{10}$, der Abwesenheit orga-

7 Siehe beispielsweise Hedley Bull, The Anarchical Society. A Study of Order in World Politics, 1977.

$8 \mathrm{Zu}$ den ambitionierten politikwissenschaftlichen Reformansätzen der Vereinten Nationen dieser Zeit siehe etwa Danielle Archibugi, From the United Nations to Cosmopolitan Democracy, in: Cosmopolitan Democracy. An Agenda for a New World Order, hg. von Danielle Archibugi / David Held, 1995, 121-162.

9 Siehe dazu Martii Koskenniemi, Fragmentation of international law: difficulties arising from the diversification and expansion of international law Report of the Study Group of the International Law Commission (2006), UN Doc. A/CN.4/L.682. <http://legal.un.org/ilc/documentation/english/a_cn4_1682. $\mathrm{pdf}>(12.06 .2019)$.

10 Darin, dass es zwar ein Gewaltmonopol gibt, aber nicht in zentralisierter Form, liegt für Hans Kelsen der eigentliche Mangel eines primitiven Rechtssystems, siehe Hans Kelsen, Peace through Law, 1944, $4 \mathrm{f}$. 
nisierten Zwangs zur Durchsetzung von Gerichtsentscheidungen ${ }^{11}$ sowie dem Mangel an zentraler Gesetzgebung ${ }^{12}$, dem Fehlen einer Erkenntnisrege ${ }^{13}$ etc. lediglich den bisherigen Endpunkt einer Skalierung dar. Die Herausforderungen, die durch die Fragmentierungsdiagnose offenbar werden, bleiben indes in der Völkerrechtsdebatte nicht unbeantwortet. In der aktuellen Völkerrechtsliteratur kündigt sich bereits eine Lösung im Umgang mit der Dispersion von Autorität ${ }^{14}$, Akteuren ${ }^{15}$ und „self-contained-regimes ${ }^{\text {"16 }}$ an. Die Hoffnungen ruhen in einer Konstitutionalisierung des Völkerrechts. ${ }^{17}$ Das Versprechen ${ }^{18}$, das mit einer „Transposition“"19 des Verfassungsbegriffs in das internationale Recht bzw. dessen Konstitutionalisierung ${ }^{20}$ einhergeht, besteht in der Realisierung von Einheit als Antwort auf Fragmentierung, der Zentralisierung als Antwort auf Pluralisierung sowie einer Einhegung und dem Schutz des öffentlichen Raums vor zunehmender Privatisierung. ${ }^{21}$

Die Konstitutionalisierung des Völkerrechts bzw. ein globaler Konstitutionalismus wird - grob gesprochen - in zwei Formen gedacht. Eine Strategie, Verfassungsstrukturen im Völkerrecht zu identifizieren, operiert dabei mit semantischen Umdeutungen. ${ }^{22}$ Der Verfassungsbegriff wird an verschiedene Begriffe assimiliert und so uminterpretiert, was es erlaubt, etwa von einer Verfassung der internationalen Gemeinschaft zu

11 So etwa Herbert Hart, Der Begriff des Rechts, 2011, 251.

12 Hart (Fn. 11), 270.

13 Hart (Fn. 11), 274-277.

14 Siehe dazu Jan Klabbers, Setting the Scene, in: The Constitutionalization of International Law, hg. von Jan Klabbers / Anne Peters / Geir Ulfstein, 2009, $11 \mathrm{f}$.

15 Klabbers (Fn. 14), 12.

16 So erstmals Bruno Simma, Self-Contained Regimes, NYIL 15 (1985), 111-136.

17 Die Bezugnahme auf konstitutionelle Strukturen oder gar einer Verfassung im Völkerrecht sei ein Gemeinplatz geworden. Siehe Oliver Diggelmann / Tilmann Altwicker, Is There Something Like a Constitution of International Law? A Critical Analysis of the Debate on World Constitutionlism, ZaöRV 68 (2008), $623-650(623)$.

18 Die großen Erwartungen, die in dem Konzept einer Konstitutionalisierung ruhen, formuliert Jan Klabbers auf folgende Weise: „[C] onstitutionalization carries the promise that there is some system to the madness after all; there is something which helps keep the system together. Klabbers (Fn. 14), 18.

19 Anne Peters, Rechtsordnungen und Konstitutionalisierung: Zur Neubestimmung der Verhältnisse, ZÖR 65 (2010), 3-63 (11,) weist darauf hin, dass der globale Konstitutionalismus nicht einfach als Extrapolation des nationalen Verfassungsbegriffs verstanden werden kann. Trotzdem meint sie, dass damit der Verfassungsbegriff nicht ermäßigt würde. Was das genau heißen soll, bleibt unklar.

20 Unter dem Begriff der Konstitutionalisierung soll eine inkrementielle, prozesshafte Herausbildung „verfassungsartiger und konstitutionalistischer Elemente in der internationalen Rechtsordnung “ verstanden werden. Peters (Fn. 19), 11. Eine historische Einbettung liefert Martin Loughlin, What is Constitutionalisation?, in: The Twilight of Constitutionalism?, hg. von Petra Dobner / Martin Loughlin, 2010, 47-69; Ebenso kritisch dazu Alexander Somek, Constitutionalization: Constitution-Making for Individualists, in: Is there a European Common Good?, hg. Sonja PuntscherRiekmann / Alexander Somek / Doris Wydra, 2013, 86-113.

21 Siehe dazu Klabbers (Fn. 14), $18 \mathrm{f}$.

22 Siehe Diggelmann/Altwicker (Fn. 17), 633-636. 
sprechen. ${ }^{23}$ Die andere Ermöglichungsstrategie, um von einer Verfassung im Weltmaßstab sprechen zu können, bedient sich einer juristischen Methode, die bezeichnender Weise im Privatrecht oft zur Anwendung kommt und die juristische Einbildungskraft aufgrund der Abwesenheit politischen Entscheidens prämiert: die Analogie. Staatliche Vorstellungen und Begriffe des Konstitutionalismus werden in dieser Strategie als Referenzpunkt angenommen, um eventuelle Ähnlichkeiten und Übereinstimmungen mit Entwicklungen im Völkerrecht herauszustreichen. ${ }^{24}$ Emblematisch wird diese Denkweise eines globalen Konstitutionalismus, wenn der Versuch unternommen wird, die Verfassungsqualität der UN-Charter nachzuweisen. Der elaborierteste Versuch stammt von Bardo Fassbender ${ }^{25}$, dem ich mich im Folgenden widmen werde.

2. UN-Charter als Weltverfassung?

Fassbenders Ansatz verfolgt sein Ziel, indem er durch Vergleich mit den unterschiedlichen nationalstaatlichen Verfassungen einen Idealtyp ${ }^{26}$ - im weberianischen Sinn konstruiert, der es ihm ermöglicht die funktionalen Eigenschaften von Verfassungen zu destillieren. Im Ergebnis jedenfalls kommt Fassbender zu dem Schluss, dass die UN-Charter aufgrund bestimmter Funktionen, die sie erfüllt, auch eine Verfassung sei. So würde durch die UN-Charter eine Form der Gewaltenteilung hervorgebracht, die zwar nicht voll entwickelt und deshalb nicht so präzise wie die nationaler Verfassungen sei, ${ }^{27}$ aber dennoch in der Charter angelegt sei und damit einer zukünftigen Weiterentwicklung offen stünde. ${ }^{28}$ Ebenso komme der UN-Charter durch den Art. 103 eine Vorrangstellung gegenüber anderen internationalen Abkommen zu, was für Fassbender den Schluss zulässt, dass die UN-Charter damit eine Normenhierarchie im Sinne einer Verfassung hervorbringe. ${ }^{29}$ Nationalen Verfassungen ähnelnd, würde die UN-Charter Abänderungsprozeduren festlegen, nicht aber ihre Aufkündigung oder Beendigung. ${ }^{30}$ Über-

23 Siehe dazu Hermann Mosler, The International Society as a Legal Community, 1974; Bruno Simma, From Bilateralism to Community Interest in International Law, RdC 250 (1994-VI) 217-384; Christian Tomuschat, Obligations Arising for States Without or Against Their Will, RdC 241 (1993-IV) 195-374.

24 Siehe mit weiteren Nachweisen Diggelmann/Altwicker (Fn. 17), 637-639.

25 Siehe dazu Bardo Fassbender, The United Nations Charter as Constitution of the International Community, Col. J. Transnat'l L. 36 (1998), 529-619; ders., „We the Peoples of the United Nations“ Constituent Power and Constitutional Form in International Law, in: The Paradox of Constitutionalism, hg. von Martin Loughlin / Neil Walker, 2007, 269-290; ders., Rediscovering a Forgotten Constitution: Notes on the Place of the UN Charter in the International Legal Order, in: Ruling the World? Constitutionalism, International Law, and Global Governance, hg. von Jeffrey Dunoff/Joel Trachtman, 2009, 133-147; ders., The United Nations Charter as the Constitution of the International Community, 2009.

26 Fassbender (Fn. 25), Rediscovering, $138 \mathrm{f}$.

27 Fassbender (Fn. 25), United Nations Charter 2009, 95.

28 Fassbender (Fn. 25), United Nations Charter 2009, 101.

29 Fassbender (Fn. 25), United Nations Charter 2009, 103-107.

30 Fassbender (Fn. 25), United Nations Charter 2009, $107 \mathrm{ff}$. 
dies würde die UN-Charter - universell - für alle Mitglieder einer Gemeinschaft gelten, nämlich den anerkannten Staaten als Mitglieder der Internationalen Gemeinschaft. ${ }^{31}$

Der Vorteil, den eine solche Analogiestrategie - mögliche Unterschiede zu nationalstaatlichen Verfassung beiseite gestellt ${ }^{32}$ - mit sich bringt, insbesondere von Fassbenders Unternehmen, liegt auf der Hand. Abseits von nebulösen naturrechtlichen Prinzipien und Ableitungszusammenhängen, kann auf einen einheitlichen, positivierten Normtext Bezug genommen werden, der den Zielen des Friedens und der Menschenrechte rechtliche Gültigkeit verleiht. Dieser Normtext selbst, so Fassbender, wurde in einem „,constitutional moment“" ${ }^{\text {“3 }}$ festgelegt und setzt so ein eminent politisches Handeln voraus. Mit der Betonung auf den politischen Moment der Inauguration der UN-Charter in San Franciso bietet sich sogleich eine weitere Analogie zu nationalstaatlichen Verfassungen an: die verfassungsgebende Gewalt.

\section{Eine globale verfassungsgebende Gewalt?}

Der Präambel Text der Charter weist, so Fassbender, am Beginn selbst auf eine verfassungsgebende Gewalt hin: „We the Peoples of the United Nations ... have resolved to combine our efforts to accomplish these aims." Die Völker würden als verfassungsgebende Gewalt der internationalen Gemeinschaft agieren, die sich in Form der UN-Charter ihre Verfassung, die Verfassung der Völker gegeben hätten. Die Formulierung am Anfang der Präambel bringt für Fassbender die Bedeutung des „,constitutional moment" zum Ausdruck, deren sich auch die Delegierten in San Francisco bewusst gewesen wären. ${ }^{34}$ Dass am Ende der Präambel jedoch von den Regierungen, die durch Vertreter repräsentiert waren, die Rede ist und die Völker als handelnde Subjekte nicht mehr aufscheinen, scheint Fassbender aber zu einer Klarstellung zu bewegen. Dabei führt er die Kritik von Hans Kelsen an, der den Wortlaut der Präambel als „rechtlich nicht korrekt" auszuweisen versucht:

The Charter is an international treaty concluded by states represented by their governments. These governments, not the „peoples“, were represented at the San Francisco Conference. [...] Not the „peoples“, but the governments „resolved“ to combine their efforts to accomplish these aims. [...] [T] he governments are not organs of the peoples, but of the states. ${ }^{35}$

31 Fassbender (Fn. 25), United Nations Charter 2009, 109-115.

32 Siehe dazu etwa Michael Doyle, The UN Charter - A Global Constitution?, in: Ruling the World? Constitutionalism, International Law, and Global Governance, hg. von Jeffrey Dunoff / Joel Trachtman, 2009, $113-132$.

33 Fassbender (Fn. 25), United Nations Charter 2009, $86 \mathrm{f}$.

34 Fassbender (Fn. 25), Constituent Power, 288.

35 Hans Kelsen, The Law of the United Nations. A Critical Analysis of its fundamental problems, 1950, 7. 
Kelsens Kritik soll für Fassbender zum Ausdruck bringen, dass es nicht die Völker selbst oder ein durch sie beschicktes Organ war, das die UN-Charter ratifiziert hat, sondern bloß Vertreter von Regierungen. Deshalb sei es rechtlich nicht korrekt, von den Völkern zu Beginn der Präambel zu sprechen.

1. Eine Schmittianische Suggestion: das vorgängige "Wir"

Interessant ist die Verwendungsweise dieses Zitats insofern sie unweigerlich eine Unterscheidung suggeriert, die Kelsen so nicht im Sinn gehabt haben kann, wenngleich seine Formulierung nicht glücklich gewählt ist. ${ }^{36}$ Fassbender zitiert Kelsen nämlich so, als würde er zum Ausdruck bringen wollen, dass es grundsätzlich eine Möglichkeit gäbe, nach welcher Völker „direkt“ an der Entstehung der UN-Charter beteiligt gewesen sein könnten. Da es aber tatsächlich nur Regierungsvertreter waren, die die Charter angenommen haben, würde dieser Umstand keine Formulierung erlauben, die auf die Völker als unmittelbar handelnde Akteure verweist. Fassbender nimmt diesen Einwand beim Wort und erklärt sogleich: „As a matter of fact [Kursivierung d. Verf.], the adoption of the Charter as a treaty was the only legal method practically available to the founders of the United Nations in the actual conditions of $1945 .{ }^{\text {“37 Der Abschluss }}$ als Vertrag und damit durch Delegierte von Staaten war historisch-praktischen Umständen geschuldet. Der Mangel an verfassungsgebender Gewalt, der damit verbunden sei, würde zwar den Abstand zu historischen Gründungsakten markieren, vermag aber den Verfassungscharakter der Charta nicht zu beeinträchtigen.

Im Folgenden will ich die Voraussetzungen klären, die eine solche Argumentation überhaupt ermöglichen, damit das eigentliche Problem der verfassungsgebenden Gewalt und des Verfassungsverständnisses bei Fassbender zum Vorschein kommt. Die Weise, wie das Zitat Kelsens eingesetzt wird, sowie die Replik Fassbenders erscheinen nämlich nur im Lichte eines bestimmten Verhältnisses zwischen konstituierender Gewalt und konstituierter Gewalt sinnvoll. Die Diskussion suggeriert eine durch ein Vorrangverhältnis qualifizierte Opposition im Augenblick der Gründung: Präsenz vor Repräsentation. Den Inhalt dieser Suggestion hätte Kelsen so nicht ernst genommen. Jedoch bewegt sie Fassbender zu einer Argumentation, die an die Gegenüberstellung von präsenter, verfassungsgebender Gewalt und repräsentativer, verfasster Gewalt bei Carl Schmitt erinnert.

36 Kelsens eigentliches Ziel in dem Abschnitt, aus dem Fassbender kleine Passagen zitiert, besteht darin, den Rückbezug auf das „Volk“ sowohl im Falle der amerikanischen Unabhängigkeitserklärung als auch für die UN-Charter als Ideologie zu enttarnen. Für Kelsen hat der Begriff der verfassungsgebenden Gewalt schlicht keinen juristischen Sinn. Siehe Kelsen (Fn. 35), 6 ff.

37 Fassbender (Fn. 25), Constituent Power, 288. 
Schmitts Begriff der verfassungsgebenden Gewalt setzt zwei Unterscheidungen voraus: die Unterscheidung zwischen „politischer Einheit des Volkes ${ }^{{ }^{38} 8}$ und „Verfassung als Gesamtentscheidung über Art und Form der politischen Einheit ${ }^{\text {“39, }}$, sowie die Unterscheidung, die Schmitt in den Verfassungsbegriff einzieht, indem er zwischen Verfassung als Gesamtentscheidung und Verfassung im Sinne der Menge an Verfassungsgesetzen trennt. ${ }^{40}$ Die Verfassung im Sinne einer Gesamtentscheidung versucht Schmitt anhand von Bestimmungen aus der Weimarer Verfassung zu exemplifizieren, wie beispielsweise „die Staatsgewalt geht vom Volke aus". Solche Bestimmungen würden keine reinen Verfassungsgesetze darstellen, sie bringen vielmehr etwas zum Ausdruck, sie statuieren, legen einen Status fest. Schmitt schreibt: „Sie sind mehr als Gesetze und Normierungen, nämlich die konkreten politischen Entscheidungen, welche die politische Daseinsform [...] angeben und die grundlegende Voraussetzung für alle weiteren Normierungen, auch diejenigen der Verfassungsgesetze, bilden." ${ }^{41}$ Dieses "Mehr" steht bei Schmitt emblematisch für ein Vorrangverhältnis zwischen Verfassung im Sinne einer Gesamtentscheidung und bloßen Verfassungsgesetzen. Schmitt deutet mit diesem „Mehr“ den Vorrang der Entscheidung vor jeglicher Norm und Regelhaftigkeit an. Der Unterschied, den Schmitt zwischen Verfassung als Gesamtentscheidung und Verfassung als Verfassungsgesetz formuliert, ist letztlich Ausdruck für die Prämierung der Entscheidung, des politischen Aktes, der aller Normativität und jedem Regelsystem vorausgeht. ${ }^{42}$

Dieses Vorrangverhältnis zwischen Entscheidung und Norm, Dezision und Regel, das das eminent politische Moment in Schmitts Verfassungslehre gegenüber normativen Ableitungsverhältnissen ausweist, durchläuft in der Unterscheidung zwischen "politischer Einheit" und „Verfassung als Gesamtentscheidung" eine entgegensetzte Wandlung. Zwar wird „Form und Art der politischen Einheit“"43 durch „eine grundlegende politische Entscheidung des Trägers der verfassungsgebenden Gewalt "44 festgelegt,

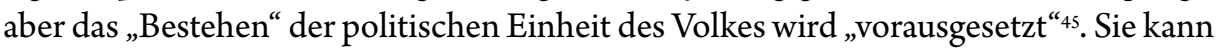
laut Schmitt nicht dadurch entstehen, dass „,eine Verfassung gegeben' wird“" ${ }^{\text {“6 }}$. Vielmehr stellt sich die politische Einheit für Schmitt als vorgängig und nur rein äußerlich modifizierbar dar, wenn die Verfassung als Gesamtentscheidung „nur [Kursivierung

\footnotetext{
38 Carl Schmitt, Verfassungslehre, 2017, 21.

39 Schmitt (Fn. 38), 20.

40 Siehe dazu Schmitt (Fn. 38), 76.

41 Schmitt (Fn. 38), 24.

42 Schmitt (Fn. 38), 22, wo Schmitt schreibt: „Jedes Gesetz als normative Regelung, auch das Verfassungsgesetz, bedarf zu seiner Gültigkeit im letzten Grunde einer ihm vorhergehenden politischen Entscheidung, $[\ldots]$ “.

43 Schmitt (Fn. 38), 21.

44 Schmitt (Fn. 38), 23.

45 Schmitt (Fn. 38), 21.

46 Schmitt (Fn. 38), 21.
} 
d. Verf.] die bewußte Bestimmung der besonderen Gesamtgestalt"47 von ihr sein soll. Die Verfassung der politischen Einheit ist nach Schmitt daher logisch sowie zeitlich als Genetivus subjectivus zu verstehen. Als Akt der politischen Gemeinschaft ist die Gesamtentscheidung aber nicht unbestimmt, noch willkürlich. Indem Schmitt der Entscheidung das Prädikat existentiell zur Seite stellt, gibt er damit zu verstehen, dass die Entscheidung sich entlang eines absolut vorfindlichen Seins, dem Sein der politischen Einheit bewegt und darin ihr Kriterium findet. Das Sein, die konkrete Existenz bestimmt die Entscheidung, verleiht ihr Sinn. ${ }^{48}$ Die Verfassung als Gesamtentscheidung und der dahinterstehende Wille wird dadurch aber depotenziert, der Wille wird akzidentiell. Jede Gestalt „kann sich ändern“49. Sie ist nicht von Bedeutung. Die Entscheidung verkümmert damit zur bloßen Ableitung dessen, was eine politische Gemeinschaft immer schon ausmacht: die „Substanz"so. Das Vorrangverhältnis zwischen politischem Akt und Norm, das dem Unterschied zwischen Verfassung im positiven Sinn und Verfassungsgesetz zugrunde liegt, wandelt sich im Verhältnis der politischen Einheit zur Gesamtentscheidung in einen Vorrang der Substanz vor der Form. Der Substanzbegriff wird von Schmitt durch einen Gleichheitsbegriff im Sinne einer Gleichartigkeit ${ }^{51}$ erläutert, der letztlich auf ein homogenes Kollektiv hinausläuft. Die verfassungsgebende Gewalt und dessen Entscheidung degeneriert vor diesem Hintergrund zu einem Reflex einer vorgängigen, politischen Einheit, die als kollektive Substanz gedeutet wird. Substanz und Vorgängigkeit indes bilden nicht das Terrain von Entscheidungen, schon gar nicht von politischen. ${ }^{52}$ Die Entscheidung droht just an diesem Punkt bei Schmitt ihr politisches Moment zu verlieren, wenn sie zum bloßen Ausdruck einer sich selbst immer schon präsenten vorgängigen kollektiven Einheit wird. Eine mit sich selbst idente Substanz, ein „anwesendes, wirklich versammeltes Volk“"s3, ein in unmittelbarer Weise durch Akklamation sich äußerndes Volk, bilden gerade keinen Hintergrund der Unentscheidbarkeit. Solche Vorstellungen geben stattdessen Auskunft über ein unwandelbares Vorverständnis, das keinen politischen Streit und keine Auseinandersetzung kennt. Die politische Einheit als kollektives Subjekt ist spinozistische natura naturans ${ }^{54}$, nur in säkularisierter Form. Anders gewendet: Schmitt betreibt

47 Schmitt (Fn. 38), 21.

48 So schreibt Schmitt auch: „Sie [die Verfassung, J. G.] beruht auf einer, aus politischem Sein hervorgegangenen politischen Entscheidung über die Art und Norm des eigenen Seins." Schmitt (Fn. 38), 76.

49 Schmitt (Fn. 38), 21.

50 Schmitt (Fn. 38), 228.

51 Siehe dazu Schmitt (Fn. 38), 234.

52 Auch wenn Carl Schmitt bemüht ist, das spezifische Terrain des Politischen anhand der Unterscheidung zwischen Freund und Feind zu „encadrieren“, so wird wiederum das Politische durch das „Wesen“ des Fremden, „daß er in einem besonders intensiven Sinne existentiell etwas anderes und Fremdes ist“ bestimmt. Alles Politische hängt letztlich vom Wesen politischer Einheiten ab. Siehe Carl Schmitt, Der Begriff des Politischen, Text von 1932 mit einem Vorwort und drei Corollarien, 2015, 26.

53 Schmitt (Fn. 38), 243.

54 Siehe dazu Schmitt (Fn. 38), 79. 
mit seinem Begriff der verfassungsgebenden Gewalt politische Theologie, da ihm der Gründungsakt als Gesamtentscheidung lediglich äußerer Ausdruck, deprivierte Form einer präsentischen Substanz des Volkes im Sinne eines ens increatum gelten kann. ${ }^{55}$

\section{Das „Wir” als Gegenstand der Verfassung}

Hypostasiert man Kollektive qua politischer Einheiten nicht zu Substanzen, die deshalb immer schon über ein präsentisches, kollektives Vorverständnis in Form einer konkreten Verfassungs-Ordnung verfügen, verschwindet der archimedische Punkt, von dem aus die Schmittsche Logik operiert. Es stellt sich unweigerlich die Frage, ob es dann vor dem Akt der verfassungsgebenden Gewalt überhaupt etwas geben kann, das als reflexives kollektives Subjekt, als ein „Wir“ fungiert und so „in einem bewußten Akt“" ${ }^{\text {“6 }}$ über seine Form und seine Verfassung im positiven Sinn selbst entscheidet. Hans Lindahl hat in seiner Beschäftigung mit dem Begriff der konstituierenden Gewalt ${ }^{57}$ gezeigt, dass, sobald die Mär von einem in Substanzbegriffen gefassten, sich selbst gegenwärtigen Kollektivsubjekt aufgegeben wird ${ }^{58}$, es der Akt der Einsetzung einer Verfassung ist, der allererst ein politisches Kollektiv, ein „Wir“ hervorbringt. ${ }^{59}$ Entgegen der Vorstellung bei Schmitt, wonach der Akt der Verfassungsgebung als spontane Willensbetätigung eines immer schon selbstvergewisserten Kollektivsubjekts verstanden wird, legt Lindahl konträr dazu zunächst eine Passivität im Akt der Verfassungsgebung frei. ${ }^{60}$ Der konstitutive Akt, der ein „Wir“ hervorbringt, beruht zunächst auf einem Akt der Schließung, der Festlegung wer dazu gehört so wie der Entscheidung, welches Programm, welche gemeinsamen Zwecke durch die kollektive Anstrengung verfolgt werden. ${ }^{61}$ Der Akt der Hervorbringung bleibt Setzung und entspricht damit der Gesamtentscheidung im Schmittianischen Sinn. Nur erweist sich das Kollektiv gegenüber dem Akt der SchlieBung, der Setzung als passiv, es schafft nicht, es wird geschaffen. Die Menge oder Mul-

55 Vgl. zu dieser Kritik am theologischen Gehalt in Schmitts Begriff eines substanzhaften Kollektives auch Hans Lindahl, Constituent Power and Reflexive Identity: Towards an Ontology of Collective Selfhood, in: The Paradox of Constitutionalism Constituent Power and Constitutional Form, hg. von Martin Loughlin / Neil Walker, 2007, 9-24 (16f.).

56 Schmitt (Fn. 38), 23.

57 Hans Lindahl (Fn. 55); Hans Lindahl, The Paradox of Constituent Power. The Ambiguous Self-Constitution of the European Union, Ratio Juris 20 (2007), 485-505.

58 Lindahl (Fn. 55), $16 \mathrm{f}$.

59 Siehe dazu auch Jacques Derrida, Unabhängigkeitserklärungen, in: Nietzsche - Politik des Eigennamens. Wie man abschafft, wovon man spricht, hg. von Jacques Derrida / Friedrich Kittler, 2010, 9-19 (12). Das amerikanische Volk „existiert nicht, nicht vor dieser Erklärung [der Unabhängigkeitserklärung, J. G.], nicht als solches. Durch jene Unterzeichnung bringt es sich als freies und unabhängiges Subjekt, als möglicher Unterzeichner zur Welt." Der entscheidende Punkt ist auch bei Derrida, dass die politische Einheit des amerikanischen Volkes erst durch die Unterschrift „seiner“ Repräsentanten hervorgebracht wird.

60 Siehe dazu Lindahl (Fn. 55), 18.

61 So Lindahl (Fn. 55), 18. 
titude wird im Augenblick der Verfassungsgebung erst geformt und so zu einem „Wir“, einer politischen Einheit besondert. Zudem ändert sich der Stellenwert der Form. Bedeutet bei Schmitt die Gesamtentscheidung als Verfassung nur akzidentielle „Bestimmung der besonderen Gesamtgestalt “ ${ }^{\text {}} 2$ einer unwandelbaren Substanz so meint hier Verfassung Gesamtentscheidung und Besonderung als Hervorbringung eines kollektiven Subjekts. Es gibt also in dieser Version von verfassungsgebender Gewalt im Ursprungsakt keine spontane, aktive Substanz, sondern nur eine Menge, die erst zu einer politischen Einheit bestimmt werden muss. Zudem bedeutet Form nicht nur Setzung wie bei Schmitt, sondern Form meint auch Formierung und Disziplinierung im Sinne von Bildung eines kollektiven „Wir“. Die Verfassung der politischen Gemeinschaft, so könnte man sagen, ist nicht mehr akzidentiell, sondern konstitutiv für das „Wir“, die Sequenz ist als Genetivus objectivus zu verstehen. Auf diese Weise offenbart die Bildung, die Hervorbringung politischer Einheiten immer einen passivierenden, nicht reziproken, auf Zwang beruhenden, autoritären Akt.

Wenn es nun kein Kollektives „Wir“ vor der Verfassung geben kann, weil dieses erst durch die Verfassung entsteht, dann erweist sich die Debatte bei Fassbender, ob die Gemeinschaft der Völker als „Wir“ direkt oder vermittelt an der Gründung der Vereinten Nationen anwesend waren, als irreführend. Es ist einerlei, ob Vertreter von Staaten, also Regierungen, oder Delegierte von Völkern, durch welchen Mechanismus auch immer sie bestimmt sein mögen, an der Annahme und in Kraftsetzung der Charter beteiligt waren. Die Debatte wird relativiert, sie handelt nur noch von einem graduellen Unterschied in der Länge der Delegationskette. Jedes rechtliche Verfahren aber bedeutet bereits Formgebung und birgt so eine repräsentative Struktur, das gilt auch für einen möglichen Verfassungskonvent mit direkt gewählten Delegierten.

\section{Selbstreferenz des Rechtssystems}

In schlussendlicher Ermäßigung der Frage, wie die Beteiligung der Völker tatsächlich vollzogen wurde ${ }^{63}$, bringt Fassbender noch zwei Argumente vor, um einen Analogiebruch in dieser heiklen Frage zu vermeiden. Einerseits sei die UN-Charter „im Namen der Völker der Vereinten Nationen"64 verabschiedet worden, womit ihr deshalb ein Verfassungscharakter zukäme. Andererseits würden durch sie Frieden, Sicherheit und sozialer wie ökonomischer Fortschritt aller Völker als Ziele und Zwecke ausgegeben, was so ohne Beispiel sei. Die normativen Werte, die sie verkörpert, würden ihren Verfassungscharakter bestätigen. ${ }^{65}$

62 Schmitt (Fn. 38), 21.

63 Siehe dazu Fassbender (Fn. 25), Constituent Power, 288.

64 Ebd.

65 Ebd. 
Das erste Argument schließt an der vorhin gemachten Beobachtung an, wonach das „Wir“ nicht Akteur, sondern Gegenstand der Verfassungsgebung ist. Zudem ist das „Wir“ nicht nur nicht aktiv, sondern in seinem Ursprung auch repräsentiert. Die Delegierten handeln „im Namen der Völkerrechtsgemeinschaft" ${ }^{\text {"66 }}$, indem sie sie hervorbringen. In dieser Hinsicht gründet der Akt der verfassungsgebenden Gewalt nicht nur die politische Einheit durch eine Gesamtentscheidung, der Gründungsakt ist selbst wesentlicher, aber nicht direkt gegebener, immer nur repräsentierter Bezugspunkt eben dieser Einheit: er bildet einen „focus imaginarius“"67, einen virtuellen Bezugspunkt $^{68}$ der politischen Einheit, oder - mit Kelsen gesprochen - einen Zurechnungspunkt ${ }^{69}$.

Mit diesem Argument trifft Fassbender einen wichtigen Punkt. Ein politisches Kollektiv kann sich nur vermittels eines Bezugspunktes instituieren, soll es als Einheit gelten. Ohne einen solchen virtuellen Bezugspunkt kann es keine Identität politischer Kollektive geben. Das Problem aber besteht darin, dass der „focus imaginarius“ im Sinne der Gründung der Vereinten Nationen hier bloßer Bezugspunkt einer retrospektiven Zuschreibung bleibt. Es besteht damit die Gefahr, dass konstituierte Akteure sich die Rolle einer konstituierenden Gewalt selbst zuschreiben, sich selbst ermächtigen, um im Namen der Völkerrechtsgemeinschaft zu handeln. Die Bezugnahme konstituierter Gewalten auf eine konstituierende Funktion birgt damit das Risiko, dass ein politisch fragwürdiges Handeln mit einer Legitimitätsreserve ausgestattet wird, für dessen Missbrauch ein legalistischer Blick blind bleiben muss.

Die Einsicht, dass diejenigen Individuen und Gruppen, die an der Entstehung der Verfassung beteiligt waren, im Namen der politischen Gemeinschaft gehandelt haben, also als konstituierte Gewalt in Erscheinung treten, verdankt sich einem Argument Kelsens, das mit einer Korrektur der Fragstellung beginnt. Anstatt zu fragen, wie Staaten bzw. politische Einheiten handeln können, müsse man fragen, „welches das Kriterium ist, nach dem gewisse, von bestimmten Menschen gesetzte Akte dem Staate zugeschrieben, die Akte als Staatsakte oder Staatsfunktionen qualifiziert, oder was dasselbe ist, warum bestimmte Menschen in der Setzung bestimmter Akte als Organe des Staates angesehen werden“"70 Kelsens Antwort lautet: Zurechnung. ${ }^{71}$ Nur wenn sich die Akte einer Gesamtrechtsordnung zurechnen lassen können, dann gelten sie

\footnotetext{
66 Lindahl (Fn. 55), 18 f. Die Delegierten als Repräsentanten der Völker haben damit die Verfassung hervorgebracht. In ähnlicher Weise macht auch Lindahl auf diesen Punkt aufmerksam. Der Augenblick der Gründung ist selbst nur repräsentiert, er ist nicht unmittelbar gegeben.

67 Immanuel Kant, Kritik der reinen Vernunft 2, Werke (hg. von Wilhelm Weischedel), Bd. 4, 2014, 565.

68 Siehe dazu Martin Loughlin, The Concept of constituent power, European Journal of Political Theroy 13 (2014) 218-237 (229), der von einer ,virtual equality of citizens“ spricht, um eine Gleichsetzung mit einer tatsächlichen Menge zu entgehen.

69 Siehe Kelsen, Reine Rechtslehre, 1992, 294.

70 Kelsen (Fn. 69), 293.

71 Siehe dazu Kelsen (Fn. 69), 154.
} 
auch als Akte dieser Gesamtrechtsordnung. Die Frage nach der Zurechnung lässt sich demnach als Frage nach der Gültigkeit von Rechtsakten übersetzen. ${ }^{72}$ Gültigkeit kann ein Rechtsakt nur für sich in Anspruch nehmen, wenn derjenige, der ihn setzt, auch von der Rechtsordnung dazu ermächtigt ist. ${ }^{73}$ Jeder gültige Rechtsakt ist deswegen gültig, weil der Akteur hierzu von einer Norm ermächtigt ist. Die Ermächtigungskette funktioniert nicht nur in die eine Richtung, indem bestimmt wird, wer zur Setzung von Rechtsakten befugt ist. Sie beinhaltet gleichzeitig eine retrospektive Perspektive und so eine repräsentative Komponente ${ }^{74}$, die den Gründungsakt in jedem einzelnen Akt zu wiederholen scheint. Denn der jeweilige Akteur, der von der Rechtsordnung bzw. einer bestimmten Norm derselben ermächtigt ist, Rechtsakte zu setzen, setzt sie zugleich virtuell im Namen der gesamten Rechtsordnung. Übersetzt man Rechtsordnung mit politischer Einheit (oder Staat), so erweist sich jeder, durch eine höhere Norm gedeckte Rechtsakt als im Namen der politischen Einheit gesetzt. Jeder gesetzte und von der Rechtsordnung ermächtigte Rechtsakt ist damit Instanziierung der ursprünglich repräsentativen Struktur des Gründungsaktes.

Dieses rechtspositivistische Argument hat zwar den Vorteil, mit einer Präsenz-Repräsentations-Dichotomie im Ursprungsakt zu brechen, weil die Akteure an der Hervorbringung dessen beteiligt sind, wovon sie bereits Repräsentanten sind. Aber Kelsens Argument hinsichtlich der Ermächtigung offenbart eine merkwürdige Schwäche, die seinem Reinheitsgebot geschuldet ist und so für Kritik Anlass gibt. Die politische Einheit wird in der Logik des Ermächtigungszusammenhangs durch konstituierte Gewalten vertreten und agiert durch diese. Wenn man sich wieder dem Ursprung der Verfassung bzw. der politischen Einheit zuwendet, stellt sich die Frage, wohin denn der Ermächtigungsverweis führt. Die Idee des Stufenbaus macht diese Bewegung in Form eines hierarchischen Verweiszusammenhangs anschaulich: Jeder Rechtsakt, egal welcher Stufe, muss sich letztlich durch die historisch erste Verfassung ermächtigt wissen. Aber woher beziehen die konstituierten Gewalten, die Individuen, die die historisch erste Verfassung erlassen, ihre Ermächtigung. Durch Selbstermächtigung, so die Antwort Kelsens. Doch diese Selbstermächtigung ist für die „reine“ rechtswissenschaftliche Betrachtung nicht mehr von Bedeutung. Als Selbstermächtigung ist sie nur de facto Ermächtigung, da sie aus Sicht eines Rechtssystems widersprüchlich erscheint. Kein Akteur im Rechtssystem kann sich selbst ermächtigen, er wird ermächtigt. Aus diesem Grund wird der Begriff der verfassungsgebenden Gewalt letztlich aus dieser Analyse als politischer Begriff ausgespart. Stattdessen muss ebenso der Gründungsakt der Rechtsordnung als durch konstituierte Organe vorgestellt, interpretiert werden, er

72 Siehe dazu Loughlin (Fn. 68), 222.

73 „Einen Akt menschlichen Verhaltens der Gemeinschaft zuzuschreiben, heißt gar nichts anderes, als diesen Akt auf die die Gemeinschaft konstituierende Ordnung beziehen, ihn als einen von der normativen Ordnung (im weitesten Sinne des Wortes) ermächtigten Akt begreifen." Kelsen (Fn. 69), 154.

74 Siehe dazu Hans Kelsen, Allgemeine Staatslehre, 1993, 310. 
wird so in die Rechtsordnung eingebaut und zwar durch die Grundnorm. ${ }^{75}$ Die normative Kraft der Rechtsordnung und der Verfassung als ihre höchste Normschicht ist eine Denk-Voraussetzung ${ }^{76}$, im Fall der UN-Charter eine Voraussetzung, die viel juristischer Einbildungskraft bedarf.

Die retrospektive Zuschreibung von Rechtsakten zu Rechtssystemen führt nun einerseits dazu, dass die politische Einheit völlig in das Rechtssystem kippt, in diesem aufgeht. Andererseits bedingt sie eine problematische Reduktion von Fragen der Legitimität auf Fragen der Legalität. ${ }^{77}$ Die Frage der verfassungsgebenden Gewalt verkommt also zu einem reinen Selbstbezug des juristischen Textes. Darin liegt das eigentliche Problem von Fassbenders Ansatz, aus der UN-Charter eine Verfassung zu machen. Nur weil ein Verfassungstext bzw. bestimmte Passagen diesen als solchen ausweisen und dementsprechend konstituierte Akteure sich als „im Namen der Völkerrechtsgemeinschaft" berufen sehen, zu handeln, bedeutet das nicht, dass die UN-Charter eine Verfassung ist. Das politische Moment bleibt in dieser rein legalistischen Betrachtungsweise ausgespart, womit eine problematische Usurpation konstituierender Gewalt ${ }^{78}$ durch konstituierte Akteure nicht hinreichend kritisch betrachtet werden kann.

\section{Verfassungsgebende Gewalt als Relation}

Der Versuch von Fassbender, den klassischen, am Nationalstaat orientierten Verfassungsbegriff auf die globale Ebene zu extrapolieren, offenbart zum einen die ambivalente Diskussion über einen essentialistischen Begriff der politischen Einheit des Volkes und zum anderen die Problemfelder eines normativistischen Umgangs mit dem Konzept einer konstituierenden Gewalt. Beide Positionen eint ihre nicht-dialektische Betrachtungsweise, sie begreifen die verfassungsgebende Gewalt nicht dynamisch,

75 Zur Grundnorm siehe Kelsen (Fn. 69), 196 f.

76 Loughlin (Fn. 68), 222.

77 Siehe dazu ebd.

78 Darauf macht Jean Cohen, Globalization and Sovereignty. Rethinking Legality, Legitimacy, and Constitutionalism, 2012, 268, aufmerksam, wenn die ständigen Mitglieder des UN-Sicherheitsrates in Folge ihrer Vetoposition sich anmaßen können, im Namen der Internationalen Gemeinschaft aufzutreten. Siehe zu dieser Kritik auch Kolja Möller, From constituent to destituent power beyond the state, Transnational Legal Theory 9 (2018) 32-55 (33 f.); Kolja Möller, Die Konstituierende als Destituierende Macht: Zur Transnationalisierung der Lehre vom pouvoir constituant, in: Grenze und Demokratie - Praktiken der Schließung und Überschreitung, hg. von Nele Kortendiek / Martina Martinez Mateo, 2017, 200-225 (201). Wobei kritisch bemerkt werden muss, dass in diesem Ansatz die verfassungsgebende Gewalt sogleich mit „Kompetenzen“ gleichgesetzt wird, die „nur den Bürgern, Menschen oder Staatsvölkern vorbehalten waren“ (ebd. 201). Versucht man verfassungsgebende Gewalt mit Kompetenzen gleichzusetzen, die einem bestimmten Akteur vorbehalten wären, so läuft man wieder Gefahr verfassungsgebende Gewalt in der Rechtsordnung aufgehen zu lassen. Kompetenzen sind nur eine andere Bezeichnung für Ermächtigungen. Ebenso Loughlin (Fn. 68), 233, der auf die Gefahr institutioneller Usurpation zu sprechen kommt. 
d.h. nicht geschichtlich. Sie sind damit unfähig in ihren einseitigen Perspektiven, den wesentlichen Gehalt verfassungsgebender Gewalt auszumachen. Dennoch beinhalten beide Ansätze wichtige Momente, mit denen sich ein relationaler ${ }^{79}$ Begriff verfassungsgebender Gewalt skizzieren lässt. Diesen relationalen Ansatz möchte ich nun kurz umreißen und mit der These abrunden, dass der globale bzw. transnationale Raum keine angemessene Voraussetzung für dieses Verständnis bereitstellt.

Reduziert der essentialistische Standpunkt verfassungsgebende Gewalt einerseits auf konkrete, existierende Größen, ${ }^{80}$ so lassen sich jedoch einer Schmittianischen Begrifflichkeit, vor allem der Unterscheidung zwischen Verfassung als Gesamtentscheidung und Verfassung als die Summe von Verfassungsgesetzen einige wichtige Hinweise entnehmen. Ebenso produktiv ist die Sichtweise, wonach die verfassungsgebende Gewalt sich weder in der Verfassungsgebung - verstanden als einmaliges Er-

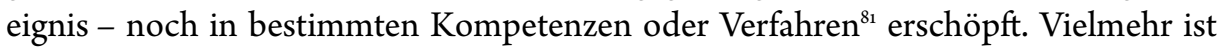
sie durch ein „[s] tändiges Vorhandensein (Permanenz)“82 gekennzeichnet. Andererseits reduziert der normativistische ${ }^{8_{3}}$ Standpunkt verfassungsgebende Gewalt auf die Ausübung bestimmter Kompetenzen. Er transferiert sie damit völlig ins Rechtssystem oder behandelt sie, in letzter Konsequenz, gar als überflüssig. ${ }^{{ }^{4}}$ Trotzdem muss an der normativistischen Einsicht festgehalten werden, dass der Bezugspunkt einer politischen Gemeinschaft symbolischer - genauer: repräsentativer - Natur ist. Dieser symbolische Bezugspunkt ist conditio sine qua non einer sozialen Aneignung. Darin muss dem Normativismus gefolgt werden. Der Normativismus allein ist aber unzureichend, da die symbolische Ebene allein keine conditio per quam sozialer Aneignung darstellt. Es muss eine Institutionalisierung hinzutreten.

Soziale Aneignung beruht auf einer gegenseitigen Unterstellung, ein gemeinsames emanzipatorisches Projekt - ein Versprechen zur Freiheit, das in den revolutionären Verfassungen der Aufklärung in Amerika und Frankreich sein Paradigma hat ${ }^{85}-\mathrm{zu}$ verfolgen. Insofern diese Unterstellung ein „Volk“ konstituiert, ist dieses nur symbolisch, mithin nur als Form und dadurch repräsentiert zu haben. Das Versprechen, die Gleichfreiheit aller zu garantieren darf nicht mit einer homogenen Gleichartigkeit al-

79 Vgl. Loughlin (Fn. 68).

80 Vgl. dazu Loughlin (Fn. 68), 231, der eine solche Reduktion auch bei Antoni Negri ausmacht, wenn dieser von „multitude“ spricht.

81 Vgl. Carl Schmitt (Fn. 38), 84-87, der verschiedene Verfahren anführt, die bei ihm aber lediglich dem Zweck einer „Ausführung und Formulierung der [...] politischen Entscheidung“ dienen, wie etwa eine verfassungsgebende Nationalversammlung, ein Konvent verbunden mit einem darauffolgenden Referendum, eine allgemeine Volksabstimmung etc.

82 Carl Schmitt (Fn. 38), 91.

83 Vgl. Martin Loughlin (Fn. 68), der darunter sowohl positivistische als auch anti-positivistische Ansätze versteht.

84 So beispielsweise David Dyzenhaus, Constitutionalism in an old key: Legality and constituent power, Global Constitutionalism 1 (2012) 229-260.

85 Siehe dazu nur Dieter Grimm, Die Zukunft der Verfassung II, 2012, 11-29. 
ler verwechselt werden. Es richtet sich gegen ein essentialistisches Bild, das ein Entsprechungsverhältnis zwischen Volk und homogener Gleichheit behauptet. Dieses Versprechen zur Freiheit bleibt aber dann kein leerer Begriff, kein „perennierendes Sollen " ${ }^{\text {"86 }}$, solange es sich instanziiert, sich in Institutionen im Sinne einer Gesamtentscheidung ${ }^{87}$ für alle einer politischen Einheit und im umfassenden Sinn festlegt und besondert. Erst dadurch, indem dieses Versprechen in konkreten gesellschaftlichen Einteilung sichtbar wird, sich in Privilegierungen von Lebensformen ${ }^{88}$ etc. manifestiert, der "gesellschaftliche Raum sich als Raum des Intelligiblen entfaltet" ${ }^{\text {"89 }}$, kann soziale Aneignung stattfinden, und hat so bereits stattgefunden. Dabei muss soziale Aneignung immer als affirmatives Hervorbringen und zugleich gegenwendiges Zirkulieren von Gründen verstanden werden, die sich innerhalb von Lebensformen und praktischen Vollzügen herauskristallisieren.

Konstituierende Macht gibt es nur, solange es eine Wechselbeziehung zwischen abstraktem Bezugspunkt, dem Versprechen zur Freiheit des Volkes, dem Versprechen in kollektiv gleichfreier Weise (Genetivus subjectivus) die individuelle Gleichfreiheit aller (Genetivus objectivus) zu ermöglichen, einerseits und den konkreten Instanziierungen dieses Versprechens andererseits gibt. Das bedeutet, konstituierende Macht politisch zu verstehen. In dieser Hinsicht lässt sich auch die Weise verstehen, wie Martin Loughlin die konstituierende Gewalt begreift. Sie bezeichnet für ihn die Quelle, die die Machtbeziehung speist und erhält..$^{90}$ Loughlin erläutert diese Beziehung etwa anhand einer Spaltung des Volksbegriffs, durch die der Gründungsakt seine paradoxale Natur erhält, weil er einerseits im Namen aller agiert und andererseits die Gesellschaft teilenden Machtverhältnisse hervorbringt. „In this foundational moment, so too must ,the people' be grasped in a double sense, conceptualized not only as a virtual unity (the nation/state) but also as a non-institutionalized entity established in opposition to the constituted authority (the ordinary people, the people-as-the governed)." ${ }^{91}$ Nur in dem „Zwischen“ der symbolischen Offenheit (nicht Ziellosigkeit) und den politischen Kämpfen ${ }^{92}$ um ihre prekäre Okkupation entfaltet sich eine Verfassung als „unse-

86 Georg Wilhelm Friedrich Hegel, Grundlinien der Philosophie des Rechts oder Naturrecht und Staatswissenschaft im Grundrisse, Werke (hg. von Eva Moldenhauer / Karl Markus Michel), Bd. 7, 1986, 253.

87 Loughlin verwendet den Begriff „droit politique“, um die symbolische Ebene in der Hervorbringung einer politischen Einheit hervorzuheben. Er schreibt dazu: „,[T] he constitution of a political unity through a legal order refers not to the positing of a legal order (in a strict sense) but to the constitution of political unity through droit politique. [...] Political unity is formed through the way in which droit politique operates to frame the constitution of the state." Martin Loughlin (Fn. 68), 230.

88 Zum Begriff der Lebensform siehe Rahel Jaeggi. Kritik von Lebensformen, 2014.

89 Claude Lefort, Die Frage der Demokratie, in: Autonome Gesellschaft und libertäre Demokratie, hg. von Ulrich Rödel, 1990, 281-297 (284).

90 Siehe dazu Martin Loughlin (Fn. 68), 231.

91 Martin Loughlin (Fn. 68), 233.

92 Als Beispiele solcher politischer Kämpfe gelten die Frauenrechtsbewegung sowie die Bürgerrechtsbewegung in den USA. 
re eigene“, als ein Projekt zur Freiheit der politischen Gemeinschaft. Dass dieses Projekt als „eigenes“ gilt und nur geschichtlich funktionieren kann, kann uns ein Vergleich mit dem Paradox der Autonomie zeigen. Zudem spitzt dieser Vergleich das Konzept der verfassungsgebenden Gewalt hin zum Begriff der Befreiung zu.

Der Autonomiegedanke erläutert das Verhältnis von Freiheit und Gesetz radikal anders als bisherige Freiheitstheorien. Er bringt beide Begriffe in ein Erläuterungsverhältnis, und zwar so, dass beide aufeinander bezogen werden und nur in diesem Bezug ihren Sinn erhalten. Freiheit erlangt man, indem man einem Gesetz entspricht. Einem Gesetz zu unterstehen, bedeutet frei zu sein. Doch dieses Erläuterungsverhältnis bleibt aufklärungsbedürftig. Fragt man nämlich nach dem woher des Gesetzes, so gibt das Autonomieparadigma als Antwort: Selbstgesetzgebung. Nur diejenigen Gesetze, die man sich (individuell oder kollektiv verstanden) selbst gibt, können dem Erläuterungsverhältnis zwischen Freiheit und Gesetz, das das Autonomiekonzept erklärt, entsprechen. Fragt man aber danach, wie der Akt der ursprünglichen Einsetzung des Gesetzes zu verstehen ist, so scheint das Autonomiekonzept geradewegs in eine Paradoxie zu münden. Denn entweder ist dies ein Akt des Gehorsams, der Entsprechung mit einem bereits gegebenen Gesetz, oder der Akt der Einsetzung ist willkürlich.93 Die Frage nach der verfassungsgebenden Gewalt scheint ähnlich paradoxal gefasst zu sein. Denjenigen, die verfassungsgebende Gewalt an einem Sein, dem Sein der politischen Einheit ausrichten, wie das Carl Schmitt tut, kann Willkür vorgeworfen werden. Willkür, weil sich über das Sein der politischen Existenz nichts weiter sagen lässt, dass es ist. Was immer der Wille der politischen Einheit entscheidet ist Verfassung. Die Verfassung ist heteronom durch das Sein bestimmt. Der Position, die Werte im Sinne naturrechtlich gültiger und unhintergehbarer Prinzipien annimmt, denen eine verfassungsgebende Gewalt zu entsprechen hätte, ${ }^{94}$ würde der Vorwurf zuteil, vorgegebene, äußere Heteronomie darzustellen.

Christoph Menke zeigt auf eindrucksvolle Weise, dass die Lösung des Autonomieparadoxes in einem ersten Schritt darin besteht, das Verhältnis von Selbst und Gesetz, hier von politischer Einheit und Verfassung anders zu bestimmen. Der Schlüssel liegt in der Aufgabe der Vorstellung, ein Selbst würde sich Gesetze geben. Diese Konstellation suggeriert ein distanziertes Wahlverhältnis zwischen Subjekt qua politischer Einheit außer und vor jeder Verfassung und der Palette an möglichen Verfassungen, die sie sich wählend gibt. Die Pointe besteht nun darin, dass jedes Subjekt, jede politische Einheit bereits gesetzlich verfasst ist, aber nicht in dem Sinne, dass die politische Einheit sich diese oder jene Verfassung gegeben hat, sondern so, dass die politische Einheit sich selbst Verfassung, sich selbst Gesetz ist. ${ }^{95}$

93 Siehe dazu Christoph Menke, Autonomie und Befreiung, 2018, $19 \mathrm{f}$.

94 So beispielsweise Matthias Kumm, Constituent power, cosmopolitan constitutionalism, and post-positivist law, ICON 14 (2017), 697-711.

95 Siehe dazu Christoph Menke (Fn. 93), 24 ff. 
Nur dieses Verständnis von Verfassung/Gesetz und kollektivem Subjekt, in dem die Verfassung die Identität der politischen Einheit bestimmt, kann wahrhaft eine Verfassung entsprechen, insofern sie die Vollzüge der politischen Gemeinschaft bestimmt. An dieser Stelle lässt sich aber eine weitere Stufe der Kritik formulieren. Denn in dieser Weise ist die politische Einheit im Haben und Vollziehen einer Verfassung nicht frei, es ist die Unfreiheit des „bloß Lebendigen“" ${ }^{96}$ im Sinne einer natürlichen Verfassung. Die politische Gemeinschaft steht unter der Knechtschaft seiner eigenen Identität. Erst durch die Tat kann sich eine politische Gemeinschaft eine Verfassung zu seiner eigenen machen und damit einer freien Aneignung, einer ewigen Ironie ausliefern. Dies kann aber erst geschehen, wenn sich in der Tat die Verknüpfung, die Identität von Verfassung und politischer Einheit löst und aufgebrochen wird. Dieser Akt heißt Befreiung von der zur zweiten Natur gewordenen, natürlichen Verfassung. ${ }^{97}$

Beides ist aber wesentlich: Sowohl die Identität im Sein, von Verfassung und politischer Einheit und zugleich Freiheit als Befreiung von der unmittelbaren Identität von Verfassung und politischer Einheit. Diese einander wiedersprechenden Bestimmungen können nur dann Sinn ergeben, wenn sie geschichtlich gedacht werden. Politische Gemeinschaften als politische Einheiten werden durch Verfassungen geordnet, sie geben sich nicht selbst Verfassungen, sondern haben eine, indem sie eine sind. In ihnen sind die sozialen Kräfte in bestimmter Weise zueinander geordnet, im Namen der Freiheit. Doch diese verfasste Freiheit, im Sinne einer Gesamtentscheidung verordnete Freiheit, die disziplinierend und bildend wirkt, wird zur Unfreiheit, dort wo sie zur Natur gerät und die Freiheit der Tat unterbindet. Dann versuchen andere Konstellationen, andere soziale Kräfte ihre Vorstellung der Freiheit im Namen aller, d. h. in Form einer Gesamtentscheidung zur Verfassung umzusetzen und so wiederum anzueignen. Das gemeinsame Projekt zur Freiheit besteht in diesem Hin und Her zwischen Identität und Befreiung, in dem sich zugleich die politische Gemeinschaft mit ihrer Geschichte bildet.

\section{Verfassungslyrik oder bloß destituierende Gewalt}

Verfassungsgebende Gewalt als relationales, dynamisches Element zwischen symbolischer Offenheit und institutioneller Schließung verliert sich im globalen bzw. transnationalen Kontext. Der Versuch, mit dem Nationalstaat verwobene Begriffe auf eine transnationale Ebene zu transponieren, scheitert daran, dass dort der dynamische $\mathrm{Zu}$ sammenhang zwischen politischer Einheit und Verfassung fehlen muss. Der Versuch etwa eine globale Verfassung in die UN-Charter hineinzulesen, scheitert schon daran,

96 Menke (Fn. 93), 59.

97 Siehe Menke (Fn. 93), 61. 
dass die Vereinten Nationen kein Projekt darstellen, das eine umfassende Verrechtlichung und Gestaltung, ${ }^{98}$ nicht nur des zwischenstaatlichen Handelns, sondern auch bezogen auf das Agieren aller mit Autorität versehenen Institutionen vorsehen würde. Sie bildet kein umfassendes System, in dem die Koordination aller Institutionen zueinander aufgrund von Kompetenzbestimmungen geregelt wäre. Im Unterschied zu nationalen Institutionenarrangements, deren Idealbild eines zusammenhängenden Kompetenz- und Institutionensystems zwar auch einer Realität aus Konflikt und Auseinandersetzung zwischen Institutionen gegenübersteht, lässt sich aber im Fall des transnationalen Raums von einem „systemic pluralism“ anstatt eines „institutional pluralism" sprechen. ${ }^{99}$ Meint Letzterer die Auseinandersetzung verschiedener Institutionen in ein und demselben Rechtssystem, so besteht bei ersterem kein gemeinsamer Referenzpunkt in Form eines übergreifenden Systems aus Regeln und Normen. Mit ihrem Ziel der Friedenssicherung - einem nichtsdestotrotz wichtigen Ziel - bildet sie lediglich Teil eines globalen bzw. transnationalen institutionellen Arrangements. ${ }^{100}$ Darin besteht, trotz aller aufgewendeten juristischen Einbildungskraft, der nicht zu kaschierende Analogiebruch zwischen nationalstaatlicher Einheitsvorstellung, die durch die Verfassungsterminologie imaginiert wird, und globaler, fragmentierter Realität. Schlussendlich erweist sich die Verfassungsterminologie, die noch dazu mit dem Anspruch, eine verfassungsgebende Gewalt ausfindig zu machen, auftritt, in Anbetracht des fragmentierten transnationalen Rechtsraums als bloße Politur. ${ }^{101}$

Entspringt eine globale Verfassung letztlich einem Perspektivenwechsel, ${ }^{102}$ durch den Rechtsdokumente idealisiert werden, so wird damit das Problem überdeckt, dass es keinerlei Aneignungsmoment in Form politischen Handelns gibt. ${ }^{103}$ Globale verfassungsgebende Gewalt verkümmert hier zu einem bloßen Selbstbezug von Rechtsdokumenten. Gegenüber dem legalistischen Selbstbezug vermeinen einige aktuelle Ansätze, doch noch einen Rest verfassungsgebender Gewalt im transnationalen Kontext ausfindig zu machen. Dabei werden politische wie soziale Bewegungen als Akteure einer destituierenden Gewalt identifiziert. Das Spektrum theoretischer Ansätze zur transnationalen destituierenden Gewalt reicht von einer Überlappung mit Phänome-

98 Siehe für den nationalen Kontext Dieter Grimm, The Achievement of Constitutionalism and its Prospects in a Changed World, in: The Twilight of Constitutionalism?, hg. von Petra Dobner / Martin Loughlin, 2010, 3-22 (7).

99 Zur Unterscheidung zwischen „systemic pluralism“ und „institutional pluralism“ siehe Nico Krisch, Beyond Constitutionalism: The Pluralist Structure of Postnational Law, 2010, 71-78.

100 Vgl. Nico Krisch, Pouvoir constituent and pouvoir irritant in the postnational order, ICON 14 (2016) 657-679 (669).

101 Siehe die Kritik bei Alexander Somek, From the Rule of Law to the Constitutionalist Makeover: Changing European Conceptions of Public International Law, Constellations 18 (2011) 567-588.

102 So auch die bezeichnende Wendung bei Jan Klabbers, wo „[c]onstitutionalism, as far as we are concerned, signifies not so much a social or political process, but rather an attitude, a frame of mind." Klabbers (Fn. 14), 10.

103 Vgl. Somek (Fn. 101), 577. 
nen des zivilen Ungehorsams, ${ }^{104}$ über die von Michael Hardt und Antonio Negri konzipierte Macht der Menge im Anschluss an Marx und Spinoza ${ }^{105}$ bis hin zu Versionen destituierende Gewalt als entsetzende Gewalt ${ }^{106}$, theoretisch ausgearbeitet bei Giorgio Agamben. Das Problem solcher Ansätze besteht zum Teil darin, dass sie jedwede dialektische Beziehung zwischen verfasster Ordnung und sozialen, konfliktorischen Aneignungsprozessen als bereits falsche juridische Pervertierung ursprünglich reiner sozialer Bezüge deklarieren. ${ }^{107}$ Sie vollführen eine geradezu spiegelbildliche Bewegung zu der Verfassungslyrik, wie sie etwa bei Fassbender zu beobachten ist. Werden dort Aneignungsprozesse völlig übersehen, indem verfassungsgebende Gewalt sich in juridische Selbstreferenzen zurückzieht und mit konstituierten Organen verwechselt wird, tritt die destituierende Gewalt in Form sozialer Selbstorganisation und Entsetzung rechtlicher Zusammenhänge als eigentliche, präsentische Form „wahrer Demokratie“ oder gar als messianische Politik des reinen Mittels ${ }^{108}$ auf. Die Konsequenz ist fatal: Jede Form repräsentativer, rechtlich verfasster Politik wird so als pervertierender Faktor ${ }^{109}$ verworfen und zugleich jede soziale Bewegung mit einer basisdemokratischen Weihe ${ }^{110}$ versehen. Das konfliktorisch, destituierende Moment gerinnt zum alleinigen Prinzip, wodurch auch in diesem Fall die dialektische Beziehung zwischen Verfassung und sozialer Aneignung gekappt wird. Beide Weisen, transnationale/globale verfassungsgebende Gewalt zu denken, sowohl in Form juridischer Selbstbezüglichkeit als auch in Form seines destituierenden Pendants mit seiner Gleichsetzung mit nicht-repräsentativen, basisdemokratischen Politikformen, sind damit Ausdruck

104 Siehe dazu Robin Celikates, Constituent power beyond exceptionalism: Irregular migration, disobedience, and (re-)constitution, JIPT 15 (2019) 67-81; Peter Niesen, Reframing civil disobedience: Constituent power as a language of transnational protest, JIPT 15 (2019) 31-48. Siehe generell den Schwerpunkt des Journal of International Political Theory der ersten Ausgabe 2019.

105 Siehe dazu Michael Hardt / Antoni Negri, Multitude: Krieg und Demokratie im Empire, 2004; Antonio Negri, Insurgencies: Constituent Power and the Modern State (Theory Out Of Bounds), 2009. An Hardt und Negri anschließend auch Isabell Lorey, Constituent power of the multitude, JIPT 15 (2019) 119-133.

106 Giorgio Agamben, What is a destituent power?, Environment and Planning D: Society and Space 32 (2014) 65-74.

107 So etwa die Gegenüberstellung bei Lorey (Fn. 105), 123: „The multitude, with its unpolitical and private positioning, reveals the gendered and racialized aspects of the distinction between people, representation, the public sphere, and political action on one hand, and multitude, immediacy/non-representation, the private realm, and (political) incapacity on the other." Dabei werden auch Schmittianische Dichotomien wiederholt, hier eben Repräsentation und Unmittelbarkeit.

108 Siehe Agamben (Fn. 106), 71.

109 Die Abgrenzung gegenüber etalbierter Politik, Staat und repräsentativen Demokratieformen geht oft mit einem Exodus Motiv einher. Ziel ist nicht Transformation durch die dialektische Beziehung zwischen Allgemeinheit, Verfassung und politischer Macht, sondern Transformation durch Auszug aus allen dialektischen Beziehungen. Dies geht oft mit einer verklärten Sicht auf kleine Gemeinschaftsformen einher.

110 Oliver Marchart prägt für Formen „wahrer Politik“ die hier auch treffende Bezeichnung „emancipatory apriorism" Oliver Marchart, Post-Foundational Political Thought. Political Difference in Nancy, Lefort, Badiou and Laclau, 2007, 159. 
eines stärker werdenden Ohnmachtssyndroms, dessen Ursache in der postnationalen Konstellation liegt.

Dass sich der nationale Begriffshaushalt mit einem fragmentierten transnationalen Institutionenarrangement nicht verträgt, ist eine Konsequenz. Die andere besteht darin, dass selbst dort, wo die demokratischen Kanäle, also die Inputlegitimität transnationaler Rechtssysteme am weitesten entwickelt ist, nämlich in der EU, sich die Auswirkung eines fehlenden Zusammenhangs zwischen Rechtsunterworfenheit und Praxen sozialer Aneignung in innerpolitischen Entwicklungen der Mitgliedstaaten wiederspiegelt. Dort verhalten sich in zunehmenden Maße zwei Entwicklungen wie kommunizierende Gefäße: Entweder das Ohnmachtssyndrom greift um sich und verwandelt sich in individuelle Betroffenheit, die sich nur mehr in subjektiven Rechten und sonst einer politischen Enthaltsamkeit artikuliert, auf diese Weise politischer „Interpassivität“" ${ }^{\prime 11}$ Vorschub leistend, oder das bisherige gemeinsame emanzipatorische Projekt wird pervertiert und nationalistisch, zum Teil auch völkisch, verklärt. Die zwei Weisen, in denen sich die stetige Aushöhlung kollektiver Handlungsmacht äußert, sind dann nichts anderes als Symptome einer Postpolitik: entweder Politikverdrossenheit oder nationalistische Identitätspolitik (ohne Befreiung). Die Trennung zwischen Recht und Politik scheint damit im transnationalen Kontext vollzogen. Es gibt nur mehr Recht ohne Demokratie, d.h. Rechtsunterworfenheit, die nicht mehr in einem Zusammenhang mit der Verfolgung eines gemeinsamen politischen Projekts gedeutet werden kann. Und es gibt nur mehr Demokratie ohne Recht, d.h. eine Demokratie, deren Inhalte zusehends den Anschluss an das Rechtsmedium verlieren und stattdessen auf Symbolpolitik setzen, oder, was noch schlimmer ist, die ein emanzipatorisches Projekt der Zukunftsgestaltung in ein rückwärtsgewandtes Unternehmen pervertiert - mit verheerenden Auswirkungen für Minderheiten und Außenstehende.

111 Siehe Alexander Somek, Constituent Power in National and Transnational Contexts, Transnational Legal Theory 3 (2012), 31-6o. 



\title{
Radikale Freiheit oder Leitkultur? \\ Individuelle Freiheit, kollektive Selbstbestimmung und normativer Grundkonsens
}

\author{
TIMO GREGER
}

\section{Radical Freedom or Leitkultur?}

Individual Freedom, Collective Self-Determination and Basic Normative Consensus

\begin{abstract}
Democracy is more than the mere aggregation of individual preferences, contrary to what popular proto-liberal views suggest. It is not solely constituted by a general will that results from a procedural modus vivendi and incorporates all citizens' interests. Democracy rests upon a comprehensive pre-political normative consensus. The consensus' normativity ultimately stems from three sources: a rationalist, a pragmatist and an identity-based one. Indeed, against the backdrop of the currently discernible need for collective identities, democracy is dependent on positively developing a liberal, inclusive collective identity if it aims to stand up to competing identity offers.
\end{abstract}

Keywords: democracy, preference aggregation, consensus, modus vivendi, Leitkultur, collective identity

\section{Die Demokratie im 21. Jahrhundert: Ende der Geschichte oder legitimatorische Krise?}

Francis Fukuyama hatte 1992 die westlich liberale Demokratie als das „Ende der Geschichte“, als die - in einem hegelianischen Sinne - letzte evolutionäre Stufe der politischen Systementwicklung beschrieben sowie den Zusammenbruch des kommunistischen Blocks und die damit einhergehende Entscheidung der jahrzehntelangen Systemkonkurrenz zwischen Sozialismus und Liberalismus bzw. Marktwirtschaft zugunsten der letzteren für entschieden gedeutet. Die liberale, freiheitliche Demokratie verkörpert - um in diesem Bild zu bleiben - den Bestimmungsort menschlicher 
Geschichte. Im Wettbewerb der großen Systementwürfe des 20. Jahrhunderts galten fortan die freiheitseinschränkenden Zwänge der kollektivistischen Ideologien als gescheitert und die individuelle Freiheit und Selbstbestimmung traten als Sieger hervor. Obwohl die liberale, auf Verfassungs- und Sozialstaatlichkeit basierende, rechtsstaatliche Demokratie seit Mitte der 9oer Jahre zweifelsohne zum vorherrschenden Paradigma, insbesondere in der europäischen Zivilisation, wurde, so scheint diese Vormachtstellung derzeit beträchtlich unter Druck zu geraten: Der in Polen und Ungarn zu beobachtende Versuch sich den inter- und supranationalen Institutionen durch einen neuen „Souveränismus“ zu entziehen, die Stück für Stück erodierenden verfassungsmäßig garantierten Grundrechte, eine verstärkte Tendenz zu kulturell fragilen "gelenkten Demokratien", wie beispielsweise in Russland, oder auch das Aufkommen des globalen Phänomens des Populismus, sowohl von rechts als auch von links, sind die sichtbarsten Symptome dieser tiefgreifenden legitimatorischen Krise der liberalen Demokratien. Verstärkt durch Prozesse wie Digitalisierung und Globalisierung sowie durch Migration und Flucht realpolitisch relevant gewordener Probleme, bestimmen in den liberalen Demokratien kulturelle Verlustängste und das Bedürfnis nach (kollektiven) Identitäten deutlich den gesellschaftlichen Diskurs und fordern damit die liberale Demokratie beträchtlich heraus. Dieses neu aufkeimende starke Bedürfnis nach Identität kann im extremsten Fall in an sich schon instabilen Demokratien einen fruchtbaren Nährboden für neoimperialistische und nationalistische Identitätspolitiken bieten, welche von entsprechenden Machthabern dankbar zur Stützung von autokratischen Tendenzen und zur Rückabwicklung von demokratisch-freiheitlichen Errungenschaften missbraucht werden kann, was sich bspw. in den letzten Jahren in der Türkei u.a. im Zusammenhang mit dem strategisch verfolgten Neoosmanismus und Neonationalismus unter Erdogan augenscheinlich gezeigt hat. ${ }^{2}$

Während also die liberale Demokratie, als einziges wirksames politisches System zur Verwirklichung von individueller Freiheit und Selbstbestimmung, noch Mitte der 9oer Jahre zum scheinbar unbestrittenen Erfolgsmodell avancierte, so befinden wir uns gegenwärtig nicht nur in einer Phase „demokratischer Rezession“, wonach die Gesamtzahl demokratischer Staaten in den letzten rund zehn Jahren praktisch überall weltweit zurückgegangen ist ${ }^{3}$, sondern so gerät die liberale Demokratie selbst - d.h. von Innen her - unter Druck. Ausgehend von den oben dargestellten Prozessen entscheidet

1 Francis Fukuyama, Das Ende der Geschichte. Wo stehen wir?,1992.

2 Das Konzept des Neoosmanismus wurde zunächst als eine außenpolitische Doktrin unter Außenminister Davutoglu skizziert, steht aber in einem engen Zusammenhang mit der gezielten türkisch-nationalistischen Identitätspolitik sowohl innerhalb als auch außerhalb der Türkei, insbesondere auch auf dem Balkan. Vgl. Wolfgang Gieler, Die Neuorientierung der türkischen Außenpolitik zwischen „Neo-Osmanismus und regionalem Führungsanspruch“ - Eine Bestandsaufnahme, in: Die Türkei im Wandel. Innen- und außenpolitische Dynamiken, hg. von Olaf Leiße, 2013, 37-54.

3 Diese Analyse liefert: Larry Diamond, Facing Up to the Democratic Recession, Journal of Democracy 26 (2015), 141-155. 
sich die Fortexistenz der liberalen Demokratie im 21. Jahrhundert also nicht mehr in Gegenüberstellung zu einer konkurrierenden Ideologie, wie der des Kommunismus oder Faschismus, oder aufgrund einer realpolitischen externen Bedrohung, sondern aufgrund innerer legitimatorischer Defizite. Diese inneren Bedrohungen erstrecken sich vor allem auf kulturelle Verlustängste, einem Unbehagen gegenüber der gestiegenen Pluralität an Lebensentwürfen in den westlichen Migrationsgesellschaften, aber vor allem auf das Bedürfnis nach individuellen wie kollektiven Identitäten, welches im Angesicht von konkurrierenden Identitätsangeboten wie Nationalismus oder Islamismus, adäquat und hinreichend von den liberalen Gesellschaften beantwortet werden muss, wenn ihre eigene Fortexistenz garantiert werden soll. Somit ergibt sich das ambige Bild, dass die liberale Demokratie zwar „das Ende der Geschichte“ zu sein scheint, sie aber trotzdem von Innen, auf einer spezifisch kulturellen Ebene, bedroht wird. Diese Ambiguität veranlasste Francis Fukuyama in seiner jüngsten Monografie zwar nicht dazu seine These von 1992 zu revidieren, sie aber doch dahingehend deutlich zu ergänzen, dass die zentrale „[...] Herausforderung für zeitgenössische liberale Demokratien angesichts der Zuwanderung und der wachsenden Vielfalt [darin] besteht [...], eine inklusive nationale Identität zu erschaffen, die der vielförmigen gesellschaftlichen Realität gerecht wird und Neuankömmlinge assimiliert." ${ }^{4}$ Die zentralen Herausforderungen für die liberale Demokratie liegen also fortan darin, sich mit ihren eigenen kulturellen Voraussetzungen, ihrem freiheits- und gemeinschaftsverbürgendem „einigenden Band“ zu beschäftigen und eine kollektive, inklusive Identität zu entwickeln, welche ihrem eigenen normativen Fundament gerecht wird. Die Rechtfertigung vor dem Hintergrund historischen Leides und Unrechts sowie freiheitlicher Errungenschaften mag künftig alleine nicht mehr hinreichend sein.

\section{Zwei Idealtypen: Radikale Freiheit oder Leitkultur}

Im Anschluss an diese eher skizzenhafte Analyse wird zum einen deutlich, dass die aktuelle Krisendebatte um die liberale Demokratie wesentlich vom spannungsreichen Verhältnis individueller Selbstbestimmung und berechtigter, konsensualer Ansprüche seitens der Gesamtgesellschaft bzw. dem Ausbilden einer gemeinsamen Identität abhängt; zum anderen ist es daher auch nicht verwunderlich, dass in jüngerer Zeit die Debatte um die Vereinbarkeit bzw. Notwendigkeit von kollektiven Identitäten, einer „Leitkultur“ oder eines Grundkonsenses mit den fundamentalen Prinzipien der liberalen Demokratie sowohl im alltäglichen wissenschaftlichen als auch öffentlichen Diskurs wieder mehr an Relevanz gewonnen hat. Kern dieser, nicht erst in jüngster Zeit entfachten, Debatte ist: Inwiefern darf eine liberale Demokratie gewisse normative Vorstel-

4 Francis Fukuyama, Identität. Wie der Verlust der Würde unsere Demokratie gefährdet, 2019, 171. 
lungen als allgemeinverbindlich einfordern, ohne ihren eigenen individuell-freiheitlichen Anspruch aufzugeben? Ausgehend von der mittlerweile klassisch gewordenen These von Ernst-Wolfgang Böckenförde, der behauptet, dass der freiheitliche Staat von Voraussetzungen lebt, die er selbst - mittels autoritativem Gebot und Rechtszwang - nicht garantieren kann, sondern darauf angewiesen sei, dass die Bürgerschaft selbst ihre freiheitlich-ethischen Voraussetzungen reproduziert ${ }^{5}$, findet sich eine breite und mannigfaltige philosophische Debatte, innerhalb der liberalen Theorieschule. Um nur einige wenige, mittlerweile kanonisch gewordene, Vorschläge zu nennen: John Rawls bspw. lehnt vor dem Hintergrund eines faktischen gesellschaftlichen Pluralismus moderner liberaler Staaten umfassende, verpflichtende moralische Konzeptionen ab und plädiert stattdessen für einen overlapping consensus, der die Idee der Gesellschaft als ein faires System der Kooperation und die Idee des Bürgers als vernünftige, freie und gleiche Person beinhaltet und von jedem Mitglied dieser Gesellschaft notwendig anerkannt werden müsse. ${ }^{6}$ Jürgen Habermas hingegen griff die, zunächst von Dolf Sternberger ${ }^{7}$ vorgebrachte, Idee eines Verfassungspatriotismus' auf, wonach sich die Loyalität und Übereinkunft der Bürger auf universelle Prinzipien einer Verfassungskultur - im Kern Menschenrechte und Demokratie - beziehen sollen und nicht auf eine, wie auch immer geartete, partikulare, nationale Identität. ${ }^{8}$ Und drittens, sich gegen einen Werterelativismus wendend und für einen verpflichtenden westlich-liberalen Wertekonsens, welcher bspw. Menschenrechte, individuelle Freiheit und Toleranz beinhalten solle, eintretend, sprach sich Bassam Tibi bereits Mitte der 9oer Jahre für einen leitenden, europäischen Wertekonsens - in seinen Worten eine „europäische Leitkultur“ - aus und lieferte damit auch einen wesentlichen Topos für eine breite öffentliche Debatte. ${ }^{9}$

Systematisch betrachtet, lassen sich die zahlreichen in dieser Debatte vorgebrachten - wohlgemerkt liberalen (!) - Vorschläge, wofür die obengenannten nur als grobe Referenzpunkte dienen sollen, zwischen zwei idealtypischen und konträr zueinander stehenden Konzeptionen verorten. Darüber hinaus lassen sich die beiden wesentlichen öffentlich diskutierten vortheoretischen Vorstellungen mittels dieser Idealtypen

5 Ernst-Wolfgang Böckenförde, Die Entstehung des Staates als Vorgang der Säkularisation, in: ders., Staat, Gesellschaft, Freiheit. Studien zur Staatstheorie und zum Verfassungsrecht, 2016 [1967], 60.

6 John Rawls, Die Idee eines übergreifenden Konsenses, in: ders., Politischer Liberalismus, 2017 [1993], 219-265 (231-238).

7 Dolf Sternberger, Verfassungspatriotismus, 1990.

8 Die Idee des Verfassungspatriotismus wurde von Habermas in unterschiedlichen Schriften und nicht zusammenhängend entwickelt. Vgl. besonders: Jürgen Habermas, Über den doppelten Boden des demokratischen Rechtsstaats, in: ders., Eine Art Schadensabwicklung, 1987, 11-17; ders., Nochmals: Zur Identität der Deutschen - ein einig Volk von aufgebrachten Wirtschaftsbürgern?, in: ders., Die nachholende Revolution, 1990, 205-224; ders., Faktizität und Geltung. Beiträge zur Diskurstheorie des Rechts und des demokratischen Rechtsstaats, 1998, 632-660.

9 Bassam Tibi, Europa ohne Identität. Die Krise der multikulturellen Gesellschaft, 1998. 
hinreichend genau repräsentieren. Diese beiden Idealtypen möchte ich an dieser Stelle als Radikale Freiheit $(R)$ und Leitkultur $(L)$ bezeichnen. Sie lassen sich wie folgt definieren:

R: $\quad$ Der Typus Radikale Freiheit besagt, dass die liberale Demokratie wesentlich auf der freien und gleichen Entfaltung der Persönlichkeit beruht. Weitere Einschränkungen der individuellen Freiheit, jenseits der wechselseitigen Anerkennung als vernünftige, freie und gleiche Bürger ${ }^{10}$, sind nicht nur nicht gestattet, sondern gar unvereinbar mit den zentralen normativen Vorstellungen der liberalen Demokratie. Die sich daraus ergebende Demokratievorstellung kann als ein prozeduraler modus vivendi begriffen werden, wonach der individuellen Selbstbestimmung eine strikte Prärogative zukommt und Demokratie als ein kollektives Verfahren verstanden wird, in welches ein jeder Bürger seine Präferenzen in den öffentlichen Diskurs / in ein Entscheidungsverfahren einbringen kann. Weitere konsensuale Elemente, welche die wechselseitige Anerkennung als vernünftige, freie und gleiche Bürger übersteigen, werden strikt abgelehnt und als illiberal suspendiert.

L: $\quad$ Der Typus Leitkultur hingegen besagt, dass zur Aufrechterhaltung der liberalen gesellschaftlichen Ordnung notwendig diverse weitere, für die westlich liberale Demokratie essentielle, normative Vorstellungen in der alltäglichen politisch-gesellschaftlichen Praxis verwirklicht sein müssen, um die Gesellschaft als eine tolerante und liberale aufrecht erhalten zu können. Dieser Typus zeigt sich in unterschiedlichem Ausmaß offen dafür diese leitenden Werte mit kulturellen Praktiken, historischen Traditionen, religiösen Kulten und (trans-)nationalen Identitätspolitiken zu verbinden. Die sich hieraus ergebende Demokratiekonzeption betont stark, dass die individuellen politischen Präferenzen nur genau dann in den öffentlichen Diskurs / in ein Entscheidungsverfahren Einzug finden können, wenn sie den umfassenden, die liberale Gesellschaft stützenden, normativen Vorstellungen, der tradierten politischen Praxis oder der etablierten Kultur und Identität gerecht werden. Diese umfassenden konsensualen Elemente werden in dieser Vorstellung explizit oder implizit mit der Stützung der liberalen Demokratie gerechtfertigt und deshalb als notwendig betrachtet.

10 Diese Einschränkung ,jenseits der wechselseitigen Anerkennung als vernünftige, freie und gleiche Bürger" ist bereits eine beträchtliche und vor allem moralische Einschränkung der individuellen Freiheit und bedeutet eben explizit nicht - wie manchmal akzentuiert - „anything goes“. Fundamentale Menschenrechte, wie bspw. die gleiche Menschenwürde, sind hier bereits vorweggenommen. Hinter diesen, durch Ralws explizierten, Minimalkonsens scheint in der liberalen Fachdebatte niemand mehr zurück zu wollen, auch wenn diese deutliche normative Einschränkung im populären, öffentlichen Diskurs so nicht immer explizit gemacht wird bzw. eingefordert wird. 
Typische und besonders kontroverse Konflikte zwischen diesen beiden Idealtypen in Bezug auf die Frage, inwieweit die (Mehrheits-)Gesellschaft einzelne Bürger oder Gruppen zu gewissen sozialen Praktiken verpflichten darf oder nicht treten bspw. in den Bereichen der Religionspolitik („Burkaverbot“), bei divergierenden gesellschaftlichen Konventionen zwischen autochthoner und allochthoner Bevölkerung („Händeschütteln") oder der Gleichberechtigung der Geschlechter auf. Wesentlicher Konfliktpunkt ist hierbei in der Regel nicht, ob diese oder jene Praktik erwünscht ist oder nicht, sondern die Frage, ob der liberale Staat bzw. eine offene Gesellschaft legitimerweise solche Praktiken überhaupt einschränken dürfe. D.h. ob diese Praktiken in den Bereich des Politischen und kollektiv zu Bestimmenden einzuordnen sind oder zumindest gewisse negative Einflüsse darauf haben (L) oder, ob diese Praktiken vom fundamentalen Freiheits- und Selbstbestimmungsrecht gedeckt seien, also der freiheitssichernden Autonomiesphäre zuzuordnen sind und, falls der liberale Staat hier versuchen würde diese Praktiken zu suspendieren und einen liberalen Konsens durchzusetzen nicht gegen seine eigenen normativen Prinzipien verstoßen würde (R). Der Konflikt bezieht sich also in der Regel darauf, ob eine liberale Demokratie berechtigterweise einen von liberalen Werten getragenen Konsens jenseits der wechselseitigen Anerkennung als vernünftige, freie und gleiche Bürger einzufordern berechtigt ist oder ob dies die individuelle Freiheit unzulässig und willkürlich einschränken würde. In Bezug auf die Argumentation R, ergibt sich hieraus eine Demokratievorstellung als prozeduraler modus vivendi, welche die Etablierung eines verpflichtenden Konsenses ablehnt und Demokratie lediglich als ein Entscheidungsverfahren begreift, in welches jeder Bürger alle denkbaren individuellen Präferenzen einzubringen berechtigt ist und sich seine individuelle Freiheit, jenseits der persönlich garantierten Autonomiesphäre, durch dieses kollektive Verfahren verwirklicht. Eine Einschränkung der Präferenzen bzw. eine durch einen Grundkonsens unterbundene Verwirklichung wird in dieser Konzeption als illiberale und unzulässige Freiheitsbeschränkung betrachtet. Demzufolge sei jeglicher die individuelle Freiheit einschränkender verbindlicher Konsens, jenseits der wechselseitigen Anerkennung als vernünftige, freie und gleiche Bürger illiberal und illegitim.

In den folgenden Ausführungen soll deshalb das Verhältnis von Demokratie und Konsens im Zentrum der Auseinandersetzung stehen. Das heißt, es soll konkret geprüft werden, ob sich für eine liberale Demokratie legitimerweise ein, potentiell die individuelle Freiheit einschränkender, normativer Grundkonsens rechtfertigen lässt, und ob ein solcher sich sogar als notwendig erweist. Das bedeutet, es geht konkret um die Grenzen individueller Freiheit und den normativen Voraussetzungen kollektiver Selbstbestimmung: Dabei muss geprüft werden, ob sich die Vorstellung Radikale Freiheit $R$ aufrechterhalten lässt und Demokratie als ein prozeduraler modus vivendi begriffen werden kann, oder ob die liberale Demokratie nicht vielmehr auf einem umfassenden normativen Grundkonsens angewiesen ist. Dieser, sich als Propädeutik zu einer Leitkultur-Debatte verstehende, Beitrag erhält seine Relevanz dadurch, dass das em- 
pirisch eindeutig feststellbare Bedürfnis nach Identität in Verbindung mit kulturellen Verlustängsten noch lange keine hinreichende Begründung dafür ist, dass eine liberale Demokratie mit einem umfassenden normativen Grundkonsens vereinbar ist. Vielmehr bedarf es notwendigerweise diese und weitere philosophische Klärungen, sofern man nicht in einen bloßen Voluntarismus abgleiten möchte. Zur Klärung dieser Frage soll in einem ersten Schritt das die vortheoretische Vorstellung R stützende Verständnis von Demokratie offengelegt werden (III). Anschließend soll, u. a. mittels zentraler Ergebnisse der Social-Choice-Theory, eine solche als prozeduraler modus vivendi verstandene Demokratiekonzeption als logisch unhaltbar zurückgewiesen werden (IV), um daraufhin die Notwendigkeit eines umfassenden normativen Grundkonsenses für eine liberale Demokratie explizit zu machen (V). Abschließend sollen noch zentrale Charakteristika eines solchen normativen Grundkonsenses expliziert und zu klären versucht werden, woraus sich die Normativität eines solchen Grundkonsens speist und zumindest angedeutet werden, wie dieser erhalten werden kann (VI).

\section{Demokratie als prozeduraler modus vivendi}

Die mit dem Idealtypus R einhergehende Vorstellung von Demokratie nimmt ihren Ausgang in der Problematik der Vereinbarkeit von individueller Freiheit und kollektiver Autonomie bzw. Demokratie. Indem diese Vorstellung weitere Einschränkungen der individuellen Freiheit, jenseits der wechselseitigen Anerkennung als vernünftige, freie und gleiche Bürger, strikt ablehnt und als illiberal zurückweist, postuliert sie eine vortheoretische Vorstellung von Demokratie, welche sich stark an das kollektivistische Verständnis von Demokratie als Volkssouveränität anlehnt, welches auch in weiten Teilen der zeitgenössischen Demokratietheorie, insbesondere dem staatsrechtlichen Legitimationsprinzip, weit verbreitet ist. ${ }^{11}$ Diese modus vivendi-Vorstellung speist sich aus fundamentalen Ideen und Konzepten des Liberalismus, welche ihren Ursprung in den klassischen liberalen Theorien der Moderne, insbesondere derer Lockes und Rousseaus, haben. Als systematischer Ausgangspunkt dieser Theorien und des liberalen Paradigmas generell lässt sich der normative Individualismus identifizieren, welcher jedes, mit moralischer Autonomie ausgestattete, Individuum aus kollektiven Rechtfertigungszusammenhängen herauslöst, die gesetzgebenden Autoritäten Gottes und der Natur durch das individuelle Recht auf Selbstbestimmung ersetzt und jegliche Form der gesetzlichen Freiheitsbeschränkung an die - reale oder hypothetische - Zustimmung jedes einzelnen bindet. ${ }^{12}$ Dieser normative Individualismus bildet das philosophische Fundament der liberalen Idee und beschreibt das von Natur aus

11 Ernst-Wolfgang Böckenförde, Demokratie als Verfassungsprinzip, in: ders., Staat. Verfassung. Demokratie, 1991, 289-378.

12 Wolfgang Kersting, Die Politische Philosophie des Gesellschaftsvertrags, 1994, 17. 
freie, gleiche und autonomiefähige Individuum als letzte Instanz, vor welcher sich alle politischen Entscheidungen sowie Herrschaft an sich bzw. jegliche Form von Autonomiebeschränkung rechtfertigen muss. Demzufolge bedürfen alle Freiheitseinschränkungen und alle politischen Entscheidungen der rationalen Zustimmung der unterworfenen freien und gleichen Individuen bzw. müssen deren Interessen oder Belangen gerecht werden; eine Rechtfertigung aufgrund höherwertiger Gründe oder anderer Interessen als die des autonomen Individuums schließt der normative Individualismus aus. Diesem Paradigma zufolge rückt also die gleiche Freiheit eines jeden Individuums ins Zentrum der politischen Legitimation und jede öffentliche Ordnung rechtfertigt sich aufgrund der möglichen rationalen Zustimmung eines jeden einzelnen Individuums zum Staat an sich sowie den politischen Entscheidungen im Allgemeinen. ${ }^{13}$

Ausgehend von diesem Paradigma verschob sich ab dem 17. Jahrhundert, im Zuge einer Kritik an der hobbesschen Staatstheorie, der Blickwinkel auf die Vereinbarkeit von individueller und kollektiver Selbstbestimmung - und damit wurde die entscheidende Frage der modernen, neuzeitlichen politischen Philosophie zum Gegenstand der Debatte erhoben: Die Frage nach der Koexistenz von individueller und kollektiver Autonomie, die Frage nach der Vereinbarkeit von individueller Freiheit und kollektiver Selbstbestimmung. Im Zuge dieser, genuin das Autonomie bzw. Freiheitsproblem thematisierenden, Kritik an der hobbesschen Staatstheorie, entwickelten sich zwei Theoriestränge, die beide für die Vorstellung der Demokratie als modus vivendi essentiell sind, aber auch das heutige Demokratieverständnis generell wesentlich prägten.

Der erste steht in der, die individuelle Autonomiesphäre betonenden und an John Locke anschließenden Theorietradition, welche eine individuelle, dem kollektiven Entscheidungsraum entzogene, autonomiesichernde Freiheitssphäre als konstitutiv für eine legitime Demokratie konstatiert. Diese Theorietradition nimmt ihren Ausgang in Lockes Second Treatise und sollte insbesondere in den anglo-amerikanischen Demokratien zum dominanteren Paradigma werden. Gemäß John Lockes Staatstheorie verfügt der Mensch über gewisse, fundamentale natürliche Grundrechte, nämlich das Recht auf Leben, Freiheit und Eigentum, welche dem Zugriff der staatlichen Gewalt entzogen und nicht Gegenstand kollektiver Entscheidungsprozesse sind. Im lockeschen, durch Vertrag konstituierten Staat, ist es primäre Aufgabe der Staatsgewalt diese Rechte zu achten und zu schützen. Eine allmächtige, unbegrenzte staatliche Gewalt gibt es in dieser Theorie nicht - vielmehr findet sie ihre Grenzen in eben diesen individuellen Grundrechten und ist ihrer Verwirklichung und Sicherstellung verpflichtet; darüber hinaus wird die Konstitution der staatlichen Gewalten auch nicht als unwiderruflicher Autonomieverzicht betrachtet, sondern als genuin treuhänderische auf die souveräne Gewalt der Bürger rückführbare und in regelmäßigen Abständen zu wählende Delega-

13 Dietmar von der Pfordten, Normativer Individualismus versus normativer Kollektivismus in der Politischen Philosophie der Neuzeit, Zeitschrift für philosophische Forschung, 54 (2000), 491-513 (500). 
tion. ${ }^{14}$ Diese starke Betonung der individuellen Freiheit und der strikten Prärogative der autonomiesichernden Freiheitssphäre, welche von Seiten der Staatsgewalt nicht nur geachtet, sondern aktiv geschützt und verteidigt werden muss, begründet das erste Charakteristikum unserer modus vivendi-Vorstellung: Die Freiheit eines jeden Bürgers wird u. a. dadurch sichergestellt, dass die Staatsgewalt einen - i.d.R. durch spezifisch normierte Grundrechte - definierten, individuellen Autonomiebereich achtet und sowohl von staatlichen als auch gesellschaftlichen Eingriffen schützt. Kollektive Ansprüche, z. B. in Form eines einzufordernden leitenden Konsenses über Werte, Praktiken, Lebensentwürfe oder auch Identitäten, werden aus dieser individuellen Freiheitssphäre suspendiert und als heteronome, die Freiheit gefährdende Akte verstanden.

Neben diesem ersten, die individuelle Freiheitssphäre und fundamentale Grundrechte, betonenden Charakteristikum, ist für die modus vivendi-Vorstellung von Demokratie aber noch ein zweites essentiell, welches sich für die hier aufgeworfene Frage als wesentlich problematischer erweisen sollte. Dieses zweite Charakteristikum bezieht sich auf den Bereich des Politischen und betrifft die Frage der kollektiven Autonomie und versucht das Problem der Vereinbarkeit von individueller Freiheit sowie kollektiver Selbstbestimmung zu lösen. Dieses wesentlich von Rousseau beeinflusste Paradigma erhebt grob folgende Forderung: Die individuelle Freiheit, als fundamentales Menschenrecht, darf auch im Bereich des Politischen nicht eingeschränkt werden; eine solche Freiheitsbeschränkung fände insbesondere durch die Einschränkung der individuellen Partizipation am öffentlichen Willen bzw. Gemeinwillen statt, also durch Diskriminierung bestimmter Präferenzen, wie sie vom Typ L gefordert wird. Aufgrund dessen, dass einzig und allein der eigene Wille bzw. die individuellen Präferenzen gesetzgebend sein dürfen und jede Einschränkung und Fremdbestimmung gegen die individuelle Freiheit verstoßen, so die Vorstellung, verlange Demokratie die Konstitution eines die Gesamtheit der Bürger repräsentierenden kollektiven Akteurs, dessen Äußerungen, welchen durch Gesetze und Verordnungen Ausdruck verliehen wird, als Aggregation aller bürgerschaftlichen, individuellen Interessen zu einem kollektiven Gemeinwillen anzusehen ist. D.h. die individuelle, den grundrechtlich geschützten Bereich übersteigende, Freiheit wird durch die Partizipation an der Bildung dieses Gemeinwillens als hinreichend verwirklicht betrachtet. Die individuellen Willen der freien und gleichen Individuen werden als auf diesen kollektiven Akteur als kollektiver Wille übertragen gedacht. Eine individuelle Freiheitseinschränkung findet dieser Vorstellung gemäß auch hier nicht statt, da dieser kollektive Wille als ein alle Individualwillen internalisierender Gemeinwille gedacht wird.

Gemäß dieser Vorstellung gestaltet sich der Prozess der kollektiven Selbstbestimmung also lediglich als ein modus vivendi, über welchen hinaus keine weiteren Voraussetzungen notwendig wären: Alle Bürger haben, jenseits der individuellen Frei-

14 John Locke, Über die Regierung, hg. von Peter Cornelius Mayer-Tasch, 1974 [1689]. 
heitssphäre, diverse Präferenzen in Bezug auf den Bereich des Politischen. Alle diese Präferenzen dürfen in ein kollektives Entscheidungsverfahren Eingang finden und sichern, durch den so gebildeten und als ihren eigenen Willen anzusehenden Gemeinwillen, ihre individuelle Freiheit auch im Politischen. Eine Beschränkung dieses Verfahrens oder einer Diskriminierung von gewissen Präferenzen wäre nicht nur unzulässig im Sinne des Verfahrens, sondern eine explizite Einschränkung individueller Freiheit und damit für die beschränkten Individuen ein heteronomer Akt. Das bedeutet, dass eine solche modus vivendi-Demokratie essentiell auf ein Entscheidungsverfahren angewiesen ist, welches alle individuellen Interessen zu einem kollektiven Interesse aggregiert. Im Zuge dieses Verfahrens müssen also alle individuellen Präferenzen zu einer kollektiven Präferenz aggregiert und als kollektiver Wille explizit gemacht werden. Dieser Kollektivwille ist hiernach als ein alle individuellen Interessen repräsentierender Wille anzusehen und ist dadurch funktional freiheitsverbürgend. Im Zuge dieses Verfahrens wird jeder, den rawlsschen Minimalkonsens der wechselseitigen Anerkennung als vernünftige, freie und gleiche Individuen übersteigende, sowohl konstitutiv als auch regulativ einzufordernde Konsens, als unzulässige Freiheitseinschränkung abgelehnt. Die individuelle wie auch kollektive Autonomie verwirklicht sich in einer modus vivendi-Vorstellung durch ein offenes Aggregations- und Entscheidungsverfahren, welches alle Präferenzen gleichberechtigt und ohne weitere Voraussetzungen berücksichtigt. Wenn man Demokratie als ein solches prozedurales Aggregationsverfahren betrachtet, lässt sich ein starker normativer Grundkonsens nicht rechtfertigen, da jede dieser Einschränkungen mit dem normativen Fundament der liberalen Demokratie kollidiert; das Verfahren selbst soll ja gerade die individuelle gleiche Freiheit sicherstellen. Die Bevorzugung von Präferenzen in Hinblick auf gewisse kulturelle Praktiken oder eine Privilegierung derjenigen Präferenzen, die eine kollektive Identität begünstigen, wie sie Typ L fordert, sind in der modus vivendi-Vorstellung freiheitseinschränkend, damit grundsätzlich dem eigenen normativen Fundament zuwiderlaufend und nicht rechtfertigbar.

Dreh- und Angelpunkt dieses Demokratiekonzepts ist demnach also die rousseausche Vorstellung des durch einen einheitlichen kollektiven Willen, dem volonté générale, regierten Volkes. Diesem Demokratieverständnis gemäß ist es wesentliche Aufgabe der Demokratie, diesen Gemeinwillen zu identifizieren und ihm in Form von allgemeinen, einheitlichen Gesetzen Ausdruck zu verleihen. Das, was durch diese Konzeption sichergestellt werden soll, ist das von Rousseau in seinem problème fondamental skizzierte Programm, nämlich dass ein jeder genauso frei bleibt wie zuvor und dass ein jeder nur von seinem eigenen - an den Kollektivkörper transformierten Willen regiert wird ${ }^{15}$. In dieser zweiten, von Rousseau ausgehenden, kollektivistischen

15 Jean-Jacques Rousseau, Du contrat social. Vom Gesellschaftsvertrag, übers. und hg. von Hans Brockard, $2010[1762]$, Buch I, Kap. 6. 
Theorietradition ist es nicht ausreichend, dass die Staatsgewalt lediglich im Interesse des Volkes ausgeübt wird, das Volk selbst muss direkt und unmittelbar Träger dieser Staatsgewalt sein und diese, über die repräsentative Ebene des Parlaments und der davon abhängigen Organe, auch selbst ausüben. Das rousseausche demokratische Prinzip der Volkssouveränität legt der Staatsgewalt nicht nur die Pflicht auf die individuelle autonomiesichernde Freiheitssphäre zu schützen und damit die individuelle Autonomie effektiv zu gewährleisten. Sondern im rousseauschen Demokratieprinzip wirkt das freie Individuum der Staatsgewalt gegenüber nicht per se herrschaftsbegrenzend, vielmehr herrschaftsermächtigend; die individuelle Autonomie ist hier nicht Grenze und Ankerpunkt aller Staatsgewalt; die natürlichen Freiheitsrechte, die Selbstbestimmung und Souveränität, welche im Naturzustand jedem einzelnen zukamen, werden in dieser Vorstellung als auf das einheitliche Volk als Kollektivkörper übertragen gedacht. Die individuelle Freiheit wird in diesem Konzept durch die aktive Teilhabe am kollektiven, souveränen und gesetzgebenden Volkswillen verwirklicht. ${ }^{16}$ Folglich kann die sowohl individuelle Freiheit eines jeden Einzelnen als auch die kollektive Freiheit des ganzen Volkes nur sichergestellt werden, wenn jedes lebensweltliche Auftreten von Staatsgewalt, jedes Gesetz, jede Verordnung sowie jeder Verwaltungsakt auf eben diesen einheitlichen Volkswillen rückführbar ist; jede Form von öffentlich wirkender Staatsgewalt, jede Amtsgewalt und jede Ermächtigung zu hoheitlichem Handeln wird von diesem einheitlichen, den Gedanken des volonté générale repräsentierenden, souveränen Willen aus legitimiert. Damit wird dieser einheitliche, durch öffentliche Deliberation und Diskussion zu identifizierende, im Parlament durch Mehrheitsentscheid zu bildende und in Form von Gesetzen normierte Wille des Volkes zum Metakriterium für eine rechtmäßige Demokratie - ohne die Möglichkeit eines eben solchen einheitlichen Willens muss jede Form von Staatsgewalt, jedes Gesetz und jede Ermächtigung als undemokratisch, illegitim und freiheitsbeschränkend angesehen werden. Das bedeutet: Ohne die logisch mögliche Existenz eines solchen kollektiven Willens, eines solchen einheitlichen Interesses ist dieser Vorstellung gemäß Demokratie nicht möglich.

Diese theoretischen Vorstellungen sind es, welche eine modus vivendi-Konzeption von Demokratie stützen. Dieses Identitäts-Konzept des volonté générale ist es, was kollektive Ansprüche, wie eines einzufordernden leitenden Konsens über Werte, Praktiken oder Lebensentwürfe bzw. eine Privilegierung von Präferenzen, welche bestimmte Praktiken zu stützen helfen, für illegitim erachten lassen. Jede Einschränkung, normative Begrenzung des Politischen ist hier auch immer eine Einschränkung der individuellen Freiheit. Doch dies ist an sich noch nicht der kritische Punkt, sondern die implizierte umgekehrte Behauptung: Sofern der Bereich des Politischen keinen normativen Einschränkungen unterworfen ist, so behauptet es die Theorie, findet

16 Böckenförde (Fn. 11), 291-296. 
überhaupt keine Einschränkung der individuellen Freiheit statt. In einer reinen modus vivendi-Vorstellung von Demokratie wird die individuelle und kollektive Autonomie durch die Partizipation am Entscheidungsverfahren hinreichend verwirklicht. ${ }^{17}$

Diese grundlegenden theoretischen Vorstellungen haben für die modus vivendi-Konzeption des Typs R drei Konsequenzen: Erstens wird die individuelle Freiheit zunächst durch eine grundrechtlich geschützte Autonomiesphäre vor heteronomen Akten bewahrt. Zweitens wird kollektive Autonomie nur möglich, wenn alle individuellen Präferenzen notwendig Eingang in das Entscheidungsverfahren finden können, da die sich hieraus ergebenden Entscheidungen des kollektiven Akteurs als Entscheidungen eines jeden Einzelnen betrachtet werden. Das führt notwendig zu folgender, dritten Konsequenz: Fundamentale Prämisse dieser Demokratievorstellung ist also die logisch mögliche Existenz eines solchen kollektiven und einheitlichen Willens, ohne welchen die gesamte Theorie in sich zusammenbricht bzw. nicht ohne weiteres aufrecht erhalten werden kann, wie es bereits von Rousseau selbst vorweg genommen worden ist: „Das Gemeinsame nämlich in diesen unterschiedlichen Interessen bildet das gesellschaftliche Band, und wenn es nicht irgendeinen Punkt gäbe, in dem alle Interessen übereinstimmen, könnte es keine Gesellschaft geben. ${ }^{18}$ Ohne die logisch mögliche Existenz eines kollektiven einheitlichen Willens - oder abgeschwächt einer solchen kollektiven Präferenz bzw. Präferenzrelation, ohne die Möglichkeit der Aggregation aller individuellen Interessen zu einem kollektiven Interesse, bricht die rousseausche - und damit auch die modus vivendi- - Demokratietheorie in sich zusammen.

\section{Kollektive Selbstbestimmung und Social-Choice-Theory}

Seit Mitte des vergangenen Jahrhunderts wurden im Bereich der Logik Kollektiver Entscheidungen (Collective oder Social-Choice-Theory), einer Subdisziplin der Entscheidungstheorie, zentrale Forschungsergebnisse erzielt, welche auch für die philosophische Demokratietheorie von höchster Relevanz sind. Auch wenn diese Ergebnisse hauptsächlich in einer kleinen interdisziplinären Gruppe von Logikern, Spieltheoretikern, Ökonomen und Philosophen erarbeitet wurden und nach wie vor hauptsächlich dort rezipiert werden, so müssen diese Ergebnisse dennoch auch im Rahmen einer adäquaten philosophischen Theoriebildung Berücksichtigung finden, insbesondere weil sie der philosophischen Demokratietheorie nicht unwesentliche Restriktionen auferlegen. Die im Rahmen der Logik Kollektiver Entscheidungen bewiesenen Theoreme

17 Dies gilt, zumindest theoretisch, auch abgeschwächt, wenn man das Mehrheitskriterium als hinreichend betrachtet.

18 Rousseau (Fn. 15), Buch II, Kap. 1. 
sind demnach nicht als unabhängig von den oben explizierten normativen Vorstellungen der liberalen Demokratie zu betrachten, vielmehr schränken sie den Bereich der logisch gültigen Demokratietheorien durchaus beträchtlich ein. Diese Einschränkungen sind nicht empirischer, sondern lediglich formaler Natur; sie ergeben sich aus der logischen Gültigkeit bzw. der Konsistenz der implizierten Regelsysteme - sie sind also apriorisch und zunächst unabhängig von pragmatischen oder normativen Urteilen.

Insbesondere unterminieren die zentralen Ergebnisse dieser Theoreme die an Rousseau anknüpfende Forderung, die Demokratie verlange die Konstitution eines die Gesamtheit der Bürger repräsentierenden kollektiven Akteurs, indem sie die Vorstellung der Aggregation aller bürgerschaftlichen, individuellen Interessen zu einem kollektiven Gemeininteresse als logisch unmöglich beweisen. Dies hat unmittelbar zur Folge, dass das reduktionistische Verständnis von Demokratie, welches die individuelle Freiheit durch die vollendete Partizipation an der Bildung des kollektiven Willens als hinreichend verwirklicht betrachtet, als nicht adäquat angesehen werden muss. Damit greifen diese Ergebnisse auch das, sich aus der gängigen Vorstellung von Volkssouveränität ableitende, demokratische Legitimationsprinzip, nach welchem die auf zentraler Ebene beschlossenen Gesetze als Ausdruck des kollektiven und einheitlichen Gemeininteresses anzusehen sind, frontal an. Auch wenn Aggregations- und kollektive Dezisionsprozesse in realiter in Demokratien nur eine nachgeordnete Rolle spielen, so bietet diese Theorie dennoch der Vorstellung, dass ein durch formelle Gesetze repräsentierter und durch parlamentarische Abstimmungen gebildeter kollektiver Wille, als ein alle individuellen Interessen internalisierender und damit alle Unterworfenen rein aufgrund seines Konstitutionsakts per se und ohne weitere Begründung verpflichtender Wille angesehen werden müsse, eine philosophische Grundlage. Durch die logische Widerlegung der Möglichkeit der Aggregation der individuellen Präferenzen zu einer kollektiven Präferenz, verliert diese kollektivistische Vorstellung des alle Individuen verpflichtenden Gemeinwillens ihre freiheitsverbürgende Funktion - und greift damit die grundlegende These der modus vivendi-Demokratie an: Die Vorstellung, kollektive Selbstbestimmung und individuelle Freiheit jenseits einer geschützten Autonomiesphäre könne hinreichend dadurch sichergestellt werden, indem alle Bürger sich als wechselseitig vernünftig, frei und gleich anerkennen und ihre individuellen Präferenzen - ohne weitere konstitutive oder regulative Voraussetzungen - in ein Entscheidungsverfahren einbringen, muss in dieser Form als widerlegt betrachtet werden. Das bedeutet, dass das dezisionistische Moment der kollektiven Partizipation an der Bildung des Gemeinwillens seine hegemoniale Stellung räumen muss und sich der Raum für andere demokratietheoretische Elemente, wie bspw. Deliberation, Kooperation und Konsens öffnet. Aber nicht zuletzt verliert die Vorstellung, Demokratie wäre lediglich ein Entscheidungsverfahren, mittels welchem die gesamte Bandbreite an individuellen Präferenzen qua Abstimmungsverfahren zu einem Gemeininteresse aggregiert werden würden, ihre Plausibilität, denn diese Vorstellung muss als logisch widerlegt betrachtet werden. Bezüglich dieses Aspekts muss also sowohl der Rousse- 
auismus als auch die prozedurale modus vivendi-Vorstellung des Typs $\mathrm{R}$ als unzulässig betrachtet werden.

Ein wesentliches ${ }^{19}$, für diesen Gegenstand relevantes Theorem, ist das sogenannte Unmöglichkeitstheorem. ${ }^{20}$ Dieses, vom amerikanischen Ökonomen Kenneth Arrow 1951 bewiesene, Theorem setzt bei der Frage an, welche minimalen Bedingungen ( $n a-$ tural conditions) denn ein solches, individuelle Präferenzen zu einer kollektiven Präferenzrelation aggregierendes, Verfahren überhaupt vernünftigerweise erfüllen müsste, um als im Ansatz demokratisch gelten zu dürfen. Arrow formuliert hierzu vier Minimalbedingungen, welche eine solche Aggregationsregel erfüllen müsste, die für eine jede beliebig gegebene Präferenzstruktur eine kollektive Präferenzordnung ${ }^{21}$ liefert.

Folgende vier Bedingungen nennt Arrow: Universalität bzw. uneingeschränkter Gegenstandsbereich $(U)$. Diese Bedingung besagt, dass alle beliebigen, logisch möglichen (also vollständigen und transitiven) individuellen Präferenzordnungen einer gegebenen Präferenzstruktur Eingang in das Aggregationsverfahren finden sollen (also die Aggregationsregel eine soziale Wohlfahrtsfunktion ist). Diese Bedingung lässt sich bspw. als Ausdruck der Souveränität der Bürger verstehen und kann vernünftigerweise als unverzichtbares Kriterium für ein demokratisches Aggregationsverfahren gelten. Die zweite Bedingung, Pareto-Inklusivität (P), fordert, dass eine Option x einer Option $\mathrm{y}$ kollektiv strikt vorzuziehen ist, wenn auch alle Individuen die Option $\mathrm{x}$ gegenüber y vorziehen. Dies soll also sicherstellen, dass sich ein Konsens über die Anordnung zweier Präferenzen auch immer in der kollektiven Präferenzordnung niederschlägt. Diese Bedingung scheint für ein demokratisches Entscheidungsverfahren intuitiv vollkommen plausibel zu sein, denn wenn sich alle über die Anordnung zweier Präferenzen einig sind, dann sollte es keine Gründe geben kollektiv zu einer anderen Anord-

19 Dies ist nur eines von zahlreichen Ergebnissen der Social-Choice-Theory, welches gegen die Vorstellung des Typus R spricht. An dieser Stelle möchte ich mich aber nur auf dieses eine konzentrieren, da es die essentielle Notwendigkeit eines konstitutiven Konsenses für die Demokratie beweist. Weitere wären etwa das Strategie-Theorem nach Gibbard und Satterthwaite, was die zentrale Rolle der Deliberation herausstellt, aber vor allem auch das liberale Paradoxon von Sen, was einen fundamentalen logischen Konflikt zwischen individueller Freiheit und kollektiver Selbstbestimmung aufzeigt und damit einerseits die Wichtigkeit der Trennung von privater und politischer Sphäre herausstellt, andererseits das stetige ringen um die Grenzen derselben klar vor Augen führt und die ökonomistische These, dass maximale individuelle Freiheit auch zu kollektiv optimalen Ergebnissen führt widerlegt. Mit den, meine Argumentation noch stützenden, Konsequenzen befasst sich: Julian Nida-Rümelin, Kollektive Selbstbestimmung, in: ders., Philosophie und Lebensform, 2009, 280-292.

20 Kenneth Arrow, Social Choice and Individual Values, 1951.

21 Mit dem Begriff „kollektive Präferenzordnung“ schränke ich den Bereich der zulässigen Aggregationsregeln insofern ein, dass ich fordere, dass das Ergebnis dieser Aggregation stets eine Relation ist, welche die Bedingungen der Transitivität, der Vollständigkeit und der Reflexivität erfüllen - also eine Ordnung ist. Durch die Einschränkung auf solche Aggregationsregeln die stets eine kollektive Präferenzordnung zum Ergebnis haben, also eine soziale Wohlfahrtsfunktion (SWF) sind, fordere ich, dass sich stets alle Präferenzen in eine sinnvolle Ordnung bringen lassen und etwa zyklische Präferenzrelationen ausgeschlossen werden. Ausführlicher bei: Julian Nida-Rümelin / Thomas Schmidt, Rationalität in der praktischen Philosophie. Eine Einführung, 2000, 40-43. 
nung zu gelangen. Die dritte von Arrow formulierte Bedingung, Unabhängigkeit von irrelevanten Alternativen (I), fordert, dass eine kollektive Präferenzordnung über zwei oder mehr Alternativen ausschließlich von den individuellen Präferenzordnungen über diese Alternativen abhängen darf, d.h. eine kollektive Präferenz über gegebene Alternativen darf von keinen weiteren nicht zur Disposition stehenden Alternativen abhängen. Die letzte, intuitiv schlüssigste Bedingung Kein Diktator (D) fordert, dass es keine Person als Mitglied eines Kollektivs geben darf, welche ausschließlich die kollektive Präferenzordnung bestimmt. Sie fordert den Ausschluss der Diktatur. Hierbei gilt es allerdings eine naheliegende Fehlinterpretation auszuschließen: Die Bedingung $\mathrm{D}$ fordert, dass es keine Person geben darf, die die kollektive Präferenzordnung alleine bestimmt, also bspw. wenn ein Diktator d die Alternative $\mathrm{x}$ derjenigen y vorzöge, so würde $\mathrm{x}$ auch gegenüber $\mathrm{y}$ kollektiv vorgezogen werden. Angenommen eine Person $\mathrm{p}$ des Kollektivs $\mathrm{k}$ würde ihre individuellen Präferenzen immer nach der kollektiven Präferenzordnung ausrichten, so wäre diese Bedingung D formaliter verletzt; diese logische Interdependenz als diktatorische Entscheidungsbefugnis zu interpretieren, wäre jedoch lebensweltlich und intuitiv völlig unschlüssig. ${ }^{22}$

Während die Bedingungen D, P und U für ein demokratisches Entscheidungsverfahren schon intuitiv plausibel erscheinen, so scheint Bedingung I zunächst prima facie eine durchaus anspruchsvolle Forderung zu sein. So könnte man einwenden, dass in demokratischen Verfahren durchaus die Situation zu beobachten ist, dass sich eine Präferenz für A gegenüber B ins Gegenteil verkehren könnte, wenn ich Präferenz C miteinbeziehe. Diese Situation ist nicht unplausibel, da sich bspw. eine Präferenz für Kandidat A als Bewerber um das Amt eines Parteivorsitzenden gegenüber Kandidat B durchaus umkehren kann, wenn Kandidat C, als gesetzter Kandidat für ein Vorsitzendenamt im Sinne einer Doppelspitze, hinzutritt, weil die Kombination B\&C für besser erachtet wird, als A\&C. Diese Situation zeigt aber nur, dass die Alternativen nicht sorgfältig genug aufgeschlüsselt worden sind, denn die korrekte Ordnung wäre demnach: $\mathrm{A} \&$ nonC, $\mathrm{B} \& \mathrm{C}, \mathrm{A} \& \mathrm{C}, \mathrm{B} \&$ nonC und die Bedingung I wäre erfüllt. ${ }^{23}$

Diese vier Bedingungen können nun also angesichts ihres unkontroversen Charakters plausibel als notwendige Minimalbedingungen angesehen werden, welche für eine demokratische Aggregationsregel in jedem Fall erfültt sein müssen. Angesichts dessen, dass diese vier Bedingungen zwar als notwendige, aber noch lange nicht als hinreichende Bedingungen für ein solches Entscheidungsverfahren gelten können, ist das Ergebnis des arrowschen Beweises umso zentraler: Diese vier, für ein demokratisches Entscheidungsverfahren als unverzichtbar anzusehenden Bedingungen, sind

22 Julian Nida-Rümelin, Zur Philosophie der Demokratie: Arrow-Theorem, Liberalität und strukturelle Normen, in: ders., Demokratie als Kooperation, 1999, $82 \mathrm{f}$.

23 Ebd., 84. 
logisch unvereinbar bzw. präziser: Es existiert keine Aggregationsregel, welche stets alle vier Bedingungen $U$, $P$, I und D simultan erfüllt. ${ }^{24}$

In Folge dieses Beweises hat es in der Literatur einige Vorschläge gegeben, wie das zentrale Ergebnis der logischen Unvereinbarkeit umgangen werden könnte, etwa indem die von Arrow skizzierten Minimalbedingungen modifiziert bzw. abgeschwächt werden. So interessant diese Vorschläge im Einzelnen auch sind, können sie die von Arrow aufgedeckten Probleme allerdings nicht lösen, ohne diese vier, für ein demokratisches Entscheidungsverfahren als so zentral anzusehenden, Bedingungen merklich abzuschwächen. ${ }^{25}$ Das für die Demokratietheorie zentrale Problem bleibt damit bestehen: Ein Übergang von individuellen Präferenzen zu einer kollektiven Präferenzordnung ist logisch nicht möglich. Das Ergebnis des arrowschen Beweises unterminiert also die an Rousseau anschließende Vorstellung, Demokratie verlange die Konstitution eines kollektiven Akteurs, welcher alle individuellen Bürgerinteressen zu einem Gemeininteresse aggregiert und diesem Gemeininteresse als einheitlichen alle Unterworfenen verpflichtenden Willen in Form von Gesetzen Ausdruck verleiht - ein solcher einheitlicher Wille ist logisch nicht möglich. Damit verliert aber nicht nur die Theorie des alle individuellen Willen internalisierenden Gemeinwillens ihre Plausibilität, sondern auch der demokratietheoretische Kern dieser Vorstellung an sich muss als widerlegt gelten: Das rousseausche Prinzip der Volkssouveränität bzw. das Legitimationsprinzip. Dieses Prinzip, welches die individuelle Autonomie, die politischen Freiheitsrechte sowie die individuelle Souveränität als an die kollektiv verfasste Gemeinschaft, als Volkssouveränität, übertragen gedacht ansieht und die individuelle Freiheit lediglich durch die umfassende Partizipation bei der Bildung dieses Gemeinwillens als hinreichend verwirklicht betrachtet, muss demgemäß als gescheitert angesehen werden. Durch die logische Zurückweisung der Möglichkeit der Aggregation aller individuellen Interessen zu einem kollektiven Interesse durch das Arrow-Theorem verlieren die allgemeinen und formellen Gesetze diesen freiheitsverbürgenden, die sowohl individuelle als auch kollektive Autonomie alleine durch eine hinreichende Partizipation ermöglichenden, Charakter. Freiheit und Demokratie lassen sich nicht lediglich auf einen Aggregations- und Dezisionsprozess reduzieren!

Das bedeutet, dass das Arrow-Theorem aber auf eine ganz fundamentale Problematik hinweist: Nämlich, dass Demokratie nicht lediglich als ein prozeduraler modus vivendi, indem jedes Individuum seine Präferenzen in ein Entscheidungsverfahren einspeist und dadurch kollektive Autonomie ohne weiteres ermöglicht wird, angesehen werden kann. Die Ergebnisse des Arrow-Theorems sind aber nicht notwendig so zu interpretieren, dass kollektive Selbstbestimmung logisch unmöglich ist, sondern dass diese nur nicht durch eine vollständige Transformation der punktuellen individuellen

24 Den formalen Beweis diskutieren: Lucian Kern / Julian Nida-Rümelin, Logik Kollektiver Entscheidungen, 1994, 35-39.

$25 \mathrm{Zu}$ den Abschwächungsstrategien: Julian Nida-Rümelin (Fn. 22), 81-86. 
Präferenzen in ein kollektives Gemeininteresse interpretiert werden kann: Die logische Möglichkeit von Demokratie beruht noch auf weiteren Voraussetzungen. Die Ergebnisse des Arrow-Theorems müssen also als Argument gegen die vortheoretische modus vivendi-Vorstellung von Demokratie des Typs $\mathrm{R}$, nach welcher der Übergang von individueller zu kollektiver Autonomie nahezu ohne Voraussetzung und durch bloße Partizipation und Dezision möglich ist, interpretiert werden. Vielmehr haben die Ergebnisse dieses Theorems gezeigt, dass Demokratie nicht ohne konstitutive Regeln der Entscheidungsfindung und Konfliktregulation denkbar ist. Die logische Vereinbarkeit von individueller Freiheit und kollektiver Selbstbestimmung ist also nicht ohne Voraussetzungen: Sie ist nur strukturell rekonstruierbar und beruht auf der Anerkennung fundamentaler, die punktuelle Freiheit einschränkender, weil die eigenen Interessen punktuell nicht in toto berücksichtigender Regeln der kollektiven Entscheidung.

Das bedeutet, jegliches demokratisches Entscheidungsverfahren schränkt potentiell immer die individuelle Freiheit ein und kann nicht jede individuelle Präferenz punktuell gleichrangig verwirklichen, sondern nur strukturell. Hieraus folgt, dass die Legitimität einer demokratischen Entscheidung nicht vor dem Hintergrund der eigenen Präferenzen, sondern vor dem Hintergrund des Verfahrens der Entscheidungsfindung beurteilt werden muss. Die logische Möglichkeit von Demokratie ist existentiell auf konstitutive, also dem politischen Prozess vorgelagerte, Regeln der Entscheidungsfindung angewiesen. Und diese müssen notwendigerweise von einem grundlegenden Konsens höherer Ordnung getragen werden und von allen Herrschaftsunterworfenen, idealiter einstimmig, akzeptiert werden.

\section{Konstitutive Regeln der Entscheidungsfindung und normativer Grundkonsens}

Zentral für die Legitimität der kollektiven Entscheidungen ist in dieser strukturellen Variante also nicht, ob die kollektive Praxis der Entscheidungsfindung alle individuellen Präferenzen zu einer kollektiven Präferenz aggregiert, sondern ob diese Entscheidung in einem legitimen, kooperationssichernden und in einem von einem normativen Konsens getragenen Verfahren zustande gekommen ist. Zentral für die Legitimität einzelner Gesetze, des Auftretens von Staatsgewalt oder einzelner Verwaltungsakte, ist nicht, ob sich diese auf einen dubiosen Gemeinwillen stützen können, sondern ob diese durch ein als kollektiv legitim erachtetes Verfahren autorisiert wurden. Kollektive Autonomie ist demgemäß wesentlich auf konstitutive, prozessuale, den allgemeinen Normen Legitimität verleihende, Regeln angewiesen, welche kollektive Entscheidungsfindung überhaupt erst möglich machen und deren Legitimität begründen. Diese konstitutiven Regeln sind also sekundärer Natur, sie sind „Regeln über Regeln“ und bestimmen welchen Normen, sozialen Regeln oder Institutionen verpflichtender 
Charakter zukommt und welchen nicht. Solche sekundären Regeln begründen also, welche primären Regeln als kollektiv legitim erachtet werden. Dieses Konzept der sekundären und primären Regeln wurde wesentlich durch das rechtstheoretische Konzept von H.L.A. Hart expliziert. ${ }^{26}$

Hart zufolge lässt sich Recht als Einheit von primären und sekundären Regeln beschreiben. Als primäre Regeln sind diesem Konzept zufolge die meisten einfach-positiven, formellen Gesetze anzusehen. Primäre Regeln halten Menschen dazu an, gewisse Handlungen zu tun oder zu unterlassen, sie legen ihnen Pflichten auf und betreffen allgemein „Handlungen als physische Bewegungen“. Sekundäre Regeln hingegen sind diesen primären Regeln sekundär gegenüber - oder wie Hart auch sagt, sie sind "parasitär“; d.h. es existieren keine zwei disjunkte Klassen an Regeln, sondern eine Regel ist in Bezug auf eine andere als sekundär anzusehen. Diese sekundären Regeln bestimmen, welche Person oder welche Instanz in welcher Art und Weise neue Regeln des ersten Typs einzuführen, zu modifizieren oder aufzuheben berechtigt ist. Diese sekundären Regeln bestimmen also die Art und Weise, das Verfahren oder die Institutionen, welche berechtigt sind, neue primäre Regeln mit verpflichtenden Charakter zu erlassen, zu modifizieren oder zu vernichten - sie definieren also das Verfahren der kollektiven Entscheidung. ${ }^{27}$ In einer entwickelten und demokratischen Gesellschaft existieren Hart zufolge eine Vielzahl solcher verschiedener sekundärer Regeln. Die meisten von ihnen lassen sich in drei verschiedene Klassen mit drei spezifischen Funktionen untergliedern: Zum einen existieren diverse Erkenntnisregeln, welche das Problem der Unbestimmtheit zu lösen helfen. Solche Erkenntnisregeln dienen dazu, zu identifizieren, welche Regeln in einer Gesellschaft verpflichtenden Charakter entfalten können und welche nicht; sie dienen also der möglichst eindeutigen Identifizierung von primären, verpflichtenden Regeln. Solche Erkenntnisregeln könnten bspw. lediglich solche Regeln als legitim klassifizieren, welche in einem besonderen Gesetzesblatt veröffentlicht wurden, oder komplexer solche Regeln, welche aufgrund ihrer Tradition von jeher bereits als legitim erachtet wurden, wie bspw. die sog. „Allgemeinen Rechtsgrundsätze der Kulturvölker" im Völkerrecht. Die zweite Klasse an sekundären Regeln löst das Problem der Statik und lässt sich als die Klasse an Änderungsregeln bezeichnen. Solche Regeln bestimmen, wer und in welcher Form neues Recht setzt bzw. wie es gesetzt oder geändert wird. In ihrer einfachsten Form könnten solche Änderungsregeln definieren, dass denjenigen Regeln verpflichtender Charakter zukommt, welche durch eine besondere gesetzgebende Körperschaft, wie ein Parlament, erlassen worden sind. Indem solche Änderungsregeln einer bestimmten Körperschaft - oder auch einer Einzelperson - die Autorität verleihen, primäre Regeln zu erlassen und zu definieren, kommt einer, von einer solchen Institution erlassenen, Regel oftmals schon lediglich

26 Herbert L. A. Hart, Der Begriff des Rechts, 2011 [1961], vor allem Kap. V. und VI.

27 Ebd., 101. 
aufgrund des als legitim erachteten Konstitutionsverfahren Geltungsgrund zu. So erhalten bspw. die vom deutschen Bundestag erlassenen Gesetze oftmals allein deswegen verpflichtenden Charakter, weil sie einem, als legitim erachteten und im Grundgesetz normierten Verfahren gemäß entstanden sind. Als dritte Klasse lassen sich Entscheidungsregeln benennen, welche eine bestimmte Institution oder Person mit Autorität versehen, den Bruch von primären Regeln zu identifizieren, zu sanktionieren und den Schaden zu kompensieren. Diese, das Problem der Unwirksamkeit zu lösen versuchenden, Regeln können klassischerweise als die Judikative und Exekutive ermächtigende Regeln verstanden werden ${ }^{28}$ Diese Verbindung von primären und sekundären Regeln, welche Hart als das „Herz“ eines jeden Rechtssystem bezeichnet, können auch als ein System der kollektiven Entscheidungsfindung interpretiert werden.

Solche sekundären Regeln sind für die kollektive Selbstbestimmung konstitutiv, denn sie bestimmen, in welcher Art und Weise bzw. nach welchem Verfahren der kollektiven Entscheidung sich individuelle Präferenzen der einzelnen Personen verwirklichen lassen. Diese sekundären Regeln sind also für die Funktionsfähigkeit kollektiver Selbstbestimmung zentral. Dieser Zusammenhang lässt sich an einem für die Demokratie fundamentalen Beispiel gut plausibilisieren, nämlich am Beispiel der Mehrheitswahlregel ${ }^{29}$.

Angenommen, die Delegierten einer politischen Partei sind aufgefordert, einen neuen Parteivorsitzenden für ihre gemeinsame Partei zu wählen und haben hierbei die Wahl zwischen Kandidat A und Kandidat B. Im Zuge eines umfassenden Deliberations- und Diskussionsprozesses haben alle Delegierten die Möglichkeit, sich von den je individuellen Qualitäten der beiden Bewerber zu überzeugen. Wir nehmen also an, dass ein jeder Delegierte durch dieses Bewerbungsverfahren eine eindeutige und feste individuelle Präferenz entweder für Kandidat A oder B entwickelt hat. Im Zuge des stattfindenden Parteitages sind somit auch weitere Aussprachen und Bewerbungsreden rein formaler Natur, denn jeder Delegierte hat bereits im Verlauf des vorgelagerten Bewerbungsprozesses eine eindeutige Präferenz entwickelt. Als Verfahren der kollektiven Entscheidung wird, den Parteistatuten gemäß, nun die Mehrheitswahlregel angewendet und als Ergebnis des Abstimmungsverfahrens erhält nun Kandidat A $48 \%$ und Kandidat B $52 \%$. Diesem Ergebnis zufolge ist Kandidat B demnach als neuer Vorsitzender der gesamten Partei, also auch des unterlegenen Teils, gewählt. Dies bedeutet, dass lediglich $52 \%$ der Delegierten ihre individuelle Präferenz verwirklichen konnten und $48 \%$ dem gegenüber nicht. Trotzdem ist es in der Regel höchst realis-

28 Ebd., 112-121.

29 Darüber hinaus ist die Mehrheitswahlregel für die Demokratietheorie an sich noch besonders interessant. Zum einen weil Demokratie in einem vortheoretischen Sinne oftmals mit ihr gleichgesetzt wird, aber auch, weil sie als einzige Entscheidungsregel die Bedingungen der Anonymität und der Neutralität erfüllt. $\mathrm{Zu}$ der Bedeutung der Mehrheitsregel und der beiden Bedingungen: Lucian Kern/Julian Nida-Rümelin (Fn. 24), 91-93. 
tisch, dass sich auch die unterlegenen $48 \%$ loyal zum neuen Parteivorsitzenden verhalten, sofern die Wahl in einem fairen Verfahren zustande gekommen ist. Das bedeutet, das eigentliche demokratische Prinzip und das wird an diesem Beispiel klar, ist nicht der konkrete Akt der Wahl, sondern die kollektive Anerkennung der sekundären Regel „Mehrheitswahl“. Der verpflichtende Charakter dieser kollektiven Entscheidung geht also nicht von der eigentlichen Dezision - also dem Wahlakt - aus, sondern vom Konsens über das Verfahren der kollektiven Entscheidung. Eine demokratische Ordnung ist also wesentlich auf einen solchen Konsens höherer Ordnung angewiesen; kollektive Autonomie kann also nur solange wirklich werden, wie ein Konsens über diese sekundären Regeln besteht. Eine demokratische Ordnung wird demzufolge nicht essentiell durch die kollektive Entscheidung an sich charakterisiert, sondern wird wesentlich durch einen solchen Konsens höherer Ordnung über das Verfahren der kollektiven Entscheidung getragen. ${ }^{30}$

So lässt sich an dieser Stelle festhalten: Jede kollektive Entscheidung - und damit auch jedes Gesetz und jeder staatliche Gewaltakt - schränkt potentiell die punktuelle Verwirklichung der individuellen Präferenzen erster Ordnung ein, denn die Aggregation aller individuellen Präferenzen zu einem Gemeininteresse ist schlicht logisch nicht möglich. Das zentrale Versprechen des Typs R muss also als unplausibel verworfen werden. Dieses Ergebnis widerlegt die Vorstellung, Demokratie verlange die Konstitution eines kollektiven Akteurs, im Zuge dessen alle individuellen Freiheitsrechte an ein Kollektiv als übertragen gedacht werden und somit die individuelle Autonomie und Freiheit lediglich über die vollständige Partizipation bei der Bildung dieses Gemeinwillens verwirklicht werden. Darüber hinaus müssen diese punktuellen Freiheitseinschränkungen im Zuge kollektiver Entscheidungen aber nicht per se als heteronome Akte im strengen Sinne verstanden werden, denn diese können als strukturell rational sowie autonomiesichernd und -verwirklichend rekonstruiert werden. Damit kollektive Autonomie aber strukturell möglich wird, bedarf es konstitutiver Regeln der Entscheidungsfindung und Konfliktregulation, welche als sekundäre Regeln, als Regeln über Regeln, von allen anerkannt werden müssen. Diese sekundären Regeln wiederum müssen von einem fundamentalen Konsens höherer Ordnung getragen werden; einem Konsens darüber, was dem öffentlichen Raum, der kollektiven Entscheidung sowie was der autonomiesichernden individuellen Freiheitssphäre zugeschrieben werden soll; einem Konsens darüber, aufgrund welcher sekundärer Regeln, nach welchen Verfahren und mit welchen Institutionen kollektive Autonomie verwirklicht werden soll. Dieser Konsens höherer Ordnung kann als normatives Fundament eines kooperativen Systems kollektiver Entscheidung verstanden werden. Demokratie ohne diesen grundlegenden, normativen Konsens ist schlicht nicht möglich. Das bedeutet und

30 Die strukturelle Rekonstruktion von kollektiver Autonomie und die Idee eines Konsenses höherer Ordnung geht wesentlich zurück auf: Julian Nida-Rümelin (Fn. 22), 92-100. 
soviel scheint mir bis hierher völlig klar geworden zu sein: Demokratie im Sinne des Typs R, lediglich verstanden als ein Entscheidungsverfahren, in welchem individuelle Präferenzen in einen kollektiven Willen übertragen, werden ist logisch schlicht nicht möglich. Vielmehr ist jedes demokratische System auf konstitutive Regeln der Entscheidungsfindung, der Konfliktregulation und der Meinungsbildung, also sekundäre Regeln, angewiesen. Und diese sekundären Regeln sind nicht erst durch das politische Verfahren zu setzen, sondern ermöglichen dasselbe erst, d.h. sie sind vorpolitischer Natur. Demnach können diese sekundären Regeln ihre Geltung nur aufrechterhalten, sofern sie von einem grundlegenden normativen Konsens getragen werden.

\section{Normativität, Praxis und Identität}

Demokratie - das scheint mir aus dem bisherigen einsehbar geworden zu sein - beruht auf einem konstitutiven, normativen Konsens, welcher die Verfahren, Regeln und Institutionen zur kollektiven Entscheidungsfindung legitimiert und ohne welchen kollektive, d.h. politische Entscheidungen nicht möglich sind. Das bedeutet, Demokratie und der Idealtypus Radikale Freiheit, welcher außer der wechselseitigen Anerkennung als vernünftige, freie und gleiche Personen keine weiteren verpflichtenden konsensualen Elemente zulassen möchte, sind nicht vereinbar. Betrachtet man die bisherigen Ergebnisse aus einer lebensweltlichen Perspektive, so wird einem dieses konsensuale Element der Demokratie intuitiv vollkommen klar: Selbstverständlich muss ein Konsens über Entscheidungsregeln, wie z. B. der Mehrheitsregel bestehen; selbstverständlich muss ein legitimierender Konsens darüber bestehen, wer in einem Gemeinwesen Recht spricht und wer Gesetzesübertritte ahndet und selbstverständlich muss ein Konsens darüber bestehen, welche Körperschaften oder Personen mit der Ausfertigung und Bildung der Gesetze betraut sind; selbstverständlich scheint klar, dass eine Demokratie hier keinen - zumindest nicht auf Dauer - substantiellen Dissens verträgt. Sofern man diese konsensualen Elemente akzeptiert, könnten kritische Stimmen an dieser Stelle nun zur Rettung einer abgeschwächten Vorstellung des Typs R folgende zwei Einwände vorbringen: Erstens, so könnte man anführen, bezieht sich dieser Grundkonsens lediglich auf fundamentale Praktiken der kollektiven Selbstbestimmung und rechtfertige keinen einschränkenden Konsens über diverse Praktiken und persönliche Präferenzen; man müsse lediglich die etablierten Institutionen anerkennen und akzeptieren, dass seine persönlichen Präferenzen, aufgrund des Mehrheitsverfahrens, nicht immer verwirklicht werden können. An dieser Stelle muss allerdings auf das weite Feld demokratischer Kooperation hingewiesen werden, welches die persönliche Selbstbestimmung in Bezug auf konträre Praktiken und Präferenzen potentiell einschränkt, denn Demokratie ist nicht - und das sei hier nochmals wiederholt - lediglich ein Abstimmungs- oder Entscheidungsverfahren, sondern wesentlich Deliberation und Kooperation. Demnach bezieht sich dieser normative 
Grundkonsens auch auf ein ebenso weites Feld an kulturellen, kooperationsstützenden Praktiken, Institutionen und Verfahren: Die Art und Weise der kollektiven Entscheidung - beginnend von der Entscheidungsregel bis zur konkreten Praxis; die Anerkennung kooperationssichernder und handlungsermöglichender Institutionen und Organe, wie Parlamente oder Regierungen, öffentlich bestellte Richter, die autorisiert wurden Recht zu sprechen oder staatlich beauftragte Beamte die Gesetzesübertritte sanktionieren. Darüber hinaus die Frage des Privaten und des Politischen, also was überhaupt in welchem Umfang öffentlich entschieden werden und was dem Bereich des Privaten angehören sollte. Und schließlich vor allem auch kulturell etablierte Praktiken der Kommunikation und Deliberation, wie Regeln der Höflichkeit, des Anstandes oder alltägliche Regeln der Sprache. Denn Sprache darf nicht lediglich auf ein strategisches Instrument zur Äußerung von Präferenzen reduziert werden, sondern sie ist selbst schon wesentlich kooperativ verfasst. Sprache ist eine kulturell etablierte, kollektiv akzeptierte, kooperative Institution, sie beruht auf umfassenden normativen Regeln - wie denen der Wahrhaftigkeit, Vertrauen und Verlässlichkeit - und erfordert ein hohes $\mathrm{Ma} ß$ an Konformität mit diesen konstitutiven Regeln der sprachlichen Gemeinschaft. ${ }^{31} \mathrm{Um}$ an dieser Stelle Missverständnisse zu vermeiden: Offenkundig ist das $\mathrm{Ma} ß$ an Konformität mit all diesen Regeln und Verfahren nicht absolut zu setzen, sondern graduell und nicht jede Nonkonformität gefährdet die Demokratie substantiell. Vielmehr halten all diese Regeln ein gewisses $\mathrm{Ma}$ an Abweichungen sehr gut aus und es führt nicht zum Zusammenbruch des demokratischen Kooperationssystems. Vielmehr ist die Nonkonformitäts-Toleranz graduell und gegenstandsspezifisch zu betrachten. Jedoch verträgt ein demokratisches System kein exklusives und dauerhaftes, die eigenen individuellen Präferenzen, optimierendes Verhalten, denn all diese Elemente sind für eine kooperative, demokratische Gesellschaft essentiell und müssen Bestandteil eines umfassenden Konsenses sein.

Der zweite mögliche Einwand bezieht sich auf den Charakter dieser Regeln. So mag man einwenden, dass diese Regeln und Institutionen ja lediglich Konventionen und daher grundsätzlich kontingent und veränderbar seien. Dies ist zweifelsohne richtig, dennoch sollte zunächst noch einmal die essentiell wichtige Rolle von Konventionen betont werden, welchen, wie die wegweisenden Arbeiten David Lewis ${ }^{{ }^{32}}$ gezeigt haben, eine zentrale Rolle bei der Koordination von kollektiven bzw. sozialen Handlungen und der Kooperation im Allgemeinen zukommen. Des Weiteren sind für diesen Einwand noch zwei zentrale Charakteristika dieses Konsenses relevant: Zum einen der dynamische Charakter. Generell gilt, dass jede legitimierende Entscheidungsregel, jede Institution oder jede Praktik zum Bestandteil dieses Konsenses werden kann. Die Elemente dieses Konsenses sind weder statisch, noch orientieren sie sich an einen be-

31 Julian Nida-Rümelin, Structural Rationality and other Essays on Practical Reason, 2019, Kap 6, 33-40.

32 David Lewis, Convention. A Philosophical Study, 1969. 
stimmten Zeitpunkt der Geschichte einer sozialen Gruppe (die vermeintlich früheren, besseren Zeiten) und können jederzeit zur Disposition stehen. Dies jedoch mündet direkt in das zweite Charakteristikum, denn genauso wie dieser Konsens dynamisch ist, so ist er auch explizit normativ und nicht relativistisch: Nicht jeder kulturellen Praktik, Konvention, Regel der Kommunikation oder Institution wird der gleiche Wert zugeschrieben, d.h. in letzter Konsequenz, dass diejenigen Praktiken o. ä., die in Konflikt mit dem normativen Fundament der liberalen Demokratie geraten, aus dem Bereich des Konsenses und damit aus dem der Demokratie generell, suspendiert werden sollten. ${ }^{33}$ Damit die Vorstellung eines Konsenses nicht zur Leerformel wird, die letztlich auch eine Diktatur legitimeren könnte, ist eine Demokratie existentiell auf einen wehrhaften und klar wertenden Konsens angewiesen: Kulturelle Praktiken, die mit dem normativen Fundament der liberalen Demokratie nicht vereinbar sind, dürfen in einer Demokratie nur eine Randerscheinung bleiben, sofern sie ihren eigenen Fortbestand nicht gefährden will. Nicht jede Praktik - und sei sie noch so sehr mit der individuellen Selbstbestimmung gerechtfertigt - ist mit dem normativen Fundament der Demokratie vereinbar und sollte dementsprechend auch keine allgemein akzeptierte Geltung erreichen. ${ }^{34}$ Ein solcher die Demokratie tragender Konsens hat also normativen Charakter, ist klar wertend, per definitionem diskriminierend und tendenziell emanzipatorisch - er ist existentiell darauf angewiesen antidemokratische Elemente $\mathrm{zu}$ suspendieren oder zu schwächen und liberale, demokratische zu privilegieren ${ }^{35}$ oder um es mit Fukuyama zu sagen: „Die liberale Demokratie hat ihre eigene Kultur, und diese muss höher eingestuft werden als Kulturen, die demokratische Werte ablehnen." ${ }^{36}$

33 Als eine solche kulturelle Praktik könnte bspw. die in Europa lange bis ins 20. Jahrhundert tradierte Verweigerung der Gleichberechtigung der Frau betrachtet werden.

34 Obwohl hier nur der wertende Charakter des Konsenses Gegenstand ist, also was praktisch legitim Bestandteil eines solchen Konsenses sein kann und was nicht, soll trotzdem auf eine naheliegende heikle Frage hingewiesen werden: Im Zuge der Identifikation und Diskreditierung von solchen antidemokratischen Praktiken ist eine sehr saubere Analyse notwendig und praktische Sanktionen nur sehr bewusst und sensibel zu vollziehen, da dies leicht in eine antiliberale Praxis umschlagen kann. Bspw. kann eine offensichtliche Diskriminierung der sexuellen Selbstbestimmung bzw. der freien Partnerwahl, z. B. bei der Praktik der Zwangsverheiratung, sehr klar mit dem Argument des liberalen Grundkonsenses diskreditiert werden. Bei anderen Praktiken ist der Verstoß nicht ganz so offenkundig und bedarf einer wesentlich genaueren Analyse, wie bspw. die Debatte um das „Burka-Verbot“ und das vorgebrachte Argument der individuellen Selbstbestimmung gezeigt haben. Sicherlich gäbe es für beide Positionen gute Gründe, dennoch ist eine umfassende Analyse und Debatte notwendig, um erstens den Fehler zu vermeiden, mittels autoritärer Maßnahmen die individuelle Freiheit und Gleichheit zu gefährden und zweitens Gefahr zu laufen, mit scheinbar liberalen Argumenten eine antiliberale und die Demokratie gefährdende Praxis zu stützen.

35 Diese Forderung rechtfertigt noch lange keinen liberalen Imperialismus, denn die Prinzipien der Demokratie sind zwar universell, aber noch lange nicht frei von kulturellen Voraussetzungen, sodass eine liberale Demokratie nicht so ohne weiteres exportiert werden kann und sollte.

36 Fukuyama (Fn. 4), 195. 
Angesichts der Eingangs skizzierten Herausforderungen der gegenwärtigen Demokratien stellt sich die Frage, wie denn dieser liberal-demokratische Grundkonsens, angesichts der kulturellen Verlustängste und dem gestiegenen Bedürfnis nach Identität erhalten werden und weitere Hinwendungen zu antidemokratischen Identitätskonzepten wie Nationalismus oder Islamismus unterbunden werden können. Dies mündet in die viel grundlegendere Frage, woraus sich denn die Normativität eines solchen liberalen Grundkonsenses, also der Kern der Demokratie, speist. Welche Elemente tragen dazu bei seine Geltung aufrecht zu erhalten? Wie lassen sich diese Wurzeln der Normativität fruchtbar erneuern, um die Fortexistenz der liberalen Demokratie vor dem Hintergrund ihrer eigenen inneren Bedrohungen hoffnungsvoll zu stärken, ohne den liberalen Kern der Demokratie über Bord zu werfen? Das, worauf sich die Normativität dieses Grundkonsenses gründet, meine ich vorläufig - d. h. unter dem Vorbehalt weiterer Reflexion und Korrektur - mit den folgenden drei Quellen identifizieren zu können:

Die erste Quelle der Normativität des liberal-demokratischen Konsenses ist eine rationalistische. Die normative Kraft des liberalen Konsenses speist sich aus der fundamentalen Einsicht in universelle rationale Prinzipien, wie die universelle Würde des Menschen, die Menschenrechte im Allgemeinen, die gleiche Freiheit aller Menschen, dem Toleranzgebot, der Religions- und Gewissensfreiheit etc. Diese universellen rationalen Prinzipien, welche sich im Partikularen, also der konkreten politischen Kultur verwirklichen und stets vor dem Hintergrund einer konkreten historisch-sozialen Situation erneuert werden müssen, verschaffen dem liberalen Konsens Geltung und müssen stets, d. h. intellektuell, durch Bildung und öffentlichem Diskurs erneuert werden - sie erhalten ihre Geltungskraft nicht lediglich dadurch, dass sie in Verträgen, Dokumenten und Gesetzen positiv normiert worden sind, d. h. sie müssen stets wiederangeeignet werden. An dieser Stelle wird klar, dass die Kritik an Jürgen Habermas, sein Konzept des Verfassungspatriotismus wäre bloß ein rationalistischer Gedanke nicht berechtigt ist, da sich eben diese universellen Prinzipien auch immer im Partikularen verwirklichen, nur die Loyalität sich eben nicht auf die partikulare Kultur, sondern die dahinterstehenden universalistischen Prinzipien bezieht. ${ }^{37}$

Die zweite Quelle der Normativität ist eine pragmatistische. Demokratie ist nicht nur lediglich eine Regierungs- oder wie hier dargelegt worden ist, eine kollektive Entscheidungsform. Demokratie ist in erster Linie eine Form des Zusammenlebens, der Kooperation und der gemeinsam geteilten Erfahrung und Handlungspraxis. ${ }^{38}$ Ein Gesellschaftsentwurf kann nur dauerhaft Normativität beanspruchen, sofern er auch ganz praktisch und lebensweltlich ein mehr an Freiheit, Sicherheit, sozialer Partizipation und anderen Gütern ermöglicht und nicht nur von einem rationalistischen Versprechen zehrt, d.h. die Demokratie ist auch ausdrücklich auf eine erfolgreiche poli-

37 Jan-Werner Müller, Verfassungspatriotismus, 2010, 43.

38 John Dewey, Demokratie und Erziehung. Eine Einleitung in die philosophische Pädagogik, hg. von Jürgen Oelkers, 2011 [1915], 120-122. 
tische Praxis angewiesen, sofern sie weiterhin Geltung beanspruchen möchte. Der bloße Verweis auf die rationalen, universalistischen Prinzipien wird die Normativität des liberalen Konsenses auf Dauer nicht aufrechterhalten können, sofern diese nicht mit einer erfolgreichen Praxis einhergehen.

Die dritte und letzte Quelle der Normativität liegt in einer zu den ersten beiden Quellen korrespondierenden kollektiven Identität, denn die normative Kraft der liberalen, freiheitlichen Demokratie fußt auch wesentlich auf einer geteilten kollektiven Identität der westlich-europäischen Zivilisation. Diese kollektive Identität ist stark von einem kollektiven historischen Bewusstsein des, im Laufe des 11.-18. Jahrhundert in Europa vollzogenen, Säkularisationsprozesseses geprägt. ${ }^{39}$ Das bedeutet, dass trotz der Universalisierbarkeit der rationalen Prinzipien der liberalen Demokratie, sich die normative Überzeugungskraft derselben nicht ohne dieses kollektiv geteilte historische Bewusstsein verstehen lässt; vielmehr aktualisiert sich die Normativität der liberalen Demokratie immer wieder vor dem Hintergrund dieser epistemischen Vorbedingung - oder um mit Hans-Georg Gadamer zu sprechen, vor dem Hintergrund dieses „Vorurteils“.40 Die liberale Demokratie ist auch wesentlich eine kulturelle Errungenschaft der westlich-europäischen Zivilisation, die ihre normative Kraft aus der Negation der Säkularisationserfahrung und der Affirmation der kulturellen Errungenschaft einer rationalen politischen Praxis speist.

Vor dem Hintergrund des Eingangs skizzierten gestiegenen Bedürfnisses nach kollektiven Identitäten und der damit verbundenen immanenten Bedrohung, ist es also eine existentielle Aufgabe der liberalen Demokratien, diese drei Quellen der Normativität zu erhalten und zu erneuern und damit den für die Demokratie konstitutiven liberal-demokratischen Grundkonsens zu sichern sowie, sofern sie gegen die konkurrierenden Identitätsangebote wie Islamismus und Nationalismus bestehen will, selbstbewusste, mit den universellen Prinzipien der liberalen Demokratie vereinbare kollektive Identitäten auszubilden. Zentrale Herausforderung für die liberale Demokratie ist es demnach also, durch engagierte Kultur- und Bildungspolitik, durch ein selbstbewusstes Eintreten für die eigenen Werte und Praktiken, liberale, aufgeklärte, humanistische, gradualistisch-plurale und inklusive kollektive Identitäten positiv zu entfalten, sie mit gemeinschaftlichen, performativen Praktiken zu stützen und so die Kohäsionskraft von konkurrierenden Identitätsangeboten zu mindern, anstatt sich auf eine modus viven$d i$-Vorstellung zurückzuziehen und sich ihrem vermeintlichen Schicksal zu ergeben.

39 Diese These lässt sich lebensweltlich leicht erhärten. Würde man eine offene Umfrage in Deutschland durchführen und fragen „Warum Demokratie?“, darf mit guten Gründen angenommen werden, dass die Antwort sehr oft auf die negativen historischen Erfahrungen der Religionskriege, des Dreißigjährigen Krieges oder auch den Erfahrungen während des Nationalsozialismus oder Sozialismus abzielen wird. Diese kollektiven historischen Erfahrungen haben die europäische Identität fundamental geprägt und dürfen in Bezug auf die Normativität der Demokratie nicht unterschätzt werden.

40 Hans-Georg Gadamer, Wahrheit und Methode. Grundzüge einer philosophischen Hermeneutik, 2010 [1960], 271-290. 



\title{
Zeit und Raum als basale Problemfelder der Krise der Demokratie
}

\author{
BENJAMIN SCHMID
}

Time and Space as Basal Problem Areas of the Crisis of Democracy

\begin{abstract}
The current phenomena of the crisis of democracy are the result of a distorted perception of time and space. The foundations for democratic forms of political order have been disintegrating as a result of acceleration processes since the Industrial and the French Revolution. In reaction to this dissolution, it is necessary to counteract acceleration with a restrainer that offers the possibility of regaining time and space for democracy. This text presents time and space as basis for the political sphere, designates the effects of the disturbed perception of time and space, and discusses ways of countering this disturbance.
\end{abstract}

Keywords: crisis, democracy, time and politics, space and politics, acceleration, basic income

\section{Einleitung}

Es liegt in ihrem Wesen, dass die Demokratie immer mehr Krise als Nicht-Krise ist; immer ist sie gefährdet und angefochten. ${ }^{1}$ Zumindest insofern man sie als mehr versteht als nur eine politische Ordnungsform, die Legitimation über Wahlen erzeugt. Denn zum Wesen der Demokratie gehören auch bürgerliche Freiheitsrechte und effektive Regierungsgewalt, ein System der Gewaltentrennung und -kontrolle sowie politische Partizipationsrechte im öffentlichen Raum, Elemente also, die sich nicht immer in einem Gleichgewicht befinden. ${ }^{2}$

1 Hans Vorländer, Demokratie. Geschichte, Formen, Theorien, München 2. Aufl. 2010, 12 und 119.

2 Wolfgang Merkel, Herausforderungen der Demokratie, in: Demokratie und Krise. Zum schwierigen Verhältnis von Theorie und Empirie, hg. von Wolfgang Merkel, Wiesbaden 2015, 7-42 (14-21). 
Für die Bundesrepublik Deutschland beispielsweise wurden wieder und wieder Krisen festgestellt. Wiederholt wurde etwa gefragt, ob Bonn, ob auch Berlin ein neues Weimar werde. Weswegen der Bundesrepublik ein reflexartig beschworenes „Weimar-Syndrom “3 wie auch ein „Weimar-Komplex“4 diagnostiziert wurde. Der bereits in den 5oer Jahren gegebene Befund Fritz René Allemanns „Bonn ist nicht Weimar“ war offenbar nicht überzeugend. ${ }^{5}$ In den 6oer Jahren wurde eine Krise der Demokratie im Zuge der Notstandsgesetzgebung festgestellt; ${ }^{6}$ in den 7oer, 8oer und 9oer Jahren war die Rede von einer Krise des Parteiensystems, das Parteien- sogar Politikverdrossenheit nach sich ziehe. ${ }^{7}$ Krisen schließlich auch in der jüngeren Vergangenheit. Vom Abdriften in einen postdemokratischen Zustand ist hier etwa die Rede, in dem politische Entscheidungsprozesse von ökonomischen Interessen okkupiert werden; ${ }^{8}$ oder vom Zerfall der Demokratie und der Bedrohung des Rechtsstaats durch den Populismus; ${ }^{9}$ weniger drastisch und doch krisenhaft wird von westlicher Demokratie gene-

3 Volker Ullrich, Das Weimar-Syndrom. Zur Geschichte und Aktualität der Parteienverdrossenheit in Deutschland, in: Extremismus und Mitte. Vom rechten Verständnis deutscher Nation, hg. von Hans-Martin Lohmann, Frankfurt a. M. 1994, 51-69 (67-68).

4 Sebastian Ullrich, Der Weimar-Komplex. Das Scheitern der ersten deutschen Demokratie und die politische Kultur der frühen Bundesrepublik 1945-1959, Göttingen 2009, 15.

5 Fritz René Allemann, Bonn ist nicht Weimar, Köln, Berlin 1956, 411.

6 Äußerte sich die Kritik an den Notstandgesetzen zuerst noch in Form einer befürchteten Aushöhlung des Grundgesetzes, wurde das Vokabular später schärfer und es wurde etwa auch vor einem „neuen Faschismus" und „Präfaschismus" gewarnt. Maren Krohn, Die gesellschaftlichen Auseinandersetzungen um die Notstandsgesetze, Köln 1981, 58-60 und 288. Weiter beispielsweise auch Michael Schneider, Demokratie in Gefahr. Der Konflikt um die Notstandgesetze: Sozialdemokratie, Gewerkschaften und intellektueller Protest (1958-1968), Bonn 1986, 113 .

7 Rolf Ebbighausen, Legitimationskrise der Parteiendemokratie und Forschungssituation der Parteiensoziologie, in: Parteiensystem in der Legitimationskrise. Studien und Materialien zur Soziologie der Parteien in der Bundesrepublik Deutschland, hg. von Jürgen Dittberner / Rolf Ebbighausen, Opladen 1973, 13-32 (30). Christian Graf von Krockow / Peter Lösche, Vorwort, in: Parteien in der Krise. Das Parteiensystem der Bundesrepublik und der Aufstand des Bürgerwillens, hg. von Christian Graf von Krockow / Peter Lösche, München 1986, 7-9 (7-8). Die in den 9oer Jahren attestierte Politikverdrossenheit sei zwar nicht neu, aber auch mehr als eine bloße Mode. So konstatiert Jürgen Rüttgers, Dinosaurier der Demokratie. Wege aus der Parteienkrise und Politikverdrossenheit, Hamburg 1993, 12. Ähnlich spricht auch Günter Rieger von einer allgemeinen Parteienverdrossenheit, die aber die Demokratie noch nicht infrage stelle. Günter Rieger, „Parteienverdrossenheit“ und "Parteienkritik“ in der Bundesrepublik Deutschland, Zeitschrift für Parlamentsfragen 3 (1994), 459-471 (459 und 470). Skeptisch zum Befund der Parteien- und Politikverdrossenheit in den 9oer Jahren Christof Erhart / Eberhard Sandschneider, Politikverdrossenheit: Kritische Anmerkungen zur Empirie, Wahrnehmung und Interpretation abnehmender politischer Partizipation, Zeitschrift für Parlamentsfragen 3 (1994), 441-458. Angemerkt wird etwa, dass im Begriff der Politikverdrossenheit komplexe Zusammenhänge vereinfacht würden und damit eine verzerrte Wahrnehmung politischer Realität hergestellt werde. Ebd. 451.

8 Colin Crouch, Postdemokratie, Frankfurt a. M. 2008, 10-11.

9 Yascha Mounk, Der Zerfall der Demokratie. Wie der Populismus den Rechtsstaat bedroht, München 2018, 7-9. Der Autor befürchtet etwa, dass sich zwei Befunde stellen lassen: (a) vielerorts habe sich ein System des Rechts ohne Demokratie etabliert, (b) dem nun ein System der Demokratie ohne Recht entgegengestellt werden. $\mathrm{Ob}$ es den Verteidigern der liberalen Demokratie gelinge diese politische Ordnung zu erhalten, bliebe daher vorerst fraglich. Ebd. 292-293. 
rell schließlich derart gesprochen, dass sie ihren historischen Höhepunkt inzwischen überschritten habe und sich nun allmählich auf dem absteigenden Ast befinde, gewissermaßen in ihrer mid-life crisis angekommen sei. ${ }^{10}$

Allenthalben und zu allen Zeiten also Krisen. Dabei könnte man es belassen und gegenwärtige Geschehnisse als übliche Abweichung von einem Ideal abtun. Fraglich ist dann allerdings, ob eine auf Dauer gestellte Situation der Krise überhaupt noch Krise sein kann? „Krisen können kein Dauerzustand sein“, befindet Wolfgang Merkel." Differenzierter dahingegen die Betrachtung bei Reinhart Koselleck, der in der Begriffsgeschichte drei semantische Modelle von Krise unterscheidet. Krise könne „einen einmaligen sich beschleunigenden Vorgang bezeichnen“; sie könne als letztentscheidender Zukunftsbegriff die schlechthin finale Krise der Geschichte meinen, die sich im Jüngsten Gericht offenbare; schließlich kann sie auch einen Prozessbegriff bezeichnen: Geschichte als Dauerkrise, die Weltgeschichte als das Weltgericht. ${ }^{12}$ Auf das letztgenannte semantische Modell von Krise wird sich das Folgende stützen.

Gegenwärtig erleben wir Symptome einer fundamentalen Krise, resultierend aus einer aus den Fugen geratenen Wahrnehmung von Zeit und Raum. ${ }^{13}$ In drei Schritten gilt es sich mit diesem Befund zu befassen: Zuerst wird auf die basale Bedeutung von Zeit und Raum für das Politische eingegangen. Sodann sollen Auswirkungen der durch Beschleunigung bewirkten Störung von Zeit und Raum erörtert werden. Schließlich ist eine Antwort auf die Frage nach der Bewertung dieser Störung für die Demokratie zu finden. In der Einführung eines Aufhalters, der eine grundlegende Umgestaltung der Arbeitswelt und der durch sie erzeugten Ereignisdichte bewirkt, wird das Potential gesehen der Krise der Demokratie zu begegnen.

10 David Runciman, How Democracies End, London 2018, 216-218.

11 Wolfgang Merkel, Schluss: Ist die Krise der Demokratie eine Erfindung?, in: Demokratie und Krise. Zum schwierigen Verhältnis von Theorie und Empirie, hg. von Wolfgang Merkel, Wiesbaden 2015, 473-498 (473).

12 Reinhart Koselleck, Begriffsgeschichten. Studien zur Semantik und Pragmatik der politischen und sozialen Sprache. Mit zwei Beiträgen von Ulrike Spree und Willibald Steinmetz sowie einem Nachwort zu Einleitungsfragmenten Reinhart Kosellecks von Carsten Dutt, Frankfurt a. M. 2006, 207-208.

13 Die räumlichen und zeitlichen Erfordernisse der Demokratie skizziert etwa Herfried Münkler, Verkleinern und Entschleunigen oder die Partizipationsformen neu arrangieren? Beratungszeit und Handlungsmacht: antike und moderne Demokratie, in: Die Zukunft der Demokratie. Kritik und Plädoyer, hg. von Friedrich Wilhelm Graf/Heinrich Meier, München 2018, 83-119 (86-88). Vgl. auch die Veränderungen zum Moment der Demokratie bei Crouch (Fn. 8), 35-36. Zur Frage nach der räumlichen Größe der Demokratie etwa auch Dirk Jörke, dessen zentrale These von einem Verlust demokratischer Herrschaftsausübung in supranationalen Räumen ausgeht. Dirk Jörke, Die Größe der Demokratie. Über die räumliche Dimension von Herrschaft und Partizipation, Berlin 2019, 10-13. 


\section{Zur Bedeutung von Zeit und Raum für das Politische}

Als klassisches Motiv politischer Gründungserzählungen ist seit der Antike die Raumnahme Bestandteil der Bildung politischer Ordnungsformen. Mit der Raumnahme eng verwoben ist die Trennung eines Wir von einem Sie. Entsprechende Befunde für die Bedeutung beider Elemente bei der Gründung einer Gemeinschaft finden sich bei den antiken Griechen, etwa bei Homer, Heraklit und Herodot, ${ }^{14}$ finden sich weiter im Gründungsmythos Roms, ${ }^{15}$ in der biblischen Erzählung von Kain und Abel, im politischen Denken des Mittelalters und der Neuzeit. ${ }^{16}$

$\mathrm{Zu}$ der nach außen gerichteten Exklusion gehört die nach innen gerichtete Inklusion durch die Erzeugung eines für die Politik vorgesehenen öffentlichen Raums. Dem eingenommenen Raum wird durch Architektur eine Form gegeben. Sei es durch Mauern, Plätze oder Repräsentationsbauten. In dieser Form materialisiert sich Macht und wird politische Herrschaft repräsentiert. Architektur wird damit zu einem Versuch, sich der Herrschaft der Zeit zu entziehen und politische Herrschaft auf Dauer zu stellen. ${ }^{17}$ Rückwirkend formt der architektonisch gestaltete Raum wiederum auch die in ihm verortete Gesellschaft. ${ }^{18}$ Auf Partizipation beruhende politische Ordnungsformen

14 Bei Homer, Herodot und Heraklit sind die Mauern Identifikationsmerkmal der Polis und werden teils auch als das Gewährsmittel autonomer Existenz der Polis ausgewiesen: Homer, Odyssee. Griechisch und deutsch. Übertragen von Anton Weiher. Mit Urtext, Anhang und Registern. Einführung von A. Heubeck, München 6. Aufl. 1980, VI,7-10, 157. Herodot, Historien. Erster Band: I-V. Griechisch-deutsch. Herausgegeben von Josef Feix, München 1963, IV,46, 537. Herodot, Historien. Zweiter Band: Bücher VI-IX. Griechisch-deutsch. Herausgegeben von Josef Feix, München 1963, VII,140-144, 969-975. Hermann Diels / Walther Kranz (Hg.), Die Fragmente der Vorsokratiker. Bd. 1, Dublin, Zürich 14. Aufl. 1969, 22 B 44, 160. Heraklit, Fragmente. Griechisch und deutsch. Herausgegeben von Bruno Snell, München, Zürich 8. Aufl. 1983, B 114, 35.

15 Plutarch, Große Griechen und Römer. Bd. 1. Eingeleitet und übersetzt von Konrat Ziegler, Zürich, Stuttgart 1954, Romulus 10-11, 87-89. Titus Livius, Römische Geschichte. Buch I-III. Lateinisch und deutsch herausgegeben von Hans Jürgen Hillen, München, Zürich 2. Aufl. 1991, I,6,3-I,7,3, 23. Ovid, Fasti. Festkalender. Lateinisch - deutsch. Auf der Grundlage von Wolfgang Gerlach neu übersetzt und herausgegeben von Niklas Holzberg, Düsseldorf 3. Aufl. 2006, III,59-72, 101-103 und IV,807-848, 193-195. Properz, Gedichte. Lateinisch und deutsch von Rudolf Helm, Berlin 2. Aufl. 1978, IV,1,56-57, 199.

16 1. Mose, IV,16-17. Für Mittelalter und Neuzeit exemplarisch: Hrabanus Maurus, De Universo libri vinginti duo, Opera omnia (PL 111), Bd. 5, Paris 1864, 384. Ibn Khaldūn, Die Muqaddima. Betrachtungen zur Weltgeschichte. Aus dem Arabischen übertagen und mit einer Einführung von Alma Giese. Unter Mitwirkung von Wolfhart Heinrichs, München 2011, V,24, 376. Leon Battista Alberti, Zehn Bücher über die Baukunst. Ins Deutsche übertragen, eingeleitet und mit Anmerkungen und Zeichnungen versehen durch Max Theuer, Darmstadt 1975, IV,1, 179-180. Jean-Jacques Rousseau, Abhandlung über den Ursprung und die Grundlagen der Ungleichheit unter den Menschen. Aus dem Französischen übersetzt und herausgegeben von Philipp Rippel, Stuttgart 2008, 74. Carl Schmitt, Der Nomos der Erde im Völkerrecht des Jus Publicum Europaeum, Berlin 5. Aufl. 2011, 36-38. Vgl. hierzu auch Benjamin Schmid, Kommentar: Bürgererfahrung und das politische Denken in der mittelalterlichen Aristoteles-Rezeption, in: Zur Geschichte des politischen Denkens. Denkweisen von der Antike bis zur Gegenwart, hg. von Dirk Lüddecke / Felicia Englmann, Stuttgart, Weimar 2014, 51-71 (52-57). 17 Marc Augé, Nicht-Orte, München 4. Aufl. 2014, 65-66.

18 Als die politischste aller Künste sei seit jeher die Architektur anzusehen, so Klaus von Beyme, Die Kunst der Macht und die Gegenmacht der Kunst. Studien zum Spannungsverhältnis von Kunst und Politik, Frankfurt a. M. 1998, 311. 
etwa finden ihre Verortung historisch auf der Agora, dem Forum, der Piazza. ${ }^{19}$ Diese Form sich im öffentlichen Raum vollziehender politischer Willensbildung und -äußerung findet ihren Ausdruck zum Teil noch heute, man denke etwa an die Geschehnisse auf dem Majdan-, Tahrir- oder Taksim-Platz, in Kiew, Kairo und Istanbul. Vorrangig jedoch ist der für Politik relevante öffentliche Raum heutiger großräumiger Formen politischer Ordnung der Raum der Parlamente beziehungsweise der durch die Massenmedien vermittelte, geformte und erzeugte Raum. In ihnen verortet sich Politik. ${ }^{2}$

Getrennt wird schließlich nicht allein eine Gemeinschaft von der anderen, sondern auch das Individuum von der Gemeinschaft. Erst die Trennung des oikos von der polis, die Trennung des privaten Raums vom öffentlichen Raum, gibt gerade demokratischer Politik ihre topologische differentia specifica. Insbesondere der durch die eigenen vier Wände erzeugte Raum ist von grundlegender Bedeutung für bürgerliche Freiheitsrechte. ${ }^{21}$

Neben diese topologische tritt eine chronologische Dimension als grundlegend für Politik. Drei Aspekte der chronologischen Dimension sind folgend hervorzuheben: Erstens gehört Herrschaft über die Zeit zum Instrumentarium der Politik. Zeit fungiert als Ordnungsfaktor und dient der Ausübung von Macht. Zum Beispiel sind im Setzen von Fristen und Ultimaten, aber auch in der Etablierung einer kollektiv verbindlichen Zeitrechnung, Ausdrucksformen einer solchen Herrschaft über die Zeit zu erkennen. ${ }^{22}$ Die Vereinheitlichung der Zeit bewirkt weiter eine Normierung sozialen Verhaltens. ${ }^{23}$ Zugleich ist Herrschaft über die Zeit auch symbolisches Ausdrucksmit-

19 Die Agora nennt als das bestimmende Merkmal der Polis der Perserkönig Kyros II. in Herodot (Fn. 14), I,153, 143. Hierzu und zur Etymologie der Agora siehe Frank Kolb, Agora, in: Der neue Pauly. Enzyklopädie der Antike. Bd. 1: A-Ari, hg. von Hubert Cancik / Helmuth Schneider, Stuttgart, Weimar 1996, 267-273 (267) und Ludger Schwarte, Philosophie der Architektur, München 2009, 264. Zur Bedeutung des Stadtplatzes generell ebd. 171-172. Zur Bedeutung der Agora für die Polis Tonio Hölscher, Öffentliche Räume in frühen griechischen Städten, Heidelberg, 2. Aufl. 1998, $29 \mathrm{ff}$.

20 Vorländer (Fn. 1), 116-117. Merkel (Fn. 2), 16-17. Schwarte (Fn. 19), 316-326.

21 Vgl. Michael Walzer, Zivile Gesellschaft und amerikanische Demokratie, Berlin 1992, 38. Tobias Prüwer, Welt aus Mauern. Eine Kulturgeschichte, Berlin 2018, 21.

22 So lange sich indes noch kein universell verbindliches Zeitregime etablierte, werden einer Herrschaft über die Zeit ihre Grenzen beim Versuch sie in ein anderes Zeitregime zu übertragen aufgezeigt. Exemplarisch offenbarte sich die Machtlosigkeit des europäischen Zeitregimes beim Versuch es auf China zu übertragen. Als Instrument zur Zeitrechnung war die mechanische Uhr Europas in China praktisch bedeutungslos. Carlo M. Cipolla erklärt diesen Umstand mit der Struktur und den Bedürfnissen der chinesischen Gesellschaft. Neben der gebildeten Elite stand die Masse an Bauern, für die Zeit nicht in Stunden und Minuten, sondern in Tagen und Jahren gemessen wurde. Carlo M. Cipolla, Gezählte Zeit. Wie die mechanische Uhr das Leben veränderte, Berlin 2011, 104-114. Politische Macht kam dem europäischen Zeitregime in diesem speziellen Fall auf andere Art und Weise zu. Als begehrte Geschenke öffneten Uhren den Europäern den Zugang nach China. Die mechanische Uhr wurde somit zu einem Mittel Zugang zu Machthabern zu erhalten. Ebd. 104 und 118. Zur Thematik des Zugangs zum Machthaber Carl Schmit, Gespräche über die Macht und den Zugang zum Machthaber, Stuttgart 2008, 21-23.

23 Rüdiger Safranski, Zeit. Was sie mit uns macht und was wir aus ihr machen, Frankfurt a. M. 4. Aufl. 2018, 90-92. Die durch Julius Caesar im antiken Rom vorgenommen Vereinheitlichung der Zeit hatte etwa zur Folge, dass von nun an die genaue Beachtung der Zeit als Ausweis von Bildung und Macht aufgefasst wur- 
tel politischer Autonomie. ${ }^{24}$ Schließlich geht die Etablierung und Durchsetzung eines Zeitregimes mit der Entmachtung von zeitlichen Nebenordnungen einher und hat dadurch Teil an der Etablierung moderner Staatlichkeit. ${ }^{25}$

Zweitens ist Herrschaft auf Zeit ein Wesenskern insbesondere der Demokratie. ${ }^{26}$ Bestimmungen zur Amtszeit der zu wählenden Repräsentanten oder der Legislaturperiode von Parlamenten gehören untrennbar zu einer demokratischen Verfassung. Dagegen scheint die Jahrhunderte währende Praxis dynastischer Thronfolge dem Prinzip von Herrschaft auf Zeit zunächst zu widersprechen. Der König ist tot, lang lebe der König ist die Formel, mit der dynastische Kontinuität pointiert zusammengefasst wurde. ${ }^{27}$ Doch greift Herrschaft auf Zeit auch hier in Form etwa mahnender vanitas-Stillleben oder dem Rad der Fortuna: alles bleibt vergänglich. Nicht nur der eigene Körper, sondern auch Ruhm und Ehre, Macht und Herrschaft. ${ }^{28}$ Wer sich den qualità de'tempi nicht anzupassen vermag, dessen Untergang sei gewiss. ${ }^{29}$

de. Arno Borst, Computus. Zeit und Zahl in der Geschichte Europas, Berlin 2. Aufl. 2013, 21. Cipolla (Fn. 22), 43-44.

24 Vgl. hierzu etwa die symbolische Bedeutung von Stadtturm und Stadtglocke. Gerhard Dohrn-van Rossum, Die Geschichte der Stunde. Uhren und moderne Zeitrechnung, München, Wien 1992, 185-186.

25 Das Scheitern einer solchen Durchsetzung ist beispielsweise in den protestantischen Teilen Deutschlands zu beobachten. In ihnen wurde die gregorianische Reform des julianischen Kalenders bis 1700 abgelehnt, da es sich um eine päpstliche Zeitrechnung handele. Heinz Schilling, 1517. Weltgeschichte eines Jahres, Bonn 2017, 20. Der französische Revolutionskalender wiederum entmachtete jedwedes kirchliche Zeitregime, indem er den Sonntag durch die Etablierung eines Dezimalsystems mit neun in der Woche aufeinanderfolgenden Werktagen negiert und erst den zehnten Wochentag als Ruhetag festsetzt. Vgl. Michael Meinzer, Der französische Revolutionskalender (1792-1805). Planung, Durchführung und Scheitern einer politischen Zeitrechnung, München 1992, 46-47.

26 Gisela Riescher, Politik und Zeit, in: Lexikon der Politik. Bd. 1: Politische Theorien, hg. von Dieter Nohlen, Frankfurt a. M., Wien 1995, 445-453 (447). Als der Demokratie wesenseigen weist auf den Grundsatz der Herrschaft auf Zeit und dem mit ihm verbundenen Prinzip parlamentarischer Diskontinuität auch das Bundesverfassungsgericht hin. Innerhalb der Vorgaben des Grundgesetzes können spätere Gesetzgeber daher „Rechtsetzungsakte früherer Gesetzgeber revidieren“, um „dem durch die Wahl zum Ausdruck gebrachten Willen des Volkes“ Rechnung zu tragen. BVerfGE 141,1, 21-22. Zur Frage der Amtszeit gewählter Repräsentanten klassisch etwa Hamilton, Alexander/Madison, James / Jay, John: Die Federalist-Artikel. Politische Theorie und Verfassungskommentar der amerikanischen Gründungsväter. Mit dem englischen und deutschen Text der Verfassung der USA. Herausgegeben von Angela Adams und Willi Paul Adams, Paderborn, München, Wien, Zürich 1994, 319-320.

27 Ernst H. Kantorowicz, Die zwei Körper des Königs. Eine Studie zur politischen Theologie des Mittelalters, München 1990, 36-37. Zur Übertragung fürstlicher Körperlichkeit auf das Parlament Philip Manow, Im Schatten des Königs. Die politische Anatomie demokratischer Repräsentation, Frankfurt a. M. 2008, 37-53.

28 Exemplarisch für das Genre etwa Antonio de Pereda Der Traum des Ritters von 1655. Vgl. hierzu Norbert Schneider, Stilleben. Realität und Symbolik der Dinge. Die Stillebenmalerei der Frühen Neuzeit, Köln 2003, 8o-81. Zum Rad der Fortuna beispielsweise Claudia Brink, Fortuna, in: Politische Ikonographie. Ein Handbuch. Bd. I: Abdankung bis Huldigung, hg. von Uwe Fleckner / Martin Warnke / Hendrik Ziegler, München 2014, 353-359 (353-354).

29 Niccolò Machiavelli, Il Principe/Der Fürst. Italienisch/Deutsch. Übersetzt und herausgegeben von Philipp Rippel, Stuttgart 1986, 191-197. Niccolò Machiavelli, Von Fortuna. Für Giovan Battista Soderini, in: Niccolò Machiavelli. Dichter-Poeta. Mit sämtlichen Gedichten deutsch/italienisch, hg. von Dirk Hoeges, Frankfurt a. M. 2006, 114-119. 
Drittens vollzieht sich Politik in der Zeit. ${ }^{30}$ In der europäischen Mythologie und Kulturgeschichte sind Politik und Zeit aneinander gebunden. Erst mit dem Verlassen des für ihn zeitlosen Gartens Eden eröffnet sich dem Mensch ein Handlungsraum, gelegen zwischen Genesis und Apokalypse, zwischen Anfang und Ende der Zeit. ${ }^{31}$ Innerhalb dieses dem Menschen gegebenen Zeitraums wird das Erkennen des kairos und der occassione, das Erkennen des rechten Augenblicks, der günstigen Gelegenheit, mit politischer Dezision verbunden..$^{32}$ Demgegenüber wird seit ihrer Darstellung durch Ambrogio Lorenzetti auch die Mäßigung (temperantia) und das Absehen von einer übereilten Entscheidung mit der Zeit assoziiert. ${ }^{33}$ In diesen Zusammenhang gehört, dass Politik vom Moment des Innehaltens zehrt. Selbst wenn von Politik nicht mehr verlangt wird als die Kapazität zu kollektiv verbindlichen Entscheidungen, wird dieser Moment des Innehaltens benötigt, da die Klärung von etwas Ungewissem Voraussetzung dafür ist, von einer Entscheidung sprechen zu können. ${ }^{34}$ Ohne diese Überführungsleistung im Moment des Innehaltens gibt es folglich kein Entscheiden und Politik schwindet dahin. Erst dieser Moment macht politisches Entscheiden möglich, da sonst alles Handeln alternativ- weil zeitlos wird. ${ }^{35}$ Man bliebe verhaftet in der Diktatur des Jetzt, die sich in einer hektischen Jagd nach der nächsten sich bietenden Gelegenheit äußert. Da Vergangenes bereits gewesen und Zukünftiges noch nicht ist, bleibt allein die flüchtige Gegenwart. ${ }^{36}$ Möglich wird eine Entscheidung zwischen Alternativen daher erst im Aufbrechen dieser Hast durch Innehalten, Zaudern und Zögern.

30 Riescher (Fn. 26), 451.

31 Siehe 1. Mose 2,17 und 1. Mose 3,19. Mit seiner Zeitlichkeit wird der Mensch erst im postlapsarischen Zustand konfrontiert, da die gegenüber Adam und Eva ausgesprochene Todesdrohung von Gott nicht oder nicht unmittelbar umgesetzt wird. Erst im auf den Sündenfall folgenden Zustand wird dem Menschen seine Sterblichkeit bewusst. Claus Westermann, Genesis. 1. Teilband. Genesis 1-11, Biblischer Kommentar Altes Testament (hg. von Siegfried Herrmann / Hans Walter Wolff), Bd. I/1, Neukirchen-Vluyn 3. Aufl. 1983, 305-306 und 362-363.

32 Brigitte Schaffner, Kairos (Kaıрóৎ), in: Der neue Pauly. Enzyklopädie der Antike. Altertum. Bd. 6: Iul-Lee, hg. von Hubert Cancik / Helmuth Schneider, Stuttgart, Weimar 1999, 138-139 (138). Niccolò Machaivelli, Von der Gelegenheit. Für Filippo de’Nerli, in: Niccolò Machiavelli. Dichter-Poeta. Mit sämtlichen Gedichten deutsch/italienisch, hg. von Dirk Hoeges, Frankfurt a. M. 2006, 137-138.

33 Borst (Fn. 23), 106.

34 Niklas Luhmann, Die Politik der Gesellschaft, Frankfurt a. M. 2000, 83 f. Claus von Bormann, Entscheidung (griech. кpíøıৎ, lat. decisio, dän. afgørelse), in: Historisches Wörterbuch der Philosophie. Bd. 2: D-F, hg. von Joachim Ritter, Basel, Stuttgart 1972, 541-544 (541).

35 Joseph Vogl, Über das Zaudern, Zürich, Berlin 2014, 42-44. Byung-Chul Han, Duft der Zeit. Ein philosophischer Essay zur Kunst des Verweilens, Bielefeld 12. Aufl. 2015, 103-104. Die zumindest zeitweilige Bedeutung zögernden Handelns für die Politik erkennt mit Niccolò Machiavelli auch ein entschiedener Verfechter politischen Dezisionismus' an. Vgl. hierzu Machiavellis Ausführungen zu Fabius Maximus cunctator. Niccolò Machiavelli, Discorsi. Gedanken über Politik und Staatsführung. Deutsche Gesamtausgabe. Übersetzt, eingeleitet und erläutert von Rudolf Zorn. Mit einem Geleitwort von Herfried Münkler, Stuttgart 3. Aufl. 2007, III,9, 326-328.

36 Vgl. Aurelius Augustinus, Bekenntnisse. Aus dem Lateinischen übertragen und mit einer Einführung von Wilhelm Thimme, München 11. Aufl. 2010, 312-315. Erläuternd hierzu etwa Kurt Flasch, Augustin. Einführung in sein Denken, Stuttgart 4. Aufl. 2013, 269-277. 
Des Weiteren ist der Moment zögernden Innehaltens nicht nur eine Bedingung für das Ermöglichen von politischen Entscheidungen, sondern ist zeitphilosophisch auch eine Voraussetzung für Zukunft. In der analytischen Zeitphilosophie hat sich die Unterscheidung von sogenannten A-Reihen oder Geschichtlichkeit (Vergangenheit, Gegenwart, Zukunft) und B-Reihen oder Chronologie (vorher, gleichzeitig, nachher) etabliert. ${ }^{37}$ Während mit A-Reihen ein lineares Geschichtsverständnis mit offener Zukunft bezeichnet wird, sind B-Reihen durch eine zirkuläre Abfolge von Prozessen gekennzeichnet. ${ }^{38}$ Als idealtypisches Paradigma für die zeitphilosophische Unterscheidung von A- und B-Reihen kann auf die politischen und gesellschaftlichen Veränderungen im Zuge der Französischen und industriellen Revolution verwiesen werden. In diesem Zeitraum vollzieht sich eine Beschleunigung sozialen Wandels, die dazu führt, dass soziale Praktiken, die für die in einer Agrargesellschaft lebenden Großelterngeneration noch galten, für die in der Industriegesellschaft lebenden Enkel keine Relevanz mehr besitzen. ${ }^{39}$ Übertragen auf das zuvor Geschilderte hat die Unterscheidung von Geschichtlichkeit und Chronologie zur Folge, dass eine am Diktat des Jetzt orientierte Politik, die den Moment zögernden Innehaltens ausspart, ihre Urteile anhand der Gegebenheiten des Ist-Zustands fällt. Von diesem Zustand aus werden alle weiteren Ereignisse in Relation gesetzt, sind daher vorher, gleichzeitig oder nachher. Zukunft ist einer solcherart strukturierten Form von Politik folglich wesensfremd, weil sie ihr keine eigene Bedeutung zuschreiben kann. Das Künftige bliebe lediglich in Relation zum Gegenwärtigen fassbar. Es fehlt an einem Soll-Zustand, der als Orientierungspunkt den Weg in die Zukunft weisen kann.

\section{Auswirkungen der gestörten Wahrnehmung von Zeit und Raum}

Diese die Politik fundamental formenden Dimensionen sind einem Prozess der Beschleunigung unterworfen, der sie mehr und mehr aus den Fugen geraten lässt. Beschleunigung ist hierbei nicht als ein temporales Phänomen zu verstehen. Physikalisch wird Zeit nicht beschleunigt, sie vergeht ebenso schnell oder langsam wie seit jeher. Beschleunigung entsteht durch eine Vermehrung gleichzeitig oder in kürzerer Folge zu bewältigender Ereignisse. ${ }^{40}$

Der Beschleunigung erzeugende Prozess der Vermehrung setzte mit der industriellen gleichwie mit der Französischen Revolution ein. Die industrielle Revolution

\footnotetext{
37 John McTaggart Ellis McTaggart, Die Irrealität der Zeit, in: Klassiker der modernen Zeitphilosophie, hg. von Walther Ch. Zimmerli und Mike Sandbothe, Darmstadt 1993, 67-86 (68).

38 Gunter Weidenhaus, Soziale Raumzeit, Berlin 2015, 32.

39 Hartmut Rosa, Beschleunigung und Entfremdung. Entwurf einer Kritischen Theorie spätmoderner Zeitlichkeit, Berlin 6. Aufl. 2018, 22. Weidenhaus (Fn. 38), 33 und 198.

40 Safranski (Fn. 23), 107.
} 
brachte durch Innovationen im Transportwesen, in der Telekommunikation und der Maschinisierung der Produktion unter anderem ein Schrumpfen des Raumes mit sich. ${ }^{41}$ Räumliche Distanzen konnten nun schneller überwunden werden. Durch die Notwendigkeit, beispielsweise Fahrpläne zu synchronisieren, bewirkte sie weiter eine Vereinheitlichung von Zeitsystemen. Schließlich sorgte sie für eine nachhaltige Veränderung des Sozialverhaltens. Der Mensch hatte sich dem Zeitdiktat der Maschinen zu unterwerfen, er wurde zur Pünktlichkeit gezwungen, konnte sich die Arbeit nicht mehr selbst einteilen..$^{42}$ Die Ablösung der Agrar- durch die Industriegesellschaft verschiebt damit die dominante Zeitordnung fort von Chronologie hin zu Geschichtlichkeit. Bestimmend für die Alltagswirklichkeit der Menschen werden nun weniger prozesshaft sich wiederholende Abläufe im Sinne von Chronologie, sondern lineare Veränderungen im Sinne von Geschichtlichkeit. Durch diese Verschiebung lebt die Generation der Enkel im Zeitalter der Industrialisierung in einer systematisch anderen Welt als die Generation der Großeltern. ${ }^{43}$

Einen Beschleunigungsschub bewirkte auch die Französische Revolution. Sie übertrug auf die Politik, was einst der Religion vorbehalten war: An die Stelle eines jenseitigen Heilsversprechens trat die an die Politik gerichtete Erwartung auf persönliche Befreiung und soziale Verbesserung. ${ }^{44}$ Mit dem Wegbrechen einer auf das Jenseits verweisenden Endzeit erhalten wiederum Gegenwart und Zukunft eine ungleich größere Dringlichkeit. Nun hat Politik im Diesseits zu liefern, was dereinst die Religion für das Jenseits versprach. ${ }^{45}$ In Gelassenheit die Welt wahrzunehmen wie sie ist, eben nur als Welt, ist damit kein mögliches Mittel des Umgangs mit der Erfahrung von Beschleunigung mehr. ${ }^{46}$ Das Wegfallen einer Endzeit lässt das Jetzt zur Dauerkrise werden. Ohne ein am Ende der Zeit tagendes Weltgericht, wird jeder Tag zum Jüngsten. Jede Situation ist vom gleichen Zwang zu Entscheiden geprägt, da es kein jenseitiges Urteil mehr

41 Vgl. bezüglich den Abweichungen dieser neuen Beschleunigungsformen von vorherigen Paul Virilio, Revolutionen der Geschwindigkeit, Berlin 1993, 7-8. In anderer Qualität und Quantität kann ein Schrumpfen des Raums infolge von Beschleunigungsprozessen beispielsweise bereits durch die Etablierung des Postwesens im Europa der Frühen Neuzeit beobachtet werden. Schilling (Fn. 25), 68.

42 Karl Marx / Friedrich Engels, Manifest der Kommunistischen Partei, MEW, Bd. 4, Berlin 1972, 465. Paul Lafargue, Das Recht auf Faulheit. Zurückweisung des „Rechts auf Arbeit“ von 1848. Aus dem Französischen übersetzt von Ute Kruse-Ebeling, Stuttgart 2018, 7-8. Borst (Fn. 23), 131-132. Safranski (Fn. 23), 89-92. Han (Fn. 35), 22. Virilio (Fn. 41), 7-8.

43 Weidenhaus (Fn. 38), 33 und 198.

44 Safranski (Fn. 23), 112-113. Jörke (Fn. 13), 34-35. Vgl. hierzu auch die Entwicklung des Sozialstaats. Wolfgang Reinhard, Geschichte der Staatsgewalt. Eine vergleichende Verfassungsgeschichte Europas von den Anfängen bis zur Gegenwart, München 3. Aufl. 2002, 459-463.

45 Safranski (Fn. 23), 144. Han (Fn. 35), 36.

46 Rosa (Fn. 39), 110-111. Beispielhaft dafür sein Los in christlicher Gelassenheit anzunehmen Augustins Ratschläge an die Bewohner des $410 \mathrm{n}$. Chr. von Alarichs Westgoten geplünderten Roms. Aurelius Augustinus, Vom Gottesstaat (De civitate Dei). Vollständige Ausgabe in einem Band. Buch 1 bis 1o. Buch 11 bis 22. Aus dem Lateinischen übertragen von Wilhelm Thimme. Eingeleitet und kommentiert von Carl Andresen, München 2007, I,10, 18-22. 
über richtig und falsch gibt. Die Krise des Politischen wird damit nicht als einmaliger sich beschleunigender Vorgang offenbart, sondern als Resultat eines langwirkenden Prozesses im Sinne des eingangs vorgestellten semantischen Krisenmodells Kosellecks. ${ }^{47}$

Als Ergebnis der umschriebenen Mehrung der Ereignisse beginnen sich Zeit und Raum aufzulösen. Selbst fern liegende Ereignisse rücken nun in das nahe Blickfeld. ${ }^{48}$ Die aus dieser Nähe erzeugte Verdichtung bewirkt zugleich, dass einzelne Ereignisse nicht mehr getrennt voneinander betrachtet werden können. ${ }^{49}$ Und so erodiert das Vertrauen in die Konstanz des von einer Gemeinschaft beanspruchten und eingenommenen Raums. Die zu beobachtende Errichtung neuer Grenzbefestigungen etwa dient vor diesem Hintergrund als psychopolitische Behelfskonstruktion, mittels der dem ungewiss gewordenen Raum wieder Konstanz gegeben werden soll..$^{\circ}$

Zugleich ist auch die Erfahrung des Raums innerhalb der Außengrenzen eines Gemeinwesens einem den sozialen Zusammenhalt verändernden Wandel unterzogen. In Analogie zum psychopolitischen Agieren an den Außengrenzen wird auch der öffentliche Raum mit gleichsam psychopolitischen Maßnahmen befestigt: Betonsperren, sichtbare Militärpräsenz oder Videoüberwachung sind Ausdruck eines modernen Gesellschaften Eigen gewordenen Polizeifetisch. ${ }^{51}$ Transparenz und Überwachung lassen auch den privaten Schutzraum der eigenen vier Wände porös werden und verwischen so die Trennung von oikos und polis. ${ }^{52}$ Ein Prozess, der durch die digitalen Medien vorangetrieben wird, da sie neue und weitere Möglichkeiten der Überwachung und Transparenz generieren und deren Nutzer zugleich dazu neigen Privates in Öffentliches zu verwandeln..$^{53}$

An Stabilität verliert schließlich auch der für demokratische Politik notwendige parlamentarische Raum. Beschleunigung bewirkt Nähe auch fernliegender Ereignisse. Nebenfolge einer globalisierten Welt ist daher die Stärkung der Exekutive auf Kosten der Legislative, da Lösungsvorschläge globaler Probleme zumeist intergouvernemental ausgehandelt werden. Über das einmal Ausgehandelte wird im parlamentarischen Raum in der Regel nur noch in Gänze abgestimmt, ohne am eigentlichen Aushandlungsprozess beteiligt gewesen zu sein. ${ }^{54}$ Eine weitere Schwächung erfährt der par-

47 Koselleck (Fn. 12), 207-208.

48 Paul Virilio, Die Verwaltung der Angst, Wien 2011, 32. Virilio (Fn. 41), 56.

49 Virilio (Fn. 48), 22.

50 Wendy Brown, Mauern. Die neue Abschottung und der Niedergang der Souveränität, Berlin 2018, 9-11.

51 Michael Zinganel, Auf Angst gebaut, Aus Politik und Zeitgeschichte 17 (2010), 33-38 (36-37). Loïc Wacquant, Die verdammten der Stadt. Eine vergleichende Soziologie fortgeschrittener Marginalität, Wiesbaden 2018, XXXIX-XL.

52 Byung-Chul Han, Transparenzgesellschaft, Berlin 2012, 72-73. Wolfgang Sofsky, Verteidigung des Privaten. Eine Streitschrift, Bonn 2007, 23.

53 Andreas Reckwitz, Die Gesellschaft der Singularitäten. Zum Strukturwandel der Moderne, Bonn 2018, 238.

54 Reimund Seidelmann, Außenpolitik, in: Lexikon der Politik. Bd. 6: Internationale Beziehungen, hg. von Dieter Nohlen, Frankfurt a. M. 1994, 42-49 (47-48). Christoph Möllers, Gewaltengliederung. Legitimation 
lamentarische Raum dadurch, dass Beschleunigung zu einer Gefährdung der verfassungsmäßigen Ordnung der Demokratie werden kann. Durch ihre Verfassung sollten die Fährnisse der Zeit für politische Ordnungsformen zumindest reduziert und dem politischen Raum eine Verankerung gegeben werden. Idealiter soll eine Verfassung auf Dauer gelten. Sie soll nicht den Wechselläufen der Zeit und des politischen Alltagsgeschäfts unterworfen sein. ${ }^{55}$ Die Störung von Zeit und Raum aber wirft die Verfassung durch die Gefahr einer Verstetigung ausnahmezustandsähnlicher Lagebeschreibungen aus ihrer Zeitlosigkeit. Beschleunigung vermag demokratische Verfassungsinhalte zu gefährden, weil die Demokratie durch Beschleunigung an Funktionsfähigkeit zu verlieren droht. Wenn Not zur Eile drängt, hinken Parlamente hinterher und nicken Entscheidungen nur noch $a b . .^{56}$

Aus der Krise des Politischen resultiert somit die Krise der Demokratie. Auch Demokratien erfahren die Auswirkungen von Beschleunigung. Durch Beschleunigung bedingte Veränderungen von Zeit und Raum können sich Demokratien nicht entziehen, reagieren darüber hinaus seit jeher sensibler auf derartige Veränderungen als nicht-demokratische Formen politischer Ordnung. ${ }^{57}$ Entscheidungsprozesse sind in Demokratien zeitintensiver, weil abhängig etwa von vergangenen oder erwarteten künftigen Wahlergebnissen, parlamentarischen Abläufen oder der Deliberation im öffentlichen Raum. ${ }^{58}$

Die zeitlichen Folgen der Beschleunigung treiben das Skizzierte weiter voran. In der Augenblicklichkeit der Ereignisse löst sich die Dreiteilung von Vergangenheit, Gegenwart und Zukunft auf..$^{99}$ Was bleibt ist die Orientierung am Jetzt und der von ihm ausgehenden Unterscheidung von vorher, gleichzeitig und nachher (B-Reihe). Mit der an

und Dogmatik im nationalen und internationalen Rechtsvergleich, Tübingen 2005, 359-363. Safranski (Fn. 23), 119. Exemplarisch hierfür etwa die unklare Beteiligung nationaler Parlamente an den Verhandlungen zum Freihandelsabkommen TTIP. Davor Jančić, TTIP and Legislative-Executive Relations in EU Trade Policy, West European Politics 1 (2017), 202-221 (202).

55 Hierzu etwa Gisela Riescher, Zeit und Politik. Zur institutionellen Bedeutung von Zeitstrukturen in parlamentarischen und präsidentiellen Regierungssystemen, Baden-Baden 1994, 89-90. Obgleich das Grundgesetz der Bundesrepublik Deutschland anfänglich nur als temporäres Provisorium verstanden worden ist, weist es eine Bestandsgarantie für die demokratischen Grundlagen der Bundesrepublik auf, die der Zeit enthoben werden (Art. 79(3) GG). Im Wortlaut der ursprünglichen Präambel des Grundgesetzes ist von Geltung nur für eine Übergangszeit die Rede. Hierin spiegelt die Präambel den medizinischen Ursprung des Worts Verfassung als veränderlicher Zustand des Körpers wider. Vgl. Heinz Mohnhaupt, Verfassung (II.), Konstitution, Grundgesetz, in: Geschichtliche Grundbegriffe. Historisches Lexikon zur politisch-sozialen Sprache in Deutschland. Bd. 6: St-Vert, hg. von Otto Brunner / Werner Conze / Reinhart Koselleck, Stuttgart 1990, 831-862 (832).

56 Hartmut Rosa, Beschleunigung. Die Veränderung der Zeitstrukturen in der Moderne, Frankfurt a. M. 2005, 394-396 und 407-410. Hartmut Rosa, Resonanz. Eine Soziologie der Weltbeziehung, Berlin 2016, 376.

57 Zur räumlichen Dimension der Demokratie Jörke (Fn. 13), 10-13. Ferner auch bereits Charles-Louis de Secondat de Montesquieu, Vom Geist der Gesetze. In neuer Übertagung eingeleitet und herausgegeben von Ernst Forsthoff. Bd. 1, Tübingen 1951, VIII,19, 175 .

58 Riescher (Fn. 55), 86-88. Rosa (Fn. 39), 79-80.

59 Virilio (Fn. 48), 76. Safranski (Fn. 23), 79. 
die Politik gerichteten Erwartung auf eine bessere Zukunft aber ist eine an Geschichtlichkeit (A-Reihe) orientierte Form politischer Ordnung gefordert. Beschleunigung lässt so ein paradoxes Nebeneinander von Gleichzeitigkeit und Chronologie entstehen.

Die Permanenz der Gegenwart verschärft sich nicht zuletzt im Zuge der Digitalisierung. Im Digitalen verschwimmen die Grenzen von Raum und Zeit. Das Hier und Jetzt ist in ihm bestimmend, weil der Momentcharakter des Neuen das Digitale dominiert und derart den Bezug zu Vergangenheit wie Zukunft schwächt. ${ }^{60}$ Eine Grundlage politischen Entscheidens im öffentlichen Raum, das zögernde Abwägen von Alternativen, droht in der flüchtigen Aufmerksamkeitsstruktur des Digitalen verlorenzugehen. ${ }^{61}$ Verloren auch, weil in der globalisierten Permanenz digitaler Gegenwart Alternativen nicht mehr ohne weiteres zur Verfügung gestellt werden. Eine Vereindeutigung der Welt einerseits, ${ }^{62}$ ein Auseinanderdriften des öffentlichen Raums in eine Vielzahl unverbunden nebeneinander stehender Räume andererseits. ${ }^{63}$ Derart wird das Potential des Virtuellen, einen egalitären Kommunikationsraum zu erschaffen, durch die Dezentralisierung all der in ihm zu vernehmenden Botschaften unterlaufen. ${ }^{64}$

\section{Zur Bewertung der Störung von Zeit und Raum}

Wie kann den im Vorherigen umrissenen Krisensymptomen begegnet werden? Hängt man einer optimistischen Sichtweise an, so wird man womöglich versucht sein, das Vorherige nicht als Krise zu bezeichnen, da der Befund unzutreffend sei. Gerade der technische Fortschritt führe nicht zu Beschleunigung, sondern zu Entschleunigung, da durch Automatisierung Zeit freigesetzt werde. ${ }^{65}$ In diesem Sinne kann auch der die Moderne mitgestaltende Prozess der Rationalisierung gedeutet werden. Angetrieben von einem Telos der Optimierung ist dieser Prozess unter anderem eine Reaktion auf die Knappheit der Ressource Zeit. Durch Rationalisierung werde Zeit wieder freigesetzt, da Resultate nun schneller erreicht werden können. Diese Freisetzung von Zeit

60 Han (Fn. 35), 66. Reckwitz (Fn. 53), 241-242.

61 Rosa (Fn. 39), 80-81.

62 Thomas Bauer, Die Vereindeutigung der Welt. Über den Verlust an Mehrdeutigkeit und Vielfalt, Stuttgart 6. Aufl. 2018, 84-85.

63 Cass R. Sunstein, \#Republic: Divided Democracy in the Age of Social Media, Princeton 2017, 59-60. Reckwitz (Fn. 53), 261-262. In diesen beiden Phänomenen zeigt sich, dass Virilio mit seiner Aussage wonach Geschwindigkeit Relativität und Relativität das Politische sei, zu widersprechen ist, da die durch Beschleunigung erzeugte Geschwindigkeit eben keine dem Politischen zugrundeliegende Relativität bewirkt. Virilio (Fn. 48), 27.

64 Jürgen Habermas, Ach Europa: Kleine politische Schriften XI, Frankfurt a. M. 2008, 161-162.

65 Auf die paradoxen Folgen technischen Fortschritts weist etwa Hartmut Rosa hin. Rein logisch erhöhe technischer Fortschritt die Verfügungsmöglichkeit über Zeit, tatsächlich führt er aber zu einer weiteren Verknappung von Zeit. Rosa (Fn. 39), 30-32. 
ist indes ergebnisoffen. Indem Zeit eingespart wird, kann der Prozess der Rationalisierung Entschleunigung erwirken, weil ein Resultat mit weniger Zeitaufwand erreichbar wird. Er kann aber auch beschleunigend wirken, weil die freigewordene Zeit mit der Umsetzung neuer Resultate gefüllt wird. Ausschlaggebend wird daher der Umgang mit der freigewordenen Zeit. ${ }^{6}{ }^{6}$ Weil wir sie nicht verlieren wollen und sie mit unseren alltäglichen Beschäftigungen füllen, haben wir keine Zeit. ${ }^{67}$ Folglich bestehe ein Problem - wenn überhaupt - beim Anwender technischer Hilfsmittel. Ließen wir uns alle mehr Zeit, wäre das Problem gelöst. ${ }^{68}$ Ausgeblendet wird damit der Einfluss fremder Systemlogiken auf die Politik: nicht nur auf den Politiker, sondern auch auf den Bürger und auf die von der Politik zu bearbeitenden Aufgaben - dies insbesondere, wenn Politik mehr sein soll als nur auf Herausforderungen reagierend, sie vielmehr auch schützend oder gestaltend wirken soll. Dann wirkt die Beschleunigung der Arbeitswelt oder der Finanzmärkte auf Politik ein. Der Krisenbefund bleibt demnach bestehen.

Optimistisch könnte weiter eingewandt werden, dass die wehrhafte Demokratie sich behaupten wird, wie sie es auch schon in vergangenen Krisen getan habe. Analytisch widerspricht dies aber dem Befund, dass wir eben keine Krise im Sinne eines „einmaligen sich beschleunigenden Vorgang[es]" ${ }^{\text {"69 }}$ erleben, sondern eine sich über die Geschichte erstreckende prozesshafte Krise, die deshalb nicht ohne weiteres mit vorherigen Krisen vergleichbar ist. Hinzu kommt, dass Demokratie eine paradoxe politische Ordnungsform darstellt: Einerseits benötigt der Moment demokratischer Deliberation Zeit. Insofern ist die Demokratie verlangsamend. Andererseits ist der Demokratie ein begrenzter Zeithorizont zu eigen, die Herrschaft auf Zeit, die zu einer Befriedigung der Bedürfnisse des Augenblicks neigt. ${ }^{70}$ Demgemäß bewirkt Demokratie selbst Beschleunigung.

Demokratie daher weiter zu beschleunigen, damit sie ihrerseits mit der allgemeinen Beschleunigung Schritt halten kann, ist ein Irrweg. ${ }^{71}$ Zwar können Entscheidungsprozesse in der Demokratie beschleunigt werden, derart ist sie zu schnellem Entschluss fähig, doch erfolgt eine solche Erhöhung des Entscheidungstempos nicht zu Gunsten zeitaufwändiger Diskussion im öffentlichen und parlamentarischen Raum. ${ }^{72}$ Die Zunahme der

66 Reckwitz (Fn. 53), 28-32.

67 Martin Heidegger, Die Grundbegriffe der Metaphysik. Welt - Endlichkeit - Einsamkeit, Gesamtausgabe, Bd. 29/30, Frankfurt a. M. 1983, 195 .

68 Han (Fn. 35), 69-73. Vgl. diesbezüglich auch Lafargue (Fn. 42), 30.

69 Koselleck (Fn. 12), 207.

70 Vgl. Vorländer (Fn. 1), 116. Borst (Fn. 23), 13.

71 Rosa (Fn. 39), 81-82. Münkler (Fn. 13), 118. Vgl. auch den Ausblick auf die Amtseinführung eines künftigen US-Präsidenten im Jahre 2053 bei Runciman (Fn. 10), 220-222.

72 Für die Frage der Messbarkeit von Entscheidungstempi im Gesetzgebungsprozess der Bundesrepublik Deutschland siehe grundlegend Jasmin Riedl, Time to Legislate. A Database to Analyse the Temporal Dynamics of the German Legislature, in: Electronic Participation. $10^{\text {th }}$ IFIP WG 8.5 International Conference, ePart 2018 Krems, Austria, September 3-5, 2018, Proceedings, hg. von Noella Edelmann / Peter Parycek / Gianluca Misuraca / Panos Panagiotopoulos / Yannis Charalabidis / Shefali Virkar, Charm 2018, 117-128 (120-123). 
Ereignisdichte führt vielmehr zu einer „Zeitkrise des Politischen“, die „das Risiko zum Regelfall der Politik“ werden lässt. ${ }^{73}$ Durch die Auflösung von Vergangenheit und Zukunft hat die Risikogesellschaft Vergangenheit und Zukunft in sich aufzunehmen. Die Wiederkehr von vermeintlich Vergangenem und die Vorsorge vor potentiell Zukünftigem lässt Risiko fortwährend gegenwärtig sein. ${ }^{74}$ Zwar ist in Risiken nicht allein die Gefahr zu sehen etwas zu verlieren, sondern auch die Möglichkeit gegeben etwas zu gewinnen. ${ }^{75}$ Doch damit die kontingente Natur von Risiken gewinnhaft bewältigt werden kann, gilt es, einen Moment wahrer Entscheidung herbeizuführen, der auf mehr als nur Entscheidungsdruck beruht. Jedweder Gewinn droht sonst Resultat bloßen Zufalls zu sein. Die Begeisterung der Anhänger des accelerationism für die Folgen von Beschleunigung ist daher nicht zu teilen. Sie verkennen die Bedeutung eines ruhenden Momentums nicht allein für die Demokratie, sondern für Politik generell. ${ }^{76}$ Eine Beschleunigung der Demokratie stellt daher keine Lösung dar, sie gießt lediglich Öl ins Feuer.

Nötig erscheint daher ein Aufhalter, ein katéchon, ${ }^{77}$ der die Folgen der Beschleunigung zumindest mildert und neuerlichen Halt gibt. Auf den ersten Blick kann die Herausforderung durch den Populismus vermeintlich als solch ein katéchon wirken. Durch den Populismus gestört wird vormals als alternativlos Verstandenes wieder dem politischen Diskurs zugeführt. Vermeintlich etablierte politische Verfahren sind neuerlich zu begründen und zu verteidigen, obwohl es den Anschein hatte, sie seien konsensual anerkannt und dem politischen Diskurs dadurch entzogen. ${ }^{78}$ Den skizzierten Folgen der Beschleunigung wird damit jedoch nicht begegnet. Zwar könne als positiver Effekt für die Demokratie notiert werden, dass rechtspopulistische Parteien in Teilen eine mobilisierende Wirkung entfalten, die einen Anstieg der Wahlbeteiligung nach sich ziehe, ${ }^{79}$ für die Demokratie ist dies aber nur dann ausreichend, wenn mit dem Wahlakt der Demokratie bereits Genüge getan ist, der Bürger also seine Stimme abgegeben hat und danach verstummt. ${ }^{80}$ Ist von der Demokratie jedoch mehr als ein solcher Mini-

73 Karl-Rudolf Korte, Beschleunigte Demokratie: Entscheidungsstress als Regelfall, Aus Politik und Zeitgeschichte 7 (2012), 21-26 (21).

74 Safranski (Fn. 23), 78-79.

75 Wolfgang Bonß, Die Rückkehr der Unsicherheit: Zur gesellschaftstheoretischen Bedeutung des Risikobegriffs, in: Risikoforschung zwischen Disziplinarität und Interdisziplinarität. Von der Illusion der Sicherheit zum Umgang mit Unsicherheit, hg. von Gerhard Banse, Berlin 1996, 165-184 (167-168).

76 Siehe die Skizze der Diskussion um accelerationism bei Runciman (Fn. 10), 198-202. Zu den Vorboten des accelerationism ist der Lobpreis der Beschleunigung und der Geschwindigkeit im Futurismus zu betrachten. Etwa bei Filippo Tommaso Marinetti, Manifest des Futurismus, in: Futurismus. Geschichte, Ästhetik, Dokumente, hg. von Hansgeorg Schmidt-Bergmann, Reinbek bei Hamburg 1993, 75-80 (77-78).

77 2. Thess. 2,7. Klassisch zum katéchon Schmitt (Fn. 16), 28-30.

78 Zum politikaversen Habitus vor allem der bürgerlichen Mitte etwa Christoph Möllers, Wir, die Bürger(lichen), Merkur 71 (2017), 5-16 (5-6).

79 Stefan Haußner / Arndt Leininger, Die Erfolge der AfD und die Wahlbeteiligung: Gibt es einen Zusammenhang?, Zeitschrift für Parlamentsfragen 1 (2018), 69-9o (89).

80 Vgl. hierzu etwa das Demokratiemodell von Joseph A. Schumpeter, Kapitalismus, Sozialismus und Demokratie. Einführung von Eberhard K. Seifert, Tübingen, Basel 7. Aufl. 1993, 416-417 und 427-428. 
malismus gefordert, ist ihr damit noch nicht Genüge getan. Ebenso ist auch die den Populismus prägende Etablierung selbstreferenzieller Systeme im öffentlichen Raum für die Demokratie als ungenügend zu erachten. ${ }^{81}$

Gilt Beschleunigung als Ereignissteigerung bedeutet dies, dass mittels eines katéchon die Zahl der Ereignisse reduziert werden muss, um Zeit und Raum zurückzugewinnen. Reduzierbar ist jedoch nicht jede Ereignisart. Politische Ereignisse können nicht reduziert werden. Einerseits, da deren Tagesordnung nicht in Gänze kontrollierbar ist. Globale Interdependenzen ebenso wie die Information über globale Geschehnisse können dazu nötigen, über Ereignisse zu entscheiden, die nicht der eigenen Kontrolle unterliegen. Andererseits, da politische Ereignisse - will man die Demokratie stärken - nicht ohne weiteres dem demokratischen Verfahren entzogen werden können, ohne die Demokratie zu beschädigen. Potentiell reduzierbar sind jedoch Ereignisse solcherart, über die ein Gemeinwesen befinden kann und die zugleich maßgeblich zur Beschleunigung beitragen.

Dies betrifft vorrangig die durch die Arbeitswelt erzeugten Ereignisse. Ein „Imperativ der Arbeit“, $8_{2}$ aufgrund dessen vorrangig „bezahlte Arbeitszeit als funktional sinnvoll verbrachte Zeit angesehen wird“, ${ }_{3}$ ist für die gegenwärtige Krise ein maßgeblicher Faktor. ${ }^{84}$ Die Flexibilisierung der Arbeitswelt kann daher eine Entzerrung der Ereignisdichte und damit sogar eine Revitalisierung der Demokratie ermöglichen. Als demokratische Konsequenz wird erst ein sicheres Grundeinkommen aller dem Geist der Demokratie gerecht ${ }^{85}$ und ein anderer Umgang mit den durch die Beschleunigung verknappten Ressourcen von Zeit und Raum ermöglicht. ${ }^{86}$

Als Alternative zu einem sicheren Grundeinkommen aller ist der Mindestlohn in Betracht zu ziehen. In seiner gegenwärtigen Form und dem Verständnis des mit ihm zu Bewirkenden erweist sich der Mindestlohn jedoch nicht als geeignete Antwort auf das hier geschilderte Erfordernis, eine Reduktion der durch Arbeit erzeugten Ereignisse zu erwirken. Geeignet wäre der Mindestlohn dann, wenn mit ihm kein Mindestmaß bemessen würde, sondern er sich auf einem Niveau befände, das seinen Beziehern eine Reduktion ihrer für Arbeit aufgebrachten Zeit ermöglichen würde. Doch ist dies dem Mindestlohn und der mit ihm verbundenen Intention wesensfremd. Der Mindestlohn

81 Kai Hirschmann, Der Aufstieg des Nationalpopulismus. Wie westliche Gesellschaften polarisiert werden, Bonn 2017, 193-196.

82 Han (Fn. 35), 8.

83 Eva Douma, Sicheres Grundeinkommen für alle. Wunschtraum oder realistische Perspektive? Bonn 2018, 84-85.

84 Rosa (Fn. 39), 35-38. Safranski (Fn. 23), 114-115.

85 Sascha Liebermann, Demokratische Konsequenz, in: Soziale Zukunft. Das Bedingungslose Grundeinkommen. Die Debatte, hg. von Philipp Kovce, Stuttgart 2017, 95-105 (105).

86 Harald Welzer, Zeitenwende, in: Soziale Zukunft. Das Bedingungslose Grundeinkommen. Die Debatte, hg. von Philipp Kovce, Stuttgart 2017, 207-209 (208-209). 
orientiert sich an einem „angemessenen Mindestschutz.${ }^{87}$ Der Imperativ der Arbeit soll durch ihn nicht infrage gestellt werden. Ebenso wird auch die anthropologische Prämisse nicht infrage gestellt, ob der Mensch zur Arbeit gezwungen werden muss, ob dieser Zwang zum Lohnerwerb also primärer Antrieb zur Aufnahme von Arbeit ist. ${ }^{88}$ Durch eine Neuausrichtung des mit dem Mindestlohn verbundenen Lohnniveaus könnte indes eine Reduktion der durch Arbeit erzeugten Ereignisdichte erreicht werden, so dass auch über Mittelwege zwischen einem sicheren Grundeinkommen und der gegenwärtigen Situation, wie eine Verringerung von Arbeitszeit, nachzudenken möglich wäre.

In der kontrovers geführten Debatte um ein sicheres Grundeinkommen aller finden sich kritische Stimmen etwa zu Fragen der Finanzierbarkeit, ${ }^{89}$ den Auswirkungen auf unser Verständnis von Arbeit, ${ }^{90}$ Professionalität ${ }^{91}$ und zu anthropologischen Prämissen generell..$^{22}$ Mit Gewissheit ausschließen lässt sich nicht, dass ein sicheres Grundeinkommen etwa dazu führt, dass infolge der ins Diesseits verlagerten Heilserwartung hedonistisches Handeln bestärkt wird..$^{93}$ Ein sicheres Grundeinkommen beinhaltet also das Risiko politischen Partizipationswillen aufzulösen, weil das Streben nach Erlebnissen wirkmächtiger sein könnte. Der Wegfall von durch die Arbeitswelt erzeugten Ereignissen demzufolge dazu genutzt wird nach immer neuen Singularitätsgütern zu streben..$^{94}$

Ferner ergibt sich aus einem sicheren Grundeinkommen noch keine direkte Stärkung des parlamentarischen Raums. Die zuvor umrissenen Erschwernisse parlamentarischer Tätigkeit werden durch ein sicheres Grundeinkommen nicht direkt tangiert. Nach wie vor gilt es sich mit den im parlamentarischen Raum zu bewältigenden Ereignissen auseinanderzusetzen. Potentiell gestärkt hingegen wird der öffentliche Raum und die Möglichkeit zu politischer Information und Diskussion in ihm. Indirekt kann sich die Stärkung des öffentlichen Raums sodann auch auf den parlamentarischen Raum auswirken, indem eine Lösung nicht nur für die Probleme mangelnder Zeit,

$87 \int 9(2)$ Gesetz zur Regelung eines allgemeinen Mindestlohns (Mindestlohngesetz - MiLoG).

88 Liebermann (Fn. 85), 101. Otfried Höffe, Arbeit für alle, in: Soziale Zukunft. Das Bedingungslose Grundeinkommen. Die Debatte, hg. von Philipp Kovce, Stuttgart 2017, 59-70 (65).

89 Douma (Fn. 83), 125 ff. Guido Raddatz, Das bedingungslose Grundeinkommen - ein unhaltbares Versprechen, List Forum für Wirtschafts- und Finanzpolitik 1 (2014), 37-64 (59-62).

90 Raddatz (Fn. 89), 53-54. Höffe (Fn. 88), 67. Daniel Binswanger, Frei von Arbeit?, in: Soziale Zukunft. Das Bedingungslose Grundeinkommen. Die Debatte, hg. von Philipp Kovce, Stuttgart 2017, 23-25 (24).

91 Etwa Ralf Stegner, Wider die menschliche Natur, in: Soziale Zukunft. Das Bedingungslose Grundeinkommen. Die Debatte, hg. von Philipp Kovce, Stuttgart 2017, 164-172 (169-170) oder Sahra Wagenknecht, Gute Arbeit, in: Soziale Zukunft. Das Bedingungslose Grundeinkommen. Die Debatte, hg. von Philipp Kovce, Stuttgart 2017, 191-206 (203-205).

92 Raddatz (Fn. 89), 53-54. Enno Schmidt, Zeitgeist und Menschenbild, in: Soziale Zukunft. Das Bedingungslose Grundeinkommen. Die Debatte, hg. von Philipp Kovce, Stuttgart 2017, 144-159 (149).

93 Rosa (Fn. 39), 39-41.

94 Reckwitz (Fn. 53), 141-143. 
mangelnder Muße und des Erwerbszwangs angeboten wird, sondern auch für das Problem mangelnder Abkömmlichkeit. Die Stärkung des öffentlichen Raums stärkt den parlamentarischen Raum somit indirekt durch eine Erhöhung des Reservoirs der in den parlamentarischen Raum gewählten Repräsentanten..$^{95}$ Überdies wirkt eine indirekte Stärkung des parlamentarischen Raums dadurch, dass der Öffentlichkeit Existenzängste genommen werden können, wodurch der Druck zu beschleunigtem Handeln aus dem parlamentarischen Raum in Teilen entweichen kann. ${ }^{96}$ Im Zuge der im Vorherigen skizzierten Säkularisierungsprozesse löst sich die Verbindung religiösen und kapitalistischen Zeitverschwendungsverbots auf.97 War ökonomischer Erfolg einstmals noch Zeichen für gewährte göttliche Gnade, bricht diese Gewissheit weg. An die Stelle religiös begründeter Sicherheit - der Gewissheit bereits im Diesseits erkennbarer göttlicher Gnade - tritt die tatsächliche oder auch nur vermeintliche Versicherung des Geldes gegen die Risiken einer kontingenten Zukunft. ${ }^{8}$ Eine derart ungewiss gewordene Zukunft erhöht Existenzängste potentiell, wenn Zukunft nicht mehr ins Jenseits verlagert wird, sondern auch mittels des Verfügens über Geld schon im Diesseits zu bewältigen ist. Ein sicheres Grundeinkommen kann somit dabei helfen solche Ängste zu lindern.

Weiter stimmen die Beobachtungen für die positive Wirkung eines sicheren Grundeinkommens hoffnungsvoll, dass gerade jene sich politisch engagieren, die über Zeit verfügen. Rentner, Pensionäre und Vorruheständler, aber auch Schüler. Jene also, die sich nicht mehr oder noch nicht auf dem Arbeitsmarkt behaupten müssen. ${ }^{99}$ Sie nutzen die Möglichkeit, im öffentlichen Raum politisch zu partizipieren. Nicht zuletzt ist hierin ein Hinweis auf die Relevanz von Zeit zur Bildung und Weiterbildung für die Demokratie zu erkennen. Dass die Demokratie Demokraten und eine entsprechende Bildung ihrer Bürger benötige, wurde bereits in Antike und Mittelalter hervorgehoben. ${ }^{100}$ Nichts hat sich an der Bedeutung dieses Befundes verändert. ${ }^{101}$ Eine Antwort

95 Dolf Sternberger, Der Staat des Aristoteles und der unsere, Schriften, Bd. IV, Frankfurt a. M. 1980, 49-51

96 Rosa (Fn. 56), Beschleunigung, 407-409. Rosa (Fn. 56), Resonanz, 730-731.

97 Max Weber, Soziologie. Weltgeschichtliche Analysen. Politik. Mit einer Einleitung von Eduard Baumgarten. Herausgegeben und erläutert von Johannes Winckelmann, Stuttgart 1956, 359.

98 Weidenhaus (Fn. 38), 209.

99 Hierzu etwa Sabrina Oesterle / Monica Kirkpatrick Johnson / Jeylan T. Mortimer, Volunteerism during the Transition to Adulthood: A Life Course Perspective, Social Forces 3 (2004), 1123-1149 (1138-1141). Felix Butzlaff, Die neuen Bürgerproteste in Deutschland. Organisatoren - Erwartungen - Demokratiebilder, Bielefeld 2016, 34-36.

100 Aristoteles, Politik. Schriften zur Staatstheorie. Übersetzt und herausgegeben von Franz F. Schwarz, Stuttgart 2003, VIII,1, 1337a, 369. Albertus Magnus, Politicorum libri VIII, Opera omnia. Cura ac labore Augusti Borgnet, Bd. 8. Paris 1891, 751 und 756. Klaus Bernath, Bildung als politische Aufgabe. Bemerkungen zum Politik-Kommentar Alberts des Großen, in: Albert der Große. Seine Zeit, sein Werk, seine Wirkung, hg. von Albert Zimmermann, Berlin, New York 1981, 134-140 (137-138). Schmid (Fn. 16), 61-62.

101 Aufmerksam auf die Bedeutung demokratischer Bildung machte jüngst etwa Mounk (Fn. 9), 279280. 
auf die Krise der Demokratie liegt somit eben nicht in der Einführung epistokratischer Elemente und Gremien, ${ }^{102}$ sondern in der Ermöglichung zu lebenslangem Lernen.

An den Anfängen der Demokratie steht das antike Athen. Eine Gesellschaft, deren Bürger durch die Arbeit ihrer Frauen, Sklaven und die Zahlung von Diäten zur politischen Reflexion und Partizipation freigestellt wurden. ${ }^{103}$ Wer mit seiner eigenen Hände Arbeit seinen Lebensunterhalt erwirtschaften müsse, der könne kein Bürger sein, nicht am Regieren und Regiert-Werden teilnehmen. ${ }^{104}$ So Aristoteles, so aber auch Immanuel Kant, der als Bürger nur jene anerkannte, die ihre Kräfte nicht veräußern müssen um zu leben. ${ }^{105}$ In diesem Sinne bietet ein sicheres Grundeinkommen aller durch eine Rückbesinnung auf die Anfänge der Demokratie die Möglichkeit der gegenwärtige Krise der Demokratie beizukommen.

102 Exemplarisch ist hier die Einführung eines epistokratischen Rats mit Vetorecht gegen die politischen Entscheidungen des Wahlvolks genannt. Jason Brennan, Gegen Demokratie: Warum wir die Politik nicht den Unvernünftigen überlassen dürfen, Berlin 2017, 370-371.

103 Die Bedeutung der Sklaven für die Demokratie in Athen einordnend Jochen Bleicken, Die athenische Demokratie, Paderborn, München, Wien, Zürich 4. Aufl. 1995, 112-114. Der Sklave, ein belebtes Besitztum, dem Werkzeug vergleichbar, würde allerdings in jenem Moment überflüssig, an dem das Werkzeug auf einen Befehl hin sein Werk selbst vollführt. Die Arbeitskraft des Sklaven somit verzichtbar werde. Aristoteles (Fn. 100), I,4, 1253b, 81. Zur Bedeutung der Diäten für die Demokratie: Jochen Bleicken, aaO., 329-337. Darauf hinweisend, dass es neben der Arbeit der Sklaven nicht minder, sogar noch mehr, die Arbeit der Frauen war, die den (männlichen) Bürgern politische Partizipation ermöglichte Angela Pabst, Die athenische Demokratie, München 2003, 94. Zu den ökonomischen Tätigkeiten der Frauen Sarah B. Pomeroy, Frauenleben im klassischen Altertum, Stuttgart 1985, 106-111.

104 Aristoteles (Fn. 100), III,1, 1275a, 154-157 und III,5, 1277b-1278a, 164-165.

105 So sei der Friseur im Gegensatz zum Perückenmacher kein Bürger, da er nur durch Veräußerung seiner Kräfte leben kann, während der Perückenmacher durch Veräußerung des von ihm gefertigten Produkts lebt. Immanuel Kant, Über den Gemeinspruch: Das mag in der Theorie richtig sein, taugt aber nicht für die Praxis, Werke (hg. von Wilhelm Weischedel), Bd. 11, Frankfurt a. M. 1968, A246-247, 151. 
IV. Demokratische Teilhabe und Weltanschauung als Problem und Lösungsansatz 



\title{
Partizipation durch Mobilisierung Gerichte als Teil demokratischer Deliberation
}

\author{
BERIT VÖLZMANN*
}

\section{Participation through Mobilization}

Courts as Part of Democratic Deliberation

\begin{abstract}
The article argues that court proceedings can be part of democratic processes. It is based on the deliberative democratic theory of Jürgen Habermas and applies it to the enforcement of law in court. The idea is to understand democracy not only as a legitimation of governance, but also as a mode of deliberative processes: on the discourse and the possibility of questioning norms. Access to justice can be a central means of promoting individual participation in social discourses.
\end{abstract}

Keywords: Deliberative theories of democracy, Habermas, mode of problematization, courts, subjective rights

Verantwortungsstrukturen werden - zumal im Mehrebenensystem - zunehmend fragmentiert und undurchsichtig. Bürger*innen fühlen sich ohnmächtig gegenüber Politik und Verwaltung. Es kommt die Sorge auf, mit Wahlen nichts (mehr) verändern zu können. Dieser (Krisen-)Zustand kann als Gelegenheit verstanden werden. Er kann als Anlass dienen, das (in der deutschen Staatsrechtslehre) bisher dominierende, zentral auf den Wahlakt und eine ununterbrochene Legitimationskette setzende Demokratieverständnis zu überdenken und ggf. zu erweitern. Dazu gehört insbesondere die Suche nach weiteren Partizipationsmöglichkeiten. Der Beitrag zeigt einen Weg verstärkter Teilhabemöglichkeit über den Zugang zu Gerichten auf.

* Für konstruktive Anmerkungen danke ich Rike Krämer-Hoppe, Anna Katharina Mangold und Ute Sacksofsky. 


\section{Der demokratische Prozess der Deliberation}

Die Beschäftigung mit „der Demokratie“ verlangt nach einer theoretischen Annäherung. Dieser Beitrag bedient sich der deliberativen Demokratietheorie. Jürgen Habermas, einer ihrer einflussreichsten Theoretiker, konzipiert ein weites Verständnis von Demokratie, die er als demokratischen Prozess verstanden wissen will. Wesentlicher Kern dieser Theorie ist, dass Demokratie auch den öffentlichen Austausch der Zivilgesellschaft umfasst und nicht auf demokratische Verfahren im engeren Sinne, wie Wahlen und Abstimmungen, beschränkt ist. Mehr noch: Die Politik gewinnt ihre legitimierende Kraft gerade aus der diskursiven Struktur einer öffentlichen Meinungsund Willensbildung. ${ }^{1}$ Habermas räumt der demokratischen Meinungs- und Willensbildung insofern eine zentrale Rolle ein, als sie die Ausübung politischer Macht „mehr oder weniger auch programmiert “ und nicht lediglich nachträglich kontrolliert. ${ }^{2}$ Die demokratische Willensbildung habe weder ausschließlich die Funktion, die Ausübung politischer Macht zu legitimieren (so die liberale Auffassung), noch die Funktion, die Gesellschaft als ein politisches Gemeinwesen zu konstituieren (so die republikanische Auffassung). Vielmehr fungierten Verfahren und Kommunikationsvoraussetzungen der demokratischen Meinungs- und Willensbildung „als wichtigste Schleuse einer an Recht und Gesetz gebundenen Regierung und Verwaltung“; wobei es Habermas hier ausdrücklich um mehr geht, als um bloße Legitimation. ${ }^{3}$ Grundlage institutionalisierter Demokratie ist nach Habermas öffentliche Deliberation. Darunter versteht er die Begegnung und Diskussion von Bürger*innen als Freien und Gleichen. Das deliberative Argumentationsverfahren gründet auf der von ihm entwickelten Theorie kommunikativen Handelns. ${ }^{4}$

Wie öffentliche Deliberation auf institutionalisierte politische Prozesse Einfluss nimmt, konzeptualisiert Habermas in seinem „Schleusenmodell“.5 Grundgedanke ist, dass die öffentliche Meinungsbildung in der Zivilgesellschaft nicht unverbunden neben dem staatlichen Bereich, also Parlamenten, Gerichten und Verwaltung, steht. Vielmehr sind beide Sphären stets miteinander verbunden und strukturell gekoppelt. Habermas unterteilt rechtsstaatlich verfasste politische Systeme in ein Zentrum und die Peripherie. Als Zentrum bezeichnet er den Kernbereich des politischen Systems. Dazu gehören die „institutionellen Komplexe [...] der Verwaltung (einschließlich der Regierung), des Gerichtswesens und der demokratischen Meinungs- und Willensbildung (mit parlamentarischen Körperschaften, politischen Wahlen, Parteien-

\footnotetext{
1 Jürgen Habermas, Faktizität und Geltung, 1994, 369.

2 Jürgen Habermas, Faktizität und Geltung, 1994, 364.

3 Jürgen Habermas, Faktizität und Geltung, 1994, 363 f.: Rationalisierung.

4 Jürgen Habermas, Theorie des kommunikativen Handelns, 1981; kondensiert zusammengefasst in Jürgen Habermas, Faktizität und Geltung, 1994, $15 \mathrm{ff}$.

5 Jürgen Habermas, Faktizität und Geltung, 1994, 429 ff.; er stützt sich dabei auf das von Bernhard Peters entwickelte Modell: Bernhard Peters, Die Integration moderner Gesellschaften, 1993, $344 \mathrm{ff}$.
} 
konkurrenz usw.).“' Zur Peripherie zählt er insbesondere die Zivilgesellschaft mit ihren Verbänden, Vereinigungen und Interessengruppen, aber auch Institutionen mit Selbstverwaltungsrechten (etwa Universitäten und Stiftungen). ${ }^{7}$ Beide Sphären sind insofern verbunden, als die von Bürger*innen getragene öffentliche Deliberation die institutionalisierte Politik erreicht über ,die Schleusen demokratischer und rechtsstaatlicher Verfahren am Eingang des parlamentarischen Komplexes oder der Gerich-

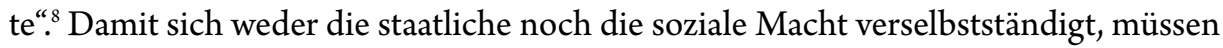
bindende Entscheidungen, um legitim zu sein, einerseits stets die Schleusen demokratischer und rechtsstaatlicher Verfahren einhalten, andererseits von Kommunikationsflüssen gesteuert sein, die von der Peripherie ausgehen. ${ }^{9}$

Habermas unterscheidet sodann zwei Operationsmodi: Routine und Problematisierung. Der größte Teil der Operationen im Kernbereich des politischen Systems laufe nach Routinen ab. Dazu zählt er das Fällen von Gerichtsurteilen, die Vorbereitung und Verabschiedung von Gesetzen, das Führen von Wahlkämpfen. Der Modus der Problematisierung, der den Routinemodus in Konfliktfällen überlagere, sei hingegen gekennzeichnet durch Krisenbewusstsein, erhöhte öffentliche Aufmerksamkeit und intensivierte Suche nach Lösungen. Als Anstoßgeberin für diesen Modus sieht Habermas insbesondere die Zivilgesellschaft. Die staatlichen Institutionen seien aufgrund des Zeitdrucks, unter denen sie ihre Entscheidungen im Routinemodus treffen müssen, einerseits wenig empfindlich für latente Probleme, die innerhalb der routinierten Prozesse nicht oder nur unzureichend erfasst werden, und andererseits auch kaum in der Lage, neu anfallende Probleme erfolgreich aufzuarbeiten. ${ }^{10}$ Es ist die Aufgabe der Peripherie, solche Probleme ,aufzuspüren, zu identifizieren, wirksam zu thematisieren und über die Schleusen des parlamentarischen Komplexes (oder der Gerichte) in das politische System so einzuführen, daß dessen Routinemodus gestört wird. “"1

Diese wesentliche Rolle der Zivilgesellschaft im demokratischen Prozess - dem Anstoßen des Problemverarbeitungsmodus, also der Initiative „Fälle zu Konfliktfällen zu machen ${ }^{{ }^{\prime 12}}$, - ist für die Überlegungen dieses Beitrags zentral. Wenn die öffentliche Deliberation in der Zivilgesellschaft essentieller Teil von Demokratie ist und wenn eine zentrale Aufgabe der Zivilgesellschaft das Einbringen neuer, bisher unzureichend erfasster Fälle in die Routinen des politischen Systems ist, dann ist zentral, wer an dieser öffentlichen Deliberation teilhat, wer seine Argumente und die Perspektiven aus

\footnotetext{
6 Jürgen Habermas, Faktizität und Geltung, 1994, 430.

7 Jürgen Habermas, Faktizität und Geltung, 1994, 430 f.

8 Jürgen Habermas, Faktizität und Geltung, 1994, 432.

9 Jürgen Habermas, Faktizität und Geltung, 1994, 432.

10 Jürgen Habermas, Faktizität und Geltung, 1994, $432 \mathrm{f}$.

11 Jürgen Habermas, Faktizität und Geltung, 1994, 434.

12 Jürgen Habermas, Faktizität und Geltung, 1994, 433.
} 
seiner Lebensrealität in den Diskurs einbringen kann. ${ }^{13}$ Dies gilt insbesondere auch für den Zugang zu bestimmten Diskursorten, auch innerhalb des Zentrums des politischen Systems. Gemeint ist hier der Zugang zu Gericht. Darauf wird noch zurückzukommen sein.

In der aktuellen theoretischen Diskussion wird die deliberative Demokratietheorie besonders häufig fruchtbar gemacht, dies gilt insbesondere für den - auch - theoretisch argumentierenden deutschen Rechtsdiskurs. ${ }^{14}$ Die deliberative Demokratietheorie scheint jedoch, bei aller Offenheit und Weite, eine bestimmte Engführung - oder zumindest eine (zu) starke Fokussierung - zu enthalten: Auf die Legitimation von Entscheidungen - konkret: der parlamentarischen Repräsentant*innen. ${ }^{*}$ Die Legitimation parlamentarischer Entscheidungen ist zwar ein nötiger Teil aller demokratischen Prozesse, aber möglicherweise nicht die einzige demokratische Beteiligungsmöglichkeit für Bürger*innen. Carole Pateman, eine Vertreterin der sogenannten partizipativen Demokratietheorie, fordert, dass Bürger*innen nicht nur wie Konsument*innen behandelt werden, sondern im Gegenteil das Recht haben sollen „to participate in decision-making about their collective life and to live within authority structures that make such participation possible. However, this alternative view of democracy is now being overshadowed" (durch die deliberative Demokratietheorie). ${ }^{16}$ Sie stellt gar die Frage, ob ,in the rich countries, there is any longer either the political culture or the political will to pursue genuine democratization. ${ }^{17}$ Unabhängig davon, wie eine solche Partizipation, eine über Deliberation ${ }^{18}$ hinausgehende Beteiligung an Entscheidungen konkret aussieht, ist hier die Änderung des Blickwinkels zentral: Demokratietheoretisch entscheidend ist nicht nur die Legitimation eines Ergebnisses, sondern auch die tatsächliche Teilhabe von Bürger*innen, der Weg zu einem solchen Ergebnis und die möglichst starke Beteiligung. Habermas deliberative Demokratietheorie ist, so

13 Grundlegend: Iris Marion Young, Justice and the Politics of Difference, 1990; kritisch in Bezug auf die Repräsentation benachteiligter Gruppeninteressen in der deliberativen Demokratietheorie nach Habermas: Markus Linden, Die politische Repräsentation schwacher Interessen bei Jürgen Habermas, in: Deliberative Demokratie in der Diskussion, hg. von Claudia Landwehr / Rainer Schmalz-Bruns, 2014, 339-367; zu Einbeziehungsansätzen und Unzulänglichkeiten deliberativer Demokratietheorien bezüglich benachteiligter Gruppen: Monique Deveaux, Deliberative Democracy and Multiculturalism, in: The Oxford Handbook of Deliberative Democracy, hg. von André Bächtiger / John Dryzek/Jane Mansbridge / Mark Warren, 2018, $156-170$.

14 Zuletzt etwa Anna Katharina Mangold, Demokratische Inklusion durch Recht, 2019; Christoph Möllers, Die drei Gewalten, 2008.

15 So auch Carole Pateman, Participatory Democracy Revisited, Perspectives on Politics 1/2012, 7, Fn. 11.

16 Carole Pateman, Participatory Democracy Revisited, Perspectives on Politics 1/2012, 7, 15.

17 Carole Pateman, Participatory Democracy Revisited, Perspectives on Politics 1/2012, 7, 15.

18 Vgl. aber auch zur seit den zoooer Jahren systematisch betriebenen empirischen Deliberationsforschung, die insbesondere auch nach Mechanismen sucht, wie Deliberation in der Realität verwirklicht werden kann: André Bächtiger, Empirische Deliberationsforschung, in: Zeitgenössische Demokratietheorie, hg. von Oliver Lembcke / Claudia Ritzi / Gary S. Schaal, 2016, $251 \mathrm{ff}$. 
meine ich, offen für eine solche Weiterentwicklung. Dies gilt insbesondere angesichts des von ihm beschriebenen Problematisierungsmodus.

\section{Zugang zu Gericht als Teil deliberativer Demokratie}

Nach herkömmlichem Verständnis gilt das Verhältnis zwischen Rechtsprechung und Demokratie als eine „- wenn auch durch Tradition und Gewohnheit gut versorgte Wunde der Staatstheorie“. ${ }^{19}$ Andere sprechen von „Ungereimtheiten mit langer historischer Tradition“ hinsichtlich der demokratischen Legitimation von Richter*innen. ${ }^{20}$ Wird das Verhältnis von Justiz und Demokratie beleuchtet, dann liegt der Fokus häufig auf der Rechtfertigung hoheitlichen Handelns. Ausdifferenziert werden die Legitimation der Rechtsprechung ${ }^{21}$ und die Legitimation des Rechts ${ }^{22}$. Insbesondere mit Blick auf die sich aus dem Grundgesetz ergebende Befugnis der Richter*innen zur Rechtsfortbildung ${ }^{23}$ wird die ausreichende demokratische Legitimation in Frage gestellt und nach zusätzlichen Legitimationsformen gesucht. Dazu gehört etwa auch eine stärkere Anbindung an die Gesellschaft: Partizipation als weicher Legitimationsfaktor. ${ }^{24}$ Andere fordern Legitimationsverschiebungen vom Volk als Ganzem auf einen im Einzelfall näher abzugrenzenden Kreis von Betroffenen ${ }^{25}$ oder erkennen die Willensbetätigung individueller Subjekte als legitimationsstiftend an. ${ }^{26}$

Hier soll nicht allein auf die Legitimation bestimmter Entscheidungen abgestellt werden, sondern vor allem auf den Weg zur Legitimation - den Modus der Deliberation, insbesondere mit Blick auf die Teilhabe der Bürger*innen in deliberativen Prozessen. Habermas möchte mit seinem prozeduralen Rechtsparadigma den Blick des

19 Gerd Roellecke, Zur Demokratischen Legitimation der rechtsprechenden Gewalt, in: Freiheit und Eigentum. Festschrift Walter Leisner, hg. von Josef Isensee, 1999, 553, 554.

20 Rolf Stürner, Europäische Justiz und Demokratie, in: Der Wandel des Staates vor den Herausforderungen der Gegenwart. FS Winfried Brohm, hg. von Carl-Eugen Eberle / Martin Ibler / Dieter Lorenz, 2002, 153: „Gerade im Bereich der Justiz und der demokratischen Legitimation ihrer Richter ergeben sich bereits im deutschen Recht Ungereimtheiten mit langer historischer Tradition [...] Offenbar fehlt den Demokratien der Europäischen Union ein strenges Grundverständnis demokratischer Legitimation ihrer Richter."

21 Beispielhaft: Andreas Voßkuhle/Gernot Sydow, Die demokratische Legitimation des Richters, JZ 2002, 673, 676 ff.: Die Rechtsprechung durch Richter*innen ist demokratisch legitimiert: funktionell-institutionell, personell-organisatorisch und sachlich-inhaltlich.

22 Tobias Lieber, Diskursive Vernunft und formelle Gleichheit, 2007; auch Habermas geht es um die Legitimität positiver Rechtsnormen: Jürgen Habermas, Faktizität und Geltung, 1994, 141.

23 Art. 20 Abs. 2 GG: „Gesetz und Recht“; ausführlich zur Zulässigkeit schöpferischer Gesetzgebung: BVerfGE 34, 269, 286 f. - Soraya.

24 Andreas Voßkuhle / Gernot Sydow, Die demokratische Legitimation des Richters, JZ 2002, 673 ff., 680, kritisch zur sachlich-inhaltlichen Legitimation: S. 678 f., zusätzliche Abstützungen der demokratischen Legitimation des Richters fordernd: S. 680 ff. („weiche Legitimationsfaktoren“).

25 Eberhard Schmidt-Aßmann, Verwaltungslegitimation als Rechtsbegriff, AöR 116 (1991), 329, 374

26 Christoph Möllers, Die drei Gewalten, 2008, 13, $79 \mathrm{f}$. 
Gesetzgebers auf die „Bedingungen der Mobilisierung des Rechts“ lenken. ${ }^{27}$ Auf ein Zitat Dieter Grimms zurückgreifend fordert er, Vorkehrungen zu treffen, die „die Einzelnen auch instandsetzen, Interessen auszubilden, gemeinschaftlich wahrzunehmen und im staatlichen Entscheidungsprozeß zur Geltung zu bringen “28 ${ }^{29}$ Überlegungen zu solchen Ausgestaltungen der Mobilisierung von Recht lassen sich in die drei folgenden Gedankengänge aufteilen: die Durchsetzung von Recht als Teil demokratischer Teilhabe (1.), die Möglichkeit, an Auslegung und Weiterentwicklung von Recht innerhalb von Gerichtsprozessen teilzuhaben (2.), sowie das Anstoßen gerichtlicher Entscheidungen als Impulsfunktion für den deliberativen Prozess der Zivilgesellschaft. Auf den ersten beiden soll hier der Fokus liegen.

\section{Mobilisierung von Bürger*innen zur Durchsetzung des Rechts}

Nach Habermas fordert die „Idee der Selbstgesetzgebung von Bürgern [...], daß sich diejenigen, die als Adressaten dem Recht unterworfen sind, zugleich als Autoren des Rechts verstehen können.“30 Nun beinhaltet Autorenschaft auch eine gewisse Verantwortung für einen Text; im Falle von Gesetzen heißt dies: Verantwortung für die Durchsetzung und Weiterentwicklung des jeweiligen Rechts. Diese Verantwortung trifft in einer repräsentativen Demokratie wie der Bundesrepublik das Parlament als Vertretung des gesamten Volkes. Das Parlament als solches ist jedoch - weder tatsächlich noch rechtlich - in der Lage, diese Verantwortung im Einzelfall zu übernehmen. Es kann jedoch Einzelne oder Kollektive für die Durchsetzung des Rechts mobilisieren. ${ }^{31}$

Dabei geht es nicht um einen allgemeinen Gesetzesvollziehungsanspruch (der sich auch aus Art. 20 Abs. 3 GG nicht ergibt). Es geht vielmehr darum, dass das Parlament im Rahmen der Gesetzgebung mögliche Hindernisse bei der Durchsetzung von Recht mitbedenkt und - gegebenenfalls - entsprechende subjektive Rechte gewährt. ${ }^{32}$ Dies zum einen, um die tatsächliche Durchsetzung der Gesetze zu gewährleisten. Zum anderen, um demokratische Teilhabe zu gewähren: Gesetze, bei denen

27 Jürgen Habermas, Faktizität und Geltung, 1994, 531 f. (Hervorhebung im Original).

28 Dieter Grimm, Interessenwahrung und Rechtsdurchsetzung in der Gesellschaft von morgen, in: ders., Die Zukunft der Verfassung, 1991, 178.

29 Jürgen Habermas, Faktizität und Geltung, 1994, $531 \mathrm{f}$.

30 Jürgen Habermas, Faktizität und Geltung, 1994, 153.

31 Entwicklung dieses Konzepts: Johannes Masing, Die Mobilisierung des Bürgers für die Durchsetzung von Recht, 1996.

32 Für eine allgemein stärkere Beteiligung an der Durchsetzung von Recht: Helge-Marten Voigts, Die Subjektivierung von Gemeinwohlinteressen als Demokratisierung der Verwaltung, 2016, 253: Der „Einfluss der Herrschaftsunterworfenen bei der Entstehung legislativer Programmierungsakte" werde zunehmend geringer, daher „sollen die Herrschaftsunterworfenen in die Lage versetzt werden, die Umsetzung dieser Programmierungsakte verstärkt kontrollieren [zu] können." 
sich die Durchsetzung als schwierig herausstellt, sind typischerweise solche, die nicht (nur) individuelle Rechte Einzelner betreffen, sondern einen Bezug zum Gemeinwohl aufweisen oder zu Problemen, die eine größere Anzahl von Menschen betreffen oder gar strukturell sind. In die erste Kategorie fiel etwa lange das Umweltrecht. Dessen Durchsetzung lag mangels klassischer subjektiver Rechte allein in der Hand der Behörden. Mit der Geltendmachung von Rechtsverletzungen, die der zweiten Kategorie zuzurechnen sind, können einzelne Individuen aus persönlichen Gründen überfordert sein (etwa mit der Geltendmachung von Rechten nach dem Behindertengleichstellungsgesetz); in anderen Fällen fehlt es aufgrund geringer finanzieller Schäden an Klageanreizen.

Im ersten Fall, dem (weitgehenden) Fehlen subjektiver Rechte im Umweltschutz, ist bereits eine Veränderung eingetreten. Insbesondere auch durch Impulse aus dem Europarecht hat sich die Erkenntnis durchgesetzt, dass Gemeinwohlkonkretisierungen nicht allein den Behörden überlassen sein sollten. ${ }^{33} \mathrm{Zu}$ wenig im Fokus steht noch die Durchsetzung von Gesetzen, die auf die Bekämpfung struktureller oder eine größere Anzahl von Menschen betreffender Probleme zielen. Ein Mittel zur Bewältigung derartiger kollektiver Probleme sind Verbandsklagebefugnisse. Wo es um die Überbrückung mangelnder privater Klageinteressen aufgrund zu geringer finanzieller Schäden geht, sind diese schon länger verankert: Das Gesetz gegen den unlauteren Wettbewerb erlaubt etwa Verbraucherschutz- und Unternehmerverbänden das Vorgehen gegen unlautere wirtschaftliche Handlungen. Aus ähnlichen Gründen wurde zur Verbesserung des Verbraucherschutzes jüngst die zivilprozessuale Musterfeststellungsklage eingeführt. In anderen Bereichen steigt das Bewusstsein für die Notwendigkeit von Verbandsklagebefugnissen nur langsam. Das Behindertengleichstellungsgesetz enthält Verbandsklagebefugnisse, das Allgemeine Gleichbehandlungsgesetz nicht.

\section{Gerichtsprozesse als besondere deliberative Räume}

Die Überlegung, Menschen stärker die Möglichkeit zu geben, an Auslegung und Weiterentwicklung von Recht innerhalb von Gerichtsprozessen teilzuhaben, knüpft unmittelbar an den Kern der deliberativen Demokratietheorie nach Habermas an: Basis

33 Julian Krüper, Gemeinwohl im Prozess, 2009, 175 ff.; Hans-Heinrich Trute, Die demokratische Legitimation der Verwaltung, in: Grundlagen des Verwaltungsrechts, Bd. 1, hg. von Wolfgang Hoffmann-Riem / Eberhard Schmidt-Aßmann / Andreas Voßkuhle, 2. Auflage, 2012, \$ 6 Rn. 32, S. 341, 365; Eberhard Schmidt-Aßmann, in: Maunz/Dürig, Grundgesetz Kommentar, hg. von Roman Herzog / Matthias Herdegen / Rupert Scholz / Hans Klein, 85. EL November 2018, GG Art. 19 Abs. 4 Rn. 117 b: „Verwaltungsprozesse sind (auch) Foren der Gemeinwohlkonkretisierung.", restriktiver: Klaus Ferdinand Gärditz, Verwaltungsgerichtlicher Rechtsschutz im Umweltrecht, $N V w Z$ 2014, 1, 4, 6, der die Notwendigkeit einer weiteren Fassung subjektiver Rechte im Umweltrecht allerdings anerkennt. 
der deliberativen Demokratietheorie ist die Vorstellung rationaler Kommunikation, die auf der sprachlichen Vermittlung intersubjektiv nachvollziehbarer Gründe für Aussagen ruht und implizit verweist auf die ideale Sprechsituation, bei der alle potentiell Betroffenen relevante Argumente vorbringen können. Wenn aber die öffentliche Deliberation in der Zivilgesellschaft essentieller Teil von Demokratie ist, dann ist zentral, wer an dieser öffentlichen Deliberation teilhat, wer seine Argumente und die Perspektiven seiner Lebensrealität in den Diskurs einbringen kann. Insbesondere muss es Möglichkeiten geben, die Stimmen jener zu mobilisieren, denen es nicht gelingt, im Diskurs gehört zu werden oder die gar nicht erst Teil des Diskurses sind.

Gerichte gehören, auch nach Habermas, zwar zum Kern des politisch-rechtlichen Systems. ${ }^{34}$ Dass Gerichtsprozesse selbst Orte des deliberativen Diskurses sind, ist aber begründungsbedürftig. Gerichtsprozesse zielen - zumindest in der Regel - nicht auf eine gemeinsame Entscheidung, sondern auf die Entscheidung eines Schiedsrichters. Auch ist der Austausch der Argumente nicht völlig frei, sondern geordnet und zum Teil auch beschränkt durch das jeweilige Prozessrecht. Habermas fordert zumindest für den Fall, dass Gerichte über die reine Gesetzanwendung hinausgehen und auch schöpferisch tätig werden, dass „die juristischen Anwendungsdiskurse auf eine erkennbare Weise um Elemente von Begründungsdiskursen ergänzt werden." 35 Dafür müsse eine Rechtsöffentlichkeit institutionalisiert werden, ein justizkritisches Forum, das über die bestehende Expertenkultur hinausreicht. ${ }^{36}$ Ob Gerichtsprozesse selbst auch Orte deliberativer Prozesse - oder zumindest Teil dieser Prozesse - sein können, dazu äußert er sich nicht. Für eine solche Ausdehnung seiner Theorie sprechen jedoch gerade besondere Eigenschaften von Gerichtsprozessen (a) sowie der über sie mögliche Weg in den sogenannten Problematisierungsmodus (b).

\section{a) Die Chance auf egalitäre Begegnung im Gerichtsverfahren}

Das Ideal der deliberativen Demokratietheorie, wonach alle potentiell Betroffenen ihre Argumente vorbringen können, ist insbesondere mit Blick auf gesellschaftliche Ungleichheiten (im weitesten) Sinne kritisch zu hinterfragen. Wer kann tatsächlich sprechen und worüber? Wer wird gehört?

Feministische und psychologische Kritik an deliberativer Theorie bemängelt, dass Deliberation weniger privilegierte Gruppen benachteilige (wie etwa Frauen oder Menschen mit niedrigerer Bildung). Menschen weniger privilegierter Gruppen hätten zum Teil eine andere Sprechkultur, auch verfügten nicht alle gleichermaßen über

34 Jürgen Habermas, Faktizität und Geltung, 1994, 430 ff.

35 Jürgen Habermas, Faktizität und Geltung, 1994, 530.

36 Jürgen Habermas, Faktizität und Geltung, 1994, 530. 
die Fertigkeiten für eine erfolgreiche Teilnahme an rationalen Diskursen. ${ }^{37}$ Von besonderer Bedeutung werden damit (neben dem Kampf gegen soziale Ungleichheiten) zumindest vorübergehend auch Diskurse, die nicht zwingend selbst durch Benachteiligte geführt, aber von ihnen angestoßen werden können. Ein möglicher Ort für die Austragung solcher Diskurse ist das Gerichtsverfahren. Das Gerichtsverfahren eignet sich deshalb besonders gut, weil der Streit hier nicht durch die Benachteiligten selbst ausgetragen werden muss, ${ }^{38}$ sondern - jedenfalls soweit die Verfahrensbeteiligten prozessual vertreten sind - zwischen Personen erfolgt, die zum einen ähnlich diskussionsfähig sind und deren Aufgabe es zum anderen gerade ist, für die Interessen ihrer Mandantschaft zu streiten. Der Zugang zu Gericht kann insofern Deliberation ermöglichen.

Die Ermöglichung und Vereinfachung des Zugangs zu Gericht ermöglicht aber nicht nur grundsätzlich Austausch und Beteiligung im Sinne der deliberativen Demokratietheorie, sondern auch eine egalitäre Begegnung, die eher als im offenen zivilgesellschaftlichen Austausch tatsächlich die Chance hat, auf Augenhöhe stattzufinden. ${ }^{39}$ Dies wird ermöglicht durch die Leitung des Diskurses - durch Richter*innen - in einem besonders regulierten Diskursraum - durch das Prozessrecht -, in dem die Unterstützung durch für diesen Diskursraum besonders geschulte Menschen - Anwält*innen - üblich, zum Teil sogar zwingend ist. Die so verstandene Deliberation lässt sich durch zwei Faktoren steigern: Zum einen durch eine Erhöhung der Zahl subjektiver Rechte, auf die Menschen sich für den Zugang zu Gericht berufen können, und zum anderen durch die Erhöhung von Verbandsklagebefugnissen. Letzteres dient nicht nur der Einbeziehung auch struktureller Probleme, sondern ermöglicht auch die Einbeziehung der Stimmen jener, die sich einem Individualprozess nicht gewachsen sehen oder nicht in der Lage sind, einen solchen zu führen.

37 André Bächtiger, Empirische Deliberationsforschung, in: Zeitgenössische Demokratietheorie, hg. von Oliver Lembcke / Claudia Ritzi / Gary S. Schaal, 2016, 251; mit Blick auf die Interessen benachteiligter Teile der Bevölkerung die Aufgabe des Wahrheits- und Vernunftanspruchs in den deliberativen Theorien fordernd: Markus Linden, Die politische Repräsentation schwacher Interessen bei Jürgen Habermas, in: Deliberative Demokratie in der Diskussion, hg. von Claudia Landwehr / Rainer Schmalz-Bruns, 2014, 339-367, 363 .

38 Die Situation des Sprechens für Andere birgt freilich wiederum die Gefahr von Paternalismus und Benachteiligung, siehe dazu aus den Postcolonial Studies etwa Gayatri Chakravorty Spivak, Can the Subaltern Speak? Postkolonialität und subaltern Artikulation, 2008 (insb. 28 ff.); Encarnación Gutiérrez Rodriguez, Repräsentation, Subalternität und postkoloniale Kritik, in: Spricht die Subalterne deutsch? Migration und postkoloniale Kritik, hg. von Hito Steyerl / Encarnación Gutiérrez Rodriguez, 2. Auflage, 2012, 17, 25 ff.; María do Mar Castro Varela / Nikita Dhawan, Postkoloniale Theorie. Eine kritische Einführung, 2. Auflage, 2015, 193-198; Ina Kerner, Postkoloniale Theorien zur Einführung, 3. Auflage, 2017, $103 \mathrm{ff}$.

39 Der Charakter der Begegnung ist freilich auch in diesem Rahmen nicht völlig unabhängig von den beteiligten Personen. 
b) Gerichtsprozesse als Ermöglichung des Problematisierungsmodus (nach Habermas)

Gerichte ermöglichen zudem einen Weg in den sogenannten Problematisierungsmodus nach Habermas. Das moderne Recht operiert mit Normalitätsunterstellungen, die in die Ausgestaltung der Rechte einfließen. Die überkommene, unhinterfragte Autorität des Gesetzes erwächst daraus, dass dieses durch das Parlament als Vertretung „des Volkes“ diskutiert und beschlossen wurde. Die erste Adresse einer Überarbeitung von Normen ist daher - zumindest nach bisher herrschendem Verständnis - das Parlament (für „das Volk“). Als Organ, welches das in Rede stehende Gesetz selbst in die Welt gebracht hat, mag es zwar auch eine besondere Verantwortung für jenes Gesetz haben. Verlangt man zugunsten der steten Verbesserung und Weiterentwicklung von Rechtsnormen aber gerade, dass bisherige Normalitätsunterstellungen und damit auch bestimmte etablierte Rechtspraxen in Frage gestellt werden, ${ }^{40}$ dann ist fraglich, ob das Parlament der richtige, jedenfalls aber ob es der einzige Ort ist, an dem sich dieser Vorgang vollziehen kann.

Dagegen sprechen Struktur und Arbeitsweise des Parlaments. Ehe Normalitätsvorstellungen im Parlament diskutiert und hinterfragt werden, geschweige denn ihnen gesetzgeberisch begegnet wird, müssen die Infragestellungen bereits im Bewusstsein der Mehrheitsgesellschaft angekommen sein. Angehörige von Minderheiten, deren Lebensrealitäten sich an den vorausgesetzten Normalitätsunterstellungen reiben, für deren Interessen sich aber keine oder zu wenige Parlamentarier*innen interessieren, haben, eben aufgrund ihrer Zugehörigkeit zu einer Minderheit, kaum die Möglichkeit, ihrer Perspektive im Rahmen des parlamentarischen Gesetzgebungsprozesses Geltung zu verschaffen. Auf eine (originär) parlamentarische Lösung derartiger struktureller Probleme, auf eine Gewähr der Freiheit und Gleichheit aller durch die parlamentarische Gesetzgebung ist daher kein Verlass. Zum gleichen Ergebnis mit etwas anderer Begründung kommt Habermas, wenn er ausführt, dass „dem Parlamentarischen Komplex meistens die Kraft fehlt, von sich aus ,Fälle zu Konfliktfällen` zu machen.“41 Als Grund dafür führt Habermas den Zeitdruck an, unter denen die Institutionen stehen. Daher seien „sowohl die Empfindlichkeit für latente Probleme, die von eingespielten Routinen nicht oder nur unzureichend erfaßt werden, wie auch die Initiative zur erfolgreichen dramatischen Aufarbeitung neu anfallender Probleme [...] schwach ausgeprägt.“" ${ }^{42}$ Die Anrufung von und Argumentation vor Gerichten kann die Ein-

40 So etwa auch Francesca Raimondi, Die Zeit der Demokratie, 2014, 147 f.: um das Recht im Rahmen eines dynamischen Prozesses zu öffnen.

41 Jürgen Habermas, Faktizität und Geltung, 1994, 433.

42 Jürgen Habermas, Faktizität und Geltung, 1994, 433; ähnlich sinniert Rolf Stürner, Europäische Justiz und Demokratie, in: Der Wandel des Staates vor den Herausforderungen der Gegenwart. FS Winfried Brohm, hg. von Carl-Eugen Eberle / Martin Ibler / Dieter Lorenz, 2002, 153, 162: „Vieles spricht dafür, daß zentrale Rechtssetzung in Kodifikationen und volks- und parlamentsfernes Karriererichtertum Ausflüsse 
bringung dieser - subalternen - Perspektiven ermöglichen und damit die etablierte Rechtspraxis öffnen und verändern. Beispielhaft dafür sind insbesondere die Verfahren des Bundesverfassungsgerichts zum Recht auf Geschlechtsidentität: Mit Klagen gegen Normen des Transsexuellengesetzes (TSG) und des Personenstandsgesetzes $(\mathrm{PStG})^{43}$ konfrontierten Betroffene, deren Stimmen bisher im zivilgesellschaftlichen Diskurs untergingen und in parlamentarischen Debatten kaum eine Rolle spielten, das geltende Recht und die Rechtspraxis mit ihrer - von den Normalitätsunterstellungen abweichenden - Lebensrealität und sorgten dafür, dass Normen überprüft wurden. Sie haben damit genau jenen Problematisierungsmodus angeworfen, dessen Ermöglichung nach Habermas essentieller Teil deliberativer Demokratie sein muss. Dass es für den Anstoß eines neuen Diskurses auf das (positive) Ergebnis dieser Verfahren nicht unbedingt ankommt, zeigen die Entwicklungen nach den Entscheidungen zur Strafbarkeit von Werbung für Schwangerschaftsabbrüche.

\section{Funktion subjektiver Rechte: Ermöglichung}

Rechtsnormen, insbesondere subjektive Rechte, fungieren insoweit als Mittel und Werkzeuge für Deliberation. Ihre Funktion ist dabei zweigeteilt: Sie wirken sowohl beschränkend als auch ermöglichend. Ihre Beschränkungsfunktion liegt darin, dass sie den Zugang zu Gericht auf bestimmte Fälle - bestimmte Inhalte, bestimmte Klageberechtigte - beschränken, über die zuvor das Parlament entscheidet. Für alle anderen Fälle (Personen und Inhalte) besteht gerade kein Zugang zu Gericht. Aus Art. 20 Abs. 3 GG ergibt sich eben kein allgemeiner Gesetzesvollziehungsanspruch.

Darin erschöpft sich jedoch nicht die Funktion subjektiver Rechte: Ihre zweite zentrale Funktion ist die der Ermöglichung: Die Ermöglichungsfunktion subjektiver Rechte liegt darin, dass sie Individuen oder Kollektiven ${ }^{44}$ eine Gestaltungsmacht einräumen, die diese selbst ergreifen und ausfüllen müssen. Innerhalb dieser Gestaltungsräume werden Individuen und Kollektive ermächtigt, auf die Bestimmung und Sicherung von Freiheit und Gleichheit einzuwirken. So verstanden verwirklicht sich im Zugang zu Gerichten nicht nur das Rechtsstaatsprinzip aus Art. 19 Abs. 4 GG - bzw. der allgemeine Justizgewährungsanspruch (Art. 2 Abs. 2 GG iVm dem Rechtsstaats-

\footnotetext{
einer politischen Kultur sind, die bürgerliche Mitverantwortung zu wenig pflegt und das Gefühl für die Notwendigkeit ihrer laufenden Wahrnehmung verkümmern läßt. Nur Systeme mit ausreichendem dauerndem Störpotential bleiben stabil; wo Recht und Richter nicht in dauernder Auseinandersetzung mit dem Bürger überzeugen müssen, droht die satte Zufriedenheit eines abgehobenen, sich selbst genügenden Systems, das dem ersten schweren Stoß zum Opfer fällt." (Hervorhebung im Original).

43 BVerfGE 147, 1 - Dritte Option.

$44 \mathrm{Ob}$ im Rahmen kollektiver Rechtsdurchsetzung, etwa Verbandsklagen, subjektive Rechte wahrgenommen werden, hängt ab von der konkreten Ausgestaltung der geltend gemachten Rechte und vom Verständnis des „subjektiven Rechts“.
} 
prinzip) -, nämlich die Durchsetzung bestehender Rechte. Vielmehr wird im gerichtlichen Verfahren eine Prozeduralisierung des Rechts selbst in Gang gesetzt, an der die Verfahrensbeteiligten effektiv teilhaben: „Die Anwendung auf den Fall ist ein zentraler Ort, an dem das Recht in Kontakt mit seinem Außen und dessen Ansprüchen tritt".45 Dabei lässt sich die Ermöglichung nicht von der Beschränkung trennen: Die Beschränkung liegt gerade darin, dass subjektive Rechte nicht verliehen werden. Insofern ergeben sich aus der Gewähr subjektiver Rechte, aus der die Ermöglichung folgt, gerade auch die beschränkenden Wirkungen.

Mit einem solchen - auch die Ermöglichungsfunktion einbeziehenden - Verständnis subjektiver Rechte mag weiter an der strikten, klaren Trennung zwischen Rechtserzeugung und Rechtsanwendung gerüttelt werden, ${ }^{46}$ die dem klassischen Verständnis des Demokratie- und Rechtsstaatsprinzips zugrunde liegt. Unabhängig davon, ob eine solche Trennung überhaupt (noch) zielführend oder möglich ist: Ein Fokus auf die Ermöglichungsfunktion subjektiver Rechte zeigt, dass diese (auch) demokratische Prozesse anstoßen und fördern können.

\section{Fazit}

Gerichtsverfahren können Teil demokratischer Prozesse sein. Grundlage dafür ist ein deliberatives Demokratieverständnis. Zentral ist, Demokratie nicht allein als Legitimation von Herrschaft zu verstehen, sondern den Fokus auch auf den Modus deliberativer Prozesse zu legen: auf den Diskurs und die Möglichkeit der Infragestellung herrschender Normen. Dafür muss gerade auch die individuelle Beteiligungsmöglichkeit an gesellschaftlichen Diskursen gefördert werden. Der Zugang zu Gericht ist dafür ein zentrales Mittel. Diese theoretischen Überlegungen bieten erhebliches Potential: Das Verständnis von Gerichtsverfahren als (auch) Teil demokratischer Prozesse verlangt nach einer kritischen Überprüfung des Systems des subjektiven Rechtsschutzes in Deutschland - und ggf. seiner Rekonstruktion. Mit der hier vorgenommenen theoretischen Argumentation kann die Figur des subjektiven (öffentlichen) Rechts aus dem rein rechtsstaatlichen Kontext gelöst werden. Eine solches Überdenken des subjektiven Rechtsschutzes dürfte Auswirkungen haben auf die Fragen danach, wer wofür klagen darf und inwieweit Menschen in die Realisierung von Recht eingebunden werden können oder sollten.

45 Francesca Raimondi, Die Zeit der Demokratie, 2014, 147.

46 Infragestellung dieser Trennung bei Francesca Raimondi, Die Zeit der Demokratie, 2014, 147. 


\title{
Die direkte Demokratie zwischen Populismus und Rechtsstaat \\ Demokratietheoretische Wege aus \\ der "Populismuskrise"
}

\section{NULA FREI}

Direct Democracy between Populism and the Rule of Law

Democratic theory and populist constitutionalism

\begin{abstract}
Recent referendums in Europe (such as the Brexit referendum or the Swiss referendum on a minaret ban) seem to suggest that the institutions of direct democracy have been captured by (right-wing) populists. The threat to the rule of law associated to these developments should not be under-estimated. From a public law perspective, there are several ways in which a (direct) democratic system can deal with this threat. While one approach tries to shield the constitutional system from the populist backlash by largely foregoing popular participation and/or by giving more constitutional power to experts (such as judges or supranational technocrats), another approach tries to identify and tackle the root causes of populism and therefore advocates for a both quantitative and qualitative extension of popular participation. The paper discusses these approaches and argues for the second, which not only better addresses the underlying causes of populism, but also has the potential to strengthen direct democracy as a form of government and to free it from the „clutches" of populist instrumentalization. This second approach allows for an extended understanding of direct democracy, which also includes deliberative elements.
\end{abstract}

Keywords: populism, direct democracy, rule of law, participation, deliberation, popular constitutionalism 


\section{Einleitung}

Am 29. November 2009 hat das Schweizer Stimmvolk mit 57,5\% dafür gestimmt, dass in der Schweiz keine Minarette mehr gebaut werden dürfen. Die Wahlplakate der Befürworter zeigten eine Frau mit schwarzem Niqab vor einem liegenden Schweizer Kreuz, auf dem sich zahlreiche schwarze Minarette wie Raketen aufrichteten. Ein Jahr später stimmten 52,3\% dafür, dass ausländische Staatsangehörige, die eine Straftat begangen haben, ihr Anwesenheitsrecht in der Schweiz automatisch verlieren. Das berüchtigte „Schäfchenplakat“ der Befürworter stellte dar, wie ein schwarzes Schaf von seinen weißen Artgenossen von dem als Schweizerfahne dargestellten Weidegrund getreten wird. Diese und andere Entwicklungen in der Schweiz, aber auch in anderen Staaten (man erinnere sich an das Brexit-Referendum) haben bei (Rechts-)Populisten in ganz Europa für Faszination ${ }^{1}$ gesorgt, bei anderen hingegen eher Sorge um die Vereinbarkeit von direkter Demokratie und Rechtstaat hervorgerufen.

Angesichts dieser Entwicklungen könnte man den Eindruck erhalten, die direkte Demokratie sei vom Rechtspopulismus vereinnahmt worden. In der Tat enthalten die Instrumente der direkten Demokratie Elemente, die dem populistischen Verständnis von „Volkssouveränität“ in die Hände spielen. Die mit solchen Entwicklungen einhergehende Gefährdung rechtsstaatlicher Errungenschaften ist nicht kleinzureden. Populismus wurde bisher hauptsächlich als ein Phänomen diskutiert, das sich gegen eine zu wenig responsive repräsentative Demokratie richtet. ${ }^{2}$ Ähnlich, aber doch anders, ist die populistische Vereinnahmung der direkten Demokratie.

Aus normativer Sicht (und nur diese soll hier behandelt werden ${ }^{3}$ ) gibt es mehrere Möglichkeiten, wie Demokratien, und insbesondere die direkte Demokratie, mit diesem rechtsstaatsgefährdenden Potential populistischer Politik umgehen können. Der vorliegende Beitrag identifiziert zwei Hauptströme, welche auf unterschiedlichen demokratietheoretischen Verständnissen basieren: Einerseits einen epistokratischen Ansatz, welcher das Verfassungssystem vor dem populistischen „Backlash“ zu immunisieren versucht, indem auf Volksbeteiligung eher verzichtet wird und Gerichte, internationale Foren, Sachverständige als Gegengewichte institutionalisiert werden.

1 So fordert etwa die AfD „Volksabstimmungen nach Schweizer Vorbild“: Grundsatzprogramm der AfD, Punkt 1.1.: https://www.afd.de/grundsatzprogramm/, Stand: 12. August 2018.

2 Jan-Werner Müller, Populismus. Symptom einer Krise der politischen Repräsentation?, APuZ 4042/2016, S. 24 ff.; Markus Möstl, Elemente direkter Demokratie als Entwicklungsperspektive, in: Repräsentative Demokratie in der Krise?, hg. von Christian Walter et al., 2013, S. 374.

3 Die populistische Vereinnahmung der direkten Demokratie könnte insbesondere auch politstrategisch untersucht werden. Hinweise dafür, dass (rechter) Populismus durch (durchaus selber auch populistisch operierende) Gegenmobilisierung (,wir sind mehr“) gebremst werden kann, zeigen sich etwa in der Schweiz, wo eine starke zivilgesellschaftliche Mobilisierung (mit-)ursächlich war für die Ablehnung der "Durchsetzungsinitiative“ 2016 und der „Selbstbestimmungsinitiative“ 2018; siehe zu diesen beiden Initiativen etwas näher die Ausführungen unten, S. 139 f. 
Andererseits einen partizipativ-deliberativen Ansatz, welcher in die verfassungsrechtliche Offensive geht und in quantitativer wie in qualitativer Hinsicht eine Erweiterung der populären Mitsprachemöglichkeiten fordert. Der vorliegende Beitrag diskutiert diese Ansätze und plädiert für zweiteren, welcher, so das Argument, die dem Populismus zugrundeliegenden Ursachen stärker in die Lösungsfindung einbezieht und deshalb nicht nur die effizientere Abwehrstrategie ist, sondern auch das Potential hat, die direkte Demokratie als Regierungsform zu stärken und aus den rechtsstaatsgefährdenden Klauen des Populismus zu lösen. Nicht weniger, sondern mehr Demokratie sollte deshalb die Antwort auf die „Populismuskrise“ sein. ${ }^{4}$ Damit einher geht ein erweitertes Verständnis von direkter Demokratie, das auch deliberative Elemente einschließt. Der Beitrag illustriert die Ausführungen am Beispiel der Schweiz, die als „direktdemokratisches Laboratorium“ auch für stärker repräsentativ ausgestaltete Systeme mit direktdemokratischen Elementen Erkenntnisse generieren kann.

\section{Zur „Populismuskrise“ der direkten Demokratie}

Die direkte Demokratie stützt sich als Staatsform auf den Rousseau'schen Gedanken der radikalen Volkssouveränität und stellt damit für viele eine „Grundform“ der Demokratie dar. Allerdings hat gerade sie sich den Ruf eingehandelt, populistisch manipulierbar zu sein und damit letztlich in Konflikt mit dem Rechtsstaat zu stehen. Im Folgenden soll dieser „Krise“ näher nachgegangen werden. Nach einer Darstellung der theoretischen Fundamente und empirischen Ausprägungen der direkten Demokratie (2.1) wird die Entwicklung, die zu diesem Ruf der direkten Demokratie als eine „Prämie für jeden Demagogen"s geführt hat, näher untersucht (2.2).

1. Direkte Demokratie als institutionalisierte radikale Volkssouveränität

„Government of the people, by the people, for the people": Wie keine andere Staatsform setzt die direkte Demokratie diesen Grundsatz um, indem sie die Stimmbevölkerung an Entscheidungen über Sachfragen teilhaben lässt. Theoriegeschichtlich geht die direkte Demokratie zurück auf Jean-Jacques Rousseaus Idee der radikalen Volks-

4 „Vorwärtsverteidigung“ der Demokratie, siehe Ralf-Uwe Beck, Mehr (direkte) Demokratie wagen in Zeiten des Rechtspopulismus, Zeitschrift für Menschenrechte 2 (2018), S. $46 \mathrm{ff}$.

5 Theodor Heuss, Rede vor dem Parlamentarischen Rat (9.9.1948), in: Theodor Heuss: Vater der Verfassung. Zwei Reden im Parlamentarischen Rat über das Grundgesetz 1948/49, hg. u. bearb. v. Ernst Wolfgang Becker, 2009, S. 63. 
souveränität. ${ }^{6}$ Gemäß Rousseau liegt die Souveränität beim Volk und muss auch dort bleiben. Repräsentation ist aus seiner Sicht die Totengräberin der Demokratie und führt zur Selbstentfremdung der Menschen. ${ }^{7}$ Wichtig für Rousseaus Staatsphilosophie ist dabei die Unterscheidung zwischen der „volonté particulière“ (den Einzelinteressen der Besitzbürger), der „volonté de tous“ (der Summe aller Einzelinteressen) und der für die Staatslenkung unabdingbaren „volonté générale“. Durch Bildung sollten die Bürger die Fähigkeit erlangen, zwischen ihrer Rolle als „bourgeois“ (in seinen Privatinteressen verstrickter Besitzbürger) und als „citoyen“ (tugendhafter Staatsbürger) wechseln zu können und damit in den Kategorien der „volonté générale“ zu denken.

Eine hundertprozentige Umsetzung der Rousseau'schen Volkssouveränität sucht man in der Empirie allerdings vergeblich. Zwar finden sich in vielen Staaten - vor allem auf regionaler oder lokaler Ebene - direktdemokratische Elemente in Form von Abstimmungen über Sachfragen oder der Möglichkeit, Bürgerbegehren und dergleichen einzureichen. Aber selbst die Schweiz, welche die direkte Demokratie im weltweiten Vergleich wohl am konsequentesten umgesetzt hat, kann lediglich als halbdirekte Demokratie charakterisiert werden, da sie nebst den direktdemokratischen Elementen des Referendums und der Volksinitiative weiterhin auf allen Staatsebenen ein Parlament mit gewählten Volksvertreter*innen ${ }^{8}$ und eine gewählte Regierung kennt.

Die direkte Demokratie definiert sich hauptsächlich über ihre zwei wichtigsten Institutionen, nämlich Volksbegehren (auf der „Input-Seite“) und Referenden (im Sinne von Volksentscheiden über den „Output“). Häufigkeit und Bedeutung der Anwendung dieser Instrumente sowie der Umfang der Regulierung variieren dabei. In der Schweiz ist es beispielsweise sehr klar vorgeschrieben, welche Arten von Entscheidungen dem Stimmvolk vorgelegt werden müssen (insb. Verfassungsänderungen und andere Entscheidungen von sehr großer Tragweite ${ }^{9}$ ) oder können (Gesetze und andere Entscheidungen von großer Tragweite ${ }^{10}$ ). In vielen anderen Staaten, die keine regelmäßigen Volksbefragungen kennen, ist es währenddessen möglich, Referenden über bestimmte, als wichtig erachtete Sachfragen ad hoc anzuordnen (wie es etwa in Großbritannien mit dem Brexit-Referendum der Fall war).

Ein Vergleich verschiedener Formen direkter Demokratie muss dabei aber stets das gesamte verfassungsmäßige System berücksichtigen, welches in seiner Funktionalität doch immer sehr stark kontextabhängig ist. So würden starke direktdemokratische

\footnotetext{
6 Wenngleich Rousseau sich selber wohl nicht als Fürsprecher der direkten Demokratie gesehen hätte; vielmehr war in seiner Vorstellung der ideale Staat einer wie die Römische Republik oder Sparta, siehe Manfred G. Schmidt, Demokratietheorien, 5. Auflage 2010, S. $91 \mathrm{f}$.

7 Schmidt (Fn. 6), S. 84 .

8 Einzig auf lokaler Ebene, insbesondere in sehr kleinen Gemeinden kommt es teilweise noch vor, dass die Gemeindeversammlung, also die Versammlung aller stimmberechtigten Bürgerinnen und Bürgern die Legislative bildet und in dieser Funktion über sämtliche Geschäfte der Gemeinde abstimmt.

9 Art. 140 der Bundesverfassung der Schweizerischen Eidgenossenschaft (BV).

10 Art. 141 BV.
} 
Instrumente in einer Konkurrenzdemokratie der Opposition ein Mittel zur Blockierung der Regierungsarbeit in die Hand geben, welches das Potential zur permanenten Lahmlegung der Politik hätte. Deshalb ist auch die Schweizerische Direktdemokratie nicht isoliert vom Konkordanzsystem zu verstehen, das alle wichtigen Parteien in einer Art permanenter großer Koalition an der Regierung vereinigt, was die Anreize für Blockadepolitik verringert. In der Schweiz kommt dem Volk die „institutionalisierte Oppositionsposition " ${ }^{\text {"11 }} \mathrm{zu}$, indem es, kollektiv organisiert, Abstimmungen über eigene Vorschläge, über Gesetze oder über völkerrechtliche Verträge erzwingen kann. Gleichzeitig wirkt die „Referendumsdrohung“ mäßigend, so dass der Gesetzgeber die Interessen der referendumsfähigen Gruppen in der Regel schon im Gesetzgebungsprozess berücksichtigt. ${ }^{12}$

Der direkten Demokratie werden positive Wirkungen zugeschrieben. Neben einer stärkeren Legitimation politischer Entscheidungen ${ }^{13}$ soll sie das Vertrauen der Bürgerinnen und Bürger in die politischen Institutionen stärken, ${ }^{14}$ die kollektive Identität und politische Zufriedenheit fördern ${ }^{15}$ und tendenziell auch zu einer größeren politischen Kompetenz der Bürgerinnen und Bürger führen. ${ }^{16}$ Allerdings hat die direkte Demokratie auch einen gewissen Brems-, Verzögerungs- oder gar Blockierungseffekt, der politischen Fortschritt hemmen kann. ${ }^{17}$ Zudem ist sie, wie nachfolgend gezeigt wird, anfällig für populistische Instrumentalisierung.

11 Wolf Linder, Schweizerische Demokratie, 3. Auflage 2012, S. 267.

12 Leonhard Neidhart, Plebiszit und pluralitäre Demokratie, 1970.

13 Dieser Grundsatz ist sehr deutlich verwirklicht in der Schweiz: Je größer die politische, rechtliche, wirtschaftliche oder gesellschaftliche Tragweite eines Entscheides ist, desto höhere direktdemokratische Hürden muss er nehmen: Volk und Stände müssen zwingend über Änderungen der Bundesverfassung, den Beitritt zu Organisationen für kollektive Sicherheit oder zu supranationalen Gemeinschaften (dies betrifft v. a. die NATO und die Europäische Union), sowie dringliche Bundesgesetze, für die keine Verfassungsgrundlage besteht, abstimmen (Art. 140 Abs. 1 BV); nur das Volks- nicht aber das Ständemehr (d.h. die Mehrheit der Kantone) brauchen Entscheidungen über die Frage, ob eine Totalrevision der Verfassung durchzuführen ist; fakultativ dem Volk vorgelegt (wenn 50 ooo Stimmberechtigte dies verlangen) werden Bundesgesetze und dringlich erklärte Bundesgesetze; Bundesbeschlüsse sowie wichtige völkerrechtliche Verträge.

14 So etwa Otmar Jung / Franz-Ludwig Knemeyer, Im Blickpunkt: Direkte Demokratie, 2001, S. 68.

15 Schmidt (Fn. 6), S. 345 .

16 Jung/Knemeyer (Fn. 14), 68.

17 Schmidt (Fn. 6), 349; so ist etwa die überaus späte bundesweite Einführung des Frauenstimmrechts in der Schweiz 1971 auf die direkte Demokratie zurückzuführen; auf Kantonsebene stimmten die (männlichen) Stimmbürger an der Landsgemeinde des Kantons Appenzell-Innerrhoden noch 1990 gegen das Stimmrecht ihrer weiblichen Mitbürgerinnen. Das Bundesgericht stellte ein halbes Jahr später die Verfassungswidrigkeit dieser Situation fest (BGE 116 Ia 359) und zwang den Kanton damit zur Einführung des Frauenstimmrechts. 


\section{2. „Eine Prämie für jeden Demagogen“?}

Auf Theodor Heuss geht das Diktum zurück, die Direktdemokratie sei eine Prämie für jeden Demagogen. ${ }^{18}$ Dieser Ausspruch stand zwar noch unter dem Eindruck der negativen Erfahrungen mit plebiszitären Elementen unter der Weimarer Verfassung. Aktuelle Beispiele scheinen ihm aber erneut Recht zu geben und die Instrumente der direkten Demokratie sind scheinbar zum (Wahlkampf-)Vehikel populistischer Parteien verkommen.

Zwar ist es strittig, inwiefern Populismus überhaupt vermeidbar ist und/oder vermieden werden muss. Ernesto Laclau etwa hat die Ansicht geprägt, dass Populismus ein inhärenter Bestandteil und Folge der Konflikthaftigkeit jeder Politik ist. ${ }^{19}$ Was Populismus aber überhaupt ist, bleibt häufig schwammig; ${ }^{20}$ im Extremfall wird alles als Populismus abgetan, was nicht in die eigene Weltanschauung passt. Es lassen sich aber gewisse charakteristische Merkmale von (rechtem wie linkem) Populismus identifizieren, die auch das Verhältnis von Populisten zur direkten Demokratie erklären können: - Populismus charakterisiert sich dadurch, dass er zwischen dem „wahren Volk“ und einer (korrupten) „Elite“ unterscheidet. ${ }^{21}$ Dadurch erhält der „Volkswille“ eine zentrale, fast schon symbolische Bedeutung im populistischen Narrativ;

- $\quad$ Das populistische Weltbild ist ein polarisiertes, das klare Einteilungen zwischen Freund und Feind und damit „innen“ und „außen“ vornimmt; charakteristisch sind etwa Einteilungen nach Herkunft (Ausländer*innen), Religion (Muslime), aber auch moralisierende Kategorisierungen („Volksverräter“, Klassenfeind, etc.); $;^{22}$

- $\quad$ Populisten sind tendenziell skeptisch gegenüber demokratisch-rechtsstaatlichen Sicherungen und Verfahren, welche die Verwirklichung des „Volkswillens" behindern oder verkomplizieren. ${ }^{23}$

Für diese Eigenschaften bietet die direkte Demokratie zahlreiche Anknüpfungspunkte; sie erlaubt es besonders gut, das „Volk“ in Form der Mehrheit diskursiv als eine homogene Einheit darzustellen und den „Volkswillen“ als Trumpf gegenüber allen anderen rechtsstaatlichen Elementen, insbesondere bestimmten Minderheitenrechten

18 Heuss (Fn. 5).

19 Ernesto Laclau, On Populist Reason, 2005, 222.

20 Yves Meny / Yves Surel, The Constitutive Ambiguity of Populism, in: Democracies and the Populist Challenge, hg. von Yves Meny / Yves Surel, 2002, 1; Cristóbal Rovira Kaltwasser, Democratization 19 (2012), 184 .

21 Ana Micaela Alterio, Reactive vs structural approach: A public law response to populism, Global Constitutionalism 8 (2019), S. 275.

22 Siehe Andrew Arato, Populism and the Courts, International Journal of Constitutional Law Blog, 25. April 2017, online unter http://www.iconnectblog.com/2017/04/populism-and-the-courts.

23 Arato (Fn. 22). 
(die in der populistischen Freund/Feind Dichotomie eine störende Rolle einnehmen) und rechtsstaatlichen Sicherungen wie dem Verhältnismäßigkeitsprinzip auszuspielen. Zudem erlaubt diese Betonung des Volkswillens es den Populisten, sich als einzige Vertreter des „wahren Volkes“ zu inszenieren, die den „Eliten“ mit ihrer „antidemokratischen Agenda" die Stirn bieten. Es erstaunt deshalb wenig, wenn populistische Politiker nach mehr direkter Demokratie rufen. ${ }^{24}$

Und bisherige Referenden scheinen ihnen Recht zu geben. Das Brexit-Referendum von 2016 etwa ist schon fast zum Paradebeispiel eines populistisch instrumentalisierten Referendums geworden. Zwar sind noch immer nicht alle Hergänge und Kausalitäten aufgeklärt, aber es liegen gesicherte Erkenntnisse aus verschiedenen offiziellen Untersuchungen $^{25}$ vor, dass die Wahlergebnisse über Onlinekampagnen und gezielter Falschinformationen massiv beeinflusst worden sind. Die populistische Instrumentalisierung hat aber mit dem Referendum nicht aufgehört. Ganz im Sinne der für Populisten so charakteristischen Verabsolutierung des Volkswillens wird das Resultat des Referendums - „das Volk hat gesprochen!“ - nun für unantastbar erklärt, dies zeigte sich insbesondere bei den Diskussionen um ein zweites Referendum, ganz so, als ob sich das „Volk“ niemals irren und niemals ein zweites Mal über die gleiche Frage abstimmen dürfte (und in Kontrast zur ursprünglichen Absicht, das Referendum als unverbindliche Volksbefragung auszugestalten). ${ }^{26}$

Ähnliches spielt sich schon seit einiger Zeit in der Schweiz ab. Zahlreiche Volksinitiativen stellten rechtsstaatliche Errungenschaften mehr oder weniger direkt in Frage; nicht wenige dieser Initiativen wurden in der Abstimmung sogar angenommen und haben ernsthafte rechtsstaatliche Umsetzungskonflikte entstehen lassen, so 2004 die sog. „Verwahrungsinitiative ${ }^{{ }_{27}}$, welche eine lebenslange Haft ohne Entlassungsmöglichkeit von Sexual- oder Gewaltstraftätern in der Verfassung verankerte und somit gegen Menschenrechtliche habeas corpus Garantien im Freiheitsentzug und das Ver-

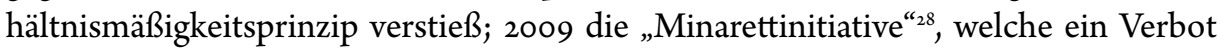
des Baus von Minaretten einführte und damit die Religionsfreiheit und das Diskrimi-

24 Siehe oben, Fn. 1; siehe allgemein dazu Nadia Urbinati, Democracy and populism, Constellations, 5 (1998), S. 111.

25 U.a. der britischen Wahlaufsichtsbehörde, siehe http://www.electoralcommission.org.uk/_data/as sets/pdf_file/oo19/244900/Report-of-an-investigation-in-respect-of-Vote-Leave-Limited-Mr-Darren-Gri mes-BeLeave-and-Veterans-for-Britain.pdf und der britischen Datenschutzbehörde https://ico.org.uk/me $\mathrm{dia} /$ action-weve-taken/2259371/investigation-into-data-analytics-for-political-purposes-update.pdf.

26 Siehe etwa The Guardian vom 6 März 2019, Theresa May's rhetoric can be as populist as Trump's, online unter https://www.theguardian.com/world/2019/mar/o6/theresa-may-british-prime-minister-populismrhetoric-is-as-rife-as-in-donald-trump-speeches.

27 Wird ein Sexual- oder Gewaltstraftäter in den Gutachten, die für das Gerichtsurteil nötig sind, als extrem gefährlich erachtet und nicht therapierbar eingestuft, ist er wegen des hohen Rückfallrisikos bis an sein Lebensende zu verwahren. Frühzeitige Entlassung und Hafturlaub sind ausgeschlossen (Art. 123a BV Schweiz).

28 Art. 72 Abs. 3 BV. 
nierungsverbot tangierte; 2010 die „Ausschaffungsinitiative“29, welche einen automatischen Verlust des Aufenthaltsrechts von straffälligen ausländischen Personen vorsah und damit gegen verschiedene menschenrechtliche Garantien im Migrationsbereich verstieß, und 2014 die „Masseneinwanderungsinitiative ${ }^{{ }_{30} 0}$ welche eine (rechtlich und faktisch unmögliche) eigenständige Steuerung der Zuwanderung mittels Höchstgrenzen verlangte. Auch auf kantonaler Ebene sind solche Entwicklungen zu beobachten, so haben etwa die Stimmbürgerinnen und -bürger in den Kantonen Tessin (2017) und St. Gallen (2018) Volksinitiativen zum Verbot der Vollverschleierung (Burka- und Niqab-Verbote) angenommen, und im Kanton Bern nahm das Stimmvolk 2013 die Initiative „Keine Einbürgerung von Verbrechern und Sozialhilfeempfängern“ an. Diese Initiativen entsprechen dem populistischen Narrativ, nicht nur weil sie von rechtspopulistischen Parteien lanciert wurden, sondern auch, weil sie das Freund/Feind Weltbild, das sich hier gegen ausländische Staatsangehörige, religiöse Minderheiten, Straftäter oder Armutsbetroffene richtete, in Verfassungsrecht übersetzen. Diese populistische Verfassungsgebung wurde in den Abstimmungskämpfen zudem jeweils stark mit der Volk/Eliten Dichotomie begründet, so etwa wenn vor den Abstimmungen zur Verwahrungs- und der Ausschaffungsinitiative den Behörden und Gerichten „Kuscheljustiz“ vorgeworfen wurde.

Inhaltlich ist all diesen Initiativen gemein, dass sie vermeintlich einfache, aber rechtsstaatlich problematische Lösungen für komplexe gesellschaftliche Probleme suggerierten. Rechtsstaatliche Errungenschaften und Grundwerte wie das Verhältnismäßigkeitsprinzip, die Religionsfreiheit, das Diskriminierungsverbot, die Gewaltenteilung, aber auch Pluralismus und Rechtssicherheit wurden zugunsten dieser einfachen und polarisierenden, an das Bauchgefühl appellierenden Lösungsvorschläge relativiert.

Mit Theodor Heuss ist also einig zu gehen, dass die direkte Demokratie jedenfalls gewisse „Einfallstore“ für populistische Politik birgt. Dass die Schweiz mit sehr ausgeprägter direktdemokratischer Tradition schon besonders früh Erfahrungen mit rechtspopulistischen Volksinitiativen machte, bekräftigt diese These zusätzlich. In jüngerer Zeit hat der Populismus die direkte Demokratie teilweise vereinnahmt und sie immer stärker in ein Spannungsverhältnis mit dem Rechtsstaat gedrängt. Während mir diese Einschätzung unzweifelhaft scheint, so unterscheiden sich die demokratietheoretischen Lösungsansätze und die daraus abgeleiteten Handlungsimperative erheblich; auf diese soll nun näher eingegangen werden.

29 Art. 121 Abs. 3 BV.

30 Art. $121 a \mathrm{BV}$. 


\section{Demokratietheoretische Wege aus der „Populismuskrise”}

Die dargestellte populistische Vereinnahmung birgt nicht unerhebliche Gefahren für den Rechtsstaat. Während gewisse politische Gegenmobilisierungsstrategien durchaus wirkungsvoll erscheinen, ${ }^{31}$ fokussiert der vorliegende Beitrag auf die normativen Fragen, die mit der „Populismuskrise“ einhergehen. Zwei gegensätzliche Reaktionsmöglichkeiten sind zu erkennen, die beide zum Ziel haben, das Spannungsverhältnis zwischen (direkter) Demokratie und Rechtsstaat wieder aufzulösen. Sie gehen damit zwar beide von deren Gleichursprünglichkeit aus, unterscheiden sich aber in ihrer demokratietheoretischen Herleitung, ihrer normativen Prioritäten, der Begründung von demokratischer Legitimation, sowie auch hinsichtlich der aus der Diagnose (Krise der direkten Demokratie durch populistische Instrumentalisierung) gefolgerten Handlungsimperativen. Während der eine Ansatz, den ich in Anlehnung an seine platonische Extremform als epistokratisch bezeichnen möchte, aus der Diagnose der Manipulationsanfälligkeit von Referenden folgert, dass solche grundsätzlich zu vermeiden sind und die Wahrung des Rechtsstaats in die Hände von Sachverständigen zu legen ist, geht der andere Ansatz davon aus, dass populistische Strömungen eine Reaktion auf eine (tatsächliche oder wahrgenommene) Abnahme von Mitsprachemöglichkeiten sind und die gebotene Reaktion deshalb in mehr anstatt weniger Beteiligungsmöglichkeiten liegt; ich nenne ihn darum den partizipativ-deliberativen Ansatz.

\section{Epistokratischer Ansatz}

Ausgangspunkte des epistokratischen Ansatzes sind die Feststellungen, dass direkte Demokratie anfällig für Populismus ist und Populismus tendenziell den Rechtsstaat in Bedrängnis bringt. Diese oben hergeleitete und meines Erachtens kaum umstrittene Feststellung führt manche zur Schlussfolgerung, dass Referenden etwas sind, das vermieden werden sollte, ${ }^{32}$ oder aber jedenfalls, dass ihre Auswirkungen und Bedeutung durch möglichst starke institutionelle Gegenspieler im rechtsstaatlichen Zaum gehalten werden sollen.

Das Beispiel aus der Schweiz kann hier wiederum zur praktischen Illustration angeführt werden: In zeitlicher Parallelität mit der Zunahme rechtstaatsgefährdender Volksinitiativen, hat sich in Fachkreisen eine Diskussion um die Einführung von Ver-

31 Siehe oben, Fn. 3. Siehe auch (anstelle vieler), Jon Henley, Change the narrative: How a Swiss group is beating rightwing populists, The Guardian vom 7. April 2019.

32 Siehe z.B. Anthony Clifford Grayling, Die Demokratie zerstört sich selbst, Zeit Online vom 22. November 2016; Bettina Gaus, Siegeszug des Populismus, TAZ vom 7. Oktober 2016. Siehe auch die Nachzeichnung des Diskurses in Deutschland bei Beck (Fn. 4), S. 47. 
fassungsgerichtsbarkeit intensiviert. ${ }^{33}$ Hintergrund ist eine Besonderheit der Schweizerischen Bundesgerichtsbarkeit, nämlich die fehlende Möglichkeit des Bundesgerichts, Bundesgesetze wegen Verfassungswidrigkeit die Anwendung zu versagen: Gemäss Art. 190 der Schweizerischen Bundesverfassung sind Bundesgesetze und Völkerrecht für das Bundesgericht und die anderen rechtsanwendenden Behörden massgebend. Der Zusammenhang mit dem hier interessierenden Themendreieck Populismus, direkte Demokratie und Rechtsstaat liegt auf der Hand, denn diese Schwächung der Judikative gegenüber den anderen Gewalten manifestiert einen Vorrang von demokratischen Entscheidungen gegenüber rechtlichen Auslegungen. Die Bundesgerichtsbarkeit in der Schweiz kann damit derzeit nur eine eingeschränkte Abwehrfunktion gegenüber rechtstaatsgefährdenden Volksinitiativen einnehmen, was sich mit der Einführung einer echten Verfassungsgerichtsbarkeit geändert hätte. Das Parlament hat die hierfür notwendige Verfassungsänderung 2012 abgelehnt, die Diskussion ist damit also realpolitisch vorerst beendet, lebt aber in Fachkreisen immer noch weiter. ${ }^{34}$ Ebenfalls diskutiert wird eine inhaltliche Vorabkontrolle von Volksinitiativen auf ihre Verfassungsmäßigkeit, entweder mittels einer Erweiterung der materiellen Ungültigkeitsgründe von Volksinitiativen (derzeit können Volksinitiativen nur dann als ungültig erklärt werden, wenn sie gegen zwingendes Völkerrecht, nicht aber wenn sie gegen Menschenrechtsverträge oder verfassungsmäßige Rechte verstoßen, Art. 139 Abs. 3 BV) oder mittels einer Art „Ampelsystem“, welches „kritische“ Initiativen markieren würde..$^{35}$ Die materielle Überprüfung sollte eine Bundesbehörde, je nach Vorschlag, das Parlament, eine Expertenkommission oder die Bundeskanzlei, durchführen.

33 So u. a. Maya Hertig Randall, L'internationalisation de la juridiction constitutionelle: défis et perspectives, in: Verfassungsgerichtsbarkeit, hg. Schweizerischer Juristentag, 2010, S. 221 ff.; Hansjörg Seiler, Verfassungsgerichtsbarkeit zwischen Verfassungsrecht, Richterrecht und Politik, in: Verfassungsgerichtsbarkeit hg. Schweizerischer Juristentag, 2010, S. 381 ff.; Martin E. Looser, Verfassungsgerichtliche Rechtskontrolle gegenüber schweizerischen Bundesgesetzen, 2011; sowie die Beiträge in der Jusletter Schwerpunktausgabe „Verfassungsgerichtsbarkeit“ vom 12. September 2011, insb. Walter Haller, Verfassungsgerichtsbarkeit im Blickfeld schweizerischer Juristinnen und Juristen; Martin Schubarth, Verfassungsgerichtsbarkeit aus rechtsvergleichender, historischer und politologischer Sicht; Oliver Diggelmann, Usurpation des Rechtsstaatsbegriffs durch die staatsrechtliche Orthodoxie?; Frédéric Bernard, L'abrogation de l'article 190 Cst. à la lumière du judicial review; Felix Uhlmann / David Hofstetter, Aufhebung von Art. 190 BV; Luc Gonin, Le problème suisse n'est pas la juridiction constitutionnelle : la question de la juridiction conventionnelle - de l'art. 190 Cst. à une révolution politique; Yann Grandjean, Le contrôle juridique préventif comme alternative à l'extension de la juridiction constitutionnelle; Alessandra Chies, Ausbau der Verfassungsgerichtsbarkeit in der Schweiz? Die Problematik um das Massgeblichkeitsgebot in Art. 190 BV hinsichtlich Bundesgesetzen, AJP 747 (2011); Giovanni Biaggini, Ausbau der Verfassungsgerichtsbarkeit. Ersatzlose Aufhebung von Art. 190 BV als optimaler Weg?, Zeitschrift des Bernischen Juristenvereins 241 (2012).

34 Als Beispiele nach 2012 etwa Andreas Zünd, Grundrechtsverwirklichung ohne Verfassungsgerichtsbarkeit, AJP 1349 (2013); Martin Schubarth, Verfassungsgerichtsbarkeit, 2. Auflage 2017.

35 So insbesondere die Vorschläge im Zusatzbericht des Bundesrats zu seinem Bericht vom 5. März 2010 über das Verhältnis von Völkerrecht und Landesrecht vom 30. März 2011. Generell dazu: Anina Dalbert / Stefan Schlegel / Fanny De Weck, Volksinitiativen und Völkerrecht. Eine Lösung, um Vertragsbrüche zu vermeiden, 2014, online unter https://www.foraus.ch/wp-content/uploads/2018/o1/Volksinitiativen_ 
Diese Diskussionen um die Einführung von Verfassungsgerichtsbarkeit wie auch um eine Vorabkontrolle von Volksinitiativen haben eines gemeinsam: Sie suchen, angesichts der Rechtsstaatsgefährdung durch populistische Volksinitiativen, nach einem institutionellen Gegengewicht, das dem populistischen Vormarsch auf der Fachebene Einhalt gebieten könnte. Dies kann ein nationales Höchstgericht (wie im ersten Fall) oder eine Bundesbehörde (wie im zweiten Fall) sein.

Faktisch soll damit das politische System „immunisiert“ werden gegen die populistische Gefahr. Institutionell führt dieser auch in anderen Staaten zu beobachtende ${ }^{36}$ epistokratische Ansatz somit zu einer stärkeren Rolle von Gerichten, Expertinnen und Experten, Kommissionen und Fachbehörden. Eine weitere Folge kann die Verschiebung von Entscheidungen auf inter- oder supranationale Ebenen sein, wo sie der populären Mitbestimmung weitgehend entzogen sind, so etwa der Versuch, große Teile der (innerstaatlich umstrittenen und populistisch regelmäßig scharf attackierten) Migrationssteuerung auf die Unionsebene im Rahmen des Schengen-Systems zu verlagern.

In dieser (berechtigten) Sorge um das rechtsstaatsgefährdende Potential der direkten Demokratie kommt ein Misstrauen gegenüber den staatsbürgerlichen Fähigkeiten - oder um es mit Rousseau auszudrücken, der „citoyenneté“ - des Stimmvolkes zum Ausdruck. Der Kalauer über „vox populi, vox Rindvieh“ drückt überspitzt aus, worum es geht: Statt durch rationale Abwägung in Verfolgung der „volonté générale" lasse sich das Stimmvolk von Emotionalität, Irrationalität und Instrumentalisierbarkeit leiten und sei mit solchen Entscheiden grundsätzlich überfordert. ${ }^{37}$ Abstimmungen bekämen eine Katalysatorfunktion, in deren Logik der Rechtsstaat ignoriert oder gar bewusst geritzt würde. Als besser geeignet für die Wahrung des Rechtsstaats werden deshalb Sachverständige gesehen, wie sich auch in den Schweizerischen Beispielen zeigt. Der hitzigen Irrationalität des Stimmvolks wird die kühle Rationalität der Expert*innen entgegengestellt.

Die Prämissen, auf die sich dieser Ansatz stützt, erscheinen aber problematisch. Die unterstellte Abwesenheit von Politikmündigkeit des Stimmvolks ist einerseits höchst pessimistisch, wenn nicht gar elististisch, und unterlässt es zudem, den tieferliegenden Ursachen von Populismus nachzugehen. Insbesondere wird damit der Blick darauf verstellt, dass eine gewichtige Ursache von Populismus im „Abgehängtsein“ relevanter

und_Volkerrecht_Kurzanalyse.pdf; siehe dazu etwa Felix H. Thomann, Die Prüfung von Teilrevisionsinitiativen auf die Verfassungswürdigkeit ihres Inhalts, sui-generis 2015, S. $90 \mathrm{ff}$.

36 Siehe insbesondere die Beispiele aus Lateinamerika bei Alterio (Fn. 21) und die Darstellung bei Michaela Hailbronner / David Landau, Introduction: Constitutional Courts and Populism, International Journal of Constitutional Law Blog, 22. April 2017, online unter: http://www.iconnectblog.com/2017/04/ introduction-constitutional-courts-and-populism/.

37 Siehe auch Alterio (Fn. 21), 280. 
Anteile der Stimmbevölkerung liegt. ${ }^{38}$ Das populistische Narrativ von „Volk“ versus „Eliten“ nährt sich direkt aus diesen Befunden sowie aus dem empfundenen und sichtbaren Mangel an Mitsprache- und Artikulationsmöglichkeiten, die durch die „selbstreferentielle Verselbständigung politischer Entscheidungsprozesse“ (Maus ${ }^{39}$ ) in Form einer Verlagerung der Politik auf höhere Ebenen (Zentralisierung, Vergemeinschaftung), in die Hände von Behörden und Regulierungsagenturen (Technokratisierung, Managerialisierung), in gerichtliche Foren (Stichwort judicial activism) oder in die Chefetagen transnationaler Unternehmen verloren gegangen sind.

Hinzu kommt, dass dieser Ansatz normativ zu Begründungsschwierigkeiten bei der demokratischen Legitimation führt: Wie kann die Verlagerung der Entscheidungsarenen weg vom „Volk“, hin zu Sachverständigen normativ begründet werden? Gewagte Versuche, demokratische Legitimation außerhalb der Volkssouveränität zu konstruieren, sind die Folge dieses Ansatzes, so etwa der Vorschlag, demokratische Legitimation durch Unparteilichkeit herzuleiten. ${ }^{40}$

Meines Erachtens ist der epistokratische Ansatz deshalb nicht in der Lage, die direkte Demokratie aus der Populismuskrise zu führen, denn letztlich schlägt er genau jene Maßnahmen als Lösung vor, die zumindest mitursächlich für die Entstehung und die Empfänglichkeit für Populismus gewesen sind. Zu prognostizieren ist daher eher, dass der epistokratische Ansatz populistischen „Scharfmachern“ noch mehr Stoff für ihr antielitäres und antipluralistisches Narrativ liefert, womit sich die rechtsstaatsgefährdenden Forderungen eher vermehren als vermindern würden.

Ein Beispiel hierfür kann wiederum in der Schweiz gefunden werden: Nachdem am 28. November 2010 die „Ausschaffungsinitiative“ angenommen worden war, welche in Art. 121 der Bundesverfassung den zwingenden Verlust des Aufenthaltsrechts von ausländischen Staatsangehörigen, die bestimmte Delikte begangen hatten, verankerte, begannen einige kantonale Ausländerbehörden schon bald, die neue Verfassungsbestimmung direkt auf entsprechende Sachverhalte anzuwenden. Mit der Zulässigkeit dieser Praxis hatte sich das Bundesgericht zu befassen, das dann 2013 festhielt, dass neue verfassungsgerichtliche Vorgaben, die im Widerspruch zu geltendem Gesetzes- und Völkerrecht stehen, nicht direkt anwendbar sind, sondern vom Gesetzgeber konkretisiert werden müssen; insbesondere komme ihnen kein Vorrang vor den Grundrechten oder den Garantien der EMRK zu. ${ }^{41}$ Diese gerichtliche Zurückdrängung der populistischen Initiative führte mehr oder weniger direkt dazu, dass die Schweizerische Volkspartei (SVP), die Initiantin der „Ausschaffungsinitiative“, zwei weitere Volksinitiativen

38 Christopher Bickerton / Carlo Invernizzi Accetti, Populism and Technocracy, in: The Oxford Handbook of Populism, hg. von Cristobal Rovira Kaltwasser u. a., 2017, S. $326 \mathrm{ff}$.

39 Ingeborg Maus, Sinn und Bedeutung von Volkssouveränität, Kritische Justiz 2 (1991), S. 138.

40 So etwa Pierre Rosanvallon, Democratic Legitimacy. Impartiality, Reflexivity, Proximity, 2011.

41 BGE 139 I 16, E. 4.3.1 ff. 
formulierte: Einerseits die sogenannte „Durchsetzungsinitiative“42, welche den Text der „Ausschaffungsinitiative“ präzisierte und verschärfte und damit eine „pfefferscharfe Umsetzung “43 erzwingen wollte, und andererseits, und das scheint mir für die vorliegende Abhandlung noch interessanter, die sogenannte „Selbstbestimmungsinitiative“, die einen absoluten Vorrang von nationalem Verfassungsrecht vor Völkerrecht aufstellen wollte, um zu verhindern, dass völkerrechtliche Garantien gegen zu extreme Verfassungsbestimmungen vorgebracht werden können, wie es das Bundesgericht 2013 getan hat. Wie davor schon die „Durchsetzungsinitiative“ wurde auch die „Selbstbestimmungsinitiative“ (u.a. dank strategischer Gegenmobilisierung) in der Volksabstimmung vom 25. November 2018 abgelehnt, sie zeigt aber exemplarisch, dass der epistokratische Ansatz eine Perpetuierung des populistischen Potenzials und eine Spirale immer extremerer Forderungen provozieren kann. Diese Erkenntnis stellt nicht die Gewaltenteilung und die rechtsstaatssichernde Funktion von Gerichten in Frage, sie macht aber meines Erachtens deutlich, dass Strategien gefunden werden müssen, um die populistische Instrumentalisierung der direkten Demokratie bereits am Entstehen zu hindern und nicht erst eine Korrektur herbeizuführen, wenn die Gefährdung schon eingetreten ist.

\section{Partizipativ-deliberativer Ansatz}

Basierend auf der Erkenntnis, dass die große Resonanz populistischer Bewegungen wesentlich zurückzuführen ist auf einen (wahrgenommenen und diskursiv instrumentalisierten) Verlust an Mitsprache- und Äußerungsmöglichkeiten, entstehend aus Technokratisierung, Globalisierung und Managerialisierung, schlägt der zweite Ansatz, der hier als partizipativ-deliberativer Ansatz bezeichnet wird, eine grundlegend andere Richtung ein als der epistokratische Ansatz und fordert einen Ausbau der Partizipationsmöglichkeiten. Nicht weniger Beteiligung, sondern (noch viel) mehr davon, ist hier also die Devise. Auch dieser Ansatz will zwar nicht auf Sachverständige, im Sinne von Gerichten, Verwaltungen und Expert*innen, verzichten, aber er fordert eine stärkere Einbeziehung, quantitativ und qualitativ, der Bürgerinnen und Bürger auf allen Stufen der Politik.

Der Ansatz zieht seine theoretische Begründung aus den beteiligungszentrierten Demokratietheorien. Diese verstehen politische Beteiligung als das Zentrum der Poli-

42 Die Initiative wurde in der Volksabstimmung abgelehnt, Details siehe unter https://www.bk.admin. $\mathrm{ch} / \mathrm{ch} / \mathrm{d} /$ pore/vi/vis433.html.

43 So der im Abstimmungskampf inflationär gebrauchte Ausdruck, siehe etwa (anstelle vieler) die „Abstimmungs-Arena" vom 5. Februar 2016 im Schweizerischen Fernsehen, https://www.srf.ch/news/schweiz/ abstimmungen/abstimmungen/durchsetzungs-initiative/arena-schafft-die-durchsetzungs-initiativemehr-sicherheit. 
tik und als einen Wert an sich sowie als Quelle prozeduralen Nutzens. ${ }^{44}$ Demokratie ist in diesen Theorien nicht nur eine Staatsform oder ein Schumpeterianischer Markt, sondern wird als Lebensform, als „Seinsweise“ (Benhabib ${ }^{45}$ ) gesehen. Diese Theorien lassen sich ihrerseits in partizipatorische und in deliberative Ansätze unterteilen.

- Die partizipatorische Demokratietheorie basiert auf ähnlichen Prämissen wie Rousseaus Konzept radikaler Volkssouveränität: ${ }^{46}$ "If democracy is a good thing (...), then more democracy should presumably be an even better thing " ${ }^{47}$, und so wird eine Demokratisierung aller Lebensbereiche, etwa der Arbeit, der Wirtschaft, der Familie, des Haushalts etc. gefordert. Es geht dabei um einen Ausbau konventioneller politischer Beteiligung (z. B. Teilnahme an Wahlen, Abstimmungen oder Petitionen) aber auch unkonventioneller Partizipation wie Demonstrationen, Streiks, etc. Mehr Partizipation soll die durch Globalisierung verloren gegangenen Entscheidungs- und Deliberationsräume ersetzen ${ }^{48}$ und soll zugleich die bereits vorhandenen deliberativen Fähigkeiten der Bürgerinnen und Bürger nutzen. In dieselbe Richtung argumentiert die feministische Demokratietheorie, welche eine partizipatorische Kompensation dafür einfordert, dass die politischen Entscheidungsforen, zu denen sich Frauen erst gerade im 20. Jahrhundert den Zugang erkämpft hatten, durch die geschilderten Prozesse erodieren. ${ }^{49}$ Diese „starke Demokratie“ im Sinne einer „Politik der Amateure“ (Barber ${ }^{50}$ ) verspricht eine bessere Demokratiemündigkeit der Bürgerinnen und Bürger, mehr Identifikation mit und Akzeptanz von politischen Institutionen. ${ }^{51}$

- Die deliberative Demokratietheorie, zu deren prominentesten Vertretern Jürgen Habermas zu zählen ist, betont den diskursiven Charakter der Demokratie und damit ebenfalls die Input-Legitimation..$^{52}$ Demokratische Legitimität genießen diejenigen politischen Ergebnisse, die in einem diskursiven

44 Jürgen Habermas, Über den Begriff der politischen Beteiligung, in: Student und Politik, hg. von Jürgen Habermas u. a., 1969, S. 11 ff.; Schmidt (Fn. 6), S. 236.

45 Seyla Benhabib, Toward a Deliberative Model of Democratic Legitimacy, in: Democracy and difference: contesting the boundaries of the political, hg. von Seyla Benhabib, 1996, S. $67 \mathrm{ff}$.

46 Vertreter sind u. a. Carole Pateman, Participation and Democratic Theory, 1970 und Benjamin Barber, Starke Demokratie. Über die Teilhabe am Politischen, 1994.

47 John S. Dryzek, Political inclusion and the dynamics of democratization, American Political Science Review 3 (1996), S. 475.

48 Robert A. Dahl, On Democracy, 1998.

49 Birgit Sauer, „Only paradoxes to offer?“ Feministische Demokratie- und Repräsentationstheorie in der „Postdemokratie“, Österreichische Zeitschrift für Politikwissenschaft, 2 (2011), S. 132; Squires, The new politics of Gender Equality, 2007, S. $16 \mathrm{f}$.

50 Barber (Fn. 46).

51 Schmidt (Fn. 6), S. 251 f.

52 Jürgen Habermas, Faktizität und Geltung. Beiträge zur Diskurstheorie des Rechts und des demokratischen Rechtsstaats, 1992; James Fishkin, Democracy and Deliberation. New Directions for Democratic Reform, 2011. 
Verfahren zu Stande gekommen sind und denen alle potentiell Betroffenen zustimmen könnten..$^{53}$ Vor diesem theoretischen Hintergrund hat sich im internationalen und vergleichenden Verfassungsrecht die Theorie des „Popular Constitutionalism" gebildet..$^{54}$ Auch diese verlangt konkret eine stärkere Rolle der Bürgerinnen und Bürger bei Entscheidungen über die Weiterentwicklung oder Änderung der Verfassung.

Populismus als eine Reaktion auf erodierende demokratische Mitsprache- und Entscheidungsmöglichkeiten zu verstehen, heißt damit letztlich, ein Input-Legitimationsproblem anzuerkennen. Aus dieser Perspektive scheint der partizipativ-deliberative Ansatz überzeugender als der epistokratische, denn er beabsichtigt, die durch Technokratie, Managerialisierung und Globalisierung verloren gegangene Input-Legitimation durch neue partizipative Verfahren zu stärken. Denn der Mangel an Input-Legitimation kann von populistischen Parteien ausgenutzt werden, so dass auch immer extremere Forderungen, die den Rechtsstaat gefährden mitgetragen werden - ein weiterer interessanter Zusammenhang zwischen Demokratie und Rechtsstaat.

Partizipative Formen des Regierens finden sich in vielen Staaten in zunehmendem Masse, und zwar nicht nur auf lokaler Ebene, wo eine stärkere Involvierung der Bürgerinnen und Bürger sehr häufig der Fall (und auch leichter umzusetzen) ist, sondern auch auf regionaler und nationaler Ebene, von einfachen Budget- und Planungsprozessen bis hin zu partizipativ-deliberativ erstellten Verfassungsentwürfen. Die weltweite Zunahme partizipativer Prozesse wird auch als "participative turn“ bezeichnet. ${ }^{55}$ Beispiele für partizipative Verfassungsprozesse sind etwa das isländische „Crowdsourcing" nach 2009, wo auf zivilgesellschaftlicher Initiative ein Entwurf für die Totalrevision der Verfassung in deliberativen Versammlungen der Bürgerinnen und Bürger formuliert wurde oder die irische "Citizens Assembly", welche ab 2016 Stellungnahmen über hoch kontroverse Verfassungsinhalte wie das Verbot der Abtreibung verabschiedete. Die Beispiele illustrieren nicht nur die Praktikabilität solcher partizipativer und deliberativer Formate, selbst auf Verfassungsstufe, sondern zeigen auch, dass Bürgerinnen und Bürger durchaus an solchen Prozessen interessiert und im rousseau'schen Sinne deliberations- und abstraktionsfähig sind.

Damit solche partizipativ-deliberativen Formen gelingen, müssen gewisse Deliberationsbedingungen gegeben sein, worauf schon Habermas mit seinem Postulat der

53 Habermas (Fn. 56), S. 138.

54 Mark Tushnet, Popular Constitutionalism as Political Law, Chicago-Kent Law Review 3 (2006), S. 991 ff.; Larry Kramer, The People Themselves. Popular constitutionalism and judicial review, 2004; Alterio (Fn. 21).

55 Laurence Bherer / Pascale Dufour / Françoise Montambeault, The participatory democracy turn: an introduction, Journal of Civil Society 3 (2016), S. 225 ff. 
„idealen Sprechsituation ${ }^{\text {"56 } 6}$ hingewiesen hat. In der Praxis muss diese ideale Sprechsituation in gerechte, nichtdiskriminierende Verfahrensregelungen übersetzt werden. Die Prozesse müssen Responsivität aufweisen, das heißt, auch einen Einfluss auf die verabschiedeten Handlungsnormen haben, andernfalls verkommt die Übung zum partizipativen Placebo ohne Wirkung. Die Demokratiemündigkeit der einzelnen Bürgerinnen und Bürger, wenngleich in jedem Menschen vorhanden ${ }^{57}$, ist m. E. eben auch eine Fähigkeit, die ausgebildet und beständig trainiert werden muss, so wie auch ein Muskel seine Kraft verliert, wenn er nicht benutzt wird. Für eine robuste „Beteiligungskultur “58 sind deshalb politische Erziehung einerseits sowie regelmäßige Deliberationsmöglichkeiten unumgänglich.

\section{Schluss}

Angesichts jüngster Entwicklungen in Europa scheint die direkte Demokratie durch den Rechtspopulismus vereinnahmt worden zu sein. Eine institutionelle Reaktion scheint notwendig, und zwar nicht nur um den Ruf der direkten Demokratie zu retten, sondern vor allem auch um die damit einhergehenden Rechtsstaatsgefährdungen abzuwenden. Referenden und Rechtsstaat für grundsätzlich unvereinbar zu erklären, scheint mir als Forderung jedenfalls vorschnell und verkürzt. Die direkte Demokratie steht nicht per se in einem Spannungsverhältnis zum Rechtsstaat, ${ }^{59}$ sie ist sogar vielmehr, wie jede andere Form der Demokratie, mit dem Rechtsstaat gleichursprünglich und steht mit diesem in einer gegenseitigen Abhängigkeitsbeziehung. Wer Referenden als Gefährdung des Rechtsstaats abtut, überlässt die direkte Demokratie kampflos den Populisten. Vielversprechender erscheint eine Erweiterung des Verständnisses von direkter Demokratie. Die Schweiz als „direktdemokratisches Laboratorium“ kann dabei auch für stärker repräsentativ ausgestaltete Systeme mit direktdemokratischen Elementen Erkenntnisse bieten. Bloße Referenden und Volksinitiativen ohne weitergehende Deliberationsmöglichkeiten („participation without deliberation“) erweisen sich jedenfalls als manipulationsanfällig, genauso wie der umgekehrte Fall („deliberation without participation“). Vielmehr sind ein Verständnis und eine darauf basierende institutionelle Ausgestaltung direkter Demokratie zu suchen, welches eine qualitative Ausweitung der Partizipations- und Deliberationsräume umfasst.

56 Jürgen Habermas, Kommunikative Rationalität und grenzüberschreitende Politik: eine Replik, in: Anarchie der kommunikativen Freiheit - Jürgen Habermas und die Theorie der internationalen Politik, hg. von Peter Niesen / Benjamin Herborth, 2007, S. 433.

57 Siehe Benjamin Barber, The Conquest of Politics, 1988, S. 210.

58 Siehe näher Beck (Fn. 4), S. 62.

59 Vgl. dazu auch Stefan Schlegel, Direkte Demokratie und Menschenrechte in der Schweiz: Die Betonung des Spannungsfeldes ist Teil des Problems, Zeitschrift für Menschenrechte 2 (2018), S. 66 ff. 
Die Lösung ergibt sich als Resultat einer Analyse der zwei hauptsächlichen demokratietheoretischen Ansätze gegen die „Populismuskrise“. Während der epistokratische Ansatz den Rechtsstaat vor dem populistischen Backlash abzuschirmen versucht, indem auf Volksbeteiligung weitgehend verzichtet wird und/oder mehr Gewicht auf Sachverständige und repräsentative Demokratie gelegt wird, geht der partizipativ-deliberative Ansatz quasi in die Offensive und fordert in quantitativer wie in qualitativer Hinsicht eine Erweiterung populärer Mitsprachemöglichkeiten.

Dieser zweite Ansatz scheint mir sowohl in seinen Grundannahmen empirisch stärker abgestützt wie auch in normativer Hinsicht überzeugender, denn er versucht, die Input-Legitimation, die durch die selbstreferentielle Verselbständigung politischer Entscheidungsprozesse verloren zu gehen droht, wiederherzustellen. Damit entkräftet er das elitenfeindliche Narrativ der Populist*innen und verhindert, dass diese die Volkssouveränität gegen rechtsstaatliche Errungenschaften wie Minderheitenrechte oder das Verhältnismäßigkeitsprinzip ausspielen können. Die überzeugendere Antwort auf populistische Politik ist also nicht das Vermeiden von Volksbeteiligung, sondern die Suche nach einer Erhöhung von Qualität und Quantität dieser Beteiligung. Damit anerkennt der partizipativ-deliberative Ansatz, dass Politik ein immerwährender Prozess und ein fortwährender Konflikt ist, welcher durch die demokratischen Institutionen zwar in friedlichere Bahnen gelenkt wird, was allerdings die Auseinandersetzung, die Deliberation, nicht überflüssig, sondern gerade eben notwendig macht.

Basierend auf diesen normativen Postulaten müssen nun in einem nächsten Schritt konkrete verfassungsrechtliche Vorschläge erarbeitet werden, um dem deliberativ-partizipativen Ansatz auch praktische Gestalt zu verleihen und ihn in konkrete nationale Verfassungskontexte zu übersetzen; geklärt werden müsste dabei auch die Frage, wie viel Partizipation ein politisches System mit Effizienzanspruch überhaupt verträgt. ${ }^{60}$ Ein für zukünftige Forschung vielversprechender Weg scheint zudem, den partizipativ-deliberativen Ansatz auch im verfassungsrechtlichen Gefüge der Europäischen Union zu situieren und dort nach Anwendungsmöglichkeiten zu suchen. Und nicht zuletzt stellt sich auch die Frage, ob der partizipativ-deliberative Ansatz in Staaten mit bereits weiter fortgeschrittenem Rechtsstaatszerfall, wie etwa in einigen populistisch regierten Staaten Osteuropas, nicht vielleicht noch eine rettende Wirkung haben kann.

60 Siehe Schmidt (Fn. 6), 248. 



\section{Demokratie und Weltanschauung Zur Krise des demokratischen Charakters}

\section{SEBASTIAN ENGHOFER}

\section{Democracy and Worldview}

On the crisis of democratic character

Abstract: For some years now there has been an ongoing discourse about the crisis of democracy. Different causes, from technocratic regimes to globalization, social acceleration or populism and fake news have been identified. Most analyses focus on the relationship between popular sovereignty and the rule of law as equiprimordially principles of liberal democracy. The crisis of democracy is thus often seen on an institutional level, when these two principles are no longer balancing each other. This paper takes the perspective of Hans Kelsen to argue for a deeper understanding: the crisis of democracy begins already with a crisis of democratic world views. Thereby it will be focused on the democratic personality as a counter model to the authoritarian personality. Enriched by findings from moral psychology, the paper closes with a conclusion on how to better understand militant democracy in the wake of a moral crisis of democracy.

Keywords: worldview, crisis of democracy, moral psychology, political education, democratic personality, polarization

\section{Die Krise der Demokratie - ein institutionelles Problem?}

In den letzten Jahren wurden verschiedene Ursachen für das „Sterben der Demokratie“ (Steven Levitsky) identifiziert, sei es aufgrund „postdemokratischer “ ${ }^{{ }_{1}}$, „technokratischer" ${ }^{{ }_{2}}$ oder „postfaktischer" ${ }^{{ }^{3}}$ Entwicklungen.

1 Colin Crouch, Postdemokratie, Berlin: Suhrkamp, 2008.

2 Jürgen Habermas, Im Sog der Technokratie, Kleine politische Schriften, XII, Berlin: Suhrkamp, 2013.

3 Marie-Christine Kajewski, „Wahrheit und Demokratie in postfaktischen Zeiten“, Zeitschrift für Politik 64, Nr. 4 (2017): 454-67. 
In den Kern dieser Analysen rückt dabei stets das Verhältnis von Demokratie und Rechtsstaatlichkeit. Bekanntermaßen handelt es sich bei beiden zwar um „gleichursprüngliche“4, jedoch zugleich latent inkommensurable Prinzipien: das „demokratische Paradoxon" "s, inwieweit minimale Rechtsgarantien der Bürgerrechte durch Mehrheitsentscheide ausgehöhlt werden dürfen, hat im Zuge des postmodernen Diskurses um „radikale Demokratie“6 an Aktualität gewonnen. Gegenwärtige Krisenanalysen der liberalen Demokratie konstatieren dementsprechend häufig eine (drohende) Auflösung dieses Paradoxons zugunsten eines monistischen Demokratieverständnisses, welches sich durch eine Überhöhung der Volkssouveränität gegenüber dem Prinzip der rechtsstaatlichen Bindung von Mehrheitsentscheiden auszeichnet. Meist werden dabei jedoch nur institutionelle Veränderungen betrachtet, so beispielsweise die Aushöhlung der Verfassungsgerichtsbarkeit, die formelle Einschränkung der Presse oder der Wahlfreiheit ${ }^{7}$. Auch im Diskurs um postdemokratische Tendenzen blickt bspw. Colin Crouch vornehmlich auf die gewandelte Rolle von Parteien, Parlamenten und Verbänden ${ }^{8}$, während Ingolfur Blühdorn in seiner Betrachtung der „simulativen Demokratie“9 ebenfalls auf die veränderte Funktionslogik demokratischer Institutionen in der Postdemokratie zu sprechen kommt.

Ernst-Wolfgang Böckenfördes Diktum zufolge „lebt [der freiheitliche, säkularisierte Staat] von Voraussetzungen, die er selbst nicht garantieren kann “ ${ }^{10}$ In vielen aktuellen Krisendiagnosen der Demokratie bleibt jedoch dieser Aspekt unterbelichtet: warum geht auf der sozialpsychologischen Ebene der Wille zur Demokratie verloren? Inwiefern lässt sich noch von einer demokratischen Weltanschauung sprechen?

Bevor die These eingelöst werden kann, dass die gängige Krisendiagnose der Demokratie zu sehr auf Symptome und zu wenig auf zugrunde liegende weltanschauliche Ursachen fokussiert, soll zuerst anhand der Anthropologie von Hans Kelsen herausgearbeitet werden, worin die weltanschaulichen Grundlagen des demokratischen Rechtsstaates liegen.

\footnotetext{
4 Jürgen Habermas, Faktizität und Geltung: Beiträge zur Diskurstheorie des Rechts und des demokratischen Rechtsstaats, Frankfurt am Main: Suhrkamp, 1992.

5 Chantal Mouffe, The democratic paradox, London: Verso, 2000.

6 Ernesto Laclau und Chantal Mouffe, Hegemony and socialist strategy: towards a radical democratic politics, 2nd ed, Radical thinkers, London: Verso, 2014.

7 Steven Levitsky und Daniel Ziblatt, How democracies die, First edition (New York: Crown, 2018); Yascha Mounk, The people vs. democracy: why our freedom is in danger and how to save it, Cambridge: Harvard University Press, 2018.

8 Crouch (Fn 1), Postdemokratie.

9 Ingolfur Blühdorn, Simulative Demokratie, Berlin: Suhrkamp, 2013.

10 Ernst Wolfgang Böckenförde, Staat, Gesellschaft, Freiheit: Studien zur Staatstheorie und zum Verfassungsrecht, Frankfurt am Main: Suhrkamp, 1976.
} 


\section{Demokratische Weltanschauung}

Die These, wonach eine Demokratie überhaupt von individuell-weltanschaulichen Voraussetzungen lebt, ist innerhalb der politischen Ideengeschichte nicht unumstritten. Prägnant erscheint hier beispielsweise Kants Diktum, wonach ein politisches System auch für ein „Volk von Teufeln ${ }^{{ }_{11}}$ funktionieren müsse - also eine individuelle Eignung für die Demokratie als notwendige Bedingung gerade negiert wird. Demgegenüber existiert in der Ideengeschichte auch eine auf das Individuum ausgerichtete Perspektive, welche ausgehend von der platonischen Gleichsetzung von Seelenleben und Staatsstruktur individuelle Voraussetzungen für bestimmte Staatsformen erkennt. Dies setzt sich in der aristotelischen Tugendlehre fort und führt ideengeschichtlich über Spinoza, Hume und Tocqueville bis hin zu Kelsen. ${ }^{12}$

Für Kelsen ergibt sich die Notwendigkeit einer demokratischen Weltanschauung aus der Erkenntnis, dass auf struktureller Ebene Demokratie und Autoritarismus insofern einander ähnlich sind, als dass beide erst einmal inhaltlich neutrale Mechanismen zur Erzeugung einer sozialen Ordnung darstellen. ${ }^{13}$ In der Auseinandersetzung mit der frühen Psychoanalyse Sigmund Freuds sieht Kelsen jedoch nicht nur einen strukturellen Unterschied hinsichtlich der Art der Ordnungskreation, sondern vor allem auch einen Unterschied hinsichtlich „ihrer seelisch-politischen Situation“. ${ }^{14}$ Während die Demokratie darum bemüht sei, die Masse zur politischen Partizipation zu bewegen und einen Modus und Raum zur Abreaktion ihrer politischen Affekte zu schaffen, verdränge der Autoritarismus umgekehrt jene in eine unterbewusste Sphäre. In der Demokratie beruht „der soziale Gleichgewichtszustand vielleicht tatsächlich mehr auf einem Sich-gegenseitig vertragen "15 wohingegen in der Autokratie die Bereitschaft zum Gehorsam aus der gemeinsamen Unterwerfung unter den Herrschaftswillen eines Einzelnen erfolgt.

Die unterschiedliche seelisch-politische Situation von Demokratie und Autokratie korreliert für Kelsen, ähnlich dem Schmittschen Diktum zur politischen Theologie, mit der individuellen Weltanschauung der Bürger. Die unterbewusste Verdrängung des politischen Affektes in der Autokratie erfolgt aus einer Geisteshaltung heraus, welche bereits auf epistemologischer Ebene absolute Wahrheiten für erkennbar hält und

11 Immanuel Kant, Zum ewigen Frieden, Kants Werke: Akademie-Textausgabe, Bd. Band VIII (Berlin: De Gruyter, 1968), 366.

12 Für eine detailliertere ideengeschichtliche Aufschlüsselung der Verbindung von Weltanschauung und Staatsform siehe Adolf Menzel, „Demokratie und Weltanschauung“, Zeitschrift für öffentliches Recht 2 (1921): 701-18.

13 Hans Kelsen, Verteidigung der Demokratie: Abhandlungen zur Demokratietheorie, hg. von Matthias Jestaedt und Oliver Lepsius, Tübingen: Mohr Siebeck, 2006, 223.

14 Kelsen (Fn. 13), Verteidigung der Demokratie, 202.

15 Kelsen (Fn. 13), Verteidigung der Demokratie, 202. 
daraus politische Antworten auf die Frage nach dem , guten Leben' ableitet. ${ }^{16}$ Der Wille zur Unterwerfung unter einen einzelnen Herrscher und der Verzicht auf eigene aktive Partizipation am Gemeinwesen erfolgt aus dem Vertrauen in den Wahrheitsgehalt der politischen Botschaft der Führungsfigur; eine einmal erkannte Wahrheit bedarf keiner weiteren Diskussion mehr, sondern erfordert ,angesichts der alles überragenden Autorität dieses absolut Guten [...] den bedingungslosen und dankbaren Gehorsam gegenüber demjenigen, der, im Besitz des absolut Guten, dieses weiß und will, dem Führer ${ }^{\text {“17. }}$.

Die bisherige Perspektive Kelsens, wonach bestimmte Weltanschauungen mit Präferenzen für politische Formen einhergehen, wurde schon länger auch aus anderen Disziplinen beleuchtet - exemplarisch ist hier einerseits die These der politischen Theologie zu nennen, in der prägnanten Formulierung Carl Schmitts:

Das metaphysische Bild, das sich ein bestimmtes Zeitalter von der Welt macht, hat diesselbe Struktur wie das, was ihr als Form ihrer politischen Organisation ohne weiteres einleuchtet. ${ }^{18}$

Diese These lässt sich nicht nur auf klassische Religionen übertragen, sondern findet sich auch in der Diskussion um politische Kultur und politische Ideologien, welche als „politische Religionen“"19 ebenfalls eine Verbindung zwischen Weltanschauung und politischem Denken vermitteln. Anders als viele politikwissenschaftliche und anthropologische Perspektiven auf diese Verbindung wird aus psychologischer Perspektive auch nach der Herkunft der individuellen Weltanschauung gefragt. Wegweisend für die Verbindung zwischen diesen beiden Konzepten waren die Studien zum autoritären Charakter ${ }^{20}$, welche aus persönlichen Einstellungen und Charaktereigenschaften heraus eine Neigung hin zu autoritären und faschistischen Tendenzen ableiten. Allerdings krankt die Perspektive, welche in der Einstellungsforschung fortgesetzt wurde, an der Fokussierung auf Faschismus-förderliche Persönlichkeitsmerkmale und Einstellungen; andere Formen der antidemokratischen Gesinnung, welche jedoch ebenfalls im Wiederspruch zum Kelsenschen Ideal des demokratischen Charakters stehen, lassen sich damit schwer erfassen. ${ }^{21}$

16 Insofern erscheint der Autoritarismus in diesem Sinne als ,politische Religion; da er - im Sinne Leo Strauss - auf die (ideologische) Offenbarung als Quelle der Erkenntnis setzt Leo Strauss, Studies in Platonic political philosophy (Chicago: University of Chicago Press, 1983), Kap. 7.

17 Kelsen (Fn. 13), Verteidigung der Demokratie, 242.

18 Carl Schmitt, Politische Theologie. Vier Kapitel zur Lehre von der Souveränität, Zehnte Auflage (Berlin: Duncker \& Humblot, 2015), 50.

19 Eric Voegelin, Die politischen Religionen, Paderborn: Fink, 2007.

20 Max Horkheimer, Erich Fromm, und Herbert Marcuse, Hrsg., Studien über Autorität und Familie: Forschungsberichte aus dem Institut für Sozialforschung, 2. Aufl.; Reprint der Ausg. Paris, 1936, Schriften des Instituts für Sozialforschung 5, Lüneburg: zu Klampen, 1987.

21 Zur Kritik daran siehe zusammenfassend William F. Stone und Laurence D. Smith, „Authoritarianism: 
Kelsen definiert den demokratischen Charakter wie folgt:

Es ist der Typus des relativ herabgesetzten Ich-Gefühls, der Typus des sympathisierenden, friedliebenden, nicht-aggressiven Menschen, des Menschen, dessen primärer Aggressionstrieb nicht so sehr nach außen, sondern nach innen gekehrt ist und sich hier als Neigung zur Selbstkritik und erhöhte Disposition für Schuldgefühl und Verantwortungsbewusstsein äußert. ${ }^{22}$

Dementsprechend hält der demokratische Charakter „nicht nur die eigene, sondern [...] auch die fremde, gegenteilige Meinung zumindest für möglich ${ }^{{ }^{\prime 23}}$ und verzichtet auf die Erkenntnis absoluter Werte. Stattdessen bildet der philosophische und politische Relativismus für Kelsen die weltanschauliche Basis der Demokratie. So erscheint es folgerichtig, wenn Kelsen die Sophisten als Verfechter der Demokratie, Platon hingegen als Metaphysiker und damit Gegner der Demokratie bezeichnet ${ }^{24} .{ }^{25}$ Mit dem demokratischen Charakter verbindet Kelsen auch die die Freiheit der Wissenschaft und insbesondere den Glauben an die Möglichkeit ihrer Objektivität, drückt sich darin doch der Wunsch nach Erkenntnis als primärer Triebkraft der Wissenschaft aus. In dem Moment, in welchem Wissenschaft als Mittel zum Zwecke politischer Veränderung gesehen wird und sich Wissenschaftler denn auch als politische Akteure verstehen, verkommt sie „zu einer bloßen Ideologie der jeweiligen Macht ${ }^{{ }^{\prime 26}}$. Die Krise der Demokratie geht für Kelsen mit einer Krise der freien Wissenschaft einher.

Demgegenüber skizziert Kelsen den autoritären Charakter ${ }^{27}$ als den Typus des übersteigerten Ich-Bewusstseins, der nicht in der Lage sei, seine Mitmenschen als gleichwertig anzuerkennen und deswegen eine natürliche Präferenz für Herrschaft und Unterwerfung besitze ${ }^{28}$. Der Wille zur Macht übersteigt dabei klar den Willen zu neutraler Erkenntnis, sodass auch die Wissenschaft nicht mehr von politischen Interessen unabhängig betrieben werde. Zudem verliert sich damit auch der Glaube an die Kraft der Vernunft - die autoritäre Weltanschauung überhöht dementsprechend das Irrationale und metaphysische Denken.

Left and Right", in Strength and Weakness, hg. von William F. Stone, Gerda Lederer, und Richard Christie, New York, NY: Springer New York, 1993, 144-56.

22 Kelsen (Fn. 13), Verteidigung der Demokratie, 239.

23 Kelsen (Fn. 13), Verteidigung der Demokratie, 241.

24 Kelsen (Fn. 13), Verteidigung der Demokratie, 225.

25 Dabei zitiert Kelsen die bereits erwähnte Schrift Menzels Menzel, „Demokratie und Weltanschauung“.

26 Kelsen (Fn. 13), Verteidigung der Demokratie, 243.

27 Der Begriff des autoritären Charakters geht bekanntlich auf die Arbeiten von Wilhelm Reich, Erich Fromm und der Frankfurter Schule zurück Horkheimer, Fromm, und Marcuse, Studien über Autorität und Familie. Der Begriff wird hier bewusst verwendet, um auf die Ähnlichkeiten zur Skizze Kelsens hinzuweisen, siehe dazu Björn Milbradt, Über autoritäre Haltungen in „postfaktischen“ Zeiten, Opladen Berlin Toronto: Verlag Barbara Budrich, 2018, 22.

28 Kelsen (Fn. 13), Verteidigung der Demokratie, 286. 


\section{Die Krise der demokratischen Weltanschauung aus moralpsychologischer Perspektive}

Die Verbindung zwischen Weltanschauung und politischer Form wird von Kelsen auf die Gleichung Empirismus/Skeptizismus = Demokratie und Metapysischer Idealismus $=$ Autokratie ${ }^{29}$ verkürzt; ein erkenntnistheoretischer Idealismus, welcher absolute Wahrheiten für erkennbar hält, tendiert eher zur Autokratie, ein skeptischer Empirismus zur Demokratie. Diese Darstellung ist jedoch noch unterkomplex, da sie nicht genau erfasst, woher die Präferenz für eine empirische oder metaphysische Ausrichtung der Philosophie kommt.

Die Frage, wie bestimmte Weltanschauungen und Moralvorstellungen entstehen, wird empirisch vor allem von der Moralpsychologie betrachtet. Diesen Ansatz verfolgt auch Jonathan Haidt mit seinem „sozial-intuitionistisches Modell moralischen Urteilens “ ${ }^{\text {“о }}$. Seine Synthese aus kulturpsychologischen und aktuellen soziobiologischen Erkenntnissen zur Bedeutung von Intuitionen für menschliche Entscheidungen ${ }^{31}$ gilt als vielversprechender Ansatz für weitergehende Betrachtungen, ${ }^{32}$ nicht zuletzt da Haidt selbst sein Modell als möglichen Erklärungsansatz politischer Konfliktlinien sieht. ${ }^{33}$

Haidt geht davon aus, dass moralische Aussagen nicht aufgrund rationaler Erwägungen zustande kommen, sondern (gemäß seiner Metapher des ,intuitive dog and its rational tail “34) nur das Symptom tiefer liegender moralischer Intuitionen sind, die ihrerseits nicht unmittelbar artikuliert oder begründet werden. ${ }^{35}$ Moralische Urteile entstehen nicht als Folge rationaler Überlegung zu einem moralisch relevanten Problem; stattdessen fällen Menschen intuitiv moralische Urteile, die sie danach rational begründen. ${ }^{36}$

Diese Intuitionen sind dabei genetisch bedingt, erfahren allerdings aufgrund kultureller Überformung eine jeweils unterschiedliche spezifische Ausgestaltung. Dafür verwendet Haidt die Metapher der moral taste buds: ähnlich wie bei der Zunge Geschmacksknospen angeboren sind und den Menschen zur Empfindung unterschiedlicher Geschmäcker befähigen, existieren auch für die Entstehung von Moralurteilen ,Rezeptoren; welche auf ein bestimmtes Moralempfinden ausgerichtet sind; in welchem Umfang diese moralischen Geschmacksknospen dann aktiviert werden, hängt

\footnotetext{
29 Kelsen (Fn. 13), Verteidigung der Demokratie, 112-13.

30 Jonathan Haidt, „The Emotional Dog and Its Rational Tail: A Social Intuitionist Approach to Moral Judgment., Psychological Review 108, Nr. 4 (2001): 814-34.

31 Daniel Kahneman, Thinking, Fast and Slow, London: Penguin Books, 2012.

32 Günter Becker, Kohlberg und seine Kritiker: die Aktualität von Kohlbergs Moralpsychologie, Wiesbaden: VS, 2011, 399.

33 Jonathan Haidt, The Righteous Mind: Why Good People Are Divided by Politics and Religion, London: Penguin Books, 2013.

34 Haidt (Fn. 30), „The Emotional Dog and Its Rational Tail“.

35 Haidt (Fn. 33), The Righteous Mind, 141.

36 Haidt (Fn. 33), The Righteous Mind, Kap. 3.
} 
von kultureller Prägung und persönlichen Erfahrungen ab. ${ }^{37}$ Haidt identifiziert ursprünglich fünf, später sechs ${ }^{38}$ unterschiedliche moralische Intuitionen, welche die Wurzel bestimmter moralischer Werturteile darstellen: (1) Abwenden von Schaden von und Fürsorge für eigene Nachkommen bzw. Angehörige der eigenen Familie, (2) Fairness und Wechselseitigkeit als Ausdruck der dyadischen Kooperation mit Nicht-Verwandten, (3) Eigengruppe/Loyalität als Mechanismus zur Aufrechterhaltung der Kooperation von Gruppen, (4) Autorität und Respekt zur Aushandlung von Machtverhältnissen innerhalb der sozialen Gruppe, und (5) Reinheit/Heiligkeit zur Vermeidung von körperlichen Gefahren durch Infektion oder Vergiftung, und (6) Freiheit und Unterdrückung als Mechanismus zur Überwindung übermäßiger und dysfunktionaler Machtansprüche innerhalb und zwischen Gruppen ${ }^{39}$.

Tab. 1 Übersicht über die sechs moralischen Grundintuitionen

\begin{tabular}{|c|c|c|c|c|c|c|}
\hline & $\begin{array}{l}\text { Schaden/ } \\
\text { Fürsorge }\end{array}$ & $\begin{array}{l}\text { Fairness/ } \\
\text { Wechsel- } \\
\text { seitigkeit }\end{array}$ & $\begin{array}{l}\text { Eigengrup- } \\
\text { pe/Loyalität }\end{array}$ & $\begin{array}{l}\text { Autorität/ } \\
\text { Respekt }\end{array}$ & $\begin{array}{l}\text { Reinheit/ } \\
\text { Heiligkeit }\end{array}$ & $\begin{array}{l}\text { Freiheit/ } \\
\text { Unterdrük- } \\
\text { kung }\end{array}$ \\
\hline Zweck & $\begin{array}{l}\text { Schutz/ } \\
\text { Sorge um } \\
\text { Nachkom- } \\
\text { men und } \\
\text { Verwandte }\end{array}$ & $\begin{array}{l}\text { Nutzen zie- } \\
\text { hen aus Ko- } \\
\text { operation } \\
\text { mit nicht } \\
\text { verwandten } \\
\text { Individuen }\end{array}$ & $\begin{array}{l}\text { Bildung von } \\
\text { Gruppenzu- } \\
\text { sammenge- } \\
\text { hörigkeit }\end{array}$ & $\begin{array}{l}\text { Nutzbrin- } \\
\text { gende Be- } \\
\text { ziehungen } \\
\text { innerhalb } \\
\text { sozialer } \\
\text { Hierarchien }\end{array}$ & $\begin{array}{l}\text { Schutz vor } \\
\text { Kontamina- } \\
\text { tion }\end{array}$ & $\begin{array}{l}\text { Überwin- } \\
\text { dung dys- } \\
\text { funktionaler } \\
\text { Macht- } \\
\text { ansprüche }\end{array}$ \\
\hline $\begin{array}{l}\text { Ursprüng- } \\
\text { licher } \\
\text { Auslöser }\end{array}$ & $\begin{array}{l}\text { Leid und } \\
\text { Hilflosigkeit } \\
\text { eigener } \\
\text { Kinder oder } \\
\text { Verwandten }\end{array}$ & $\begin{array}{l}\text { Betrug, Ko- } \\
\text { operation }\end{array}$ & $\begin{array}{l}\text { Gefahr für } \\
\text { die Gruppe }\end{array}$ & $\begin{array}{l}\text { Gesten der } \\
\text { Unterwer- } \\
\text { fung und } \\
\text { Dominanz }\end{array}$ & $\begin{array}{l}\text { Abfall- } \\
\text { produkte, } \\
\text { Kranke }\end{array}$ & $\begin{array}{l}\text { Unter- } \\
\text { drückung }\end{array}$ \\
\hline $\begin{array}{l}\text { Typische } \\
\text { Emotionen }\end{array}$ & Mitgefühl & $\begin{array}{l}\text { Ärger, } \\
\text { Dank- } \\
\text { barkeit, } \\
\text { Schuldge- } \\
\text { fühl }\end{array}$ & $\begin{array}{l}\text { Stolz auf } \\
\text { Gruppe, } \\
\text { Zugehörig- } \\
\text { keitsgefühl, } \\
\text { Wut auf } \\
\text { Verräter }\end{array}$ & $\begin{array}{l}\text { Respekt, } \\
\text { Furcht }\end{array}$ & Ekel & $\begin{array}{l}\text { Wut, } \\
\text { Hilflosigkeit }\end{array}$ \\
\hline $\begin{array}{l}\text { Damit } \\
\text { verbundene } \\
\text { Tugenden }\end{array}$ & $\begin{array}{l}\text { Fürsorge, } \\
\text { Freundlich- } \\
\text { keit }\end{array}$ & $\begin{array}{l}\text { Vertrauens- } \\
\text { würdigkeit, } \\
\text { Gerechtig- } \\
\text { keit }\end{array}$ & $\begin{array}{l}\text { Loyalität, } \\
\text { Patriotis- } \\
\text { mus, Auf- } \\
\text { opferung } \\
\text { für Gruppe }\end{array}$ & $\begin{array}{l}\text { Gehorsam } \\
\text { und Ach- } \\
\text { tung }\end{array}$ & $\begin{array}{l}\text { Mäßigung, } \\
\text { Keuschheit, } \\
\text { Reinlichkeit, } \\
\text { Frömmig- } \\
\text { keit }\end{array}$ & $\begin{array}{l}\text { Eintreten } \\
\text { für Unter- } \\
\text { drückte, } \\
\text { Bekämp- } \\
\text { fen von } \\
\text { Machtmiss- } \\
\text { brauch }\end{array}$ \\
\hline
\end{tabular}

Quelle: eigene Darstellung auf Basis von Jonathan Haidt, The Righteous Mind.

37 Haidt (Fn. 33), The Righteous Mind, 132-33.

38 In der 2013 erschienen Monographie The Righteous Mind nimmt Haidt eine Erweiterung um die sechste Dimension Liberty/Oppression vor Haidt, 146; Jonathan Haidt u. a., „Understanding Libertarian Morality: The Psychological Dispositions of Self-Identified Libertarians“, hg. von Liane Young, PLoS ONE 7, Nr. 8 (21. August 2012).

39 Haidt (Fn. 33), The Righteous Mind, 213. 
Den Fluchtpunkt von The Righteous Mind bildet jedoch weniger die ausführliche Darlegung der Moralgenese, sondern vor allem die soziale Bedeutung der sechs verschiedenen „moral taste buds“" ${ }^{\text {" }}$. Unter dem Schlagwort „morality binds and blinds ${ }^{{ }^{41}}$ argumentiert er, dass Menschen zum größeren Teil soziale Wesen als isolierte Individuen seien $^{42}$. Moral trage wesentlich dazu bei, die Kooperation innerhalb einer Gruppe und zwischen Gruppen zu ermöglichen, was evolutionär vorteilhaft gewesen sei. Dementsprechend liegt der Zweck von Moralvorstellungen nicht darin, möglichst rational begründet zu sein oder einem abstrakten Gerechtigkeitsideal zu genügen, sondern darin, als sozialer Kitt zu fungieren ${ }^{43}$. Eine Konfrontation mit abweichenden Moralvorstellungen führt dementsprechend nicht primär zum Hinterfragen der eigenen Position, sondern wird als Angriff auf die eigene Identität wahrgenommen.

Für Haidt scheitert der Austausch zwischen Liberalen und Konservativen vor allem aufgrund des unzureichenden Verständnisses für die moralischen Intuitionen des jeweils Anderen. Während Liberale vor allem auf die Dimension Schaden/Fürsorge und Fairness/Wechselseitigkeit abzielten, seien Konservative tendenziell mit einer breiteren Moralmatrix ausgestattet, welche alle sechs Felder abdecke ${ }^{44}$. Eine gegenseitige Verständigung über moralischer Fragen zwischen Konservativen und Liberalen wird für Haidt somit auf zwei Ebenen behindert: zum einen würden Argumente auf einer rationalen Ebene ausgetauscht; Moral bilde sich aber vorwiegend auf intuitiv-emotionale Art und werde dann lediglich ex post rational verkleidet. Ein rationaler Austausch über moralische Fragen sei damit von vorneherein unzureichend, wenn er diese irrationale Komponente nicht berücksichtige. Zum anderen würden insbesondere Liberale, aufgrund ihrer engeren Moralkonzeption, nicht nachvollziehen, dass auch Konservative moralische Gründe für ihre Überzeugungen haben und könnten deswegen mit ihnen auch nicht auf einer Ebene miteinander in den Diskurs treten. ${ }^{45}$

Damit lässt sich an die Konzeption Kelsen anknüpfen: da der demokratische Charaktertypus ,absolute Wahrheit und absolute Werte menschlicher Erkenntnis für verschlossen hält, darf er nicht nur die eigene, sondern muss auch die fremde, gegenteilige Meinung für möglich halten“. ${ }^{46}$ Haidts Konzeption des righteous mind liefert hier eine Erklärung dafür, warum diese Aufgeschlossenheit gegenüber anderen Meinungen und Moralvorstellungen so selten gelingt.

Um die durch unterschiedliche Moralmatrizen bedingte Polarisierung aufzubrechen, fordert Haidt eine Kultivierung positiver sozialer Kontakte: nur wenn man sein Gegenüber auf einer intuitiven Ebene kennen lerne, bevor aufgrund unterschiedlicher

40 Haidt (Fn. 33), The Righteous Mind, 131.

41 Haidt (Fn. 33), The Righteous Mind, 219.

42 Haidt (Fn. 33), The Righteous Mind, 219-55.

43 Haidt (Fn. 33), The Righteous Mind, Abschn. III.

44 Haidt (Fn. 33), The Righteous Mind, 351, 357.

45 Haidt (Fn. 33), The Righteous Mind, Kap. 12.

46 Kelsen (Fn. 13), Verteidigung der Demokratie, 241. 
Moralvorstellungen der „hive switch“ Individuen in einer blockierende Verteidigungshaltung dränge, könne ein Überwinden sozialer Gräben gelingen. So werde beispielsweise die Polarisierung im Kongress auch dadurch bedingt, dass Abgeordnete kaum Freizeit in Washington verbringen und dementsprechend keine parteiübergreifenden sozialen Kontakte knüpften ${ }^{47} .{ }^{48}$ Diese Argumentation wird auch durch die vielfältige Literatur zur Kontakthypothese Gordon Allports vertreten. ${ }^{49}$

\section{Krisendiagnosen der Demokratie}

Betrachtet man nun die gängigen Krisendiagnosen der Demokratie aus der bisher entwickelten, weltanschaulich-psychologischen Perspektive, so zeigt sich, dass sich die Probleme nicht erst auf institutioneller, sondern bereits auf weltanschaulicher Ebene manifestieren. Dies soll im Folgenden exemplarisch anhand der Beziehung von Populismus zur Technokratie skizziert werden.

Als gängiges Definitionskriterium populistischer Bewegungen gilt die Gegenüberstellung von ,dem Volk' und ,den Eliten': das Volk sei als reine Entität unverdorben ${ }^{\text {so }}$ und nicht verantwortlich für politische Missstände; diese seien sämtlich die Schuld von ,Eliten', welche von Selbstgerechtigkeit, Korrumpierbarkeit, Geldgier und Hass auf das eigene Volk getrieben würden. ${ }^{.1}$ Dabei erheben Populisten ein „moralisches Monopol auf Repräsentation",s2 setzen auf das Anbieten einfacher Lösungen für komplexe Probleme und bestärken damit ein manichäisches Weltbild.

In der Auseinandersetzung mit populistischen Bewegungen links wie rechts wurde sowohl von Seiten der Forschung als auch von Seiten der dadurch herausgeforderten etablierten Politik auf Aufklärung gesetzt: populistischen Argumenten wird mit dem Aufzeigen inhaltlicher Fehler, dem Verweis auf verfassungsrechtliche Undurchführbarkeit ihrer Politik und anderen, rationalen Gegenargumenten begegnet. ${ }^{53}$ In der Metapher von Jonathan Haidt gesprochen richtet sich der antipopulistische Diskurs

47 Haidt (Fn. 33), The Righteous Mind, 363.

$48 \mathrm{Zu}$ der Veränderung der sozialen Interaktion von Kongressabgeordneten in Washington siehe Michael J. Barber und Nolan McCarty, "Causes and Consequences of Polarization“, in Solutions to Political Polarization in America, hg. von Nathaniel Persily, Cambridge: Cambridge University Press, 2015, 35, Juliet Eilperin, Fight Club Politics: How Partisanship Is Poisoning the House of Representatives, Lanham, Md.: Rowman \& Littlefield, 2007.

49 John F. Dovidio, Peter Samuel Glick, und Laurie A. Rudman, Hrsg., On the nature of prejudice: fifty years after Allport, Malden, MA: Blackwell Pub, 2005.

50 Mounk (Fn. 7), The people vs. democracy, 7.

51 Mounk (Fn. 7), The people vs. democracy, 36-41.

52 Jan-Werner Müller, „Capitalism in One Family“, London Review of Books, 2016.

53 Cas Mudde und Cristóbal Rovira Kaltwasser, Populism: a very short introduction, Very short introductions, New York, NY: Oxford University Press, 2017, Kap. 6. 
somit an den rationalen „Schwanz“, nicht jedoch an den emotionalen „Hund“54: begegnet man emotionalen Argumenten mit Fakten, ohne die zugrunde liegenden moralischen Intuitionen anzusprechen, sind die Chancen, das Gegenüber zu überzeugen, eher gering - man signalisiert damit zwar die eigene Tugendhaftigkeit gegenüber Gleichgesinnten, erreicht aber meist keinen sinnvollen Austausch. ${ }^{55}$

Das Adressieren der rationalen Komponente, welche nur die sichtbare ex-post Rechtfertigung bereits vorhandener intuitiver Moral- und Weltanschauungen darstellt, , $^{66}$ begünstigt darüber hinaus abschottende, auf Selbstrechtfertigung angelegte Verhaltensweisen und verschärft damit das Problem der Polarisierung, welches dann wiederum populistisch ausgenutzt werden kann. Der deswegen lancierten Forderung, man müsse Populisten inhaltlich ernst nehmen als Reaktion auf tatsächlich existente Problemfelder der liberalen Demokratie ${ }^{57}$ ist zuzustimmen. Aus der Perspektive der Moralpsychologie kann dabei erhellend wirken, dass Populisten - ähnlich wie es Jonathan Haidt dem (amerikanischen) Konservatismus attestiert ${ }^{58}$ - besser in der Lage sind, auf der emotionalen und intuitiven ,Klaviatur' der menschlichen Psyche zu spielen, ${ }^{59}$ wenn sie Bedürfnisse emotional aufgreifen, welche ansonsten (gefühlt) vernachlässigt wurden. Durch die Konstruktion eines vermeintlich homogenen Volkskörpers adressieren (Rechts-)populisten die Eigengruppe/Loyalität-Dimension, wenn auf die Bedrohung der Gruppe von außen wie von innen verwiesen wird; die Fairness-Dimension bspw. in Fragen der Reichweite des Sozialstaats oder Diskussionen um Dankbarkeit gegenüber dem Staat; die Autoritätsdimension im Hinblick auf abnehmenden Respekt vor Autoritätspersonen wie Lehrern, Polizisten usw.; die Reinheitsdimension in der Ablehnung einer moralischen Beliebigkeit oder Diskursen um importierte Gesundheitsprobleme; die Schadensdimension bspw. in der Ablehnung vermeintlich indoktrinierender Lehrinhalte und die Freiheitsdimension in dem Narrativ, als Einzige das unterdrückte Volk zu befreien. Auch linker Populismus adressiert - wenn auch etwas enger - verschiedene Moraldimensionen, beispielsweise Fairness in der Kapitalismus- und Globalisierungskritik; Freiheit im Emanzipationsnarrativ, oder Reinheit im Hinblick auf Umweltproblematiken.

Damit einher geht jedoch der Verlust an einer demokratischen Weltanschauung im Sinne Kelsens: die starke Moralisierung „bindet und blendet "60 und verhindert eine

54 Haidt (Fn. 30), „The Emotional Dog and Its Rational Tail“.

55 Haidt (Fn. 33), The Righteous Mind, 58.

56 Haidt (Fn. 33), The Righteous Mind, Kap. 2 und 3.

57 Philip Manow, Die politische Ökonomie des Populismus, Originalausgabe, Erste Auflage, Sonderdruck, Edition Suhrkamp 2728, Berlin: Suhrkamp, 2018.

58 Haidt (Fn. 33), The Righteous Mind, Kap. 8.

59 Martha Craven Nussbaum, The monarchy of fear: a philosopher looks at our political crisis, First Simon \& Schuster hardcover edition, New York: Simon \& Schuster, 2018.

60 Haidt (Fn. 33), The Righteous Mind, 217. 
Sichtweise auf den politischen Gegner, welche diesen als „nicht als etwas Wesensfremdes, nicht als Feind, sondern als gleich und daher als Freund, erlebt“" ${ }^{\prime}$

Eine solche Verengung der Perspektive, wonach der Autoritarismus sich dadurch auszeichne, dass er „immer schon alles weiß“, ${ }^{62}$ findet sich jedoch spiegelbildlich auch im technokratischen Krisendiskurs der Demokratie. Während der Populismus sich insofern durch ein antidemokratisches Weltbild auszeichnet, als dass die monistische Überhöhung der Volkssouveränität mit der zurückhaltenden Perspektive eines kritischen Rationalismus schwer vereinbar ist, zeichnet sich auch das technokratische Weltbild durch die Vorstellung absoluter Erkenntnis und absoluter Werte aus, welche „alternativlos“" ${ }^{\text {63 }}$ umzusetzen sind.

Die Vorstellung einer technokratischen Herrschaft im Sinne einer „Abdankung der politischen Vernunft zugunsten eines Sachlichkeits-Ideals" ${ }^{\text {"64 }}$ findet sich dabei nicht nur in der berüchtigten TINA-Rhetorik („There Is No Alternative“) einer Margaret Thatcher oder Angela Merkel, welche wesentlich zum Aufstieg der AfD (Alternative für Deutschland) beigetragen hat. ${ }^{65}$ Auch im Kontext der Digitalisierung lässt sich aus verschiedenen Richtungen das Argument vernehmen, politische und soziale Probleme ließen sich eindimensional durch technische Expertise lösen. ${ }^{66}$ Dieser „Solutionismus“ ${ }^{167}$ erscheint dabei also genauso eindimensional wie der populistische Glaube an die unbeschränkte Volkssouveränität: anstatt auf die Vielschichtigkeit sozialer Probleme und den Wert einer sozialen Ordnung zu bauen, welche als „politische Form des sozialen Friedens, des Ausgleichs der Gegensätze, der gegenseitige[n] Verständigung auf einer mittleren Linie“68 der Beschränktheit menschlichen Wissens Rechnung trägt, vertraut der „technologischer Totalitarismus“69 auf den Glauben an die Macht der Algorithmen und offenbart sich dadurch als Form der politischen Theologie.

Zusammenfassend lässt sich also festhalten, dass sowohl im Phänomen der populistischen als auch technokratischen Herausforderung der liberalen Demokratie das Problem nicht primär in der Zerstörung demokratischer Institutionen und ihrer Funktionslogik liegt. Der Ursprung liegt vielmehr bereits vorher in einer eindimensionalen, anti-pluralistischen und damit antidemokratischen Weltanschauung, welche absolute

61 Kelsen (Fn. 13), Verteidigung der Demokratie, 239.

62 Milbradt (Fn. 27), Über autoritäre Haltungen in „postfaktischen“ Zeiten, 22.

63 Zum Begriff der Alternativlosigkeit und der Verbindung zum Populismus siehe Astrid Seville, Der

Sound der Macht: eine Kritik der dissonanten Herrschaft, München: C. H. Beck, 2018.

64 Kelsen (Fn. 13), Verteidigung der Demokratie, 235.

65 Seville (Fn. 63), Der Sound der Macht.

66 Für eine populärwissenschaftliche Übersicht zu dieser Perspektive siehe Evgeny Morozov, Smarte neue Welt: digitale Technik und die Freiheit des Menschen, München: Blessing, 2013. Für eine aktuellere, jedoch deutlich differenzierte Herangehensweise an das Problem der digitalen Technokratie siehe Parag Khanna, Technocracy in America: Rise of the Info-State, 2017.

67 Morozov (Fn. 66), Smarte neue Welt.

68 Kelsen (Fn. 13), Verteidigung der Demokratie, 233.

69 Frank Schirrmacher, Hrsg., Technologischer Totalitarismus. Eine Debatte. Berlin: Suhrkamp, 2015. 
Werte für erkennbar und umsetzbar hält, darüber aber den Wesenskern der Demokratie - die Möglichkeit zum Dissens - negiert.

\section{Folgerungen für das Konzept der wehrhaften Demokratie}

Das Konzept der wehrhaften Demokratie, welches ursprünglich von Karl Loewenstein $^{70}$ in der Auseinandersetzung mit den autoritären Systemen der 193oer entwickelt wurde, versucht eine Abschaffung der Demokratie mittels ihrer eigenen Methoden zu unterbinden. ${ }^{71}$ Die Vorstellung, dass die Demokratie auch gegen den Willen einer (vermeintlichen oder tatsächlichen) Mehrheit bestehen müsse und somit einen Wert an sich darstellt, wurde von Kelsen entschieden abgelehnt:

Bleibt [die Demokratie] sich selbst treu, muss sie auch eine auf Vernichtung der Demokratie abgerichtete Bewegung dulden, muss sie ihr wie jeder andere politischen Überzeugung die gleiche Entwicklungsmöglichkeit gewähren. [...] Eine Demokratie, die sich gegen den Willen der Mehrheit zu behaupten, gar mit Gewalt zu behaupten versucht, hat aufgehört, Demokratie zu sein. ${ }^{72}$

In dieser Ablehnung der wehrhaften oder streitbaren Demokratie wird erneut Kelsens Relativismus sichtbar - die Demokratie stellt für ihn primär einen wertneutralen Mechanismus zur Schaffung einer sozialen Ordnung dar, und kreiert aus sich selbst heraus keinen Wert, dessen Verteidigung eine Verletzung der eigenen Prinzipien rechtfertigen würde. Als überzeugter Demokrat bleibt Kelsen „seiner Fahne treu [...], auch wenn das Schiff sinkt" ${ }^{\text {"73 }}$ und fasst damit das demokratische Paradoxon der Selbstzerstörung der Demokratie im Namen ihrer Verteidigung ${ }^{74}$ zusammen.

Das Konzept der wehrhaften Demokratie belastet jedoch nicht nur die normative Problematik, inwieweit ein Eingriff in demokratische Beteiligungsrechte durch Parteien- und Organisationsverbote und Einschränkungen der Meinungsfreiheit im Namen der Demokratie gerechtfertigt sein könnte. ${ }^{75}$ Darüber hinaus greift die wehrhafte Demokratie nur reaktiv ein - demokratiefeindliche Gruppierungen werden beispielsweise

70 Karl Loewenstein, „Militant Democracy and Fundamental Rights, I“, American Political Science Review 31, Nr. 3 (Juni 1937): 417-32, Karl Loewenstein, „Militant Democracy and Fundamental Rights, II“, American Political Science Review 31, Nr. 4 (August 1937): 638-58.

71 Bastiaan Rijpkema und Anna Asbury, Militant Democracy: The Limits of Democratic Tolerance, Routledge Studies in Extremism and Democracy, Volume 4, (London; New York: Routledge, 2019.

72 Kelsen (Fn. 13), Verteidigung der Demokratie, 237.

73 Kelsen (Fn. 13), Verteidigung der Demokratie, 237.

74 Rijpkema und Asbury (Fn. 70), Militant Democracy, 5.

75 Das Fehlen einer normativ gehaltvollen Begründung, inwieweit dies legitim sein könne, stellt somit einen gravierenden Makel der militant democracy dar. Vergleiche dazu zusammenfassend Rijpkema und Asbury (Fn. 70), Militant Democracy. 
erst dann verboten, wenn eine reelle Chance auf erfolgreiche Machtergreifung besteht. ${ }^{76}$ Diese Zurückhaltung der Institutionen der wehrhaften Demokratie darf angesichts des prekären Verhältnisses von Freiheit und Sicherheit und der damit verbunden Gefahr eines „zu Tode Schützens“"77 der Demokratie zweifelsohne nicht gering geachtet werden.

Vor dem Hintergrund der bisher entwickelten Ausführungen zu den Voraussetzungen der Demokratie erscheint diese Konzeption der wehrhaften Demokratie dennoch unzureichend, da sie stark auf Repression und wenig auf Prävention ausgerichtet ist. Prävention soll dabei jedoch explizit nicht im strafrechtlichen oder polizeilichen Sinne verstanden werden, sondern als Erziehung zur Demokratie. Gerade in der liberalen Traditionslinie der Demokratietheorie wird dieser Gedanke einer tugendethischen Befähigung zur Demokratie im Namen der individuellen Freiheit abgelehnt oder aus pragmatischen Erwägungen für unmöglich angesehen, was sich exemplarisch am bekannten Böckenförde-Diktum ${ }^{78}$ ablesen lässt.

Gleichwohl zeigt aber die Erfahrung der inneren Aushöhlung der Demokratie, dass ein solcher Prozess schleichend stattfindet und mit dem Verlust der demokratischen Weltanschauung im Sinne Kelsens hin zu einer „Vereindeutigung“79 beginnt. ${ }^{80}$ Die Förderung einer politischen Kultur, welche im Sinne Kelsens auf gegenseitige Verständigung abzielt und sich dabei der sozialpsychologischen Erkenntnisse hinsichtlich der Machbarkeit einer solchen Erziehung zum demokratischen Charakter bedient, erscheint somit als notwendige Ergänzung der repressiven Seite der wehrhaften Demokratie. Das bekannte Diktum Böckenfördes, wonach der Staat die moralischen Grundlagen seiner eigenen Existenz nicht schaffen kann, darf umgekehrt nicht missverstanden werden in dem Sinne, dass der demokratische Staat keinen positiven Einfluss auf die weltanschaulichen Grundlagen seiner Existenz ausüben könne. In diesem Sinne muss wehrhafte Demokratie sehr viel früher anfangen, eine Kultur der Offenheit, des Glaubens an wissenschaftliche Erkenntnis und der zivilisierten Auseinandersetzung zu fördern. ${ }^{81}$ Politische Bildung in und außerhalb von Schulen stellt somit ei-

76 Dabei sei an das NPD-Verbot in Deutschland 2017 erinnert, welches im zweiten Anlauf erneut scheiterte. Zwar wurde die Verfassungsfeindlichkeit der NPD festgestellt, ein Verbot erfolgte aber nicht. Dies wurde explizit mit der geringen Bedeutung der NPD und der Unwahrscheinlichkeit ihrer Machtergreifung begründet Bundesverfassungsgericht, „BVerfG, Urteil des Zweiten Senats vom 17. Januar 2017“, 2017, https:// www.bundesverfassungsgericht.de/SharedDocs/Downloads/DE/2017/o1/bs20170117_2bvbooo113.pdf? blob $=$ publicationFile\&v $=4$.

77 Hans-Gerd Jaschke, „Streitbare Demokratie | bpb“, bpb.de, 2006, http://www.bpb.de/politik/extre mismus/rechtsextremismus/41891/streitbare-demokratie.

78 Böckenförde (Fn. 10), Staat, Gesellschaft, Freiheit, 60.

79 Thomas Bauer, Die Vereindeutigung der Welt: über den Verlust an Mehrdeutigkeit und Vielfalt, Ditzingen: Reclam, 2018.

80 Levitsky und Ziblatt (Fn. 7), How democracies die.

81 Als ein Projekt, welches sich diesem Ziel explizit verschrieben hat, sei das Konstanzer Modell der Dilemma-Diskussion (KMDD) genannt Georg Lind, Moral ist lehrbar: Handbuch zur Theorie und Praxis moralischer und demokratischer Bildung, München: Oldenbourg, 2009. 
nen essentiellen Bestandteil einer Demokratie dar; allerdings nur solange, als sie nicht selbst zum Sprachrohr vermeintlich alternativloser Inhalte wird. Kelsens Widerstand gegen eine inhaltlich präzisierte Demokratie und sein Insistieren darauf, dass es vor allem um die Aufrechterhaltung des demokratischen diskursiven Rahmens gehe, muss hier als wertvolle Mahnung gesehen werden: eine tugendethische politische Bildung zur Demokratie darf gerade nicht inhaltliche Werte vorgeben, sondern muss sich darauf beschränken, einen zivilisierten modus vivendi mit der Pluralität und Ambiguität verschiedener, teils einander widersprechender Weltbilder zu vermitteln. 
V. Antagonisten des demokratischen Rechtsstaats 



\title{
„Political Correctness" als Kern der Politik Mit Nietzsche gegen die neue Rechte
}

\author{
KARSTEN SCHUBERT
}

"Political Correctness" as the Core of Politics

With Nietzsche Against the New Right

Abstract: The article develops the concept of "political judgement" - a new, affirmative understanding of the phenomena which are criticized as "political correctness" by both right-wing and liberal commentators. To that end, it takes the right's claims, that "political correctness" is slave morality in Nietzsche's sense seriously and proposes a systematic reading of a right-nietzschean position. Connecting current „political-correctness“-critique and Nietzsche in this way allows for a deeper understanding of the right-wing rationality and the affective energy underlying the critique. Through contrasting this right-nietzschean reading with its systematic opposite, a left-nietzschean position, the article shows that the essence of politics is to redesign norms which distribute privilege. What is critically labelled "political correctness" is, thus, better captured by the notion of "political judgment", because - given an interest in emancipation - such politics should not be demonized when they limit the freedom provided by undeserved privileges.

Keywords: political correctness, Nietzsche, New Right, Alt Right, privilege, contemporary critique, racism, homophobia, emancipation, political judgment

\section{Einleitung}

„Political Correctness“ ist zu einem zentralen politischen Kampfbegriff geworden. Der rechten Bewegung gelang es in einem langen Kampf um kulturelle Hegemonie, das Konzept der „political correctness“ im Mainstream-Diskurs zu etablieren und mit 
ihrem gezielten Übertreten Wählerstimmen zu gewinnen. ${ }^{1}$ Manche, meist rechte oder konservative Kommentatoren haben „political correctness“ mit Nietzsches Konzept der Sklavenmoral beschrieben und kritisiert. ${ }^{2}$ Ich werde im Folgenden zeigen, dass diese Verschaltung von Nietzsches Sklavenmoral und „political correctness“ zutreffend und sogar hilfreich ist. Durch die Unterfütterung mit Nietzsches Macht- und Subjekttheorie erfährt man mehr über die kritisierte Repression der „political correctness“. Dies eröffnet gleichzeitig die Möglichkeit einer tiefer angelegten Kritik der Debatte um „political correctness“, die darüber hinausgeht, nur zu zeigen, dass „political correctness" eine strategische Kampagne der Rechten ist, die Argumente der Meinungsfreiheit fälschlicherweise anführt.

Denn Nietzsches Subjekt- und Machtkritik muss nicht konservativ verstanden werden; sie kann auch progressiv interpretiert werden. Aus einer solchen - systematisch, aber nicht hermeneutisch plausibleren - Interpretation von Nietzsches Macht- und Subjekttheorie ergibt sich auch eine andere Beschreibung von „political correctness“ und ihrer Effekte. Politik ist demnach immer ein Kampf um Macht und Ansprüche. Der politische Raum und seine Diskurse sind immer verregelt und sind immer ein Verteilungssystem für Ressourcen und Privilegien. Deshalb ist es für eine progressive Position angebracht, die etablierten Normen kritisch zu hinterfragen und politische Projekte, die sie emanzipativ umschreiben wollen, zu unterstützen.

Die von mir vorgeschlagene Kontrastierung der beiden Nietzsche-Lesarten - vereinfacht als konservativ und progressiv ${ }^{3}$ bezeichnet - ist insbesondere relevant für

1 Siehe dazu Richard Feldstein, Political correctness, 1997; Moira Weigel, Political correctness: how the right invented a phantom enemy. https://www.theguardian.com/us-news/2016/nov/30/political-correct ness-how-the-right-invented-phantom-enemy-donald-trump, 2019-03-22 15:38 und Volker Weiß, Deutschlands Neue Rechte, 2011. Für die deutsche Debatte war Thilo Sarrazin zentral: Thilo Sarrazin, Der neue Tugendterror, 2014.

2 Dieser Diskurs findet sich in erster Linie in rechten Blogs, siehe aus rechter Perspektive Keith Preston, Nietzsche the Visionary. https://affirmativeright.blogspot.com/2014/10/nietzsche-visionary.html, 201903-30 13:22. Eine linke Kritik daran, die darauf abstellt, dass die Rechte Nietzsche falsch lese, unternimmt Sean Illing, The alt-right is drunk on bad readings of Nietzsche. The Nazis were too. https://www.vox. com/2017/8/17/16140846/alt-right-nietzsche-richard-spencer-nazism, 2019-03-30 10:18. Sebastian Kaufmann, Nietzsche und die Neue Rechte, in Nietzsche und die Konservative Revolution, hg. von Sebastian Kaufmann / Andreas Urs Sommer, 2018, 591-620 zeigt, wie sich die deutsche Rechte auf Nietzsche bezieht.

3 „Rechts“ bzw. „konservativ“ und „links“ bzw. „progressiv“ verwende ich als heuristische Begriffe zur Abgrenzung der geschilderten Nietzsche-Interpretationen und der damit zusammenhängenden Positionierungen zu „political correctness“ bzw. zum „politischen Urteilen“. Obwohl die Begriffe an die gängigen Verwendungen in der politischen Alltagssprache anknüpfen, soll dies nicht als eine empirische Hypothese darüber verstanden werden, dass alle (selbst- oder fremdidentifizierten) „Linken“ bzw. „Rechten“ diese Positionen teilen würden. Vielmehr sollen die Begriffe normativ verstanden werden, insofern ich das aus dem Linksnietzscheanismus entwickelte „politische Urteilen“ als eine sinnvolle und richtige Position plausibilisiere. Diese Begriffsverwendung soll auch keine grundsätzliche Gleichsetzung von rechtem und konservativem Denken bedeuten, sondern auf die strukturelle Gleichheit von rechtem und konservativem Denken bezüglich der Ablehnung des „politischen Urteilens“, also privilegienkritischer intersektionaler Politik, hinweisen. 
Linke und Liberale, die sich grundsätzlich mit progressiven Zielen identifizieren, aber dennoch die "political-correctness"-Kritik teilen, die heute weit über rechte und konservative Diskurse hinaus Verbreitung gefunden hat. Solche Linken und Liberalen unterstützen grundsätzlich emanzipative Politik, aber finden den Zwang zum Gendern, das Abhängen von Kunstwerken oder das Umschreiben von Kinderbüchern problematisch, nutzlos oder unverhältnismäßig. Ihnen gegenüber kann mit dieser Kontrastierung plausibilisiert werden, dass emanzipative Projekte auch dann unterstützenswert sein können, wenn sie auf den ersten Blick wie eine individuelle Freiheitseinschränkung wirken. Dies bringe ich durch das Konzept des „politischen Urteilens" auf den Begriff, das ein affirmatives Verhältnis zur Privilegienkritik ausdrückt, die als "political correctness" kritisiert wird. ${ }^{4}$

\section{Die rechte Nietzsche-Interpretation und „political correctness”}

Eine rechte Nietzsche-Interpretation kann hermeneutisch durchaus gerechtfertigt werden. Und Nietzsches Kritik an der Sklavenmoral, durch die eigentlich Ohnmächtige mächtig geworden sind, nun die ganze Gesellschaft dominieren und durch ein Korsett moralischer Regeln quälen, lässt sich tatsächlich auf „political correctness" beziehen. ${ }^{5}$ Weil aber niemand, auch die Rechten nicht, diese Verbindung systematisch entwickelt hat, leiste ich dies im Folgenden. Dies hilft beim Verständnis der rechten Rationalität, was die Voraussetzung für deren Kritik ist. Dabei wird die affektive Energie, mit der "political correctness“ heute kritisiert wird, durch die Lektüre Nietzsches verständlicher, weil sie in seinem Text so beeindruckend auftritt: Diese affektive Energie speist sich aus der Ablehnung der Schwachen, gerade wegen ihrer Schwäche. ${ }^{6}$ Anhand dreier Argumente von Nietzsches Kritik der Sklavenmoral, die sich systematisch auch in der Kritik an „political correctness“ finden, erläutere ich den Hass auf die Sklaven bzw. die „politisch Korrekten“. Die drei aufeinander aufbauenden Argumente sind: Das naturalistische Argument, das psychologistische Argument und der daraus folgende Unterschied zwischen schlecht und böse.

1. Naturalismus bei Nietzsche ${ }^{7}$ bezeichnet dessen Position, dass es tatsächlich und natürlicherweise Starke und Schwache bzw. Herren und Sklaven gibt und dass sich

4 Damit soll keine Verbindung zum Werk Hannah Arendts angedeutet sein.

5 Ronald Beiner, Dangerous Minds, 2018 ist allerdings die einzige aktuelle Interpretation, die Nietzsche als rechten Denker ernstnimmt und dafür kritisiert. Beiner bleibt allerdings essayistisch und gibt keine Einsichten zur "political correctness“.

6 Vgl. Friedrich Nietzsche, Zur Genealogie der Moral, in Jenseits von Gut und Böse/Zur Genealogie der Moral, 1999, 245-412 (367f.).

7 Nietzsches Naturalismus ist Gegenstand vieler Debatten und Linksnietzscheaner_innen lehnen ihn ab. Er kann aber durchaus hermeneutisch verteidigt werden, siehe Brian Leiter, Routledge philosophy guidebook to Nietzsche on morality, 2007. 
aus diesen Unterschieden „normative“ Forderungen ableiten lassen: das Recht des Stärkeren. Kurz: Es gibt Starke und Schwache, und eine Moral zu verlangen, die auf den egalitären Ausgleich dieser natürlichen Umstände abzielt, ist demnach absurd. ${ }^{8}$ Genauso basiert die zeitgenössische Debatte um „political correctness“ auf Naturalismus: Rassistische, sexistische und heteronormative Argumente werden als Naturalismen präsentiert, die aber wegen der „political correctness“ nicht ausgesprochen werden dürften.

2. Psychologismus in der Genealogie der Moral. Nietzsches Erklärung für das seiner Ansicht nach unsinnige Aufkommen der Moral ist psychologistisch. Nach Nietzsche erfinden „die Unterdrückten, Niedergetretenen, Vergewaltigten“ die Moral „aus der rachsüchtigen List der Ohnmacht heraus“.9 Sie ertragen es nicht, schwach zu sein und wollen sich ermächtigen, indem sie hinterlistig ihre eigene Schwäche als ein moralisches Gut definieren, das dann als Gerechtigkeit, Mitleid, Egalität, Rücksicht auftritt. Sie empfinden dabei Lust an der Bestrafung der Starken. Der gekränkte Schwache versuche so seine (ihm natürlich gegebene) gesellschaftliche Position umzukehren, wobei die Lust an der so motivierten Bestrafung umso ausgeprägter sei, je schwächer er ist.

Nietzsche fasst dieses psychopathologische Verhältnis zwischen Schwäche, der Lust an Regelsetzung und Sanktionierung auch mit dem Begriff des „Ressentiments“. Dieser Begriff wird heute auch benutzt, um damit die psychische Konstellation der „politisch Korrekten“ zu adressieren, deren „Tugendterror“ als eine verbitterte und aggressive Reaktion der Ermächtigung aus einer Situation der Schwäche interpretiert wird. ${ }^{10}$ Oder denen vorgeworfen wird, ihre Schwäche als politisches Kapital zu nutzen (soziale Positionierung, Selbstviktimisierungskultur). Wichtig ist hervorzuheben, dass dieses psychologistische Argument nicht ohne die erste, naturalistische Prämisse funktioniert. Den Schwachen kann nur eine solche psychische Reaktion diagnostiziert werden, wenn sie als Schwache naturalisiert werden; und auch nur dann kann man auf ihre Aggression mit solchem Hass reagieren. Würde man sie als Opponenten grundsätzlich gleichen Ranges wahrnehmen („Herren“), dann würde man ihre Aggression als Ausdruck ihrer Stärke interpretieren und ihren Sieg gegebenenfalls akzeptieren müssen. Doch auf Basis des Naturalismus führt der Psychologismus zu Hass.

3. Sklavenmoral - schlecht vs. böse. Nietzsche kritisiert auch den Effekt der Schwachen auf die Moral, den er für hochproblematisch hält. Dies beschreibt er mit dem Gegensatz von „gut und schlecht“, der die Codierung der „guten“ Herrenmoral ist. Und der Gegensatz von „gut und böse“ wiederum ist die Codierung der „schlechten“

\footnotetext{
8 Vgl. Nietzsche (Fn. 5), 279.

9 Nietzsche (Fn. 5), 280.

10 Nach diesem problematischen Muster verfährt die im Band Patsy l’Amour laLove (Hrsg.), Beissreflexe, 2017 geübte Kritik. Kritisch dazu siehe Floris Biskamp, Beissreflexe: Je böser, desto mehr freu'n sich die Leut'! https://www.ruhrbarone.de/beissreflexe-je-boeser-desto-mehr-freun-sich-die-leut/144213\#_ftn7, 17-07-04 04:44.
} 
Sklavenmoral. „Böse“ im Gegensatz zu „schlecht“ ist deshalb problematisch, weil die Moral hier immer schon mit Hass, Aggression und der Lust an der Bestrafung auftritt. Insbesondere kritisiert Nietzsche damit, dass die so entstehende Sklavenmoral rein reaktiv und negativ bleibt." Er diagnostiziert, dass die Sklavenmoral im Abendland hegemonial geworden ist und hält sie für ursächlich für die Strafkultur und das schlechte Gewissen. Denn erst durch aggressive Strafen bilde sich ein Moralgedächtnis heraus. Es werde dem Menschen quasi eingeprügelt und führe so zum schlechten Gewissen und einer quälenden und lähmenden Kultur der Schuld, wofür die Schwachen verantwortlich seien..$^{2}$

In der zeitgenössischen „political-correctness"-Kritik findet man Diagnosen des Untergangs der politischen Kultur, die nach genau demselben Muster funktionieren. Der „Tugendterror" und „Meinungsterror" durch eine Minderheit, die aber so mächtig imaginiert wird, dass sie die gesamte politische Kultur dominiere, führe zu drakonischen Strafen bei Nichtbeachtung der gerade geltenden „politisch korrekten“ Regeln. Und er führe zu einer Kultur der ständigen gegenseitigen Schuldzuweisung, Lähmung des Diskurses, zu internalisierter Selbstkontrolle und permanentem schlechten Gewissen. Damit sei „political correctness" rein negativ, reaktiv und nicht schöpferisch wie Nietzsches Sklavenmoral.

An dieser systematischen Unterfütterung der These vieler Rechter, die sich auf Nietzsche als Gewährsmann für die Kritik an „political correctness“ berufen, kann man die Tiefenstruktur der "political-correctness"-Kritik besser verstehen: sie beruht auf den drei vorgestellten Argumenten mitsamt ihren Prämissen. Alle drei Argumente das naturalistische, das psychologistische und das vom Bösen - formen, aufeinander aufbauend, eine kohärente politische Position Nietzsches und der „political-correctness"-Kritik, die sich als Privilegienverteidigung zusammenfassen lässt. Der Naturalismus essentialisiert die Differenz zwischen Starken und Schwachen, Privilegierten und Nichtprivilegierten, und bildet die Basis für die Ablehnung von privilegien- und machtkritischer Politik. Der Psychologismus unterfüttert diese Position mit Hass und disqualifiziert Privilegienkritik als Psychopathologie. Der darauf folgende Begriff des Bösen zeigt auf, welche Konsequenz die Moral der Schwachen für die Allgemeinheit bzw. für die Starken hat: Gewalt, Angst, schlechtes Gewissen, reine Negativität und daraus folgende Lähmung.

In der Rekonstruktion dieser Position wird eine zentrale Eigenschaft der „political-correctness"-Kritik sichtbar: eine Form/Inhalt Verschiebung. Ein inhaltliches Anliegen - nämlich die Verteidigung von Privilegien - soll durchgesetzt werden, doch die Argumente dafür sind auf einer formellen Ebene angesiedelt: die Kritik der rein reaktiven und negativistischen Sklavenmoral, die Freiheiten einschränkt und zur Ver-

11 Vgl. Nietzsche (Fn. 5), $270 \mathrm{f}$.

12 Vgl. Nietzsche (Fn. 5), 279 und 311. 
breitung von Qualen durch Strafen und das schlechte Gewissen führt. Die Frage danach, für welches inhaltliche Ziel welche Qualen vertretbar sind und welche nicht, kann und soll in diesem Rahmen nicht gestellt werden. Dies würde zu einer Differenzierung führen, die gerade vermieden werden soll. Die unterstellte Allgemeinheit der diagnostizierten Freiheitseinschränkungen ist ja gerade die Stärke des Wechsels auf die formale Ebene - sonst würde noch unverhohlener sichtbar sein, dass das Ziel der Schutz partikularer Privilegien ist. Diese Direktheit tritt in Nietzsches Naturalismus offener zutage als in der zeitgenössischen „political-correctness“-Kritik, die auf das Thema der Meinungsfreiheit fokussiert. Die Ausbuchstabierung von „political correctness" anhand Nietzsches Sklavenmoral zeigt so das systematische Gesicht der „political-correctness“-Kritik. Kurz: Der normative Ausgangspunkt ist eine Differenz zwischen Schwachen und Starken, Niederen und Höheren, die verteidigt werden soll. Nietzsche und die „political-correctness“-Kritik sind die Apologie des Bestehenden, stärker noch, die (Re-)Kreation autoritärer Differenz - denn Differenz so zu naturalisieren kreiert erst autoritäre Praxis. ${ }^{13}$ Politik ist für den konservativ interpretierten Nietzsche und seine zeitgenössischen Anhänger also die Durchsetzung der partikularen Werte der Starken. Sie sollte mithin radikal aristokratisch sein. ${ }^{14}$

\section{Politik als „politisches Urteilen” - die linksnietzscheanische Bewertung von "political correctness”}

Der zentrale Unterschied zwischen der rechten und der progressiven Nietzsche-Interpretation ist, dass die rechte Interpretation einen Kampf zwischen guter Herrenmoral und schlechter Sklavenmoral im Hier und Jetzt sieht, während die progressive Nietzsche-Interpretation die generelle Vermachtung aller Moral in den Mittelpunkt rückt, also einer radikalen Immanenzperspektive folgt. ${ }^{15}$ So wird Nietzsche in der progressiven Perspektive zum Stichwortgeber der kritischen Sozialphilosophie im Allgemeinen, weil er prototypisch das Verhältnis zwischen Gesellschaft und Individuum problematisiert und es als generell vermachtet darstellt. In diesem Sinne betont Martin Saar, dass Nietzsches Kritik am schlechten Gewissen auf Sozialisation in toto abzielt und auf deren Kosten hinweist ${ }^{16}$ - und das heißt gerade, dass sie nicht überwunden

13 Dieser Befund lässt sich mit empirischen Studien anreichern, beispielsweise die Diagnosen in Heitmeyers „Deutschen Zuständen“ zu einer neuen rohen Bürgerlichkeit: Wilhelm Heitmeyer (Hrsg.), Deutsche Zustände, 2015.

14 Vgl. Alfons Reckermann, Lesarten der Philosophie Nietzsches, 2008, 260, $265 \mathrm{ff}$.

15 Vgl. Paul J. M. Van Tongeren, Nietzsche and Ethics, in A Companion to Nietzsche, hg. von Keith Ansell Pearson, 2008, 391.

16 Martin Saar, Das Trauma des Werdens - Nietzsche gegen die Identität, unveröffentlichtes Manuskript, Beitrag erscheint in Anthony Jensen / Carlotta Santini (Hrsg.), Friedrich Nietzsche zwischen Geschichte und Gedächtnis. 
werden kann. Das Kernanliegen der progressiven Nietzsche-Interpretation ist dann, mit Nietzsche ein begriffliches Instrumentarium zu entwickeln, mit dem das Leiden durch und die Kosten der Sozialisation, die zum schlechten Gewissen, oder allgemeiner, zur Internalisierung von Werten und Handlungsnormen führt, aufzudecken und $\mathrm{zu}$ kritisieren. Nietzsche hilft durch seinen Konstruktivismus und seine radikale Perspektivität gerade dabei, die arbiträre und kontingente Machtverteilung in geltenden gesellschaftlichen Normen zu sehen. Er wird so zum genauen Gegenteil dessen, was die Rechten aus ihm machen, nämlich eine Optik zur Exposition von Ungerechtigkeit und gewaltvoller Unterdrückung selbst noch in neutral scheinenden Regeln, Normen und Institutionen, mit anderen Worten: zur Sichtbarmachung von Privilegien.

Um die progressive Nietzsche-Interpretation zu konturieren, kontrastiere ich die drei oben rekonstruierten Elemente der rechten Interpretation mit ihren progressiven Gegenstücken. Die Progressiven sehen Konstruktivismus statt Naturalismus, das Eintreten für die Unterdrückten statt psychologistischer Kritik, und das führt zum Begriff des „politischen Urteilens“ statt sklavenmoralischer „political correctness“. Die folgende Schilderung der progressiven Position folgt dabei einer anderen Methode als die hermeneutische Rekonstruktion der rechten Position im letzten Abschnitt. Sie führt wesentlich weiter vom Text weg und fasst zusammen, wie die zeitgenössische Sozialtheorie zentrale Elemente von Nietzsches Denken, insbesondere vermittelt durch Foucault, produktiv aufnimmt. Sie entspricht weniger dem „Geist“ von Nietzsches Text als die hermeneutisch rekonstruierte rechte Position, beruht aber auf plausibleren Prämissen. Diese plausibleren Prämissen wurden in der kritischen Sozialphilosophie von vielen Autoren gerechtfertigt, Nietzsche ist links interpretiert einer von ihnen - doch ihre Plausibilität haben sie unabhängig von Nietzsche.

1. Konstruktivismus statt Naturalismus. Nietzsches Genealogie der Moral zeigt, dass die jeweiligen Positionen der Stärke und der Schwäche in einer Gesellschaft nicht natürlich gegeben sind, sondern das Resultat von Kämpfen, Machtregimen, Institutionen und Subjektivierungen. Diese Einsicht des Linksnietzscheanismus hat insbesondere über die Foucault-Rezeption große Verbreitung in die gesellschaftskritische Theorie und Praxis gefunden. ${ }^{17}$ Um die strukturelle Dimension von Macht, die Handlungsoptionen eröffnet und verschließt, zu adressieren, wird heute der Begriff der Privilegien verwendet. Und die Kritik von Privilegien ist systematischer Kern von „political correctness“."18

17 Vgl. zu Foucaults Subjektivierungsbegriff und der daraus folgenden Neukonzipierung des Freiheitsbegriffs Karsten Schubert, Freiheit als Kritik, 2018.

18 Der Privilegienbegriff ist deswegen tiefennietzscheanisch, weil er im Gegensatz zur nur auf die, Opfer blickenden Gleichstellungspolitik auch die Profiteure der gesellschaftlichen Machtverhältnisse fokussiert. Wenn Gesellschaft ein Kampf um Macht ist, dann ist es illusorisch, die Benachteiligten besserzustellen, ohne dass die Privilegierten benachteiligt werden. Der Grund für die Benachteiligung sind die Privilegien. 
2. Perspektive der Unterdrückten statt Psychologismus. Aus dieser Interpretation von Nietzsches Macht- und Subjekttheorie leitet sich dann das Gegenteil des pathologisierenden rechtsnietzscheanischen Psychologismus ab, nämlich die Perspektive der Opfer einzunehmen. Diese normative Position kann natürlich in Nietzsches Machtmetaphysik nicht letztbegründet werden - das gilt aber für alle normativen Positionen und ist auch nicht nötig. Denn dass Moral letztlich auf Macht zurückgeführt werden kann, führt nicht zu totalem Relativismus und dem Recht des Stärkeren, sondern lässt Raum für normatives Argumentieren. Es reicht deshalb, zu zeigen, dass die Perspektive der Unterdrückten plausibler ist als die rechtsnietzscheanische Normativität des Rechts des Stärkeren. Solche postfundamentalistische Normativität kann beispielsweise durch Verfahren der immanenten Kritik plausibilisiert werden. ${ }^{19}$

3. Politisches Urteilen statt sklavenmoralischer „political correctness“. Der normative Gegenbegriff zur passiv-aggressiven und reaktiven Sklavenmoral ist die schöpferische, kreative, freie Herrenmoral, die Werte aktiv setzt, ohne dabei immer schon auf einen Feind zu reagieren. Doch die linksnietzscheanische Interpretation von Nietzsches Machttheorie der Immanenz entblößt diese Entgegensetzung als falsch. Denn die von Nietzsche als unschuldig und friedlich imaginierte Herrenmoral der freien Setzung ist tatsächlich nur denkbar als Effekt von Privilegien in bestehenden Machtstrukturen, die wiederum andere benachteiligen. Die Unterscheidung von Herrenmoral und Sklavenmoral bricht deshalb zusammen; es gibt keine freie Kreativität der Herrenmoral, durch die andere nicht eingeschränkt werden - mit Foucault würde man sagen: Es gibt kein Außerhalb der Macht. Die von Nietzsche kritisierte Sklavenmoral ist deshalb tatsächlich der Kern des Politischen. Das Politische besteht aus Machtkämpfen um die geltende Ordnung, bei der es immer Gewinner und Verlierer gibt, aber nie neutral-unschuldige Gestaltung. ${ }^{20}$ Das Errichten von moralischen Regimen, die sanktionsbewährt durchgesetzt und nach Möglichkeit internalisiert werden, ist der Kern der Politik und keine Pathologie der Schwachen. ${ }^{21}$ Die Kritik an „political correctness“ beruht also auf einem falschen Konzept des Politischen, in dem Vermachtung und Privilegien ausgeblendet werden. Nur vor der liberalen Imagination der neutralen Gewaltlosigkeit der aktuellen Ordnung kann dann „political correctness“ als Gewalt erscheinen. Dabei ist sie einfach Politik - aber eben solche, die die aktuelle Ordnung und ihre Privilegienstruktur in Frage stellt.

Wenn Politik immer im Modus der Sklavenmoral funktioniert, und Emanzipationsbestrebungen mit einer relativen Schlechterstellung der Privilegierten einhergehen,

19 Siehe dazu, wie dies in einer ,postfundamentalistischen' Theorie nach Foucault möglich sein kann, Amy Allen, The Politics of Our Selves, 2008.

20 Zum antagonistischen Konzept des politischen siehe Chantal Mouffe, Über das Politische, 2009.

21 Hier liegt also eine klare Abgrenzung vom klassischen politischen Liberalismus, der Subjekte als vorsozial konzipiert und sie vor politischem Zugriff schützen möchte. Eine solche Vorstellung ist deshalb falsch, weil es keine vom politischen Zugriff freie Subjektivität geben kann. 
ist es kein Wunder, dass "political correctness" als verletzend und aggressiv kritisiert wird - denn sie ist es. Insofern sie aber die Privilegierten verletzt, um die Unterdrückten besserzustellen, ist das völlig unproblematisch, zumindest wenn man ein Interesse an emanzipativer Politik teilt. Denn: Macht, ergo Verletzung, gibt es so oder so, die Frage ist nur, wen es trifft. Um diese affirmative Perspektive auf die Umgestaltung der herrschenden Normen mit dem Ziel der Emanzipation (und deshalb notwendig: dem Entzug von Privilegien) zu beschreiben, schlage ich den Begriff "politisches Urteilen“ vor. Denn der Begriff der "political correctness“ ist für emanzipative Politik verloren; es war ja nie ein affirmativer Begriff zur Beschreibung von emanzipativer Politik, sondern immer nur zu deren Kritik mit dem Ziel, Privilegien zu verteidigen.

Das Konzept des „politischen Urteilens“ weist also darauf hin, dass politischer Fortschritt nicht ohne Folgen für die Privilegierten bleiben kann, auch dann, wenn sie sich manchmal selbst gar nicht so wahrnehmen. Dies ist gerade bei vielen Themen, an denen sich die Gemüter der "political-correctness"-Kritik erhitzen, der Fall, wie beispielsweise bei der sprachlichen Umgestaltung. Das heißt natürlich wiederum nicht, dass es gut ist, blind allen politischen Urteilen von Aktivist_innen zu folgen. Natürlich kann und soll man weiterhin darüber debattieren, ob es beispielsweise sinnvoll ist, zu gendern, oder nicht. Aber oft geht es in den Konflikten um Symbolpolitik zweiter Ordnung. Das heißt, nicht nur die unmittelbare Ebene des Symbolischen (gendern oder nicht) spielt eine politische Rolle, sondern auch, ob und wie auf politische Urteile von Minderheiten reagiert wird. Auf dieser Metaebene geht es dann um die Sichtbarkeit von bestimmten politischen Problemfeldern und die Zeugenschaft über die Allianz mit bestimmten politischen Projekten, die gerade darüber funktioniert, dass neue Normen geschaffen werden. Dies erklärt auch die im „political correctness“ Diskurs immer wieder vorgebrachte Kritik an Konjunktur und die geringe Halbwertszeit der Begriffe und Normen des politischen Urteilens. Das heißt dann: Auch wenn man vielleicht denkt, dass eine partikulare Regelung sinnlos, schädlich oder unangenehm ist, gibt es gute Gründe, sie trotzdem zu unterstützen und eigene Komforteinschränkungen selbst für als sinnlos eingeschätzte Projekte in Kauf zu nehmen, weil die Wirkung auf der symbolpolitischen Metaebene liegt.

Natürlich gibt es auch oft Streitigkeiten darüber, wer überhaupt unterdrückt ist und durch entsprechendes politisches Urteilen bessergestellt werden sollte, gerade innerhalb der Linken. Die hier vorgeschlagene Perspektive kann selbstredend keine allgemeinen Leitlinien für solche Konflikte anbieten. Die Kritik an der „political-correctness"-Kritik zeigt aber eines: Argumente der Form verdecken meist inhaltliche Konflikte und lenken von ihnen ab, deshalb sollte Formkritik mit Vorsicht genossen werden. ${ }^{22}$ Der Linksnietzscheanismus hingegen sensibilisiert dafür, dass es keine neu-

22 Stichwort „Derailing“: Damit ist das zum Entgleisen bringen von Kritik gemeint, indem vom eigentlichen Thema abgelenkt wird. Meist geschieht dies, indem die Aufmerksamkeit auf die Form gelenkt wird. Ein aktuelles Beispiel sind die Fridays for Future Proteste. Dass die in erster Linie mit Bezug darauf, ob 
trale Form gibt, mehr noch, dass das Überschreiten der formalen Rahmungen oft ein gutes Mittel zur Kritik von Machtstrukturen sein kann. An der Debatte um „Beißreflexe" in der queeren Szene kann man die Strategie des Derailing idealtypisch betrachten. Auch dies heißt natürlich nicht, dass die Form nicht thematisiert und kritisiert werden sollte, wenn dies nötig erscheint. Es ist nur ein Plädoyer dafür, das Problem des Derailing im Bewusstsein zu halten und die strategische Sinnhaftigkeit von Formüberschreitungen im Kampf um Macht und Ordnung zu beachten.

\section{Schluss: Hyperchristliche Politik}

Die entwickelte Normativität kann aus Nietzscheanischer Perspektive als hyperchristliche Sklavenmoralität kritisiert werden: Man soll sich zurücknehmen, seine Privilegien reflektieren und sich bereitwillig verletzen lassen; selbst dann noch, wenn man darin keinen Sinn sieht. Das ist aber kein Wunder, weil Moral nur als Sklavenmoral denkbar ist - mit anderen Worten: Moral und Politik bedeuten immer Einfordern, Auffordern, Durchsetzen. Privilegien neu zu verhandeln ist ihr Kerngeschäft, und Offenheit für Forderungen von Deprivilegierten zu zeigen eine Haltung der Gerechtigkeit. Insofern ist die vorgeschlagene Position gar nicht so extrem, denn sie beruht auf bekannten Maßstäben der Gerechtigkeit. Ihre Besonderheit ist nur, dass sie diese mit postnietzscheanischer Macht- und Subjekttheorie unterfüttert. Und so führt dieser Nietzscheanismus zu angemessenem politischem Urteilen.

Schülerinnen und Schüler während der Schulzeit demonstrieren dürfen, geführt wurde, und nicht in Hinblick auf die inhaltlichen Forderungen, ist Derailing. Typischerweise - und wie gezeigt auch bei Nietzsche - geht es in der „political-correctness“-Kritik meist um eine zu aggressiv empfundene Ausdrucksweise. 


\section{Eine illiberale Demokratie und ihre Vorbilder? Die ungarische historische Verfassung in Theorie und Praxis*}

DÓRA FREY

\section{An Illiberal Democracy and its Examples?}

The Historical Constitution of Hungary in Theory and Practice

Abstract: The paper analyses the theoretical and practical issues of the application of the Hungarian historical constitution nowadays. This is a historical constitution like the British constitution, without a single code, but several legal documents, principles and conventions and was in force until the Second World War. According to the Hungarian Constitution adapted in 2011 (now referred to as Basic Law) the achievements of the historical constitution are part of the rules of interpretation of the Basic Law. The main questions of the paper are, whether this historical constitution is suitable as an example of a democratic state in the $21^{\text {st }}$ century, whether and how the achievements and even the content of the historical constitution are ascertainable, and how this is reflected in practice by the Hungarian Constitutional Court.

Keywords: Hungary, constitutional history, illiberal democracy, rule of law, historical constitution, Hungarian Constitutional Court

\section{Einführung}

Demokratie und Rechtstaatlichkeit wurden in den vergangenen Jahren in Ungarn häufig in Frage gestellt und diese Problematik ist Gegenstand hitziger innen- und außenpolitischer sowie fachlicher Diskussionen ${ }^{1}$ - von der Kritik der Opposition so-

* Die deutschen Übersetzungen von Rechtsnormen und Gerichtsurteilen stammen von der Autorin.

1 Zoltán Szente, Jogállam, in: A magyar jogrendszer állapota, hg. von András Jakab / György Gajduschek, 2016, 233-234. 
wie einiger NGOs und Wissenschaftler bis hin zum wegen Verletzung rechtstaatlicher Normen eingeleiteten Verfahren auf Grundlage des Art. 7 EUV. Ziel meines Beitrages ist, die historischen Vorbilder der heute oft in Frage gestellten ungarischen Demokratie zu untersuchen - auch kritisch reflektierend in Hinblick auf die Versuche, die ungarischen Verfassungstraditionen als Legitimationsgrundlage für gegenwärtige Bestrebungen heranzuziehen. Es soll hinterfragt werden, inwieweit die historische Verfassung für die heutige Verfassungsgebung relevant ist und überhaupt relevant sein kann. Ist die wiederholte Erwähnung der Verfassungstraditionen bloße Nostalgie, ein ernst gemeinter Versuch, Elemente früherer Verfassungen wieder in Kraft zu setzen, sind sie gar Teil der Bildung einer neuen Verfassungsidentität? Wie lassen sich Vorbilder für die - öfters als solche bezeichnete - illiberale Demokratie in der ungarischen Verfassungsgeschichte finden? Welche Narrative der nationalen Vergangenheit suggeriert das ungarische Grundgesetz und welche Elemente der „historischen Verfassung“ sind tatsächlich anwendbar und überhaupt in der heutigen Praxis relevant? All diesen Fragen soll im Folgenden nachgegangen werden.

\section{Vorbemerkungen}

Bevor die Thesen dargelegt werden, müssen einige Vorbemerkungen über Begrifflichkeiten und über die historischen Gegebenheiten in Ungarn getroffen werden, da vor allem letztere außerhalb Ungarns kaum oder zumindest nicht hinreichend bekannt sind.

Beim Begriff der illiberalen Demokratie handelt es sich um ein vergleichsweise neues Phänomen der politischen Theorie, welches zuerst 1997 von Fareed Zakaria für diejenigen Staaten benutzt wurde, die zwar formal demokratisch eingerichtet sind, ohne aber die Bedingungen für eine demokratische Machtausübung zu erfüllen, entweder weil die entsprechenden Regelungen in der Verfassung fehlen oder konsequent missachtet werden. ${ }^{3}$ In solchen Staaten werden zwar regelmäßig Wahlen abgehalten, es bestehen Legislativ- und Selbstverwaltungskörperschaften, die Gewaltenteilung und die demokratische Kontrolle der Regierung sind aber trotzdem nicht gewährleistet und die Freiheitsrechte der Staatsbürger kommen nur eingeschränkt zur Geltung. Da der Begriff erst Ende des 20. Jahrhunderts aufgetaucht ist, kann er freilich nicht als Selbstbezeichnung und Selbsteinschätzung von früheren Regimen benutzt worden sein, was die Anwendung dieses Begriffs in historischer Betrachtung erschwert.

2 Am 12. September rief das Europäische Parlament den Rat der Europäischen Union auf, das Verfahren einzuleiten; dies erfolgte schließlich am 16. Oktober 2018, als die ungarische Regierung zur Stellungnahme aufgefordert wurde.

3 Fareed Zakaria, The Rise of Illiberal Democracy, Foreign Affair 76 (1997) (https://www.foreignaffairs. com/articles/1997-11-o1/rise-illiberal-democracy). 
Ins öffentliche Bewusstsein geriet der Begriff der illiberalen Demokratie in Zusammenhang mit Ungarn viel später, als ihn Ministerpräsident Viktor Orbán am 25. Juli 2014 in seiner Rede im Rahmen des alljährlichen Treffens der Sommerakademie in Tusnádfürdő (Băile Tuşnad, Rumänien) - bei der die ungarische konservative Intelligenz und Jugend zusammenkommt -, als Kritik an den westlichen Demokratien und vor allem am Liberalismus gemeint hat. ${ }^{4}$ Da Zakaria selbst den Behauptungen von Orbán energisch widersprochen hat, ${ }^{5}$ liegt die Vermutung nahe, dass die beiden Begriffe nicht zwingend übereinstimmen. Das von Orbán bemühte Verständnis ist unpräzise, in diesem Kontext ist illiberal nämlich eher als Gegenbegriff zu liberal zu verstehen.

In Form einer zweiten Vorbemerkung muss festgehalten werden, dass die historischen Rechtsinstitute in Ungarn stets im Kontext der Gegebenheiten der damaligen Zeit beobachtet und beurteilt werden sollten - die Gegenwart darf nicht in die Vergangenheit rückprojiziert werden. Unser heutiges Verständnis von Beteiligungsrechten, Rechtsstaat und Grundrechtschutz kann nicht als Maßstab für die Vergangenheit herangezogen werden. Diesem Vergleich würde kaum ein politisches System der Vergangenheit standhalten; weder die politische und verfassungsmäßige Ordnung der Anfangsjahre der Vereinigten Staaten noch der englische Parlamentarismus des frühen 19. Jahrhunderts würden gemessen an den heutigen Maßstäben als demokratisch und rechtsstaatlich gelten - denken wir nur an das beschränkte Wahlrecht oder an die Rechtsstellung der Frauen. ${ }^{6}$ Die Untersuchung der demokratischen Traditionen verspricht trotzdem neue Erkenntnisse und vor allem gilt es zu prüfen, wie mit den teilweise fehlenden demokratisch-rechtsstaatlichen Traditionen umgegangen wird. Insbesondere dürfen die fehlenden Traditionen nicht als Entschuldigung für die Mängel des heutigen politischen Systems angeführt werden, denn auch ohne demokratisch-rechtsstaatliche Traditionen sollte der Aufbau eines tragfähigen demokratischen Rechtsstaats möglich sein, wie es viele Beispiele in der Geschichte und in der Gegenwart zeigen.

Die dritte Vorbemerkung betrifft die ungarische historische Verfassung - ein zentraler Begriff des Aufsatzes, da das neue, im Jahre 2011 verabschiedete und seit dem 1. Januar 2012 geltende Grundgesetz Ungarns auf diese bzw. auf seine Errungenschaften hinweist. Was ist die historische Verfassung Ungarns? Sie ist nicht als alter, nicht mehr geltender Verfassungstext zu begreifen, wie etwa die Weimarer Reichsverfassung, sondern vielmehr eine als eine im englischen Sinne verstandene historische Verfas-

4 Deutsche Zusammenfassung der Rede: https://www.zeit.de/politik/ausland/2014-o7/viktor-orbanungarn-demokratie.

5 Fareed Zakaria, The Rise of Putinism, The Washington Post, 31. Juli 2014 (https://www.washingtonpost. com/opinions/fareed-zakaria-the-rise-of-putinism/2014/o7/31/2c9711d6-18e7-11e4-9e 3 b-7f 2 f110c6265_ story.html).

6 Zoltán Szente, A 2011. évi Alaptörvény és a történeti alkotmány összekapcsolásának mítosza, Közjogi Szemle 1 (2019), 4. 
sung. ${ }^{7}$ Es bestand in Ungarn bis zur kommunistischen Verfassung 1949 - mit kurzfristigen Übergangslösungen im Rahmen der Räterepublik 1919 - kein einheitlicher Verfassungstext; vielmehr bestand die ungarische Verfassung aus einer Reihe von verschiedenen Rechtsnormen, die ihrerseits in unterschiedlichen historischen Epochen wurzelten, ergänzt durch Gewohnheitsrecht und grundlegende Rechtsprinzipien. Es war aber auch keine „ungeschriebene“ Verfassung, da das Gewohnheitsrecht und die grundlegenden höchstgerichtlichen Urteile in Rechtsbücher und Sammlungen zusammengefasst wurden, wie das Gewohnheitsrecht im Tripartitum von István Weböczy (1514) oder die Gerichtsurteile im Planum Tabulare (1769). ${ }^{8}$

Das größte Problem der ungarischen historischen Verfassung aus Sicht des Verfassungsrechts besteht darin, dass weder heute noch früher (zu einem Zeitpunkt, zu dem sie sogar noch in Kraft war) Einigkeit darüber herrscht und herrschte, was genau als Teil dieser historischen Verfassung betrachtet werden soll, aus welchen Dokumenten sie besteht und welche Elemente des Gewohnheitsrechtes und der Rechtsprinzipien Verfassungsrang haben..$^{9}$ Man könnte nun annehmen, dass es sich hierbei um eine akademische Fragestellung handle, mit der sich eine Handvoll Rechtshistoriker befassen sollten; da aber die Errungenschaften der historischen Verfassung als Auslegungsregel im ungarischen Grundgesetz herangezogen werden, hat die Frage seit 2012 wieder praktische Relevanz erlangt - denn es wäre schwierig, die Errungenschaften von irgendetwas zu bestimmen, wenn wir selbst nicht wissen, was eigentlich inhaltlich dazugehört. Eben deswegen erachtet ein Teil der Experten, vor allem die Verfassungsrechtler, die historische Verfassung als Auslegungshilfe oder Referenzrahmen für eine moderne Verfassung als völlig ungeeignet. ${ }^{10}$ Der in Bezug auf die historische Verfassung häufig ins Treffen geführte Vorteil ihrer organischen Entwicklung macht die Ermittlung des konkreten Inhalts umso schwerer."

Wenn man die einschlägige Literatur der letzten Jahre sichtet, entstehen - betrachtet aus dem Blickwinkel der positivistischen Geschichtswissenschaft (und der Verfassungslehre) - schwer hinnehmbare Vorstellungen über den Inhalt der historischen Verfassung. ${ }^{12}$ So soll zum Beispiel der so genannte Urvertrag oder Blutsvertrag als Teil der historischen Verfassung gelten; dieser soll irgendwann im 9. Jahrhundert

7 István Kukorelli, Alkotmánytan, 2002, 31.

8 Ádám Rixer, A történeti alkotmány lehetséges jelentéstartalmai, Jogelméleti Szemle 3 (2011) (http://jesz. ajk.elte.hu/rixer47.html).

9 So wurden bereits in der Zeit der Aufklärung diesbezüglich Überlegungen getroffen, siehe dazu: Andor Csizmadia, Hajnóczy József közjogi-politikai munkái, 1958, 236-240.

10 So zum Beispiel: Zoltán Szente, a historizáló alkotmányozás problémái - a történeti alkotmány és a Szent Korona az úja Alaptörvényben, Közjogi Szemle 3 (2011), 1-13; Imre Vörös, A történeti alkotmány az Alkotmánybíróság gyakorlatában, Közjogi Szemle 4 (2016), 44-57.

11 Barna Mezey, Magyar alkotmánytörténet, 2003, 207.

12 So etwa: Zoltán József Tóth, Magyar közjogi hagyományok és nemzeti öntudat a 19. század végétöl napjainkig, 2007; Zsolt Zétényi, Történeti alkotmányunk vívmányai és a 2011. évi Alaptörvény, 2015. 
irgendwo in der osteuropäischen Steppenlandschaft von angeblich sieben Stammesführern (oder Fürsten) der Ungaren geschlossen worden sein und das ewige Bündnis der Stämme und die Bestätigung der Nachkommen von Fürst Álmos als Herrscher der Ungaren beinhalten. ${ }^{13}$ Nach herrschender Meinung der mit der ungarischen Frühgeschichte befassten Historiker ist dieser Urvertrag nicht mehr (und nicht weniger) als eine historische Legende, die die Herrschaft des Árpádenhauses, der ersten Königsdynastie in Ungarn (den Nachkommen von Álmos), legitimieren sollte. ${ }^{14}$ Dem wird entgegengehalten, dass nicht das historische Ereignis selbst (welches wohl in der postulierten Form nie stattgefunden hat und erst recht nicht durch Quellen belegbar ist), sondern die seit Jahrhunderten bestehende Tradition entscheidend sei. ${ }^{15}$

Festzuhalten ist aber jedenfalls, dass über den genauen Inhalt - geschweige denn über die Errungenschaften der ungarischen historischen Verfassung - keine Einigkeit besteht und wohl nie bestanden hat. ${ }^{16}$ Die Thematik rückte in den letzten Jahren in den Mittelpunkt, da laut dem neuen ungarischen Grundgesetz die Errungenschaften der historischen Verfassung als Auslegungsrahmen für das Grundgesetz dienen sollen; dies wird auch von einer Vielzahl an diesbezüglichen Publikationen bestätigt. ${ }^{17}$

\section{Die fehlenden demokratischen, rechtsstaatlichen und republikanischen Traditionen in Ungarn}

Ohne auf Details der ungarischen Geschichte einzugehen, kann festgehalten werden, dass die demokratischen Traditionen lückenhaft sind - auch bedingt durch die in den parlamentarisch geprägten Epochen des Dualismus und der Zwischenkriegszeit gegebene Übermacht der Exekutive. ${ }^{18}$ Die rechtsstaatlichen Traditionen sind - vor allem mit Blick auf die Epoche des Dualismus - jedoch vorhanden. Republikanische Traditionen bestehen demgegenüber - bis auf zwei kurze und aufgrund anderer historischer Ereignisse belasteter Epochen - kaum und vor allem fehlt diese Narrative aus dem Blickwinkel des ungarischen Grundgesetzes. Ein Indiz dafür ist, dass die offizielle Bezeichnung für Ungarn nicht mehr Magyar Köztársaság, also Ungarische Republik, lautet, sondern Magyarország, also (bloß) Ungarn; zudem dient die Heilige Krone, die frühere ungarische Königskrone, als wichtiges Staatssymbol und die ehemaligen Herr-

13 Zétényi, (Fn. 12), 77.

14 Gyula Kristó, Szempontok Anonymus gestájának megítéléséhez, Acta Universitatis Szegediensis: acta historica 66 (1979), 54.

15 Zétényi, (Fn. 12), 78.

$16 \mathrm{Zu}$ den Schwierigkeiten der Feststellung der Errungenschaften der historischen Verfassung bereits in

der Zwischenkriegszeit: György Bónis, Szent István törvényének önállósága, 1939, 3-4.

17 Überblick bei Vörös, (Fn. 10), 48-50.

18 Mezey, (Fn. 11), 160. 
schaftsinsignien - Heilige Krone, Zepter, Reichsapfel, Schwert - sind im Kuppelsaal des ungarischen Parlaments ausgestellt.

Weiters muss festgehalten werden, dass die fehlenden demokratischen und republikanischen Traditionen der früheren ungarischen Geschichte eine historische Gegebenheit sind und die Frage ist, was auf dieser Grundlage aufgebaut werden kann und ob dem Verfassungsgeber bei Betrachtung der historischen Vorbilder das Fehlen der wahren demokratischen Traditionen bewusst ist.

\section{Demokratisch-rechtsstaatliche Traditionen}

Auf welche Verfassungstraditionen kann Ungarn überhaupt zurückblicken? Bis 1848 war Ungarn ein Ständestaat, in dessen Rahmen nur der Adel über politische Rechte verfügte - aus heutiger Sicht sind wenige bis gar keine Elemente der damaligen Verfassung brauchbar. Die Revolution in Pest und Buda am 15. März 1848, die darauffolgende Ernennung der ersten ungarischen Regierung und die Annahme der so genannten Aprilgesetze führten zur Schaffung einer konstitutionellen Monarchie - die Aprilgesetze erfüllten die inhaltlichen Voraussetzungen einer Verfassung größtenteils. Aufgrund des im Herbst 1848 begonnenen Freiheitskampfes gegen die Habsburger und der anschließenden Niederlage im August 1849 blieben aber die meisten parlamentarischen und konstitutionellen Rechtsinstitute unausgereift. ${ }^{19}$

Als 1867 der Ausgleich mit Österreich und dem Herrscherhaus Habsburg erfolgte, waren es aber die Errungenschaften von 1848, auf die man bei der Einrichtung der ungarischen Hälfte der Doppelmonarchie zurückgreifen konnte. Die Zeit der Österreichisch-Ungarischen Monarchie wird heute in Ungarn (und teilweise auch in Österreich) mit einer gewisse Nostalgie als „die gute alte Zeit“ oder „die glückliche Friedenszeit" betrachtet; die Befürworter einer erneuten Anwendung der ungarischen historischen Verfassung beziehen sich gerne darauf.

Man verzichtete erneut, wie schon 1848, auf eine formale Verfassungsgebung und das Konzept der historischen Verfassung als Konvolut vieler Rechtsakte entstand zu dieser Zeit in der ungarischen Rechtswissenschaft. Man verwies auch stets auf das Alleinstellungsmerkmal, wonach im Zuge des 19. Jahrhunderts alle west- und mitteleuropäischen Staaten eine Verfassung erhielten und nur England und Ungarn die historische Verfassung beibehielten. ${ }^{20}$

Zweifelsohne war Ungarn in der Zeit des Dualismus als Teil des als Realunion eingerichteten Österreich-Ungarn eine konstitutionelle Monarchie mit einer parlamentarichen Kontrolle der Regierung, einer Trennung von Verwaltung und Justiz seit 1869,

19 So etwa Gyula Csillag, A régi magyar alkotmány és az 1848-ik és 1867-ik évek közjogi alkotásai, 1871.

20 Vgl. Ákos Timon, Magyar alkotmány-és jogtörténet, különös tekintettel a nyugati államok jogfejlödésére, 1910, 13 . 
einer unabhängigen Gerichtsbarkeit, die auch eine partielle Kontrolle der Beschlüsse der Verwaltung gewährleistete ${ }^{21}$ sowie mit einer auch im europäischen Vergleich beachtlichen Kodifikationswelle, die Regelwerke auf hohem Niveau hervorbrachte und auf deren Grundlage ein modernes Rechtssystem und damit Rechtssicherheit geschaffen wurde. Gleichzeitig wurde das Wahlrecht durch einen sehr hoch angesetzten Steuerzensus stark eingeschränkt, ${ }^{22}$ um die Opposition und die nationalen Minderheiten (die zusammen mehr als Hälfte der Bevölkerung ausmachten) daran zu hindern, die Mehrheit zu erlangen. Die Opposition, die so genannte Unabhängigkeitspartei, war nicht regierungsfähig, da sie dem System des Dualismus gegenüberstand und sich nicht als politische, sondern als „öffentlich-rechtliche Opposition“ bezeichnete. ${ }^{23}$ Das Fehlen einer Verfassung machte sich weniger in der Staatsorganisation bemerkbar, als vielmehr bei den unzureichend garantierten und gewährleisteten politischen Rechten - weder Vereinigungsfreiheit noch Versammlungsfreiheit waren gesetzlich garantiert, die Pressefreiheit unterlag auch gewissen Einschränkungen. ${ }^{24}$ Zudem war Ungarn Ende des 19., vor allem aber Anfang des 20. Jahrhunderts von schweren nationalen und sozialen Konflikten geprägt, die innerhalb des politisch-konstitutionellen Systems des Dualismus nicht zu beheben waren; Reformen, z. B. die des Wahlrechtes, liefen nur schleppend voran.

Auch wenn die ungarische Verfassungsentwicklung in der Zeit des Dualismus durchaus auch positive Elemente aufweisen kann, ist sie ohne kritische Reflexion als Vorbild für einen demokratischen Rechtsstaat im 21. Jahrhundert nur bedingt geeignet - und eine kritische Reflexion erfolgt selten. Es gibt auch nur einige wenige Errungenschaften der historischen Verfassung aus der Dualismus-Zeit, die für die heutige Verfassungsauslegung brauchbar und vor allem nötig sind, weil sie ansonsten in der Verfassung fehlen. ${ }^{25}$ Gleichwohl ist diese Periode durchaus als Vorstufe der Entwicklung zu einem modernen demokratischen Rechtsstaat anzusehen, wobei diese Entwicklung aber durch historische Ereignisse aufgehalten wurde.

Die zweite, heute oft als Bezugspunkt angeführte Ära ist jene der Zwischenkriegszeit, nämlich das so genannte Horthy-Regime, als in Ungarn nach einer kurzen Epoche mit erster Republik und Räterepublik formal das Königreich als Staatsform wiederhergestellt wurde. Es war aber ein Königreich ohne König, stattdessen wurde Konteradmiral Miklós Horthy 1920 zum Reichsverweser gewählt ${ }^{26}$ und die Habsburger im November 1921 auch formal dethronisiert. ${ }^{27}$ Nach dem verlorenen Weltkrieg, dem Zerfall

21 István Stipta, A közigazgatási bíráskodás történeti modelljei, Jogtörténeti Szemle 3 (2015), 45.

22 Zsuzsanna Boros / Dániel Szabó, Parlamentarizmus Magyarországon (1867-1944), 1999, 126-128.

23 András Gergely (hg.), Magyarország története a 19. században, 2003, 374-375.

24 Mezey, (Fn. 11), 150-153.

25 Zoltán Szente, A 2011. évi alaptörvény és a történeti alkotmány összekapcsolásának mítosza, Közjogi

Szemle, 1 (2019), 6.

26 Gesetz Nr. 1 von $1920 \$ 12$.

27 Gesetz Nr. 27 von $1920 \$ 2$. 
der Donaumonarchie und dem Verlust von zwei Dritteln des Staatsgebietes infolge des Friedensvertrags von Trianon wählte man nicht den Weg eines Neuanfangs, wie dies zum Beispiel Österreich oder Deutschland taten, stattdessen wurde auf Rechtskontinuität und auf Traditionen beharrt - und damit eigentlich ausnahmslos alle verfassungsrechtlichen Altlasten der Vorkriegszeit mitübernommen. Das Regime verstand und bezeichnete sich als konterrevolutionär, verneinte aber nicht nur die Revolution, sondern auch die Modernisierung ${ }^{28}$ und versuchte die Revisionsansprüche in Bezug auf jene Gebiete, die infolge des Vertrags von Trianon verlorengegangenen waren, dadurch zu erhärten, dass man die Staatsideologie und die Staatseinrichtung der Dualismus-Zeit beibehielt. So gab es weiterhin keine einheitliche geschriebene Verfassung; vielmehr blieb die historische Verfassung in Kraft, ergänzt durch das I. Gesetz von 1920 über die vorübergehende Handhabung der obersten Staatsmacht, womit die Institution des Reichsverwesers eingeführt und der Exekutive tiefgreifende Ermächtigungen zugesichert wurde. ${ }^{29}$

Demokratische Elemente hat diese Ära aber weniger vorzuweisen und vieles, was im 19. Jahrhundert noch als zeitgemäß galt, wurde im 20. Jahrhundert zunehmend rückständig - so etwa das Fehlen eines allgemeinen Wahlrechts und die Beibehaltung öffentlicher Wahlen (mit Wahlversammlungen) außerhalb der Großstädte. Freiheitsrechte waren weiterhin gesetzlich nicht verankert und wurden eher als Zugeständnis begriffen und als solche „erteilt“.$^{30}$ Es gab einen begrenzten Parlamentarismus - die sozialdemokratische Partei durfte nur in den Städten tätig sein, gegenüber Regimekritikern wurde rigoros - teilweise mit Standrecht - vorgegangen, sowohl die kommunistischen als auch die rechtsradikalen Bewegungen wurden strafrechtlich bekämpft. ${ }^{31}$ Das System nahm immer mehr autoritäre Züge an, die Kompetenzen des Reichsverwesers und der Regierung wurden immer wieder erweitert, zu einer offenen Diktatur kam es aber nie. Oberstes Staatsziel war die Revision des Trianon-Vertrages, dementsprechend wurde Ungarn Verbündeter des Dritten Reiches. Ab Ende der 1930er Jahre wurden die ungarischen Juden zunächst benachteiligt, dann ausgegrenzt und nach der deutschen Besatzung am 19. März 1944 etwa 400.000 von ihnen in das Vernichtungslager Auschwitz deportiert und dort größtenteils ermordet. ${ }^{32}$

Ob diese Epoche und die verfassungsmäßige Ordnung als Vorbild für einen demokratischen Rechtsstaat gelten können - diese Frage kann noch eindeutiger verneint

28 Vgl. Krisztián Ungváry, A Horthy-rendszer mérlege, diszkrimináció, szociálpolitika és antiszemitizmus Magyarországon, 1919-1944, 2013.

29 Mezey, (Fn. 11), 160.

30 Mezey, (Fn. 11), 161-162.

31 Zoltán József Tóth, A rögtönbíráskodás története Magyarországon a XIX-XX. században, Iustum Aequum Salutare 13 (2017), 160-169.

32 Zur Geschichte des Holocaust in Ungarn siehe: Randolph L. Braham, The Politics of Genocide: The Holocaust in Hungary, 2016; Götz Aly / Christian Gerlach, Das letzte Kapitel. Der Mord an den ungarischen Juden 1944-1945, 2004. 
werden als mit Blick auf die Zeit der Doppelmonarchie. Es war ein Staat, der sich von einer gelenkten Demokratie zu einem autoritären System entwickelte, politische Gegner und Andersdenkende verfolgte und an der Ermordung von hunderttausenden seiner Staatsbürger aktiv mitgewirkt hat.

$\mathrm{Ob}$ es als Vorbild für eine illiberale Demokratie gelten kann? Da der Begriff erst Jahrzehnte später eingeführt wurde, taucht er in den zeitgenössischen Dokumenten nicht auf - viele Züge stimmen aber mit denen einer illiberalen Demokratie überein: Es war dies ein Staat mit einem politischen System, das zwar ein Parlament und regelmäßige Wahlen vorschrieb, in dessen Rahmen sich aber kein echter Parlamentarismus entwickeln konnte, wo die Freiheitsrechte nicht verfassungsmäßig garantiert und dementsprechend auch nicht gewährleistet wurden. Eine liberale Einstellung stand dem ganzen System wie auch der politischen Elite fern, ein konservativ-christliches Weltbild war vorherrschend. In der offiziellen Staatsideologie und in der Propaganda spielten die Traditionen - so auch die historische Verfassung und die Heilige-Krone-Lehre - eine wichtige Rolle. .3 $^{33}$

Auch in der Gedächtnispolitik eignet sich diese Ära kaum als Vorbild für eine moderne Demokratie, aus verfassungsrechtlichem und verfassungshistorischem Blickwinkel aber noch weniger. Vor allem wegen dem beinahe krampfhaften Festhalten an den Traditionen brachten diese zweieinhalb Jahrzehnte kaum neue Regelungen auf dem Gebiet des Staatsrechts und der Grundrechte, und jene, die doch verabschiedet wurden - Wahlgesetze, Rechtsnormen zur Pressefreiheit - sind alles andere als progressiv.

\section{Republikanische Traditionen}

Obwohl Ungarn heute eine Republik ist - wobei jedoch der Begriff der Republik aus der offiziellen Bezeichnung des Staates, wie bereits oben beschrieben, eliminiert wurde - und es gegenwärtig weder Absicht noch ernstzunehmende Diskussion über die Änderung der Staatsform gibt, hat Ungarn kaum republikanische Traditionen. Wir leben heute in der dritten ungarischen Republik, die ersten zwei finden aber im Grundgesetz als Teil der Verfassungstradition keine Erwähnung. Die zwei vorangegangenen ungarischen Republiken währten nur kurz und trugen die Last der jeweiligen Epoche mit sich.

Die Proklamation der ersten ungarischen Republik (die Eigenbezeichnung lautete Volksrepublik) erfolgte am 16. November 1918 im Zuge einer bürgerlich-demokratischen Revolution, der so genannten Asternrevolution (28.-31. Oktober 1918), und versprach erstmals in der ungarischen Geschichte ein allgemeines Wahlrecht (auch für

33 Mezey, (Fn. 11), 159. 
Frauen) und damit politische Beteiligungsrechte für alle gesellschaftlichen Schichten sowie weitestgehende Autonomie für die Nationalitäten des historischen Ungarns. Damit stellte sie einen radikalen Bruch zur bisherigen Gesellschafts- und Sozialordnung dar. ${ }^{34}$ Diese Republik, die am 21. März 1919 von einer Proletarierdiktatur, der so genannten Räterepublik, abgelöst wurde, hatte die Rückendeckung nur eines Teils der Bevölkerung und konnte die Herausforderungen nach dem verlorenen Weltkrieg und dem fortschreitenden Zerfall der Österreichisch-Ungarischen Monarchie und damit verbunden die Unabhängigkeitsbewegungen der Nationalitäten nicht eindämmen. In der kollektiven Erinnerung - und bestärkt durch die Propaganda der Horthy-Ära wurde die Republik folglich gleichgesetzt mit einer Zeit des Chaos und des Untergangs des historischen Ungarns (auch wenn wohl keine Staatsform und keine Regierung die Geschehnisse hätte aufhalten können), dadurch wurde die Staatsform der Republik nachhaltig diskreditiert. ${ }^{35}$

Auch der zweite Versuch einer Republiksgründung ereignete sich in einer Krisensituation nach einem verlorenen Weltkrieg - am 1. Februar 1946 wurde die zweite ungarische Republik ausgerufen, als Neuanfang nach dem Krieg. Dieser Versuch währte allerdings auch nur kurz, und trotz Bestehens eines Mehrparteiensystems mit allgemeinem Wahlrecht war eine richtige Demokratie in einem von der Sowjetarmee besetzten Land mit wachsender Übermacht der Kommunisten in weiter Ferne, und ab 1948 begann bereits der Ausbau der Alleinherrschaft der Kommunisten - mit Wahlbetrug, Einschüchterung der politischen Gegner und der demokratischen Parteien. Das Gesetz Nr. 1 von 1946 über die Staatsform von Ungarn, die so genannte „kleine Verfassung “ ${ }^{36}$, diente als Vorbild für die Ausgestaltung der Rechtsstellung des Staatspräsidenten im Zuge der politischen Wende und der Verfassungsreform 1989. Jedoch eignet sich diese zweite ungarische Republik auch nicht uneingeschränkt als Vorbild für einen demokratischen Rechtsstaat des 21. Jahrhunderts. Zum einen handelte es sich nur bedingt um eine funktionierende Demokratie, zum anderen ist sie mit einem dunklen Kapitel der ungarischen Geschichte behaftet: mit der Vertreibung von etwa 200.00o Ungarndeutschen.

Was sich als Vorbild eignen würde, wird nicht als Vorbild herangezogen - die dritte Republik, nach dem 23. Oktober 1989, als Ungarn zu einem demokratischen Staat wurde, und durch die Rechtsentwicklung des Verfassungsgerichts wurde die so genannte unsichtbare Verfassung entwickelt, die sich als tragfähige Grundlage eines demokratischen Rechtsstaates erwies. ${ }^{37}$ Darauf wird aber im neuen ungarischen Grundgesetz

\footnotetext{
34 Ignác Romsics, Magyarország története a XX. században, 2010, 72-77.

35 Mezey, (Fn. 11), 158.

36 István Kukorelli, Az 1946. évi I. törvény közjogtörténeti jelentősége és az alkotmányos jogfolytonosság, Acta Humana 1 (2017), 21-26.

37 Zur Bedeutung der unsichtbaren Verfassung vgl. Parallelbegründung von Verfassungsgerichtspräsident László Sólyom zur Entscheidung über die Verfassungswidrigkeit der Todesstrafe: „Der Verfassungsgericht $[\ldots]$ bildet mit seinem Urteilen ein kohärentes System, was über die heute noch aus tagespolitischen
} 
kein Bezug genommen, die Verfassungsänderung im Herbst 1989 wird nicht als legitim betrachtet - da sie von einem nicht frei gewählten Parlament vollzogen wurde. Die damals erfolgte Totalrevision der Verfassung mit dem Gesetz Nr. 31. von 1989 fällt in den Zeitraum (bis zu den ersten freien Wahlen 1990), die als Aussetzung der ungarischen historischen Verfassung durch die Präambel (Nationales Bekenntnis) des neuen Grundgesetzes bezeichnet wird. Die durch das Verfassungsgericht entwickelte so genannte „unsichtbare Verfassung “ wurde formal für nichtig erklärt, indem bei der vierten Änderung des Grundgesetzes 2013 alle Beschlüsse des Verfassungsgerichts, erlassen vor Inkrafttreten des Grundgesetzes, außer Kraft gesetzt wurden. ${ }^{38}$ Trotzdem wird dieser Begriff auch im Weiteren verwendet, und über dessen Inhalt scheint ein viel breiterer Konsens zu herrschen als über jenen der historischen Verfassung. ${ }^{39}$

\section{Historische Verfassung als Auslegungshilfe oder Maßstab?}

1. Die Errungenschaften der historischen Verfassung im ungarischen Grundgesetz

Nach diesen eher theoretischen Überlegungen, ob die früheren Phasen der ungarischen Verfassungsentwicklung als Vorbilder für die heutige ungarische Demokratie und den Rechtsstaat dienen könnten, ist zu fragen, wie sich die Lage nach dem heute geltenden Recht darstellt. Inwieweit sind die ungarische historische Verfassung bzw. die Errungenschaften der ungarischen historischen Verfassung heute überhaupt noch brauchbar und wie spiegeln sie sich in der Praxis wider? Diese Fragestellung ist nicht nur aus Sicht des Inhalts der historischen Verfassung von Bedeutung, sondern stellt die Verfassungsrechtler auch vor neue Herausforderungen was Begrifflichkeiten und Herangehensweise betrifft. ${ }^{40}$ Der Rechtspositivismus, der die ungarische Rechtswissenschaft stark geprägt hat, kann mit einem so unbestimmten und auch teilweise unbestimmbaren Begriff wenig anfangen und sucht nach Lösungen, wie überhaupt der Begriff der historischen Verfassung zu handhaben ist - unabhängig von deren Inhalt. ${ }^{41}$

Die Frage rückte ins Interesse der Verfassungsrechtler, als das ungarische Grundgesetz den Begriff tatsächlich aufgegriffen hat und die historische Verfassung im Text an mehreren Stellen erwähnt wird. Diese Verbindung zur historischen Verfassung wird

\footnotetext{
Interessen geänderte Verfassung steht, als unsichtbare Verfassung, als Maßstab der Verfassungsmäßigkeit dient." (Beschluss 23/1990. (X 31.)) auf Deutsch abgedruckt: Georg Brunner / László Sólyom, Verfassungsgerichtsbarkeit in Ungarn. Analysen und Entscheidungssammlung 1990-1993, 1995; Benedek Molnár / Márton Németh / Péter Tóth, Mérlegen az alaptörvény interjúkötet hazánk új alkotmányáról, 2013, 18.

38 4. Änderung des Grundgesetzes Art. 20 (verkündet am 25. März 2013, in Kraft getreten am 1. April 2013).

39 Rixer, (Fn. 8).

40 Rixer, (Fn. 8).

41 Szente, (Fn. 25), 2.
} 
von einigen begrüßt, ${ }^{42}$ von einigen als unzureichend betrachtet, ${ }^{43}$ andere tun sie als Mythos ab, der jeglicher praktischen Anwendbarkeit entbehrt ${ }^{44}$ oder behaupten, dass die Regelung diesbezüglich keine tatsächliche Rechtswirkung haben wird. ${ }^{45}$

Zum einen erwähnt die Präambel des Grundgesetzes von 2011, genannt „Nationales Bekenntnis“, die historische Verfassung wie folgt:

Wir ehren die Errungenschaften unserer historischen Verfassung und die Heilige Krone, die die verfassungsmäßige staatliche Kontinuität von Ungarn und die Einheit der Nation verkörpern. Wir bekennen uns dazu, dass die Verteidigung unserer auf unserer historischen Verfassung basierenden Identität grundlegende Pflicht des Staates ist. ${ }^{46}$

Auch wenn die Normativität einer Präambel nicht bejaht wird, wird ersichtlich, dass der Verfassungsgeber der historischen Verfassung einen hohen Stellenwert beigemessen hat und sie als Grundlage der Identität bezeichnet, die es durch den Staat zu schützen gilt.

Abgesehen von dem eher deklarativen nationalen Bekenntnis findet sich die historische Verfassung auch im unmittelbaren Normtext des Grundgesetzes und zwar im Kapitel Grundlagen Artikel R. Dieser Artikel regelt den Aufbau der ungarischen Rechtsordnung, nennt das Grundgesetz als deren Basis und erklärt, dass das Grundgesetz und die sonstigen Rechtsnormen für alle verpflichtend seien. Absatz 3 regelt die Auslegung des Grundgesetzes:

„Die Bestimmungen des Grundgesetzes sollen im Einklang mit deren Zielen, dem in ihr enthaltenen nationalen Glaubensbekenntnis und den Errungenschaften unserer historischen Verfassung ausgelegt werden. ${ }^{47}$

Die historische Verfassung wird also nicht direkt als Auslegungsmaßstab und/oder Auslegungshilfe herangezogen oder gar, wie von einigen befürchtet, wieder in Kraft gesetzt, sondern die Errungenschaften der historischen Verfassung sollen berücksichtigt werden. Ein Änderungsvorschlag zum Entwurf des Grundgesetzes, der nicht nur die Errungenschaften, sondern auch die gesamte historische Verfassung für das Verfassungsgericht als Entscheidungsgrundlage (und nicht als Auslegungshilfe) vorgeschrieben hätte, wurde innerhalb kürzester Zeit wieder zurückgezogen. ${ }^{48}$

Die Frage, wann diese historische Verfassung galt, wird von der Präambel beantwortet: „Wir anerkennen die Aussetzung unserer historischen Verfassung während

42 Rixer, (Fn. 8).

43 Zétényi, (Fn. 12), 54-57.

44 Szente, (Fn. 25), 3-5.

45 András Jakab, Az új Alaptörvény keletkezése és gyakorlati következményei, 2011, 199.

46 Grundgesetz Ungarns, Nationales Bekenntnis, Satz 21-22.

47 Grundgesetz Ungarns, Art. R Abs. 3.

48 Obwohl es von János Lázár, dem damaligen Fraktionsvorsitzenden der Regierungspartei FIDESZ, stammte. 
fremder Belagerungen nicht. ${ }^{“}{ }^{49}$ Die - nicht anerkannte - Aussetzung beginnt demnach mit der deutschen Besatzung Ungarns am 19. März 1944, die dann im weiteren Verlaufe des Krieges in die sowjetische Besatzung überging. Diese Annahme wird vom nationalen Bekenntnis bestätigt: „Wir rechnen die Wiederherstellung der am 19. März 1944 verlorenen staatlichen Selbstbestimmung unserer Heimat ab dem 2. Mai 1990, der Konstituierung der ersten frei gewählten Volksvertretung. ${ }^{\text {(50 }}$

Demnach galt die historische Verfassung Ungarns bis zur deutschen Besatzung, aber danach nicht mehr, so ist weder die 2. Republik (1946-1969) ein Teil davon während das Gesetz Nr. 1 von 1946 aber als wesentliches Vorbild für die Ausgestaltung der Rechtstellung des ungarischen Staatspräsidenten diente. Ebenso wird die durchaus vorhandene Verfassungstradition nach der politischen Wende 1989-90 nicht als Teil der historischen Verfassung anerkannt - obwohl es sich hierbei, wie oben dargestellt, um die längste demokratisch-rechtsstaatliche Periode in der ungarischen Geschichte handelt, und die ebenfalls bereits erwähnte „unsichtbare Verfassung“, also die Auslegungstätigkeit des Verfassungsgerichts, eine nicht unbeachtliche Leistung darstellte. Der „kommunistischen Verfassung von 1949“, also dem Gesetz Nr. 20 von 1949, wird allgemein die Gültigkeit abgesprochen, ${ }^{\text {s1 }}$ obwohl es mit dem Gesetz Nr. 31 von 1989 einer Totalrevision unterzogen wurde und 1990 vom ersten demokratisch gewählten Parlament noch einmal stark modifiziert wurde..$^{52}$ Allerdings findet sich in den Schlussabstimmungen des neuen Grundgesetzes folgender Hinweis: „(...) die Landesversammlung verabschiedet dieses Grundgesetz anhand des $\$ 19$ Absatz (3) Punkt a) und $\$ 24$ Absatz (3) des Gesetzes XX. vom Jahre $1949^{\text {“53 }}$ - hierbei handelte es sich um die Verfahrensregeln zur Verfassungsänderung der alten Verfassung. So sind wesentliche Perioden der ungarischen Geschichte, die durchaus eine gewisse demokratisch-rechtstaatliche Tradition aufweisen können, nicht Teil der historischen Verfassung im Sinne des Grundgesetzes - die republikanischen Traditionen werden allesamt ausgeklammert. Die „alte Verfassung“, das Gesetz Nr. 20. von 1949, nimmt aber in der Tat einen viel größeren Einfluss auf den heutigen Regelungsinhalt des ungarischen Grundgesetzes als die vielzitierte historische Verfassung. ${ }^{54}$ Die Ausgestaltung vor allem des Staatsorganisationsrechts blieb nach Inkrafttreten des Grundgesetzes nahezu unverändert - einige Bezeichnungen wurden geändert, so wurde aus dem Obersten Gerichtshof wieder die Curia, angelehnt an die historische Bezeichnung; eine nennenswerte Änderung fand aber nicht statt, wenn man von der Senkung der Zahl der Parlamentsabgeordneten absieht.

\footnotetext{
49 Grundgesetz Ungarns, Nationales Bekenntnis, 23.

50 Grundgesetz Ungarns, Nationales Bekenntnis, 27.

51 Grundgesetz Ungarns, Nationales Bekenntnis, 25.

52 Zur Kontinuität und Verfassungsrevision: Kálmán Kulcsár, Az alkotmányosság és a kontinuitás, Valóság 8 (1991), 1-16.

53 Grundgesetz Ungarns, Schluss- und gemischte Bestimmungen, Punkt 2.

54 Rixer, (Fn. 8).
} 
Die Errungenschaften der historischen Verfassung sind also in der verfassungsmäBigen Ordnung vor dem 19. März 1944 zu suchen. Deren Inhalt ist aber wegen der bereits beschriebenen Umstände - kein einheitlicher Verfassungstext, Vielzahl an Rechtsnormen, die in Betracht kommen - nicht einfach, wenn gar unmöglich, und wegen der uferlosen Deutungsmöglichkeiten sogar gefährlich, wie dies von mehreren Verfassungsrechtlern behauptet wird. ${ }^{55}$ Vieles, so zum Beispiel die Dokumente, die die Beziehungen zur österreichischen Reichshälfte oder zum Haus Habsburg regelten, wie die Pragmatische Sanction oder das Ausgleichsgesetz von 1867, sind obsolet geworden, ebenso wie alle Gesetze, die mit der Staatsform der Monarchie in Verbindung standen.

Es ist auch fraglich, welche Errungenschaften die historische Verfassung hervorgebracht hat, die im heutigen Normtext des Grundgesetzes nicht geregelt sind, also inwieweit es praktisch notwendig ist, sich darauf zu berufen. Denn all die Errungenschaften, die oft erwähnt werden, wie Gewaltenteilung, die Prinzipien des Parlamentarismus oder Solidarität, Pressefreiheit, richterliche Unabhängigkeit, sind Teil des geltenden Grundgesetzes. Auch wird in der Fachliteratur häufig die Meinung vertreten, dass dieser Bezug zu den Errungenschaften der historischen Verfassung als ein Versuch der Identitätsbildung zu betrachten sei, in deren Rahmen auf die gemeinsame Geschichte und auf die gemeinsamen Werte rekurriert wird und die das „gemeinsame Erbe aufzeigt “.56 Dagegen ist einzuwenden, dass der fehlende Konsens über Inhalt, Deutung und Wertung der historischen Verfassung diese identitätsstiftende Wirkung sicher nicht begünstigt, wenn gar unmöglich macht.

\section{Die Errungenschaften der historischen Verfassung in der Praxis}

In der Praxis zeigt sich, dass dieser Auslegungsmaßstab praktisch kaum Bedeutung hat; das Verfassungsgericht bezieht sich zwar regelmäßig auf ihn, dabei entsteht jedoch eher der Eindruck, dass mit der Erwähnung der Errungenschaften der historischen Verfassung eher eine Pflicht erfüllt als tatsächlich neue Argumente ins Treffen geführt werden. ${ }^{57}$ Es fällt auf, dass fast ausschließlich die Rechtsnormen aus der Epoche des Dualismus herangezogen werden, die - wie oben bereits beschrieben - am ehesten als Vorbild für einen demokratischen Rechtstaates dienen können.

Als erstes Beispiel, wo die Errungenschaften der historischen Verfassung tatsächlich zum Trage kommen sind, ist die richterliche Unabhängigkeit zu nennen, wobei auf die Gerichtsverfassung von 1869 und das Gesetz über die Rechtstellung der Richter von

55 Szente, (Fn. 25), 5.

56 Zusammenfassung darüber bei: Tímea Drinóczi, Az alkotmányos identitásról. Mi lehet az értelme az alkotmányos identitás alkotmányjogi fogalmának?, MTA Law Working Papers 15 (2016), 23-29.

57 Vörös, (Fn. 10), 45. 
1871 Bezug genommen wird, ${ }^{58}$ die ihrerseits Unabhängigkeit, Versetzungsverbot, Ernennung und Absetzung der Richter betreffen. Im Fall der Zwangspensionierung der Richter, Beschluss 33/2012 (VII. 17.) ABH, stellte das Gericht fest,

dass das, was zu den Errungenschaften der historischen Verfassung gehört, durch das Verfassungsgericht festzustellen ist. Zum Minimum der konsolidierten Auslegung der ungarischen historischen Verfassung gehört die Annahme, dass die Gesetze, die den bürgerlichen Übergang, vollzogen im 19. Jahrhundert, konstituiert haben, Teil der historischen Verfassung sind. Diese Gesetze haben - nach nicht unbedeutenden Vorgängern - die feste Basis für jene Rechtsinstitute geschaffen, auf denen der moderne Rechtsaat aufgebaut worden ist. Als das Grundgesetz sozusagen das Fenster für die historische Dimension unserer Verfassung öffnete, lenkte es die Aufmerksamkeit auf diejenigen institutionshistorischen Vorereignisse, ohne die unsere heutigen öffentlich-rechtlichen Einrichtungen und allgemein unsere Rechtskultur wurzellos wären. Die Verantwortung des Verfassungsgerichts ist in dieser neuen Situation außerordentlich, sozusagen historisch: Bei der Untersuchung von konkreten Fällen muss es auch die relevanten Quellen der juristischen Institutionsgeschichte berücksichtigen. ${ }^{59}$

In einem Sondervotum stellte jedoch Verfassungsrichter Pokol fest, dass diese „Auslegungsdirektive" nicht hinreichend ausgearbeitet sei und eher nur als Ausgangspunkt für weitere Diskussionen fungieren kann. ${ }^{60}$ Damit wurde die Diskussion auf den Punkt gebracht: Es ist zwar verfassungsrechtlich geboten, die Errungenschaften als Auslegungsrahmen heranzuziehen, es ist aber mit vielen theoretischen und praktischen Schwierigkeiten verbunden. Auch 2019 trifft es nach wie vor zu, dass weder über den Begriff der Errungenschaften noch über den Inhalt der historischen Verfassung eine einheitliche Auffassung des Verfassungsgerichts besteht und dementsprechend gibt es auch keine konsequente Linie in den Urteilen. ${ }^{61}$ Die Rechtsinstitutionen, die seitdem als Errungenschaft der historischen Verfassung vom Verfassungsgericht festgestellt wurden, sind zum Beispiel das Recht zum Rechtsbehelf im Rahmen eines fairen Verfahrens, ${ }^{62}$ die Unabhängigkeit der Religionsgemeinschaften als Teil der Religionsfreiheit ${ }^{63}$ oder die Autonomie der örtlichen Selbstverwaltungen (Gemeinden) ${ }^{64}$ Allesamt wichtige Bereiche, allerdings sind diese auch aus dem Normtext des Grundgesetzes abzuleiten, man „braucht“ die historische Verfassung nicht, um diese als Teil der ungarischen Verfassungsordnung betrachten zu können. ${ }^{65}$

58 Gesetz Nr. 4 von 1869 bzw. Gesetz Nr. 9 von 1871.

59 Beschluss 33/2012 (VII. 17.), ABH (2012) 99.

60 Sondervotum von Verfassungsrichter Pokol zum Beschluss 28/2013. (X. 9.); ABH (2013) 865.

61 Vörös, (Fn. 10), 46.

62 Beschluss 26/2015 (VII. 21.), ABH (2015) 651-677.

63 Beschluss 6/2013 (III. 1.), ABH (2013) 334-382.

64 Beschluss 29/2015. (X.2.), ABH (2015) 742-773.

65 Jakab, (Fn. 45), 199. 
Es ist auch anzumerken, dass Hinweise auf historische Vorgänger verschiedener Rechtsinstitute bereits vor 2012 in der Spruchpraxis des Verfassungsgerichts zu finden waren, ${ }^{66}$ wenn auch ohne explizite Erwähnung der historischen Verfassung. Inhaltlich hat also dieser neue Auslegungsrahmen oder Auslegungshilfe - sogar das Verfassungsgericht schwankt zwischen mehreren Begriffen - zur Spruchpraxis nicht viel beigetragen.

Als Verfassungstradition brauchbar wäre, wie schon zuvor erwähnt, die unsichtbare Verfassung, die vor allem unter der Leitung von Verfassungsgerichtspräsident László Sólyom entwickelt und später weiterentwickelt wurde. Offiziell sind diese „alten“ Beschlüsse aber nicht mehr in Kraft; dies seit dem 1. April 2013, als die vierte Änderung des Grundgesetzes in Kraft trat. Das Verfassungsgericht bezieht sich in seiner Argumentation jedoch bis heute auf diese früheren Entscheidungen. Es ist dies damit zu begründen, dass in der frühen Phase der ungarischen Verfassungsgerichtsbarkeit viele Grundentscheidungen getroffen und dabei solche Definitionen und Abgrenzungen festlegt wurden, die bis heute unabdingbar sind. Das Verfassungsgericht bedient sich in diesem Zusammenhang also historischer Texte, wobei dies in dem Sinne verstehen ist, dass sie nicht mehr formal in Kraft sind, aber freilich bedient es sich dieser Texte nicht im Rahmen der historischen Verfassung, wie dies der Verfassungsgeber vorgesehen hat. ${ }^{67}$ Kurz nach Inkrafttreten der oben genannten Grundgesetzänderung hat das Verfassungsgericht explizit festgelegt, dass nach Prüfung im Einzelfall und mit entsprechender Begründung die formal außer Kraft gesetzten Beschlüsse auch heranzuziehen sind:

Das Verfassungsgericht kann im Rahmen neuerer Fällen zu untersuchender verfassungsrechtlicher Fragen die in früheren Beschlüssen ausgearbeiteten Argumente, Rechtsgrundsätze und verfassungsrechtlichen Zusammenhänge anwenden, wenn es anhand der bestehenden inhaltlichen Übereinstimmung des betroffenen Artikels des Grundgesetzes mit der Verfassung, der kontextualen Übereinstimmung hinsichtlich der Gesamtheit des Grundgesetzes, der Berücksichtigung der Auslegungsregeln des Grundgesetzes und des konkreten Falles keine Hindernisse für die Anwendbarkeit der Feststellungen gibt und deren Anführung in die Begründung der zu treffenden Entscheidung als notwendig erscheint. $^{68}$

Da, wie bereits oben erwähnt, die Regelungsinhalte des Grundgesetzes mit der alten Verfassung zum überwiegenden Teil übereinstimmen, steht einer Anwendung der früher ausgearbeiteten Spruchpraxis nichts entgegen. Die Praxis der vergangenen Jahre zeigt, dass das Verfassungsgericht regelmäßig auf die Argumentationen und Begriffs-

\footnotetext{
66 Vörös, (Fn. 10), 44.

67 Vörös, (Fn. 10), 49.

68 Beschluss 13/2013. (VI.17.), ABH (2013) 618-649.
} 
bestimmungen der älteren Beschlüsse zurückgreift, auch wenn diese nicht unbestritten sind. ${ }^{69}$

Die historische Verfassung und deren Errungenschaften spielen hingegen in der Praxis bislang keine tragende Rolle und eine grundlegende Änderung dieses Umstandes ist auch in Zukunft nicht absehbar.

\section{Schlussfolgerungen}

Zusammenfassend kann gesagt werden, dass die demokratischen Traditionen in Ungarn - mit Ausnahme der letzten knapp dreißig Jahre der dritten ungarischen Republik - eher rudimentär sind, genauso wie die republikanischen Traditionen. Um die rechtsstaatlichen Traditionen steht es ein wenig besser, vor allem wenn man die Zeit der Österreichisch-Ungarischen Monarchie betrachtet. Die Frage ist demnach weniger, wie man an den demokratischen Traditionen baut, sondern vielmehr, wie man mit deren spärlich vorhandenen Elementen und überhaupt mit den fehlenden demokratischen Traditionen umgeht.

Im politischen Diskurs wird oft auf die historische Verfassung Ungarns und deren Errungenschaften hingewiesen, auch im symbolisch-gedächtnispolitischen Bereich wird vor allem die Zwischenkriegszeit oft referiert. In der juristischen Praxis u. a. des Verfassungsgerichts spielt aber die historische Verfassung kaum eine Rolle, trotz der Regelung im Grundgesetz. Dies ist auch damit zu erklären, dass deren Inhalt schwer zu bestimmen ist und für die heutige Zeit kaum brauchbare Regelungen parat hat, solche nämlich, die ansonsten im Grundgesetz nicht zu finden wären.

Fraglich ist auch, inwiefern die historische Verfassung als Vorbild für die heutige ungarische Demokratie dienen kann bzw. inwieweit sie identitätsstiftend wirkt oder wirken soll. Zum einen ist hier auch auf die fehlenden demokratisch-rechtstaatlichen Traditionen hinzuweisen, die als Vorbild für eine moderne Demokratie ohne kritische Reflexion nicht geeignet sind. Eben diese kritische Reflexion fehlt des Öfteren und auch über den genauen Inhalt und die Zusammensetzung der historischen Verfassung sowie über die historiographische Bewertung und Wertung vor allem des Horthy-Regime in der Zwischenkriegszeit fehlt ein breiter Konsens in der ungarischen Gesellschaft (und Wissenschaft).

Die fehlende lange Tradition eines demokratischen Rechtsstaates in Ungarn sollte aber nicht als Rechtfertigung für die heutigen Defizite dienen und bei der Behebung dieser Defizite sind vielmehr Gegenwart und Zukunft gefordert als die Vergangenheit.

69 Sondervotum von Verfassungsrichter Pokol zum Beschluss 36/2013. (XII. 5.), ABH (2013) 1082-1083. 

VI. Internationale Aspekte 



\title{
Polarisierung als potentielle Herausforderung für den Verfassungspatriotismus Eine vergleichende Analyse zwischen Deutschland und den USA
}

\author{
MELISSA MULLER
}

Political Polarization as a Potential Challenge to the Efficacy of Constitutional Patriotism A Comparative Analysis of Germany and the United States

\begin{abstract}
This article outlines the foundational arguments in favor of constitutional patriotism, focusing on one in particular: its ability to unite a diverse political community around a common set of values. Recent research, however, suggests that political polarization in the United States has reached the rhetoric of constitutional language itself, prompting a reconsideration of the theoretical and practical efficacy of constitutional patriotism as a means of binding and uniting a liberal democratic society. When a constitution becomes the site of bifurcated ideological attacks, its symbolic power is greatly reduced. If this applies in the United States, it may provide relevant insights for Germany, which shows the early warning signs of increasing political and societal polarization.
\end{abstract}

Keywords: constitutional patriotism, polarization, liberal-democratic values, tribalism, rhetoric, comparative constitutionalism

\section{Einführung}

1927 hat Theodor Heine seine berühmte Karikatur „Republik ohne Republikaner“ auf der Titelseite der Satirezeitschrift Simplicissimus veröffentlicht. Die Bildunterschrift lautet: „Sie tragen die Buchstaben der Firma - aber wer trägt den Geist?" Nur fünf

1 Carsten Kohlmann, Der Geist der Weimarer Republik, in: schwarzwaelder-bote.de, 27.01.2018, URL: https://www.schwarzwaelder-bote.de/inhalt.schramberg-der-geist-der-weimarer-republik.3f29fb9b-718e4907-912a-89eo84ad701 f.html; letzter Zugriff: 27.03.2019. 
Jahren später erschien ein weiteres Gedicht in derselben Zeitschrift von Hans Seiffert, welches mit den Worten endet: „Die Republik? Die war einmal. Sie ist verstorben streng legal ..." ${ }^{\prime 2}$ Beide Autoren stellen die Frage, wie ein Land und seine Bürger den Geist der Republik tragen können - wie ein Land diese Bedingungen und die Geisteshaltung der Bürgerinnen und Bürger für eine friedliches Zusammenleben kultivieren kann.

Nach dem zweiten Weltkrieg hat eine Reihe von Philosophen diese Frage zu beantworten versucht. ${ }^{3}$ Tatsächlich ist es immer noch schwierig, eine theoretische und praktische Grundlage für eine politische Gesellschaft und Selbstverwaltungsgemeinschaft zu finden. Heutzutage gibt es zahlreiche Theorien, die unterschiedliche Arten und Grade von Verbindungen zwischen Bürgern vertreten, von einem „liberalem Nationalismus“ oder einer „Wertgemeinschaft“ bis zu einem echten rassischen Nationalismus. ${ }^{4}$ Allen Theorien liegt dieselbe Annahme zugrunde, von welcher auch hier ausgegangen werden soll: Selbstverwaltungsgemeinschaften benötigen einen republikanischen Geist, auf dessen Grundlage sich Menschen mit dem Staat identifizieren können. Aber wie soll diese Identifikation ausgestaltet werden? Viele Staaten wurden auf Basis gemeinsamer Geschichte, Sprache, Rasse und der Idee eines Volkes gegründet. Dies war in Deutschland nicht möglich, wie Jürgen Habermas erklärt:

\begin{abstract}
„Der Nationalismus ist bei uns sozialdarwinistisch zugespitzt worden und ist in einem Rassenwahn kulminiert, der als Rechtfertigung hinter der Massenvernichtung der Juden gestanden hat. Deshalb ist der Nationalismus als Grundlage einer kollektiven Identität bei uns drastisch entwertet worden. Und deshalb bildet auch die Überwindung des Faschismus die besondere historische Perspektive, aus der sich eine postnationale, um die universalistischen Prinzipien von Rechtsstaat und Demokratie herum gebildete Identität versteht."
\end{abstract}

Diese Hervorhebung der Prinzipien von Rechtsstaat und Demokratie ist Teil des Versuchs, eine (neue) Art „Ersatzpatriotismus“ zu entwickeln. Dieser könnte sich gleichzeitig mit der Zukunftsentwicklung der Republik sowie der Vergangenheitsbewältigung beschäftigen.

In einem in der FAZ erschienenen Artikel aus dem Jahre 1979 erläutert Dolf Sternberger seinen Begriff des Verfassungspatriotismus, der seiner Meinung nach ein Ersatz

2 Hans Seiffert, Republik ohne Republikaner, in: Simplicissimus, 1933, 583. URL: http://www.simpli cissimus.info/index.php?id=6\&tx lombkswjournaldb pi1\% ${ }_{5}$ BissueId\%5 $\mathrm{D}=1851$ \&tx lombkswjourn aldb_pi1\%5Baction $\%_{5} \mathrm{D}=$ showIssuePages\&tx_lombkswjournaldb_pi1\%5 Bcontroller\% ${ }_{5} \overline{\mathrm{D}}=$ YearRegister \&cHash=b5e82d56912b88037d5d89d7a8555ob6.

3 Jan-Werner Müller, Contesting Democracy: Political Ideas in Twentieth-Century Europe, New Haven, 2011, S. 126-170.

4 Jan-Werner Müller, Verfassungspatriotismus, Erste Auflage, Berlin 2010, S. 10-12.

5 Jürgen Habermas, „Grenzen des Neohistorismus“, in: Die nachholende Revolution, S. 149-165; hier S. 152. 
für den Nationalismus und Grundlage der deutschen Gesellschaft sein könnte. Obwohl das Grundgesetz teilweise widerwillig verfasst und ohne Volksabstimmung in Kraft gesetzt wurde, hat er seinen Standpunkt erweitert: „Wir leben in einer ganzen Verfassung, in einem ganzen Verfassungsstaat, und das ist selbst eine Art von Vater-

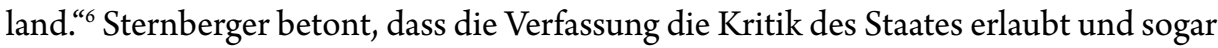
dazu ermutigt, aber Unzufriedenheit „mindert nicht die Treue, die der Verfassung geschuldet wird." ${ }^{\text {"7 }}$ Mit der Schaffung eines funktionierenden Staates und eines Rahmens für die Freiheit bietet die Verfassung selbst eine Quelle der Einheit, „gegen erklärte Feinde jedoch muß (sic) die Verfassung verteidigt werden, das ist patriotische Pflicht. ${ }^{\text {"8 }}$ Der Verfassungspatriotismus in Deutschland hat nach Sternberger also folgende Ausprägung: Die Verfassung etabliert einerseits eine Ebene für Streit und Diskurs und legitimiert solch eine Auseinandersetzung darüber hinaus, indem sie von den deutschen Bürgern Respekt, Unterstützung und sogar Patriotismus einfordert.

Jürgen Habermas, der am meisten mit dem Verfassungspatriotismus verbundene Theoretiker, vertritt eine Version, die die deutsche Geschichte und Werte des Landes als Quelle für die Einheit unter den Bürgern einschließt. Nachdem er frühere Identitäten von Nationalstaaten kritisiert hatte, schreibt Habermas, dass es sich „[a]nders verhält $[. .$.$] mit einem Verfassungspatriotismus [...]. Dabei werden die Identifikatio-$ nen mit eigenen Lebensformen und Überlieferungen überlagert von einem abstrakter gewordenen Patriotismus, der sich nicht mehr auf das konkrete Ganze einer Nation, sondern auf abstrakte Verfahren und Prinzipien bezieht." ${ }^{\text {“9 }}$ Dieser Verfassungspatriotismus setzt sich mit der Vergangenheit in einer Weise auseinander, die die Bürger mit der gemeinsamen Geschichte und den daraus resultierenden Prinzipien und Werten verbindet. Die Vorteile eines solchen Patriotismus sind klar: „Diese zielen auf die Bedingungen des Zusammenlebens und der Kommunikation zwischen verschiedenen, gleichberechtigt koexistierenden Lebensformen - im Innern wie nach außen. ${ }^{\text {"10 }}$ Aus dieser Perspektive kann der Verfassungspatriotismus den Geist eines Volkes tragen, indem er eine gemeinsame Plattform für den Diskurs bietet. Er stellt universelle Prinzipien bereit, die unterschiedlichen Gruppen von Menschen auf bestimmte Weise zugänglich sind - über Werte, Geschichte und Diskurs. Darüber hinaus gibt es ein Symbol, welches dieses abstrakte Verfahren verkörpert: Die Verfassung. Aber für Habermas war es immer wichtig, dass sich die Identität tatsächlich in der Realität widerspiegelt. So schreibt er: „Wir unterstellen damit, dass eine Gesellschaft ihre ,eigentliche“ oder

6 Dolf Sternberger, Verfassungspatriotismus, in: Gesammelte Schriften. Frankfurt am Main, 1990. Bd. 10, S. $13-16$.

7 Sternberger (Fn. 5), S. 13-16.

8 Sternberger (Fn. 5), S. 13-16.

9 Jürgen Habermas, „Geschichtsbewußtsein und posttraditionale Identität. Die Westorientierung der Bundesrepublik“, in: Eine Art Schadensentwicklung, S. 161-179, hier S. 173.

10 Habermas (Fn. 8), S. 173. 
,wahre' Identität verfehlen kann. “1 Unter Zugrundlegung dieser Einstellung kann Verfassungspatriotismus als eine diskursive Form von Patriotismus begriffen werden, die mit Geschichte und Werten verbunden ist - aber nicht alle Arten von Verfassungspatriotismus sind notwendigerweise - im Sinne Habermas' - ein wahrer Ausdruck der Staatsidentität.

In seinem Buch Verfassungspatriotismus zeigt Jan-Werner Müller, wie ein solcher ganz unterschiedliche Leute verbinden kann. Nach Müller, geht „[e]in normativ gehaltvoller Begriff des Verfassungspatriotismus [...] auf die Frage zurück, wie Bürger, die sich gegenseitig als Freie und Gleiche anerkennen, eine Form demokratischer Herrschaft etablieren und perpetuieren können. ${ }^{12}$ Was haben die Menschen im modernen Staat gemeinsam? Oder besser gefragt, was müssen sie teilen, um ihren Staat zu festigen? Grundwerte. In Deutschland gehören dazu zumindest Würde, Rechtsstaatlichkeit und Demokratie - Werte, die im deutschen Kontext eine besondere Bedeutung haben. Eine Einigung über diese Werte, aber auch ein Diskurs, um diese zu bestimmen, kann ein heterogenes Volk vereinen. Müller zitiert Habermas, um diesen Aspekt zu betonen: „Eine liberale politische Kultur bildet nur den gemeinsamen Nenner eines Verfassungspatriotismus, der gleichzeitig den Sinn für die Vielfalt und die Integrität der verschiedenen koexistierenden Lebensformen einer multikulturellen Gesellschaft schärft. ${ }^{{ }^{13}}$ Das ist die postmoderne Identität. Es geht um die Art und Weise, wie sich zwischen verschiedenen Menschen eine Gruppenidentität entwickeln kann, welche den Geist schafft, der für die Lebensfähigkeit eines Staates notwendig ist.

Natürlich gibt es viel Kritik am Verfassungspatriotismus. Nach Müller sind die Argumente für einen Verfassungspatriotismus im Kontext der Schaffung einer europäischen Identität (oder sogar einer europäischen Verfassung) relevant. Aber viele Skeptiker zweifeln, ob Europa in seiner Heterogenität dies tatsächlich schaffen und ein Verfassungspatriotismus dafür eine taugliche Grundlage darstellen könnte. Aktuelle Ereignisse in Ungarn und Polen haben die Behauptung, dass es keine geteilten europäischen Grundwerte gibt, gestärkt. Andere Argumente dagegen lauten, dass ein Verfassungspatriotismus zu abstrakt sei, um eine Wirkung zu erzielen oder, nach Ernst-Wolfgang Böckenförde, dass er bloß ein „blasse[r] Seminargedanke“ sei. ${ }^{14} \mathrm{Ab}$ gesehen von diesen Einwänden besteht eine weitere ernsthafte Herausforderung für die praktische Durchführbarkeit des Verfassungspatriotismus, die in diesem Aufsatz untersucht werden soll: Politische Polarisierung.

11 Jürgen Habermas, „Können komplexe Gesellschaften eine vernünftige Identität ausbilden?“ in: Zur Rekonstruktion des Historischen Materialismus, Frankfurt am Main: Suhrkamp 1976, S. 92-126; hier S. 92. 12 Müller (Fn. 3), S. 65.

13 Müller (Fn. 3), S. 58; Jürgen Habermas, Faktizität und Geltung: Beiträge zur Diskurstheorie des Rechts und des demokratischen Rechtsstaats, Frankfurt am Main: Suhrkamp 1994, S. 624.

14 Müller (Fn. 3), S. 14. 
Vor dem Hintergrund dieser Theorien kann man sehen, dass Verfassungspatriotismus teilweise praktisch begründet ist: Er bietet ein Forum für einheitliche Bürger, als Lösung für das Problem einer Republik ohne Bürger, die in der Lage sind, sich um eine selbstverwaltete Gesellschaft zu kümmern. Er ermöglicht und ermutigt die Bürger, eine demokratische Regierung zu festigen. Der Verfassungspatriotismus bietet etwas an, womit sich alle Bürger identifizieren können. Wie Müller argumentiert, „dient [der Verfassungspatriotismus] als Quelle des politischen Vertrauens der Bürger untereinander - und trägt damit zur Stabilität eines Gemeinwesens bei (...). Er ermutigt und befähigt die Bürger, ihre Institutionen auch immer wieder im Namen geteilter, aber nie ganz verwirklichter Werte zu kritisieren und zu verbessern. ${ }^{\text {"15 }}$ Dies setzt naturgemäß voraus, dass konstitutionelle Werte tatsächlich geteilt werden.

Davon abgesehen, ob der Verfassungspatriotismus richtig und ausreichend ist oder nicht, Fakt ist, dass er häufig in politischen Reden als Bezugspunkt für deutsche Werte und Identität verwendet wird. Aber was passiert genau, wenn die Verfassung selbst zur Quelle der Polarisierungs- und Identitätspolitik wird? Ist die Verfassung aufgrund ihrer Geschichte als Symbol einer erfolgreichen deutschen Demokratie notwendigerweise eine Quelle der Einheit? Kann man sagen, dass Verfassungspatriotismus ohne gemeinsame Werte kein Verfassungspatriotismus ist? Ich behaupte, dass die Vereinigten Staaten derzeit mit dieser Herausforderung konfrontiert sind und dass die zunehmende parteipolitische Polarisierung die praktische Wirksamkeit des Verfassungspatriotismus in den USA gefährden kann.

\section{Verfassungspatriotismus in den USA}

Ausgehend von der deutschen Tradition des Verfassungspatriotismus haben die Vereinigten Staaten eine Verfassungskultur, die in dieses Paradigma passen könnte. Es scheint ein allgemeiner Konsens darüber zu bestehen, dass die Amerikaner von ihrer Verfassung geradezu besessen sind. Der Einbürgerungseid verlangt von den neuen Bürger das Versprechen, „die Verfassung zu unterstützen und zu verteidigen“, um sicherzustellen, dass neue Mitglieder der Gemeinschaft eine grundlegende Verpflichtung gegenüber der Verfassung haben. ${ }^{16}$ Die Leiter des College Board, der wohl wichtigsten Bildungs- und Prüfungsgruppe in den Vereinigten Staaten, haben kürzlich die beiden wichtigsten Bereiche der Bildung bekanntgegeben: Computerprogrammie-

15 Müller (Fn. 3), S. 64.

16 Naturalization Oath of Allegiance to the United States of America, in U.S. Citizenship and Immigration Resources, URL: https://www.uscis.gov/us-citizenship/naturalization-test/naturalization-oath-allegianceunited-states-america, zuletzt aufgerufen am 12.09.2019. 
rung und die Verfassung. ${ }^{17}$ Es ist keine Überraschung, wenn ein Artikel vor den Gefahren von „Constitution Worship“ warnt oder fragt „Sind wir Amerikaner übermäßig von unserer Verfassung besessen? ${ }^{{ }^{18} 8}$ Darüber hinaus hat Trump sehr häufig auf , unsere geliebte Verfassung“ hingewiesen; aber wer genau die „uns“ in seinen „unsere“ sind, ist eine Frage, mit der sich dieser Beitrag zu beschäftigten versuchen wird.

Aber auch wenn Amerika eine Verfassungskultur hat, bedeutet das nicht notwendigerweise, dass es eine Form von Verfassungspatriotismus gibt. Wie Müller erwähnt, sind die USA und die Schweiz ,vielfältige Länder, die auf den ersten Blick durchaus von geteilten politischen Idealen zusammengehalten werden." Nichtsdestotrotz seien sie „de facto doch klassische Nationalstaaten, deren geteilte Werte erst durch nationale Mythen und Symbole ihre Anziehungskraft entfalteten." ${ }^{\text {"9 }}$ Aber können wir die Vereinigten Staaten so leicht ignorieren? Amerikanischer Verfassungspatriotismus ist vielleicht nicht so akademisch geprägt wie in Deutschland, aber er dient als Identifikationsquelle für alle Amerikaner, egal welchen Hintergrundes. In einer Umfrage vom Dezember 2018, in welcher gefragt wurde, welche Merkmale für einen „echten Amerikaner“ am wichtigsten sind, haben $80 \%$ „die Verfassung der USA unterstützen“ als „sehr wichtig“ eingeschätzt. ${ }^{20}$ Als weitere für Amerikaner entscheidende Eigenschaften haben sich „Menschen gleichbehandeln“ (90\%) und „Menschen unterschiedlicher Rasse akzeptieren“ ( $81 \%)$ erwiesen. ${ }^{21}$ Zum Vergleich: Merkmale, die als am wenigsten wichtig angesehen wurden, waren „in den Vereinigten Staaten geboren“ (49\%) und „den größten Teil des Lebens in Amerika gelebt zu haben“ (45\%). ${ }^{22}$ Diese Zahlen zeigen, dass die Verfassung eine Rolle bei der Selbstidentifikation von Amerikanern spielt und dass darin ein Potential zu einer gemeinsamen Identität von US-Amerikanern liegen kann. Natürlich ist diese Art des Verfassungspatriotismus ganz anders als in Deutschland. Aber meine These ist, dass es eine Art von Verfassungspatriotismus ist, welcher relevant ist, weil er als Vergleichspunkt hinsichtlich dessen Wirksamkeit dienen kann.

Verfassungspatriotismus funktioniert in den USA als Symbol für Demokratie, Rechtsstaatlichkeit und Rechte. Natürlich wird der Inhalt der Verfassung kontrovers bleiben. Dies zeigt sich selbst in der Öffentlichkeit, von Zeitungsartikeln bis hin zu Wahlkämpfen. Es ist eine Sache, darüber zu streiten, wie die Verfassung interpretiert werden soll, aber es ist eine andere, wenn sich die Bürger in polarisierter Weise mit

17 Thomas Friedman, The Two Codes Your Kids Need to Know, in: The New York Times, 12.2.2019, URL: https://www.nytimes.com/2019/02/12/opinion/college-board-sat-ap.html.

18 Joshua Keating, Are Americans too Constitution Obsessed?, in: Foreign Policy, 24.9.2010, URL: https://foreignpolicy.com/2010/o9/24/are-americans-too-constitution-obsessed/.

19 Müller (Fn. 3), S. 15.

20 Grace Sparks, Poll asks what makes a ,real American?; in: CNN, 3.12.2018, URL: https://edition.cnn. com/2018/12/o3/politics/real-american-poll/index.html.

21 Sparks (Fn. 19).

22 Sparks (Fn. 19). 
verschiedenen Aspekten der Verfassung identifizieren. Dann verschwindet die Möglichkeit eines Verfassungspatriotismus als identitätsstiftendes Verfahren. Wie man in den USA sehen kann, verfälscht Polarisierung den Diskurs. ${ }^{23}$ Sie untergräbt das Vertrauen in gemeinsame Werte und Überzeugungen und teilt das Land in ein „Wir“ und ein „Sie.“ Wenn diese Entwicklung die Verfassung selbst beeinflusst, dann lassen Habermas' gemeinsame abstrakte Normen und Werte keinen Platz für andere gleichberechtigt koexistierende Lebensformen. Im nächsten Abschnitt werde ich einen kurzen Überblick über die zunehmende parteipolitische Polarisierung in den Vereinigten Staaten geben und dafür argumentieren, dass die Verfassung in Amerika teilweise zu einer Quelle polarisierter Identität geworden ist.

\section{Wachsende parteipolitische Polarisierung in den USA}

In den Vereinigten Staaten gibt es zahlreiche quantitative Studien, die einen als „political polarization“ bezeichneten Trend bestätigen. In den USA beschreibt „Polarisierung“ die wachsende Lücke zwischen Liberalen und Konservativen, welche in in den letzten Jahren ziemlich viel mediale und akademische Aufmerksamkeit erhalten hat. Zum Beispiel hat das Pew Research Center ein Projekt, das sich auf die Polarisierung fokussiert, gegründet, und es hat zahlreiche Infografiken, Umfragen und Statistiken veröffentlicht, in denen das Ausmaß und die Art der Polarisierung beschrieben werden. Nach Pew waren „Republikaner und Demokraten nach ideologischen Gesichtspunkten (im Jahr 2014, Anm. MM) stärker gespalten als zu irgendeinem Zeitpunkt der letzten zwei Jahrzehnte" und diese ideologische Kluft habe sich immer weiter vergrößert. ${ }^{24}$ Darüber hinaus habe auch die politische Abneigung stark zugenommen, was bedeutet, dass die Parteien die Ansichten der anderen Partei eher als Bedrohung für das Wohlergehen der Nation ansehen. ${ }^{25}$ Laut Pew hat sich seit 1994 in jeder Partei die Anzahl der Menschen mit einer sehr negativen Einstellung gegenüber der Gegenpartei mehr als verdoppelt. ${ }^{26} 2019$ setzt sich dieser Trend fort. Pew stellte fest, dass die Amerikaner nicht nur unterschiedliche Ansichten darüber haben, wie die Prioritäten des Staates umgesetzt werden sollten, sondern sogar darüber, worin diese Prioritäten

23 Wie später erklärt: In den USA beschreibt „Polarisierung“ die wachsende Lücke zwischen Liberalen und Konservativen aber es geht auch um kulturelle und gesellschaftliche Polarisierung z. B. „Coastal Elites“ und „real Americans.“

24 Political Polarization in the American Public, How Increasing Ideological Uniformity and Partisan Antipathy Affect Politics, Compromise and Everyday Life, Pew Research Center, 12.6.2014, URL: https:// www.people-press.org/2014/o6/12/political-polarization-in-the-american-public/; Political Polarization, 1994-2017, Pew Research Center, 20.10.2017, URL: https://www.people-press.org/interactives/politicalpolarization-1994-2017/.

25 Political Polarization in the American Public (Fn. 22).

26 Political Polarization in the American Public (Fn. 22). 
überhaupt bestehen sollten. ${ }^{27}$ Dies schafft die Voraussetzungen für den Tribalismus in den USA, da sich die Bürger auf zunehmend polarisierte Nachrichtenquellen verlassen und in zunehmend polarisierten Gemeinschaften verkehren.

Forscher haben kürzlich quantitativ gezeigt, dass diese Polarisierung in den Vereinigten Staaten die Rhetorik in Bezug auf die Verfassung beeinflusst hat. Im Rahmen der Untersuchung analysierte ein Team von Ökonomen eine Datenbank mit Millionen von Anmerkungen des Kongresses und Zehntausenden von Zeitungsredaktionen mit einer Liste konstitutioneller Wörter und Sätze. ${ }^{28}$ Insofern diese Quellen repräsentativ für die Öffentlichkeit sind, sind die Ergebnisse bemerkenswert. Nach Angaben der Autoren zeigen die Ergebnisse „das explosive Wachstum der konstitutionellen Polarisierung in den letzten vier Jahrzehnten.“ ${ }^{29}$ Gewisse Wörter und Begrifflichkeiten, welche sich auf spezielle Teile der Verfassung beziehen, werden mit den zunehmend polarisierten Parteien assoziiert. Republikaner verwenden im Gegensatz zu den Demokraten zunehmend Begriffe wie „Originalism,“ „the First Amendment,“ Redefreiheit, „the Second Amendment,“ das Recht, Waffen zu tragen, „the Tenth Amendment,“ und Rechte der Bundesstaaten..$^{\circ}$ Diese Entwicklungen sind neu - die Polarisierung der Rhetorik in Bezug auf die Verfassung hat sich in den letzten Jahren ereignet und scheint größere Entwicklungen der amerikanischen Polarisierung im Allgemeinen widerzuspiegeln. Ihre Analyse zeigt, dass die Parteien Assoziationsblasen innerhalb der Verfassung geschaffen haben, wodurch ihre Fähigkeit eingeschränkt wird, als Quelle der Einheit zu dienen. Ihr Fazit: „Unsere Ergebnisse deuten darauf hin, dass Aufrufe zur Verfassung uns wahrscheinlich nicht retten werden. Wenn überhaupt, scheint die Konstitutionalisierung politscher Debatten die Sache noch zu verschlimmern. “31 Die Verfassung - neuerdings ein polarisierter Aspekt der amerikanischen Identität - kann die parteipolitischen Grenzen weiter verschärfen. Laut ihrer Arbeit untergräbt diese Entwicklung die Fähigkeit des Verfassungspatriotismus als Quelle der Einheit zu dienen und die Rahmenbedingungen für einen republikanischen Geist zu schaffen.

Ausschnitte aus politischen Reden bestätigen die quantitativen Ergebnisse und heben die Gefahren des polarisierten Verfassungspatriotismus hervor. Präsident Trump behauptet, dass er die Verfassung liebt und dass er sich bemühen werde, ihren Inhalt aufrechtzuerhalten. Er erklärte gegenüber Fox News im Jahr 2016: „Ich bin sehr über-

27 Bradley Jones: Republicans and Democrats have grown further apart on what the nation's top priorities should be, Pew Research Center, 5.2.2019, URL: https://www.pewresearch.org/fact-tank/2019/o2/05/ republicans-and-democrats-have-grown-further-apart-on-what-the-nations-top-priorities-should-be/.

28 David Pozen, Eric L. Talley \& Julian Nyarko, A Computational Analysis of Constitutional Polarization, Cornell Law Review, Vol. 105, 2019; Columbia Public Law Research Paper No. 14-624 (2019).

29 Pozen, Talley, \& Nyarko (Fn. 26), S. 50.

30 Pozen, Talley, \& Nyarko (Fn. 26), S. 46.

31 Pozen, Talley, \& Nyarko (Fn. 26), S. 50. 
zeugt von unserer Verfassung ... Ich bin stolz darauf, ich liebe sie.“" ${ }^{\text {32 }}$ Als isoliertes Zitat könnte dies wie ein Ausdruck eines Verfassungspatriotismus klingen. Natürlich ist Trump eine der meistpolarisierten und polarisierenden Figuren der Neuzeit, was sich etwa an seinem Verhältnis zur Verfassung widerspiegelt. Beispielsweise bezogen sich die Inhalte seiner Kurznachrichten auf Twitter im März 2019, in denen die Verfassung erwähnt wurde, auf seine Position zur Einwanderung oder seine Behauptung, dass die Medien die Verfassung beschädigt hätten. ${ }^{33}$ Er verkörpert den Rechtskonservatismus und nutzt dabei die Verfassung, um seine Agenda voranzutreiben. Auf der anderen Seite kritisierte der Präsidentschaftskandidat Kamala Harris Präsident Trumps neuen Kandidaten des Obersten Gerichtshofs: „Wir betrachten die Zerstörung der Verfassung. ${ }^{{ }^{34}}$ Diese Haltung ist bei demokratischen Präsidentschaftskandidaten üblich. Präsident Trump zu erlauben, an der Macht zu bleiben, bedeutet die Zerstörung der Verfassung und für die Republikaner bedeutet die Übergabe der Präsidentschaft an die Demokraten dasselbe.

Die Polarisierung in den USA scheint die Rhetorik in Bezug auf die Verfassung vergiftet zu haben und könnte die Fähigkeit der Verfassung, als Symbol und Wertesammlung zu dienen und einheits- und identitätsstiftend zu wirken, untergraben. Donald Trumps „beloved constitution“ und Hillary Clintons „brilliant constitution“ sind zwei grundsätzlich verschiedene Dokumente, die zwei grundsätzlich unterschiedliche Weltbilder widerspiegeln. ${ }^{35}$ Für die Republikaner geht es um eingeschränkte Regierung und ihre bevorzugten Rechte, z. B. Waffenrechte oder Rechte der Bundestaaten. Für die Demokraten geht es um Gleichheit und bürgerliche Freiheiten. Die Werte der Demokratie, der Rechtsstaatlichkeit, der Freiheit und der Gleichheit gelten nicht mehr als gemeinsame Aspekte der Verfassungsidentität in der Öffentlichkeit. Während die Vereinigten Staaten ihre Verfassung immer noch lieben und in der Politik zunehmend darauf hin- und verweisen, hat sich der Umgang mit der Verfassung polarisiert. Solange sich ein vielfältiges Land bestimmten Prinzipien verschrieben hat, kann die Verfassung eine Gruppenidentität fördern, aber die Verfassung kann wahrscheinlich ein

32 John Pitney Jr., Trump's disturbing ,love for the Constitution: Column, 16.9.2019, in: USAToday. com, URL: https://eu.usatoday.com/story/opinion/2016/o9/16/trump-constitution-libel-article-geneva -khan-first-amendment-chilling-column/90378484/.

33 Trump Twitter Archive, Created by Brendan Brown, Updated 13.4.2019, URL: http://www.trumptwit terarchive.com/archive.

34 ,We're Looking at the Destruction of the Constitution': Kamala Harris Rips Trump's Potential SCOTUS Picks, 29.6.2018, in: insider.foxnews.com, URL: https://insider.foxnews.com/2018/o6/29/kamala-har ris-rips-trump-supreme-court-destruction-constitution-coming.

35 Gabriel Pogrund and Tracy Jan, At Kansas rally, Trump touts ,tremendous victory' on Kavanaugh, 6.10.2018, in washingtonpost.com, URL: https://www.washingtonpost.com/politics/at-kansas-rally-trumptouts-tremendous-victory-on-kavanaugh/2018/10/o6/b87aoba2-c8e4-11e8-b1ed-1d2d65b86doc_sto ry.html?noredirect=on\&utm_term $=.811$ b13997039; Hilary Clinton, American Democracy is in Crisis, 16.9.2018 in: Atlantic.com, URL: https://www.theatlantic.com/ideas/archive/2018/o9/american-democra cy-is-in-crisis/570394/. 
Land nicht retten, das auf Spaltung basiert. So ist es in den USA, und so ist es im Moment mit ihrer Verfassung. Die Zeit wird zeigen, ob die nationale Identität eine solche Spaltung überleben kann.

\section{Potenzielle Polarisierung in Deutschland}

Während der Verfassungspatriotismus in Deutschland eine andere Form annimmt, gibt es Warnsignale, dass er eine ähnliche Schwäche aufweisen könnte wie in den USA. Zumindest haben die jüngsten Wahlen in Deutschland eine gewisse parteipolitische Polarisierung sichtbar gemacht, die auf einen größeren Trend hindeuten könnte. Zum Beispiel hat der Erfolg der Grünen so wie der AfD bei den bayerischen Landtagswahlen eine Diskussion über die Auswirkungen der Wahl für Deutschland ausgelöst. Nach Wahlforscher Thorsten Faas hat Polarisierung eine Rolle bei steigenden Wahlbeteiligungsraten sowie bei den Ergebnissen der AfD und Grünen gespielt: „Man kann schon sehr deutlich erkennen, dass diese Wahlbeteiligungsraten wieder steigen, seit es eigentlich wieder mehr Polarisierung im Land gibt. ${ }^{\text {“36 }}$ Aber was heißt das genau?

Es ist schwierig, die Polarisierung in Deutschland und in den USA zu vergleichen, da sie sich zum einen in politischen Ansichten, in Bezug auf das wirtschaftliche Wohlergehen, die geografische Lage und anderen Bereichen ausdrückt. Zum Beispiel eignet sich das Zweiparteiensystem in den USA für Polarisierungsmessungen, die sich nicht perfekt auf das deutsche parlamentarische System übertragen lassen. Zum anderen machen die Kommentatoren nicht immer deutlich, worauf genau sie sich beziehen. Polarisierung bezieht sich im Sinne dieses Beitrages auf die ideologische Spaltung eines Landes. Wenn die Ansichten der Menschen radikaler werden und die Bürger aufhören, andere Weltbilder als gültig anzuerkennen, kommt es zu einer Polarisierung. Dies zeigte sich beispielsweise an den erwähnten Wahlergebnissen der bayrischen Landtagswahl von 2018: Timo Lochocki interpretierte den Erfolg der Grünen und der AfD hinsichtlich der Frage der Identitätspolitik und der Spaltung wie folgt:

Die Grünen sind natürlich keine populistische Partei. Aber sie wirken dahingehend polarisierend, dass sie in der Europa- und in der Migrationspolitik fast nur progressive Positionen vertreten - während die AfD auf der Gegenseite ausschließlich konservative Positionen bei diesen Themen hat, bis hinein in den verfassungsfeindlichen Bereich. Ein öffentlicher Diskurs, der von den Grünen geprägt wäre, würde dazu führen, dass die Bevölkerung immer stärker das Gefühl hätte, sie müsste sich einem dieser Lager zuordnen. Kurz gesagt: Die politischen Prozesse, die die AfD stark machen, machen auch die Grünen stark, und

36 Interview: Mehr Polarisierung führt zu hoher Wahlbeteiligung, Thorsten Faas im Gespräch mit Liane von Billerbeck, 16.10.2018, in: deutschlandfunkkultur.de, URL: https://www.deutschlandfunkkultur.de/erke nntnisse-aus-der-bayern-wahl-mehr-polarisierung-fuehrt.10o8.de.html?dram:article_id=430646. 
umgekehrt. Der Erfolg der AfD und der Erfolg der Grünen sind zwei Seiten der gleichen Medaille. $^{37}$

Seine Beschreibung klingt ähnlich den Entwicklungen in den USA, da beide Seiten das andere Lager verunglimpfen und sich weigern, zu kooperieren oder sich auszutauschen. Soweit die Wahlergebnisse in Bayern eine wachsende Kluft zwischen den Grundwerten der Wähler aufzeigen, kann der Verfassungspatriotismus eine weniger wirksame Lösung sein. Das Versagen der Verfassung, eine gemeinsame, einheitliche Basis zu schaffen, zeigte sich Januar 2019 im bayerischen Landtag. Die Präsidentin der Israelitischen Kultusgemeinde München und Oberbayern, Charlotte Knobloch, kritisierte die AfD in einer Rede vor dem Landtag anlässlich eines Gedenkaktes für Opfer des Nationalsozialismus: „Diese sogenannte Alternative für Deutschland gründet ihre Politik auf Hass und Ausgrenzung und steht - nicht nur für mich - nicht auf dem Boden unserer demokratischen Verfassung. ${ }^{{ }^{38} 8}$ Das Ergebnis war, dass die AfD-Abgeordneten das Plenum verließen. Es muss also festgehalten werden, dass ein Verfassungspatriotismus in Fällen, in welchen das Land bereits polarisiert ist, nicht nur nicht helfen kann, sondern sogar das Potential aufweist, die Polarisierung zu verschlimmern.

Es kann sein, dass der Vorfall im bayerischen Landtag einen größeren Trend widerspiegelt. Gemäß einer Umfrage der Konrad-Adenauer-Stiftung gab es eine Polarisierung in den politischen Meinungen: „Es gibt den Autoren der Studie zufolge jedoch deutliche Unterschiede zwischen den Anhängern der Parteien. Das deute auf eine Spaltung der Gesellschaft hin. ${ }^{39}$ Auch gibt es andere Studien in Deutschland, die auf eine zunehmende Polarisierung in anderen Lebensbereichen hindeuten, die zur Meinungspolarisierung beitragen können. Zum Beispiel hat die Friedrich-Ebert-Stiftung einen Bericht veröffentlicht, der die gesellschaftliche Polarisierung in Deutschland erforscht. ${ }^{+0}$ Dieser Bericht zeigt, wie Deutschland in den letzten 15 Jahren durch wirtschaftliche Ungleichheit und Lebenserfahrungen zunehmend gespalten wurde. Diese Bedingungen könnten zur Polarisierung der politischen Meinungen und Weltansichten der deutschen Bürger beitragen. Laut dem Bericht hat „[d]ie Ungleichheit in Deutschland $[\ldots]$ sich in einer Art und Weise entwickelt, dass man ohne Übertrei-

37 Interview: Die Grünen tragen zur Polarisierung bei, Interview mit Politologe Timo Lochocki, 15.10.2018, in: $n$-tv.de, URL: https://www.n-tv.de/politik/Die-Gruenen-tragen-zur-Polarisierung-bei-article20671977. html.

38 Isabel Bernstein, AfD verlässt Plenum während Holocaust-Gedenkrede, 23.1.2019, in suddeutsche,de, URL: https://www.sueddeutsche.de/bayern/afd-landtag-gedenkveranstaltung-opfer-nationalsozialismusknobloch-1.4299382.

39 Studie sieht wachsende Polarisierung der Gesellschaft, 24.5.2018, in: tagesspiegel.de, URL: https://www. tagesspiegel.de/politik/waehler-in-deutschland-studie-sieht-wachsende-polarisierung-der-gesellschaft/ 22597670. html.

40 Alfred Pfaller, Gesellschaftliche Polarisierung in Deutschland, Ein Überblick über die Fakten und die Hintergründe, Expertise im Auftrag der Abteilung Wirtschafts- und Sozialpolitik der Friedrich-Ebert-Stiftung, 6.2012, URL: https://library.fes.de/pdf-files/wiso/o918o.pdf. 
bung von einer gesellschaftlichen Polarisierung sprechen kann. ${ }^{41}$ Es gibt jedoch eine andere Perspektive, wonach Deutschland sich grundlegend von den USA unterscheide und keine ähnliche Polarisierung stattfinde. Renate Köcher, Chefin des Instituts für Demoskopie Allensbach, unterstrich diesen Punkt: „Die Polarisierung wird überzogen wahrgenommen. “42 Laut Köcher gibt es Polarisierung, aber sie finde hauptsächlich bei den Parteiflügeln und bei gesellschaftlichen Minderheiten statt. Im Großen und Ganzen sei Deutschland „meilenweit“von den USA entfernt. Da Polarisierung schwer zu messen ist, wird die Zeit zeigen, was auf die deutsche Gesellschaft zutrifft.

\section{Theoretische Auswirkungen der aktuellen Entwicklungen}

Soweit diese aktuellen Entwicklungen die Fähigkeiten des Verfassungspatriotismus zur Stiftung einer Einheit untergraben, muss dieser Beitrag die theoretischen Auswirkungen in den Blick nehmen und analysieren. Nur weil die Vereinigten Staaten ein Problem haben, heißt das nicht, dass Deutschland dasselbe Schicksal erleiden wird. Man könnte sagen, dass Deutschland den Untergang der Vereinigten Staaten ignorieren könne. Vielleicht zeigen diese Entwicklungen, dass die USA einen unzureichenden Verfassungspatriotismus haben. Im Vergleich zu Deutschland ist der Verfassungspatriotismus in den USA $z u$ patriotisch, er setzt sich nicht mit historischen Ungerechtigkeiten auseinander und ist nicht ganz so reflektiert wie in Deutschland. Es könnte sich herausstellen, dass die Probleme der USA einzigartig sind. Gute Gründe sprechen aber dafür, dies genauer zu untersuchen.

Da sich die deutsche Parteipolitik polarisiert, liegt es nahe, dass dies auch zu einer verstärkten Polarisierung der verfassungsrechtlichen Rhetorik führen kann. Auch wenn die gegenwärtigen Entwicklungen in den USA zeigen, dass eine Polarisierung im politischen Spektrum zu einer Polarisierung der Rhetorik folgen kann, steht ein Beweis für eine Kausalität aus und wäre auch nahezu unmöglich. In den USA scheint es jedoch einen Zusammenhang zwischen polarisierten Ansichten und einer polarisierten Identifikation mit der Verfassung zu geben. Der steigende Erfolg von Parteien, die weiter vom Zentrum entfernt sind, kann letztlich auf eine Polarisierung der deutschen Wählerschaft hindeuten, die einem polarisierten Verständnis des Grundgesetzes entsprechen kann. Das deutsche Grundgesetz vermag viele politische Identitäten zu erfassen; jedoch kann es sein, dass das Grundgesetz nicht in der Lage ist, diese unterschiedlichen Identitäten in einen Diskurs einzubringen. Wie der Artikel zur konstitutionellen Polarisierung zeigt, sind die Republikaner zunehmend an bestimmte Aspekte der Verfassung gebunden; ihr „Patriotismus“ richtet sich dabei auf jene As-

41 Pfaller (Fn. 38), S. 4.

42 Kay-Alexander Scholz, Neue Studien: Deutschland ist polarisiert - wirklich?, 19.09.2018, in: dw.com, URL: https://www.dw.com/de/neue-studien-deutschland-ist-polarisiert-wirklich/a-45554124. 
pekte, die ihren Ansichten entsprechen, wie zum Beispiel Redefreiheit oder das Recht, Waffen zu tragen.

Wenn ein zentrales Ziel des Verfassungspatriotismus darin bestand, eine vielfältige Gruppe von Menschen in einem Diskurs zu vereinen, der auf gemeinsamen Werten basiert, so kann es - mit Blick auf die Vereinigten Staaten - nicht mehr als erfüllt betrachtet werden, aber auch in Deutschland ist es noch nicht erreicht. Der polarisierungsbedingte Über- und Untergang von der Gemeinschaft zum Tribalismus in den USA zeigt deutlich, dass der Verfassungspatriotismus gemeinsame Werte unterstellt, diese aber nicht alleine aufrechterhalten kann. Gemeinsame Werte sind die zentrale Voraussetzung des Verfassungspatriotismus. Wenn andere Kräfte an diesen Werten rütteln, können sie den Verfassungspatriotismus beeinträchtigen. Was bedeutet das für den Verfassungspatriotismus? Ed bedeutet, dass er aufgrund der Polarisierung möglicherweise nicht so wirksam ist wie früher.

\section{Eine Warnung für Deutschland?}

Legt man den Fokus auf die Aspekte des Verfassungspatriotismus in den USA, welche sich auf die Einigkeit eines Volkes beziehen, kann man derzeit beobachten, dass sich dieser Effekt abgeschwächt hat. Es kann sein, dass das deutsche politische Klima nicht den Entwicklungen der Vereinigten Staaten folgt, und vielleicht ist Deutschland nicht einmal auf dem gleichen Weg. In dem Maße, in welchem die politischen Kulturen vergleichbar sind, können die gegenwärtigen Verhältnisse in den USA als Warnung begriffen werden. Die Polarisierung kann den Geist der Einheit und die republikanischen Werte, die ein Volk verbinden, ernsthaft untergraben. Diese Entwicklung kann sogar die Rhetorik um die Verfassung erreichen und damit die Fähigkeit der Verfassung schwächen, als verbindendes Symbol zu dienen. Der amerikanische Fall zeigt, dass die moderne Polarisierung eine neue Bedrohung für die Wirksamkeit des Verfassungspatriotismus bei der Bildung postmoderner Staatsidentitäten darstellt. Was hat das alles für einen Zweck? Teilweise betont es etwas, was von Anfang an klar war: Ein weit verbreiteter Verfassungspatriotismus innerhalb eines Volkes ist kein statischer Zustand. Er muss von den Bürgern aktiv gepflegt und in Richtungen gedrängt werden, die es dem republikanischen Regierungsgeist erlauben, sich selbst zu verstärken. Zur Frage, wie ein Land die Bedingungen für ein Volk schaffen kann, welche für die Bürgerinnen und Bürger zentral sind, ist Verfassungspatriotismus eine Antwort. Vielleicht kann Deutschland wegweisend sein, um einen verfassungsgemäßen Diskurs zu führen, der Menschen mehr vereinigt als trennt. 



\title{
Formaler vs. konkreter Staatsbürger \\ Die Problematik des sub-citizen und der Legitimation der Staatsgewalt im Rahmen der sogenannten Latin American peripheral modernity
}

\section{BRUNO TADEU BUONICORE}

\section{Formal vs. Concrete Citizen}

The Problem of Sub-Citizen and the Legitimation of State Power within the Framework of the Latin American Peripheral Modernity

\begin{abstract}
This article will focus on the question of the extent to which the state, in the context of the so-called "Latin American peripheral modernity", has the legitimacy to apply the monopoly of force against certain citizens on the basis of an act that is contrary to the law and the facts, if the person concerned does not have concrete access to positive, fundamental basic rights provided for in the constitution, such as health, education, culture, work, quality food, basic sanitation, quality means of transport, security, quality accommodation. However, before the question is asked as to whether the citizens as described in this way may justifiably react to the state intervention with violence, it is examined whether such citizens may legitimately be subject to state power at all. It is therefore a theoretical reflection on the role of the socially excluded citizen in the democratic and social constitutional state and his legal relationship to state power.
\end{abstract}

Keywords: responsibility, criminal law, state authority, legitimation, sub-citizen, latin american peripheral modernity

Der Beitrag wird sich schwerpunktmäßig mit der Frage beschäftigen, inwiefern der Staat im Kontext der sog. „Latin American peripheral modernity“ ${ }^{{ }_{1}}$ - als ein Beispiel

1 Marcelo Neves, From Legal Pluralism to Social Miscellany, Peripheral Modernity and its Implications for Latin America, in: hg. ILSA, Law and Society in Latin America, 2003, $130 \mathrm{ff}$. 
deliberativer Demokratie ${ }^{2}$ - legitimiert ist, das Gewaltmonopol gegenüber bestimmten Staatsbürgern aufgrund einer tatbestandsmäßig-rechtswidrigen Handlung anzuwenden, wenn der Betroffene keinen konkreten Zugang zu positiven, fundamentalen, in der Verfassung vorgesehenen Grundrechten wie Gesundheit, Bildung, Kultur, Arbeit, Qualitätslebensmitteln, sanitärer Grundversorgung, Qualitätsverkehrsmitteln, Sicherung, Qualitätsunterkunft hat. Bevor aber danach gefragt wird, ob die so gekennzeichneten Staatsbürger auf den staatlichen Eingriff gerechtfertigterweise mit Gewalt reagieren dürfen, wird untersucht, ob solche Staatsbürger überhaupt legitimerweise Gegenstand der Staatsgewalt sein dürfen. Es handelt sich dabei also um eine theoretische Überlegung über die Rolle des sozial-exkludierten Staatsbürgers im demokratischen und sozialen Rechtsstaat und sein rechtliches Verhältnis zur Staatsgewalt.

Wir gehen grundsätzlich davon aus, dass die im Rahmen der in der europäischen Demokratie entwickelten herrschenden Vorstellung, ${ }^{3}$ der Staatsbürger dürfe deswegen legitimerweise Gegenstand der Staatsgewalt sein, weil ihm die kommunikative Freiheit zur „politischen Teilnahme an demokratischen Verfahren der Meinungs- und Willensbildung über die Setzung von Rechtsnormen " ${ }^{4}$ zukomme, sich keineswegs im Kontext der sog. „Latin American peripheral modernity“ reproduzieren lässt. Während die Freiheit zur politischen Teilnahme als subjektives Recht innehrhalb der sog. deliberativen Demokratie auf formaler und abstrakter Weise zugeschrieben wird, weist die soziale Realität in Lateinamerika besondere Merkmale auf, die einen alternativen theoretischen Ansatz erfordern: „One of the most problematic variables in the difficulty of the identity construction of the sphere(s) of legality in Latin American peripheral modernity is the generalization of relations of sub-integration [...] In this case, inclusion is not realized as simultaneous dependence on positive law"s - soziale Inklusion gilt meines Erachtens als Möglichkeitsbedingung der politischen Teilnahme an demokratischen Verfahren.

In diesem Sinne werden hier folgende Thesen zur Diskussion gestellt: (1) Es muss in Lateinamerika bei der Rechtfertigung der Anwendung der Staatsgewalt gegenüber bestimmten Staatsbürgern ein deutlicher normativer Unterschied zwischen bloß formaler und konkreter Staatsbürgerschaft bestehen; (2) die formale Operation der $\mathrm{Zu}$ schreibung der sog. kommunikativen Freiheit als abstraktes Merkmal des Staatsbür-

2 Hierzu siehe Jürgen Habermas, Faktizität und Geltung, 1992, 349 ff.; Jürgen Habermas, Three normative models of Democracy, Constellations, Bd. I, 1994, 1-10.

3 Ich beziehe mich hier auf Jürgen Habermas' Idee der deliberativen Demokratie und auf die darauf basierende Theorie der kommunikativen Freiheit Klaus Günthers über die Rechtfertigung der Anwendung der Staatsgewalt gegenüber dem Staatsbürger.

4 Klaus Günther, Schuld und kommunikative Freiheit, 2005, 245. Siehe dazu auch ders., Individuelle Zurechnung im demokratischen Verfassungsstaat, 1994, $143 \mathrm{ff}$.

5 Marcelo Neves, From Legal Pluralism to Social Miscellany, Peripheral Modernity and its Implications for Latin America, in: hg. ILSA, Law and Society in Latin America, 2003, 130. 
gers ${ }^{6}$ die den Einsatz des staatlichen Gewaltmonopols gegenüber dem Individuum rechtfertigt, soll durch eine konkrete Operation materieller Anerkennung ersetzt werden; (3) wenn ein bloß formaler Staatsbürger vom Staat bestraft wird, als ob er ein konkreter Staatsbürger wäre, stellt sich die Frage nach der Gerechtigkeit eines solchen Vorgehens im Rahmen des demokratischen und sozialen Rechtsstaats. Hintergrund ist die mögliche Unverhältnismäßigkeit zwischen Pflichten und Rechten im Verhältnis vom Staat zum Bürger; (4) wenn ein formaler, aber keineswegs konkreter Staatsbürger eine tatbestandsmäßig-rechtswidrige Handlung begeht, dann ist der Staat aufgrund seiner defizitären materiellen Anerkennung mitverantwortlich für das Verbrechen, da ein bloß formaler Staatsbürger nicht legitimerweise behandelt werden darf, als ob er ein konkreter Staatsbürger wäre - die materiellen sozialen Bedingungen, die den bloß formalen vom konkreten Staatsbürger trennen, müssen vor dem Einsatz der Staatsgewalt in Betracht gezogen werden.

Als zentrales theoretisches Angebot für die Diskussion liegt die Theorie des „sub-citizen" in der sog. "Latin American peripheral modernity" des brasilianischen Rechtswissenschaftlers Marcelo Neves zugrunde, und zwar im Zusammenhang mit Axel Honneths Theorie der materiellen Anerkennung, die eine „soziale Deutung“ der individuellen Freiheit des Staatsbürgers liefert.

Der brasilianische Rechtswissenschaftlicher Neves geht grundsätzlich davon aus, dass sich die Anerkennung des Einzelnen als konkreter Staatsbürger im Rahmen des demokratischen und sozialen Rechtsstaates in der sog. „Latin American peripheral modernity ${ }^{\text {"7 }}$ nicht mit der formalen Bestimmung bzw. Voraussetzung des positiven Rechts identifizieren lässt. ${ }^{8}$ Es gebe in der "Latin American peripheral modernity“ vielmehr sogar eher die Tendenz, dass die materielle Anerkennung des Individuums als Staatsbürger - mit dem Zugang zu allen in der Verfassung vorgesehenen Grundrechten - in Wirklichkeit nicht vorhanden ist: „One of the most problematic variables in the difficulty of the identity construction of the sphere(s) of legality in Latin American peripheral modernity is the generalization of relations of sub-integration and super-integration. In this case, inclusion is not realized as simultaneous access to and dependence on positive law." ${ }^{\text {"9 }}$

In Bezug auf die „sub-integration“ haben die sog. „sub-citizens“ - als bloß formale Staatsbürger - zwar die Befolgungspflicht gegenüber den staatlichen Normen, aber keinen materiellen Zugang zu den fundamental-sozialen Staatsleistungen: „On the side of the sub-integrated, concrete relations are generalized in which they do not have

6 Klaus Günther, Schuld und kommunikative Freiheit, 2005, 248.

7 Marcelo Neves, From Legal Pluralism to Social Miscellany, Peripheral Modernity and its Implications for Latin America, in: hg. ILSA, Law and Society in Latin America, 2003, $130 \mathrm{ff}$.

8 Vgl. Marcelo Neves, Between Under-Integration and Over-Integration. Not Taking Citizenship Rights Seriously, in: hg. von Jessé Souza / Valter Sinder, Imagining Brazil, 2007, $68 \mathrm{f}$.

9 Marcelo Neves, From Legal Pluralism to Social Miscellany, Peripheral Modernity and its Implications for Latin America, in: hg. ILSA, Law and Society in Latin America, 2003, 141. 
access to the benefits of the legal ordering, but depend on their uncertain prescriptions [...] Nevertheless, they lack the real conditions to exercise their constitutionally declared fundamental rights, and are not liberated from the demands and responsibilities imposed by the coercive state apparatus, radically subjecting them to its punitive structures ... For the sub-integrated, the constitutional apparatuses have relevance almost exclusively in their restrictive effects on liberties. ${ }^{\text {“10 }}$ Einerseits leiden die „sub-citizens“ in Lateinamerika unter unzureichendem Zugang zu den positiven Grundrechten; andererseits bleiben sie aber den Pflichten, Verantwortlichkeiten und restriktiven Freiheitsstrafen unterworfen: Die „sub-citizens“ sind de facto keine konkreten Staatsbürger, aber haben die im positiven Recht vorgesehene formale Staatsbürgerschaft, die ihnen die üblichen Pflichten eines Staatsbürgers auferlegt: ${ }^{11}$ „Die in verschiedenen Graden und Hinsichten marginalisierten Unterschichten (d. h. der größte Teil der Bevölkerung) werden als Verpflichtete, Angeklagte usw. in das System integriert, nicht als Berechtigte, Kläger usw.; sie sind zwar von ihm [Rechtssystem] abhängig, ohne aber Zugang (im positiven Sinne) zu dessen Leistungen zu haben." ${ }^{12}$

Es gibt in diesem Fall eine deutliche Asymmetrie zwischen Rechten und Pflichten von Staatsbürgern in ihrer normativen Beziehung zum Staat. Eine solche Asymmetrie bewirkt meines Erachtens die Ungerechtigkeit der staatlichen Bestrafung des Einzelnen, eine ungerechte Verantwortlichkeit des Individuums als Straftäter. Die Theorie der kommunikativen Freiheit Günthers wird in diesem Kontext dadurch problematisiert, dass die „sub-citizens“ doch als deliberative Staatsbürger angesehen werden, obwohl sie nicht als konkrete Staatsbürger anerkannt werden können. Da der formale Bürger anhand der Zuschreibungsoperation von individueller Freiheit so behandelt wird, als ob er ein konkreter Staatsbürger wäre, kann die Theorie Günthers der konkreten Situation der "sub-citizens“ nicht gerecht werden.

Die kommunikative Freiheit des deliberativen Bürgers ist im Fall der „sub-citizens“ in Lateinamerika nichts als eine bloße Illusion, ebenso wie die Gleichheit zwischen den Bürgern: „Die Institutionalisierung der Kommunikationsfreiheit und erst recht der Gedanke von Gleichheit vor dem Gesetz werden illusorisch, fasst man ins Auge, dass breite Sektoren der Bevölkerung sozial behindert sind, sich positiv in das Verfassungssystem zu integrieren. ${ }^{{ }^{13}}$ Daher ist die Fähigkeit zur kritischen Stellungnahme der deliberativen Bürger nichts weiter als eine formale Annahme, die bei den „sub-citizens" nicht materiell und positiv feststellbar ist. Fakt ist, dass die Fähigkeit zur kriti-

10 Marcelo Neves, From Legal Pluralism to Social Miscellany, Peripheral Modernity and its Implications for Latin America, in: hg. ILSA, Law and Society in Latin America, 2003, 141.

11 Vgl. Marcelo Neves, La Constitución y la esfera pública. Entre diferenciación sistémica, inclusión y reconocimiento, Doxa - Cuadernos de Filosofia del Derecho 37 (2014), 182.

12 Marcelo Neves, Verfassung und Positivität des Rechts in der peripheren Moderne, 1991, 94.

13 Marcelo Neves, Verfassung und Positivität des Rechts in der peripheren Moderne, 1991, 95-96. In diese Richtung siehe die Kritik Niklas Luhmann, Quod Omnes Tangit, in: hg. von Michel Rosenfeld / Andrew Arato, Habermas on law and democracy, 1998, 157-172, insbesondere 170. 
schen Stellungnahme von Staatsbürgern, die konkret keinen Zugang zu fundamentalen Grundrechten wie Lebensmittelkonsum, Gesundheit, Arbeit, Kultur usw. haben, vom Staat nicht formal zugeschrieben werden kann bzw. darf.

In diese Richtung geht die auf einer empirischen Untersuchung in Elendsvierteln in Lateinamerika basierende instruktive Stellungnahme des peruanischen Psychoanalytikers Rabanal, der zufolge es einen Zusammenhang zwischen materieller Armut und der Unfähigkeit zur Entwicklung einer autonomen Persönlichkeit gibt: ${ }^{14}$ Wer keinen konkreten Zugang zu positiven Grundrechten wie Gesundheit, Lebensmittelkonsum, Arbeit, Kultur usw. hat, kann die Fähigkeit zur kritischen Stellungnahme gegenüber sich selbst und gegenüber anderen nicht richtig entwickeln. Um solche Fähigkeiten zu entfalten, müssten hingegen die materiellen positiven Staatsleistungen konkret vorhanden sein. So würde es sich hier nicht mehr um eine rein formale Zuschreibungsoperation hinsichtlich der individuellen Freiheit des Staatsbürgers handeln, sondern um eine materielle und positive Anerkennung der individuellen Freiheit durch den Staat. D.h.: materielle Freiheit statt formaler Freiheit als Voraussetzung strafrechtlicher Verantwortung bzw. Zurechnung - das fasst im Kern den theoretischen Vorschlag der vorliegenden Untersuchung zusammen.

Auf dieser Grundlage kann eine fruchtbare Auseinandersetzung mit der auf Habermas' Sozialtheorie gegründeten Straftheorie Günthers ${ }^{15}$ angeboten werden, um die genaue Bedeutung individueller Freiheit und die Rechtfertigungsmöglichkeiten für die Anwendung der Staatsgewalt zu untersuchen. Honneth zufolge fehlt der Habermasianischen Strömung „der Entschluss zur historischen Konkretion, der zur kommunikationstheoretischen Ausgangsthese noch hinzutreten müsste, um von ihr aus einen Einblick in die institutionellen Grundlagen der Freiheit zu gewinnen. Daher hat der Ansatz von Apel und Habermas, obwohl alles in ihm darauf verweist, die Schwelle zu einem sozialen Begriff der Freiheit nicht nehmen können. ${ }^{\text {16 }}$

Im Kern dieser Diskussion über die Rechtfertigung der Anwendung der Staatsgewalt gegenüber den Staatsbürgern aufgrund einer tatbestandsmäßig-rechtswidrigen Handlung, also über die Individualisation der Verantwortung wegen eines vom Staatsbürger begehenden Verbrechens, steht die Vorstellung der individuellen Freiheit - es geht um die individuelle Freiheit des Täters zum Unrecht (das sog. Für-das-UnrechtKönnen), die die Anwendung der Staatsgewalt erst rechtfertigt. Die zentrale Idee besteht hierbei darin, die soziale Deutung der individuellen Freiheit Honneths in diesem Sinne fruchtbar für diese Diskussion zu machen.

14 Vgl. César Rodríguez Rabanal, Überleben im Slum, 1990, 29 ff. Dazu siehe auch Victor Tadros, Poverty and Criminal Responsibility, Journal of Value Inquiry 43, 2019, 391-413; Shelby Tommie, Dark Ghettos. Cambridge: Harvard University Press, 2017.

15 Klaus Günther, Schuld und kommunikative Freiheit, 2005, $2 \mathrm{ff}$.

16 Axel Honneth, Das Recht der Freiheit. Grundriss einer demokratischen Sittlichkeit, $2011,78$. 
Honneth nimmt in seinem Werk Das Recht der Freiheit den Standpunkt ein, die individuelle Freiheit sei der normative Kern und das axiologische Ziel der Gerechtigkeit in der Moderne. ${ }^{17}$ In seiner Gerechtigkeitstheorie vertritt er die Auffassung, die entscheidende Voraussetzung für die Konkretisierung menschlicher Selbstbestimmung sei der historische Prozess wechselseitiger Anerkennung. ${ }^{18}$ Um den Begriff der individuellen Freiheit in modernen Gesellschaften konkurrieren im Grunde genommen drei verschiedene interpretative Modelle: negative Idee, reflexive Idee und soziale Idee. ${ }^{19}$ Die zwei ersten Ideen sind Honneth zufolge nichts weiter als bloß formale Konzeptionen individueller Freiheit, die nur durch die soziale Idee realisiert werden können. Erst die soziale Idee könne materielle Bedingungen für die Konkretisierung individueller Freiheit im Rahmen einer institutionellen Verankerung von Anerkennungsverhältnissen schaffen. $^{20}$

Der Freiheitsbegriff bei Honneth gewinnt Konturen durch eine normative Rekonstruktion immanenter, gerechtfertigter Werte der historischen Entwicklung moderner Gesellschaften. ${ }^{21}$ Im Kern solcher Werte befinden sich intersubjektive Beziehungen wechselseitiger Anerkennung. Die sozialethische Wesentlichkeit dieser Beziehungen überwindet sowohl die bloß formale, negative Idee als auch die reflexive Idee individueller Freiheit etwa bei Habermas.22

Die negative Idee der individuellen Freiheit hängt mit der liberalen Gerechtigkeitsvorstellung zusammen, die dem Subjekt eine gegenüber der Staatsgewalt rechtlich geschützte Sphäre einräumt. Die Idee einer solchen Sphäre läuft aber auf eine bloß formale Betrachtungsweise der individuellen Freiheit hinaus. Für die Realisierung von Freiheit reicht sie nicht aus, weil sich die Selbstbestimmung und Finalität des Handelns damit nicht erfüllen lassen. Aus einer externen Perspektive des Subjekts über-

17 Siehe hierzu Axel Honneth, Das Recht der Freiheit. Grundriss einer demokratischen Sittlichkeit, 2011, 38 : „[...] nicht der Wille der Gemeinschaft, nicht die natürliche Ordnung, sondern die individuelle Freiheit bildet den normativen Grundstein aller Gerechtigkeitsvorstellung."

18 Hierzu Axel Honneth, Das Recht der Freiheit. Grundriss einer demokratischen Sittlichkeit, 2011, 35 ff., $122 \mathrm{ff}$. und $81-86$.

19 Axel Honneth, Das Recht der Freiheit. Grundriss einer demokratischen Sittlichkeit, 2011, 43.

20 Axel Honneth, Das Recht der Freiheit. Grundriss einer demokratischen Sittlichkeit, 2011, 124: „[...] was es für den einzelnen heißt, über individuelle Freiheit zu verfügen, impliziert notwendigerweise, die existierenden Institutionen zu benennen, in denen er in der normativ geregelten Interaktion mit anderen die Erfahrung der Anerkennung machen kann., siehe auch 86 und $122 \mathrm{ff}$.

21 Der methodologische Weg von Honneths Gerechtigkeitstheorie ist wohl bezeichnend für die Sozialphilosophie der Frankfurter Schule. Bei Honneth handelt es sich weder um eine soziologische Methodik im Sinne einer bloß empirischen Deskription sozialer Tatsachen noch um eine philosophische Methodik im Sinne der Annahme metaphysischer Ideale. Es handelt sich vielmehr um eine soziale Tatsache, die eine historisch immanente Normativität trägt. Das ist im Grunde genommen die von Honneth entworfene Lösung für die Kluft zwischen Sein und Sollen. Siehe hierzu Axel Honneth, Das Recht der Freiheit. Grundriss einer demokratischen Sittlichkeit, 2011, 230.

22 Axel Honneth, Das Recht der Freiheit. Grundriss einer demokratischen Sittlichkeit, 2011, 69 ff., 81 ff., 119 ff. und $221 \mathrm{ff}$. 
sieht man die für die Idee individueller Freiheit wesentlichen subjektiven Elemente der Intentionalität, der Motivation und des unabhängig von Kausalprozessen vorhandenen Verhaltenszwecks. ${ }^{23}$

Die anhand der negativen Idee verstandene individuelle Freiheit liefert ein Interpretationsmuster, das die individuelle Selbstsetzung der Finalität des Handelns nicht ermöglicht. Auf solche Weise wird die Möglichkeit von Selbstbestimmung in bloß formaler Weise angenommen und einer externen Kausalitätskette unterworfen. Die negative Idee liefert ein Erklärungsmodell, das das Verhältnis von Individuum und Norm auf einen negativen Aspekt beschränkt. Das heißt, es ermöglicht zwar ein Verständnis des Individuums als Adressat der Norm, aber nicht als Urheber. Nach Honneth bedeutet dies für die Rechtfertigung der Rechtsordnung eine pathologische Asymmetrie. ${ }^{24}$

Mit der reflexiven Idee wird die individuelle Freiheit mit der subjektiven Betrachtung der Selbstbestimmung gefüllt, und zwar so, dass die Verwirklichungsmöglichkeit des durch seine Selbstfinalität bestimmten, menschlichen Willens vorausgesetzt wird. Erst damit könnte man autonomes von heteronomem Verhalten unterscheiden. In einer ersten Phase bezieht sich die reflexive Idee jedoch auf die interne Beziehung des Subjekts mit sich selbst, wobei vorausgesetzt wird, dass das Verhalten des Individuums ein Produkt nur seiner eigenen Motivation ist. ${ }^{25}$ Diese monologische Verständnisphase der individuellen Freiheit anhand der reflexiven Idee wird im Rahmen einer intersubjektiven Umformulierung anschließend überwunden. ${ }^{26}$

Entsteht aus der negativen Idee der individuellen Freiheit ein Subjektivitätsmangel, so kann auch gesagt werden, dass die monologische Phase der reflexiven Idee einen Objektivitätsmangel hervorbringt. Die intersubjektive Phase der reflexiven Idee holt die Objektivität der individuellen Freiheit wieder zurück, da die reflexive Idee den Raum der internen Subjektivität als vorgegebenes Element hinterlässt und dann durch das kommunikative Handeln des Subjekts innerhalb einer Sprachgemeinschaft erzeugt wird, das Intersubjektivität voraussetzt. ${ }^{27}$ Die gesellschaftliche Institution des Diskur-

23 Axel Honneth, Das Recht der Freiheit. Grundriss einer demokratischen Sittlichkeit, 2011, 56-57, $129 \mathrm{ff}$.

24 Axel Honneth, Das Recht der Freiheit. Grundriss einer demokratischen Sittlichkeit, 2011, 56-57, 129 ff. und $221 \mathrm{ff}$. Nach Honneth sind Hobbes, Locke und Sartre bedeutende Autoren bei der Konstruktion dieser Sichtweise.

25 Axel Honneth, Das Recht der Freiheit. Grundriss einer demokratischen Sittlichkeit, 2011, $58 \mathrm{ff}$.

26 Hierzu sind nach Honneth Aristoteles, Rousseau und Kant bedeutende Autoren. Bei der Umgestaltung der Intersubjektivität spielen Apel und Habermas eine bedeutende Rolle. Es ist zu betonen, dass die beiden Autoren durch die sogenannte sprachphilosophische Wende zutiefst beeinflusst wurden. Zur individuellen Freiheit und ihren Prozess von Detranszendentalisierung siehe Axel Honneth, Das Recht der Freiheit. Grundriss einer demokratischen Sittlichkeit, 2011, 69: „Was bislang die Leistung eines einsamen, auf sich selbst bezogenen Subjekts sein sollte, wird durch eine solche sprachphilosophische Wende als eine kommunikative Hervorbringung der Mitglieder einer Sprachgemeinschaft interpretiert." Siehe auch $58 \mathrm{ff}$.; Dazu: Karl-Otto Apel, Transformation der Philosophie. Das Apriori der Kommunikationsgemeinschaft, 1973; Jürgen Habermas, Moralbewusstsein und kommunikatives Handeln, 1983.

27 Axel Honneth, Das Recht der Freiheit. Grundriss einer demokratischen Sittlichkeit, 2011, 69 und $81 \mathrm{ff}$. 
ses wird in dieser Konzeption als eine Operation dargestellt, aus der die Bedeutung individueller Freiheit hervorgeht und ohne die die Vorstellung von Selbstbestimmung nicht möglich wäre. So wird der Versuch unternommen, das Individuum nicht nur als Normadressat, sondern auch als Normautor zu begreifen. ${ }^{28}$

Obwohl diese zweite Phase der reflexiven Idee schon auf eine soziale Idee individueller Freiheit abzielt, verbleibt sie in einem reflexiven Raum als bloß formale Konzeption, ohne ausreichende Bedingungen für die Konkretisierung individueller Freiheit verschaffen zu können. Dabei wird die konkrete Intersubjektivitätsoperation in der Konstruktion der Bedeutung individueller Freiheit tatsächlich noch nicht realisiert. In dieser Hinsicht kann man sagen, dass die kommunikative Interpretation der reflexiven Idee eine bloß formale, eine sozusagen nur angenommene Intersubjektivität darstellt. ${ }^{29}$ Da die formale Konzeption keine nicht-instrumentalisierbare historische Normativität bzw. Ethik anzubieten vermag, liefert sie noch nicht die angemessene Basis für die hier erstrebte sozialethische Grundlage der strafrechtlichen Schuld.

Honneth pointiert genau in diesem Sinne, dass die Diskurstheorie nicht imstande ist, die Bedeutung individueller Freiheit konkret zu verwirklichen, weil ihr eine historische Konkretion fehlt. Die Idee, dass die Bedeutung individueller Freiheit im Rahmen eines innerhalb einer Sprachgemeinschaft produzierten Diskurses erfasst werden könnte, ist eine bloß formale, sie trägteine unzureichende historische Normativität für die institutionelle Konkretisierung individueller Freiheit..$^{30}$ In der Tat kann die individuelle Freiheit eine verfahrensübergreifende Objektivität nur durch die soziale Idee beanspruchen. Solche Objektivität wird durch historisch institutionalisierte, intersubjektive Beziehungen wechselseitiger Anerkennung verschaffen.

Nicht der Diskurs erzeugt die Bedeutung der individuellen Freiheit, sondern historische Beziehungen wechselseitiger Anerkennung. ${ }^{31}$ Das Verständnis individueller Freiheit als ein Produkt konkreter, intersubjektiver Beziehungen wechselseitiger Anerkennung mit im Laufe der historischen Entwicklung moderner Gesellschaften aufgebautem sozialethischem Gehalt durchbricht die formale Zirkularität des Diskurses.

28 Axel Honneth, Das Recht der Freiheit. Grundriss einer demokratischen Sittlichkeit, 2011, 81.

29 Vgl. die Kritik von Honneth an dieser Konstruktion: Axel Honneth, Das Recht der Freiheit. Grundriss einer demokratischen Sittlichkeit, 2011, 69: „Wir werden allerdings später sehen, dass auch eine solche Erweiterung des „Ich“ zum „Wir“ der Selbstgesetzgebung noch nicht ausreicht, um den Gedanken einer intersubjektiven Freiheit tatsächlich in seinem vollen Umfang zu fassen“. Siehe hierzu auch $81 \mathrm{ff}$., $119 \mathrm{ff}$. und $221 \mathrm{ff}$. 30 Hierzu wieder Axel Honneth, Das Recht der Freiheit. Grundriss einer demokratischen Sittlichkeit, 2011, 78: „Der „Diskurs“ wird in der Diskurstheorie entweder als transzendentales Geschehen oder als Metainstitution, nie aber als partikulare Institution in der Vielzahl ihrer sozialen Erscheinung verstanden; es fehlt der Entschluss zur historischen Konkretion, der zur kommunikationstheoretischen Ausgangsthese noch hinzutreten müsste, um von ihr aus einen Einblick in die institutionellen Grundlagen der Freiheit zu gewinnen. Daher hat der Ansatz von Apel und Habermas, obwohl alles in ihm darauf verweist, die Schwelle zu einem sozialen Begriff der Freiheit nicht nehmen können."

31 Axel Honneth, Das Recht der Freiheit. Grundriss einer demokratischen Sittlichkeit, 2011, 81 ff., 119 ff. und $221 \mathrm{ff}$. 
Die durch den normativen Schuldbegriff erforderte individuelle Selbstbestimmung kann Objektivität nur aus einer solch historisch institutionalisierten Bewegung schaffen. ${ }^{32} \mathrm{Da}$ die beiden anderen Sichtweisen individueller Freiheit (negative und reflexive) bloß formale Ideen darstellen, bezeichnet sie Honneth als parasitär, weil sie Pathologien erzeugen, die nicht nur die Realisierung der individuellen Freiheit verhindern, sondern auch ihre Bedeutung als ethischen Kern der sozialen Gerechtigkeitsvorstellung verfälschen ${ }^{33}$ In der Tat sind diese beiden Ideen individueller Freiheit nichts weiter als Annahmen/Zuschreibungen, die eine erkenntnistheoretisch fundierte Überwindung prozeduraler Freiheitskonzeptionen nicht ermöglichen.

Honneth füllt mit seiner sozialen Idee der individuellen Freiheit den intersubjektiven, kommunikativen Prozess mit historischen und normativen Elementen (die ethische Beziehung wechselseitiger Anerkennung), die den einer Sprachgemeinschaft eigenen deliberativen Gestaltungsspielraum des Freiheitsbegriffs einschränkt.

Schließlich sei die Hauptidee des vorliegenden Beitrags folgendermaßen zusammenzufassen: Die Suche nach einer erkenntnistheoretisch erreichbaren (intersubjektiven) - auf der epistemologischen Ebene - und gleichzeitig nicht-utilitaristischen bzw. instrumentalisierbaren - auf der ethischen Ebene - Perspektive der individuellen Freiheit, die mit der Rechtfertigung der Staatsgewalt im Rahmen des demokratischen und sozialen Rechtsstaats zusammenhängt. Mit anderen Worten: Wir suchen nach einer materiellen Anerkennungethik statt einer formellen Diskursethik als normative Voraussetzung der strafrechtlichen Zurechnung im Kontext des demokratischen und sozialen Rechtsstaats, indem ein asymmetrisches Verhältnis zwischen den (strafrechtlichen) Pflichten und den (sozialen) Rechten des Staatsbürgers gegenüber dem Staat als nicht gerechtfertigt angesehen wird.

32 An dieser Stelle sei betont, dass es das Anliegen der vorliegenden Untersuchung ist, ein Begründungsmodell zu finden, dass es schafft, objektive individuelle Freiheit zu erreichen, ohne dass eine Instrumentalisierung oder Objektivierung des Subjekts notwendig-oder sogar möglich wäre.

33 Axel Honneth, Das Recht der Freiheit. Grundriss einer demokratischen Sittlichkeit, 2011, 221. 



\title{
Demokratie, Korruption und Populismus Oder: Weshalb Montesquieu Recht behält*
}

\author{
MARIA BERTEL
}

\section{Democracy, Corruption and Populism}

Or: Why Montesquieu Was Right

Abstract: This paper analyzes the relationship between democracy, corruption and populism. Starting from an analysis of the different combinations (democracy - corruption, democracy - populism and corruption - populism against the background of democracy), three Latin American case studies (Mexico, Chile, Peru) illustrate the complex connection between the different concepts. The importance of corruption against the background of eroding democracies will be especially highlighted. Since populism is important in many cases of democratic dismantling, the relationship between these two concepts needs to be examined in particular.

Keywords: populism, corruption, representative democracy, mistrust, trust, equality

\section{Einleitung}

„Für die Republik ist es ein Unglück, wenn es keine Spaltungen mehr gibt, und dieser Fall tritt ein, wenn man das Volk durch Bestechung verdorben hat; es wird kaltblütig, es ist ihm am Gelde gelegen, aber nichts mehr an den Staatsangelegenheiten; ohne sich um die Regierung und um das, was man dort vornimmt, zu bekümmern, erwartet es

* Die Forschung für diesen Beitrag wurde teilweise von der Central European University Foundation, Budapest (CEUBPF) finanziert. Die hierin erläuterten Thesen geben ausschließlich die Auffassungen der Autorin und nicht die Meinung von CEUBPF wieder. 
ruhig seine Löhnung. ${ }^{\text {"1 }}$ Schon Montesquieu erachtete die Korruption als ein Problem für den Staat. Zwischen Demokratie, Korruption und Populismus bestehen verschiedene komplexe Zusammenhänge. So zeigt sich, dass die Demokratie ein gewisses Maß an Korruption und Populismus auszuhalten vermag. Ich möchte im Folgenden einige Zusammenhänge zwischen Demokratie und Korruption, Demokratie und Populismus sowie aufbauend darauf, zwischen Korruption und Populismus erarbeiten. Diese Verbindungen sollen exemplarisch an drei Fallbeispielen illustriert werden, bevor im Resümee nochmals auf die Bedeutung von Korruption und Populismus für die Demokratie einzugehen ist.

\section{Begriffliches}

\section{Demokratie}

Bezugspunkt meiner Analyse ist die Demokratie. Zum „Kernbestand einer ,gemeineuropäischen Demokratie““浮 sind mit Albrecht Weber folgende Elemente zu zählen: „periodische Wahlen der Staatsorgane, [und] rechtlich abgesicherte Verantwortlichkeit staatlicher Willensbildung mit der Möglichkeit der Erlangung von Herrschaft durch die parlamentarische(n) Minderheit(en).“3 Zum Kernbestand „ist auch die repräsentative parteienstaatliche Demokratie zu rechnen, wobei neben dem repräsentativen Demokratiemodell auch Institute und Verfahren unmittelbarer Demokratie wie individueller Partizipation hinzutreten; weitgehender Konsens dürfte auch darüber bestehen, dass der rechtstaatlich-menschenrechtliche Aspekt das Demokratieprinzip [...] ergänzt“.4 Hinzuzufügen ist, dass die Demokratie durch den Grundsatz der Gleichheit geprägt ist. ${ }^{5}$

Im Folgenden beziehe ich mich auf die repräsentative Demokratie als einen Teilbereich der Demokratie. ${ }^{6}$ Die Analyse bleibt auf die repräsentative Demokratie beschränkt, weil die Verbindung zwischen direkter Demokratie und Populismus sich davon unterscheidet und dies eigens zu erforschen wäre.

1 Charles Louis de Secondat de Montesquieu, Des Herrn von Montesquieu Werk vom Geist der Gesetze, 1782, Zweites Buch, Zweites Kapitel.

2 Albrecht Weber, Europäische Verfassungsvergleichung, 2010, 111.

3 aaO.

4 Weber (Fn. 2), $111 \mathrm{f}$.

5 Robert Post, Democracy and Equality, Law, Culture of the Humanities 1 (2005), 142-153.

6 Nadia Urbinati, The Populist Phenomenon, Raisons politiques $\mathrm{N}^{\circ} 51$ (2013), 137-154, 137. 
2. Korruption

Korruption gibt es nicht nur in Demokratien, sondern in jeder Form menschlichen Zusammenlebens. Je nach Zeit, Ort und Kultur ${ }^{7}$ sowie abhängig von anderen Faktoren (zB der wirtschaftlichen Entwicklung) kann aber die Einordnung des Verhaltens, welches als Korruption erachtet wird, variieren. ${ }^{8}$ Die schwierige Definitionsfrage ${ }^{9}$ hängt auch vom Maßstab ab: Eine rechtliche Einordnung einer Handlung als korrupte Handlung, oder umgekehrt als erlaubte Handlung, weicht vielfach davon ab, was für moralisch korrupt gehalten wird. ${ }^{\circ}$

Joseph Nye hat Korruption als ein Abweichen von den formalen Pflichten, die eine öffentliche Position mit sich bringt, aus privaten Gründen (zugunsten der eigenen Person, der engeren Familie oder privater Cliquen) mit dem Ziel, pekuniäre Gewinne oder Statusgewinne zu erzielen, definiert. ${ }^{11}$

Für die Zwecke der Analyse möchte ich auf eine nicht ganz so enge Definition von Korruption zurückgreifen, um auch das öffentliche Interesse als Parameter miteinbeziehen zu können. ${ }^{2}$ Darüber hinaus beinhaltet die von mir herangezogene Definition beides, die persönliche und die institutionelle Korruption. ${ }^{13}$ Eine solche weite Korruptionsdefinition wurde ua vom Tax Justice Network ausgearbeitet: „Korruption ist der Missbrauch von öffentlichem Interesse und die Untergrabung des Vertrauens der Öffentlichkeit in die Integrität von Regeln, Systemen und Institutionen, die das öffentliche Interesse fördern. " ${ }^{14}$

Neben der Definition von Korruption ist auch die Frage, wie Korruption gemessen werden kann, umstritten. Ein gewisses Maß an Transparenz vorausgesetzt, können die subjektive Wahrnehmung von Korruption einerseits sowie Umfragen von Eliten und der breiten Öffentlichkeit andererseits herangezogen werden. ${ }^{15}$

7 Alejandro Moreno, Corruption and Democracy: A Cultural Assessment, Comparative Sociology 1 (2002), 495-507.

8 Robert Klitgaard, On culture and corruption, 2017, 5 ff.; Ahmed Seleim / Nick Bontis, The relationship between culture and corruption: a cross-national study, Jnl of Intellectual Capital 10 (2009), 165-184; Joseph Nye, Corruption and Political Development: A Cost-Benefit Analysis, The American Political Science Review 61 (1967), 417-427, 418; Susan Rose-Ackerman, Corruption and government, 1999, 5.

9 Siehe zB Eric M. Uslaner, Corruption, inequality, and the rule of law, 2008, $6 \mathrm{ff}$.

10 Seumas Miller, Corruption. https://plato.stanford.edu/cgi-bin/encyclopedia/archinfo.cgi?entry=cor ruption, 10.6.2019.

11 Nye (Fn. 7), 419.

12 Nye selbst wies darauf hin, dass seine Analyse das öffentliche Interesse als Bezugspunkt nicht aufzunehmen vermochte und dass seine Definition nicht „entirely satisfactory“ sei, aaO.

13 Miller (Fn. 9).

14 Tax Justice Network, Corruption. https://www.taxjustice.net/topics/inequality-democracy/corrup tion/, 10.6.2019.

15 Uslaner (Fn. 8), $11 \mathrm{f}$. 


\section{Populismus}

Die Forschung zu Populismus kennt mittlerweile unzählige Definitionen des - im Grunde sehr vagen ${ }^{16}$ - Begriffs. Jan-Werner Müller hat zutreffend herausgearbeitet, dass es um eine moralisch aufgeladene Sichtweise auf Politik geht. Eine bestimmte Gruppe wird einer Minderheit gegenüberstellt. ${ }^{17}$ Die moralische Aufladung passiert über ein Narrativ. ${ }^{18}$

Nadia Urbinati hat jedoch herausgearbeitet, dass Populismus der repräsentativen Demokratie inhärent und parasitär ist. ${ }^{19}$ Urbinati zufolge weist Populismus auch eine gewisse Dynamik auf. Sie verweist darauf, dass ,a populist movement that succeeds in leading the government of a democratic society tend to move toward institutional forms and a political reorganization of the state that change, and even shatter constitutional democracy, like centralization of power, weakening of checks and balances, disregard of political oppositions, and the transformation of election in a plebiscite of the leader. ${ }^{\prime 20}$ Politische Bewegungen oder Politiker, die sich einer populistischen Sprache bedienen, verfolgen jedoch nicht zwangsläufig das Ziel, den Staat umzubauen, weshalb Urbinati dafür plädiert, die Begriffe Populismus und populistische Bewegungen sowie die Formen der Bewegung und der Regierung voneinander zu unterscheiden. ${ }^{21}$

In eine ähnliche Richtung geht die Definition von Populismus von Margaret Canovan. ${ }^{22}$ Grundsätzlich gehe es beim Populismus um eine Berufung auf „das Volk“ und zwar gleichermaßen gegenüber etablierten Machtstrukturen wie auch gegenüber dominanten Ideen und Wertungen in der Gesellschaft. ${ }^{23}$ Für Canovan ist Populismus Ausdruck der Ambiguität von Demokratie. In dieser sieht Canovan eine ewige Einladung für eine populistische Mobilisierung. ${ }^{24}$ Auch Canovan verweist - wie Urbinati darauf, dass Populismus das Potenzial hat, die Demokratie an ihrem wunden Punkt, nämlich der Notwendigkeit bestimmter Voraussetzungen (insbesondere liberaler Natur), zu treffen und zu verletzen. ${ }^{25}$

Die von Urbinati und Canovan herausgearbeitete Verwundbarkeit der Demokratie wird von Populisten mit rechtlichen Mitteln (mit dem Ziel des Machterhalts bzw -ausbaus) ausgenützt. Rechtliche Strategien umfassen etwa die Änderung von Wahlge-

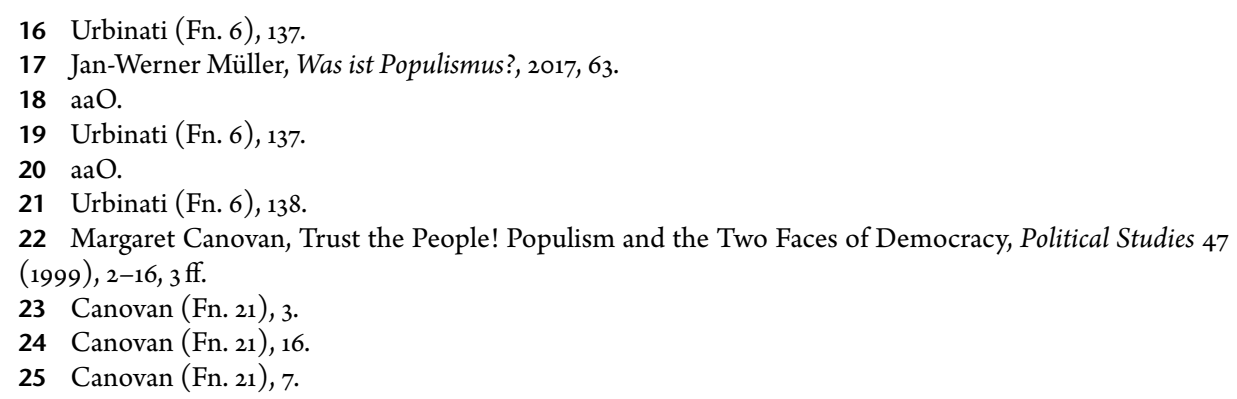


setzen $^{26}$ bzw deren Manipulation ${ }^{27}$, die Änderung der Regeln von Richterbestellungen und/oder Court Packing ${ }^{28}$ oder die Einführung einer Fachgerichtsbarkeit ${ }^{29}$.

Im Folgenden steht daher Populismus für die Berufung auf das Volk im Gegensatz zu Eliten oder gesellschaftlichen Werten mit dem Ziel, die demokratischen Spielregeln zugunsten einer bestimmten Gruppe zu ändern oder zu umgehen, um auf diese Weise den Machterhalt dauerhaft zu sichern.

\section{Demokratie und Vertrauen}

Ein gewisses $\mathrm{Ma}$ an Vertrauen ist notwendig, damit die repräsentative Demokratie funktionieren kann. ${ }^{30}$ Schon Adolf Merkl erkannte, dass „die Einrichtungen demokratischen Gepräges, [...] vom Vertrauen zur politischen Gemeinschaft eingegeben sind“ sowie dass „der Einzelne dem Staat sowohl mit Mißtrauen als auch mit Vertrauen begegnet und daß er das höchste Maß an Freiheit in einer wohlabgewogenen Mischung von Rechtseinrichtungen gegensätzlichen Ursprunges sucht und schließlich auch fin-

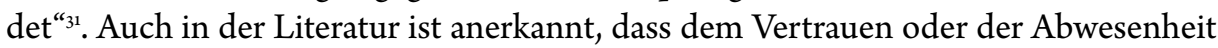
von Vertrauen eine Rolle zukommt, wobei umstritten ist, ob es so etwas wie ein Vertrauen in Institutionen (und damit auch in Institutionen der Demokratie) überhaupt gibt. Catherine Fieschi und Paul Heywood zufolge vertrauen wir Institutionen, weil wir dem Prozess, in dem Entscheidungen getroffen werden, vertrauen: „We place our trust in institutions precisely because we ,trust ' that they will act impartially and this trust stems from the fact that while the outcome of an institutional process may not be ,in our favour', the process itself was impartial. The nature of the process therefore, is what in great part legitimates trust in an institution. For this trust in the process to exist that process must be publicly debated, agreed upon and transparent throughout. Part

26 Péter Kállai / Balázs Majtényi / Alíz Nagy, „Only Fidesz“: Minority Electoral Law in Hungary, https:// verfassungsblog.de/only-fidesz-electoral-law-in-hungary/, 10.6.2019; Anna von Notz, How to Abolish Democracy: Electoral System, Party Regulation and Opposition Rights in Hungary and Poland, https://verfas sungsblog.de/how-to-abolish-democracy-electoral-system-party-regulation-and-opposition-rights-in-hun gary-and-poland/, 10.6.2019.

27 Erik J. Engstrom, Partisan gerrymandering and the construction of American democracy, 2013.

28 Anna Śledzińska-Simon, Midnight Judges: Poland's Constitutional Tribunal Caught Between Political Fronts. https://verfassungsblog.de/?p=11945, 10.6.2019.

29 Renáta Uitz, An Advanced Course in Court Packing: Hungary's New Law on Administrative Courts, https://verfassungsblog.de/an-advanced-course-in-court-packing-hungarys-new-law-on-administrativecourts/, 10.6.2019; Viktor Z. Kazai, Administrative Judicial Reform in Hungary: Who Gives a Fig about Parliamentary Process?, https://verfassungsblog.de/administrative-judicial-reform-in-hungary-who-gi ves-a-fig-about-parliamentary-process/, 10.6.2019.

30 Patti Tamara Lenard, Trust Your Compatriots, but Count Your Change: The Roles of Trust, Mistrust and Distrust in Democracy, Political Studies 56 (2008), 312-332, 315.

31 Adolf Merkl, Die politische Freiheit als Gegenstand wissenschaftlicher Erkenntnis, Anzeiger der phil.hist. Klasse der Österreichischen Akademie der Wissenschaften 1955 (1956), 285-307, 304. 
of the trust stems from our having been (however remotely) engaged in the process of deciding upon the nature of the legitimate process to be adopted from now on." ${ }^{32}$

Auch wenn das Vertrauen zentral für die Demokratie ist ${ }^{33}$, braucht die Demokratie ebenso das Misstrauen. ${ }^{34}$ Die liberale Demokratie zeigt gerade in ihrer historischen Genese auf ${ }^{35}$, dass es nicht um ein blindes Vertrauen geht.

Die für die repräsentative Demokratie konstitutiven Prozesse, wie periodische Wahlen der Repräsentanten, Meinungsfreiheit und andere grundrechtliche Verbürgungen sowie die Gewaltenteilung, ermöglichen es der Bevölkerung, das Vertrauen zu erneuern. Dies kann zu veränderten Kräfteverhältnissen im Parlament führen oder dazu, dass über öffentlichen Druck, der etwa durch Ausübung der Versammlungsfreiheit sichtbar werden kann, bestimmte Funktionsträger zurücktreten.

Die von Patti Tamara Lenard getroffene Unterscheidung in Vertrauen („trust“), Misstrauen („mistrust“) und „Nichtvertrauen“ („distrust“) ist an dieser Stelle hilfreich. ${ }^{36}$ Lenard ${ }^{37}$ betont, dass Vertrauen wichtig ist für das Funktionieren der Demokratie, weist aber gleichzeitig darauf hin, dass Demokratien fähig sind, ein bestimmtes Maß an Misstrauen und Nichtvertrauen auszuhalten..$^{38}$ Misstrauen ist für Lenard sogar ein wichtiges Korrektiv der Demokratie: Misstrauen kann als eine Form der kritischen Auseinandersetzung des Wahlvolkes mit seinen gewählten Vertretern betrachtet werden. ${ }^{39}$ Es geht darum, aufmerksam zu bleiben. ${ }^{40}$ Dies führt auch dazu, dass sich die gewählten Vertreter nie ganz sicher sein können, dass sie an der Macht bleiben. Wie noch auszuführen ist, hat diese Unsicherheit auch Einfluss auf die Korruption. ${ }^{41}$

Nichtvertrauen (iS der Abwesenheit von Vertrauen) hingegen schadet einer Demokratie langfristig. Eine Demokratie lebt davon, dass die Bürger zum einen daran glauben, dass ihre Vertreter im Interesse der Allgemeinheit (und damit aller Bürger) handeln, zum anderen sich aber auch darauf verlassen, dass der andere Bürger ebenso die Normen freiwillig verfolgt. ${ }^{42}$

32 Catherine Fieschi / Paul Heywood, Trust, cynicism and populist anti-politics, Journal of Political Ideologies 9 (2004), 289-309, 294.

33 Lenard (Fn. 29), 313.

34 Lenard (Fn. 29), 315 .

35 Mark E. Warren, Introdcution, in: Democracy and trust, hg. von Mark E. Warren, 2001, 1-21, 1.

36 Lenard (Fn. 29).

37 Siehe außerdem Patti Tamara Lenard, The Political Philosophy of Trust and Distrust in Democracies and Beyond, The Monist 98 (2015), 353-359.

38 Lenard (Fn. 29), $315 \mathrm{f}$.

39 Lenard (Fn. 29), $323 \mathrm{f}$.

40 Lenard (Fn. 29), 324.

41 Rose-Ackerman (Fn. 7), 127.

42 Lenard (Fn. 29), 328. 


\section{Korruption, Vertrauen und Demokratie}

Korruption als „Missbrauch von öffentlichem Interesse und [... der] Untergrabung des Vertrauens der Öffentlichkeit in die Integrität von Regeln, Systemen und Institutionen, die das öffentliche Interesse fördern"43 kann auch das Vertrauen der Bürger untereinander stören. ${ }^{44}$ Dies ist dann der Fall, wenn diese $\mathrm{zB}$ nicht mehr darauf vertrauen können, dass das Rechtssystem gleichmäßig für alle Bürger funktioniert. Ein grundsätzliches Vertrauen ist jedoch, wie soeben gezeigt, notwendig für eine funktionierende Demokratie. ${ }^{45}$ Je nachdem, welches Maß die Störung des Vertrauens durch Korruption erreicht, ist auch die Demokratie gefährdet, dysfunktional zu werden.

Korruption schadet der Demokratie auch deshalb, weil sie neben dem Vertrauensverlust den Glauben an die grundsätzliche Gleichheit der Bürger beeinträchtigt. ${ }^{46}$ Die Annahme, dass alle Bürger gleich sind, ist aber eines der grundlegenden Postulate der

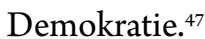

Die Gefährdung der Annahme der Gleichheit kann durch Korruption auf verschiedene Art und Weise geschehen und alle drei Staatsgewalten betreffen. Werden zB Wahlen gefälscht, so ist die Gleichheit der Stimmen verletzt. Das Manipulieren von Wahlbezirken („gerrymandering“) kann zu einem ungleichen Zählwert der Stimmen führen. Dasselbe gilt, wenn ein Wahlkampf mit illegalen Mitteln geführt wird.

Kommt ein Gesetz durch illegales Lobbying zustande, dann kann ebenso nicht mehr von der Gleichheit der Repräsentierten ausgegangen werden: Der rationale Diskurs in der Staatsgewalt Gesetzgebung, der auf der Gleichheit der Beteiligten beruht, funktioniert nicht mehr.

Ebenso problematisch im Hinblick auf den Grundsatz der Gleichheit ist Korruption in der Staatsgewalt Verwaltung: Den Grundsatz, dass Gleiches gleich zu behandeln ist, kennen die meisten demokratisch verfassten Staaten in der einen oder anderen Ausformung. ${ }^{48}$ Behandelt die Verwaltung die Rechtsunterworfenen aufgrund von $\mathrm{zB}$ Bestechung anders, dann ist Gleichheit ebenso nicht mehr gewährleistet.

Wenn schließlich die Gerichtsbarkeit korrupt ist, dann ist auch damit eine Ungleichbehandlung von Personen verbunden. Dies ist letztlich demokratiefeindlich,

43 Tax Justice Network (Fn. 13).

44 Scott A. Fritzen / Søren Serritzlew / Gert Tinggaard Svendsen, Corruption, Trust and their Public Sector Consequences: Introduction to the Special Edition, Journal of Comparative Policy Analysis: Research and Practice 16 (2014), 117-120.

45 Lenard (Fn. 29).

46 Uslaner (Fn. 8), 5.

47 Siehe dazu schon Hans Kelsen / Georg Froehlich / Adolf Merkl (Hrsg.), Die Bundesverfassung vom 1. Oktober 1920, 2003, 74; Kelsen/Froehlich/Merkl verwiesen darauf, dass im „politisch wichtige[n] Prinzip der Gleichheit vor dem Gesetz, [...] die demokratischen Errungenschaften besonders zum Ausdruck kommen".

48 Constituteproject.org; https://constituteproject.org/search?lang=en\&key=equal\&status=in_force\& status=is_draft, 10.6.2019. 
weil es das Vertrauen in die demokratisch direkt oder indirekt legitimierten Gerichte nachhaltig unterminieren kann.

Korruption kann auf verschiedene Art und Weise bekämpft werden. Susan Rose-Ackerman hat herausgearbeitet, dass ein funktionierender politischer Wettbewerb die Wahrscheinlichkeit von Korruption senkt. ${ }^{49}$ Die „Bestrafung“ der Volksvertreter an der Wahlurne ist die unmittelbarste Form der Sanktionierung von Korruption..$^{\circ}$ Dies mag auch entscheidend dafür sein, dass der Wahlvorgang ein großes Einfallstor für Korruption ist. Insbesondere die Finanzierung von Wahlkampagnen steht dabei im Mittelpunkt..$^{11}$ Die Beurteilung, ob ein bestimmtes Verhalten als Korruption einzustufen ist, hängt jedoch von der jeweiligen Rechtsordnung ab. In den Vereinigten Staaten von Amerika hat der Supreme Court über Reformen, die die Einflussnahme auf Wahlen über Spenden reguliert hätten, negativ entschieden. Parteispenden fallen nach Citizens United ${ }^{52}$ unter die Meinungsfreiheit und sind somit legal. ${ }^{53}$

Eine entscheidende Rolle kommt daher auch der Transparenz $z^{54}$ und der Meinungsfreiheit zu: Nur, wenn Informationen über korrupte Handlungen zur Verfügung stehen und bekannt werden ${ }^{55}$ sowie in weiterer Folge auch verbreitet werden können, kann sich der Wähler am Wahltag für die eine oder andere Partei oder Person entscheiden. Die gewählten Vertreter hingegen dürfen sich über das Ergebnis der Wahl nicht sicher sein, sondern müssen ihre Ablösung befürchten. Nur wenn den gewählten Vertretern Sanktionen (in diesem Fall die Abwahl) drohen, kann Transparenz präventiv wirken. ${ }^{66}$ Es muss darauf vertraut werden können, dass die Mechanismen der Kontrolle funktionieren, damit Transparenz sinnvoll Anwendung finden kann.

\section{Populismus und Demokratie}

Populismus ist eng mit der repräsentativen Demokratie verbunden und der Demokratie inhärent..$^{57}$ Insofern ist Populismus nicht zwingend und in all seinen Ausformungen schädlich für die Demokratie. Dass Populismus nicht in den Bereich des Undenkbaren

\footnotetext{
49 Rose-Ackerman (Fn. 7), 127.

50 aaO.

51 Rose-Ackerman (Fn. 7), 132.

52 U.S. Supreme Court, Citizens United v. Federal Election Commission, 558 U. S. 310 (2010).

53 Für eine Aufarbeitung der Judikatur seit der Entscheidung U. S. Supreme Court, Buckley v. Valeo, 424 U.S. 1 (1976) siehe Samuel Issacharoff, On political Corruption, Harvard Law Review 124 (2010), 118-142. 54 Catharina Lindstedt / Daniel Naurin, Transparency is not Enough: Making Transparency Effective in Reducing Corruption, International Political Science Review 31 (2010), 301-322.

55 Lindstedt/Naurin (Fn. 53), 302.

$56 \mathrm{aaO}$.

57 Urbinati (Fn. 5), 137; Canovan (Fn. 21), 2 f.
} 
gedrängt werden sollte, fordern ua Ernesto Laclau ${ }^{58}$ und Chantal Mouffe ${ }^{59}$. Auch Cas Mudde und Cristobal Rovira Kaltwasser weisen darauf hin, dass sich Populismus sowohl positiv wie auch negativ auf die Demokratie auswirken kann: „On the one hand, the democratic side of populism relies on its capacity to give voice to groups that, objectively or subjectively, are being excluded from the collective decision-making process. On the other hand, the undemocratic side of populism derives from its monist nature, which can lead to the undermining of minority rights and protections. ${ }^{\text {“60 }}$ Probleme sehen Mudde und Rovira Kaltwasser wie Urbinati und Canovan ${ }^{61}$ darin, dass Populismus und liberale Demokratie in einem Spannungsverhältnis stehen. ${ }^{62}$

\section{Verbindung von Populismus und Korruption}

So wie Demokratie und Populismus einerseits und Korruption und Demokratie andererseits miteinander verbunden sind, so lässt sich auch eine Verbindung zwischen Korruption und Populismus herstellen.

Korruption kann dazu beitragen, dass die dem Populismus innewohnende Gefahr, nämlich der Demokratie langfristig zu schaden, vermehrt zum Tragen kommt. Korruption kann dabei als Narrativ herangezogen werden. ${ }^{63}$ Umgekehrt kann eine populistische Rhetorik unter Umständen auch helfen, Korruption zu bekämpfen und eine Erneuerung der Demokratie herbeizuführen. ${ }^{64}$

Die Zahlen aus Lateinamerika zeigen auch, dass eine Korrelation zwischen einer Steigerung der gefühlten Korruption ${ }^{65}$ und dem Eindruck, dass die Demokratie dysfunktional ist, zu bestehen scheint. ${ }^{66}$ Auch ist das Vertrauen in die Regierung in Staaten, für die die gefühlte Korruption als hoch angegeben wird, tendenziell niedriger. ${ }^{67}$

58 Ernesto Laclau, On populist reason, 2005, 19.

59 Chantal Mouffe, For a left populism, 2018.

60 Cas Mudde / Cristóbal Rovira Kaltwasser, Populism in: The Oxford Handbook of Political Ideologies (hg. von Michael Freeden / Marc Stears), 2013, 493-512, 506.

61 Siehe oben.

62 Mudde/Rovira Kaltwasser, Populism, 506.

63 Niklas Kossow, Populism and corruption, https://knowledgehub.transparency.org/assets/uploads/ helpdesk/populism-and-corruption-2019-final.pdf 10.6.2019, 4 .

64 Kossow (Fn. 62), 6, siehe dazu noch bei den Fallbeispielen.

65 Transparency International (Hrsg.), Corruption Perception Index 2018, 2018.

66 Vergleiche hierzu die Zahlen aus dem Latinbarometro 2018 für Lateinamerika, wo das Vertrauen in demokratische Institutionen für alle Staaten im Sinken begriffen ist: Corporación Latinobarómetro, Informe 2018. http://www.latinobarometro.org/lat.jsp, 10.6.2019. Gleichzeitig weisen die lateinamerikanischen Staaten auch ein vergleichsweise hohes Niveau an gefühlter Korruption auf.

67 Richard Wike / Katie Simmons / Bruce Stokes / Janell Fetterolf, Globally, Broad Support for Representative and Direct Democracy, $13 \mathrm{ff}$. 


\section{Korruption als Narrativ des Populismus}

Das Argument Korruption kann dafür herangezogen werden, das Volk von der Elite abzugrenzen. Während das Volk für Natürlichkeit steht und positiv konnotiert ist, steht die Elite für Korruption und wird entsprechend negativ dargestellt. ${ }^{68}$

Eine solche Rhetorik ist weltweit zu beobachten: Donald Trump zB versprach in seinem Wahlkampf, den Sumpf zu trocknen („drain the swamp“).69 Auch der mexikanische Präsident Andrés Manuel López Obrador, kurz AMLO, bekennt sich zum Kampf gegen die Korruption. ${ }^{70}$

Das Narrativ Korruption kann dabei in populistischer Manier aufgegriffen werden, um tatsächliche Missstände bekannt zu machen und im Sinne einer funktionierenden Demokratie zu beseitigen. ${ }^{71}$ Umgekehrt kann die einmal erlangte Macht jedoch auch missbräuchlich verwendet werden. So ist es keine unbekannte Taktik, unliebsame politische Gegner durch Korruptionsvorwürfe aus dem politischen Spielfeld zu drängen..$^{2}$

Während bei anderen Narrativen, wie zB ausländischen Verschwörungen, das Substrat komplett fehlt oder bei den heraufbeschworenen Gefahren der Migration die Problematik absichtlich überzeichnet wird, ist die Ausgangslage bei der Korruption vielfach eine andere. Korruption ist nicht nur im lateinamerikanischen Kontext ein reales Problem. ${ }^{73}$

\section{Korruption als Hilfe zur Machtperpetuierung}

Insbesondere in Lateinamerika haben populistische Politiker immer wieder auf korrupte Verhaltensweisen zurückgegriffen, entweder um überhaupt Wahlen zu gewinnen oder um die einmal erlangte Macht zu behalten.

68 Vgl. hierzu Müller (Fn. 16), 42.

69 Conor Friedersdorf, It's Time for Trump Voters to Face the Bitter Truth, The Atlantic 11.5.2018, https:// www.theatlantic.com/ideas/archive/2018/05/trumps-washington/560105/, 10.6.2019.

70 Trabaja el presidente electo de México, Andrés Manuel López Obrador en dos paquetes de iniciativas de reformas, https://lopezobrador.org.mx/temas/combate-a-la-corrupcion/, 10.6.2019.

71 Beispielhaft siehe Peru, Maria Bertel, Does the President Have the Power to Call a Constitutional Referendum in Peru? http://www.iconnectblog.com/2018/o9/does-the-president-have-the-power-to-calla-constitutional-referendum-in-peru/, 11.6.2019.

72 Moisés Naím, Honest Politicians Won't Fix Corruption, The Atlantic 12.12.2017, https: / www.theatlantic. com/international/archive/2017/12/corruption-russia-venezuela-china/548159/, 10.6.2019. Vgl. auch die Situation in Ecuador, wo unklar ist, ob die Korruptionsvorwürfe von Präsident Lenin Moreno gegenüber dem Ex-Präsidenten Rafael Correa berechtigt sind, Marc Becker / Thea N. Riofrancos, A Souring Friendship, a Left Divided, NACLA Report on the Americas 50 (2018), 124-127, 124.

73 Siehe unten. 
Das erstmalige Gewinnen von Wahlen kommt vielfach auf korrekte Art und Weise zustande. Dies zeigen zB der Aufstieg von Alberto Fujimori in $\mathrm{Peru}^{74}$, von Hugo Chavez in Venezuela ${ }^{75}$ oder von Evo Morales in Bolivien. ${ }^{76}$

Bei der Ausübung der Macht beginnen Strategien zum Machterhalt eine Rolle zu spielen. Diese Strategien können darin bestehen, dass rechtliche Vorgaben umgangen oder geändert werden. Betroffen sind alle drei Staatsgewalten. Über die Gesetzgebung können - wie in Europa das polnische und ungarische Beispiel zeigen - die anderen Staatsgewalten beeinflusst werden.7 ${ }^{77}$ Der Übergang zu Regeln, die den Machterhalt einer bestimmten Gruppe oder Person ${ }^{78}$ absichern sollen, ist dabei fließend. Oft ist es schwierig, manipulierende Regeln von anderen Regeln zu unterscheiden, weil Regelungen aus einem anderen Kontext missbräuchlich eingefügt werden oder einfach aus dem Grund, weil eine neue - und an sich unproblematische Regelung - zB die Möglichkeit der Neubesetzung einer Stelle mit sich bringt und so ein Wandel herbeigeführt werden kann. Darüber hinaus ist selbstverständlich nicht jede Regelung, die Änderungen zur Folge hat, schädlich.

Bestimmte Bereiche können jedoch als besonders sensibel betrachtet werden, so zB Änderungen des Wahlrechts ${ }^{79}$ oder sonstige Änderungen, die sich auf das Wahlrecht auswirken. ${ }^{8 \circ}$ Vor allem im wahlrechtlichen Kontext kann auch das Unterlassen von Änderungen gegebenenfalls einen Vorteil für eine bestimmte Gruppe bedeuten, wenn etwa der Zensus, auf dessen Basis die Zuteilung der Wähler zu verschiedenen Wahlbezirken erfolgt, auf einen Zeitpunkt nach der kommenden Wahl verschoben wird. ${ }^{{ }_{1}^{1}}$

74 Gregory D. Schmidt, Delegative Democracy in Peru? Fujimori's 1995 Landslide and the Prospects for 2000, Journal of Interamerican Studies and World Affairs 42 (2000), 99-132, 102.

75 Steve Ellner, Hugo Chávez's First Decade in Office, Latin American Perspectives 37 (2010), 77-96.

76 Rory Caroll / Andres Schipani, Evo Morales wins landslide victory in Bolivian presidential elections, The Guardian 7.12.2009, https://www.theguardian.com/world/2009/dec/o7/morales-presidential-victory, 10.6.2019.

77 Wojciech Sadurski, How Democracy Dies (in Poland): A Case Study of Anti-Constitutional Populist Backsliding, Sydney Law School Working Paper (2018), 1 ff.; R. Uitz, Can you tell when an illiberal democracy is in the making? An appeal to comparative constitutional scholarship from Hungary, International Journal of Constitutional Law 13 (2015), 279.

78 Dass solche Regeln etwa im Fall von Beschränkungen der Amtszeit nicht unumstritten sind, macht die Beurteilung nicht einfacher, siehe allgemein Tom Ginsburg / Zachary Elkins / James Melton, On the Evasion of Executive Term Limits, William and Mary Law Review 52 (2011), 1807-1872; zB und für Lateinamerika im Speziellen David Landau, Presidential Term Limits in Latin America: A Critical Analysis of the Migration of the Unconstitutional Constitutional Amendment Doctrine, The Law \& Ethics of Human Rights 12 (2018), 225-249.

79 Notz (Fn. 25).

80 Das kann zB die Modalitäten der Wahl betreffen. Vgl. zur Registrierung als Bedingung, das Wahlrecht ausüben zu können Jennifer S. Rosenberg / Margaret Chen, Expanding Democracy: Voter Registration around the World, ohne Jahr.

81 Aktuell ist dies in Äthiopien der Fall, Ethiopia delays census again despite looming election, https://af.reu ters.com/article/topNews/idAFKCN1TB1PN-OZATP, 10.6.2019. 
Kritisch sind auch Änderungen, die die Gerichtsbarkeit betreffen. Dies betrifft nicht nur, aber zunächst einmal, die Verfassungsgerichtsbarkeit. Unter dem Stichwort „court packing“" wird der Versuch beschrieben, möglichst viele politisch günstig gesinnte Kandidaten in eine Richterposition zu bringen. ${ }^{82}$ Solange dies nach den geltenden Regeln erfolgt, kann dagegen kaum ein Einwand erhoben werden. Vielfach wird jedoch mit anderen Mitteln operiert: Schon Roosevelt versuchte in den zoer Jahren, Einfluss auf den US-Supreme Court zu nehmen, indem er einen Gesetzesentwurf schuf, wonach für jeden Richter, der das 70. Lebensjahr erreicht hatte, ein weiterer Richter aufgenommen werden sollte. ${ }^{83}$ Der Entwurf scheiterte. Manche Autoren vermuteten in der Folge, dass dieser missglückte Versuch, die Regeln zu ändern, dazu führte, dass sich das Verhalten einzelner Richter änderte. Dies bleibt aber umstritten. ${ }^{84}$

Betroffen ist aber vielfach auch die ordentliche Gerichtsbarkeit. Dort stellt sich etwa die Frage, wie Richterbestellungen erfolgen und inwieweit politischer Einfluss möglich ist. Auch hier ist über Änderungen der gesetzlichen Grundlagen eine entsprechende Einflussnahme möglich, wie zB die polnische Justizreform zeigt. ${ }^{85}$ Auch kompetenzrechtliche Änderungen, etwa durch Einführung einer Verwaltungsgerichtsbarkeit, wie in Ungarn der Fall, können eine entsprechende Einflussnahme bedeuten. ${ }^{86}$

Für beide Beispiele gilt, dass oft das zeitliche Element eine Rolle spielt: Änderungen des Pensionsantrittsalters etwa ermöglichen einer Regierung, bestimmte unliebsame Persönlichkeiten frühzeitig aus dem Amt zu entfernen, auf dem legalen Weg der Pensionierung. ${ }^{87}$

Übergangsbestimmungen schaffen die Voraussetzung dafür, dass bestimmte Personen an der Macht bleiben. Ähnliches gilt für (zeitliche) Verschiebungen von Besetzungen oder beschleunigte Verfahren.

Für den Machterhalt entscheidend sind schließlich die neuerlichen Wahlen. Strategien, die Populisten in diesem Bereich anwenden können, um ihre Chancen zu erhöhen, sind neben den schon erwähnten Änderungen des Wahlrechts ieS Änderungen im Bereich von Kampagnen- und Parteienfinanzierung sowie individuelle Strafen, wenn etwa ein Mandat nachweislich mithilfe von illegaler Finanzierung erlangt wird. ${ }^{88}$

82 So kann aber zB durch eine Gesetzes- oder Verfassungsänderung auch eine Änderung in der Struktur eines Gerichtes hervorgerufen werden und dadurch ein Richter oder mehrere Richter früher aus dem Gericht ausscheiden, vgl. hierzu EGMR (GK), Baka gegen Ungarn (23.6.2016), ECLI:CE:ECHR:2016:0623J UDoo2026112.

83 Jamie L. Carson / Benjamin A. Kleinerman, A Switch in Time Saves Nine: Institutions, Strategic Actors, and FDR's Court-Packing Plan., Public Choice 113 (2002), 301-324, 303 ff., William E. Leuchtenburg, The Origins of Franklin D. Roosevelt's „Court-Packing“ Plan, The Supreme Court Review (1966), 347-40o.

84 Laura Kalman, The Constitution, the Supreme Court, and the New Deal, The American Historical Review 110 (2005), 1052-1080.

85 EuGH, Europäische Kommission gegen Republik Polen (15.11.2018), ECLI:EU:C:2018:910.

86 Uitz (Fn. 28).

87 EuGH (Fn. 84).

88 Siehe noch unten das Fallbeispiel Chile. 
Was haben die punktuell aufgezeigten Strategien zum Machterhalt mit Korruption zu tun?

Die Verbindung zeigt sich schwerpunktmäßig an der Korruption als Narrativ. ${ }^{89}$ Populisten arbeiten mit einem faktischen oder rhetorischen Ausnahmezustand (wobei diese Grenzen verschwimmen können und oft ein faktischer Ausnahmezustand später nur mehr ein Mittel der Rhetorik ist) als Rechtfertigung für Maßnahmen, die ihnen selbst helfen, an der Macht zu bleiben. Wird ein rechtlicher Ausnahmezustand verhängt, so kann dies zur Aufhebung bestimmter gesetzlicher Bindungen und zu einer Einzementierung von Macht über den Weg von Notverordnungen der Exekutive führen. Schon deshalb beschränken Verfassungen in der Regel den rechtlichen Ausnahmezustand auf bestimmte Fälle. ${ }^{\circ}$

Für Populisten dient das Narrativ der Korruption als Legitimation für ihre Handlungen: Dies können Reformen (durch Änderungen bestehender Gesetze oder neuen Gesetzesvorhaben) sein, aber auch das (ausnahmsweise) Abweichen von bestehenden Gesetzen.

\section{Demokratie, Korruption und Populismus am lateinamerikanischen Fallbeispiel}

1. Fallbeispiel: Mexiko - Beschränkung der Wiederwahl als Mittel gegen Korruption?

Die Literatur zu Begrenzungen der Amtsdauer ist uneinheitlich, was die positiven bzw negativen Effekte von Amtszeitbeschränkungen in Bezug auf Korruption betrifft. ${ }^{11}$ Viele populistische Führungsfiguren sind versucht, möglichst lange an der Macht zu bleiben.92 Da Populisten in der Regel Wert auf Wahlen legen, muss der Machterhalt durch mehrere Amtszeiten erfolgen. Mehrere Amtszeiten können zwar zu Stabilität

89 Vgl. beispielhaft zum Präsidenten López Obrador, Alejandro García Magos, López Obrador in Democratic Mexico, in: Oxford Research Encyclopedia of Latin American History, hg. von Alejandro García Magos, 2018.

90 Die Fälle, in denen der Ausnahmezustand erklärt werden kann, haben sich in den letzten Jahren tendenziell ausgeweitet, so Christian Bjørnskov / Stefan Voigt, The architecture of emergency constitutions, International Journal of Constitutional Law 16 (2018), 101-127, $106 \mathrm{f}$.

91 Für eine Übersicht über die Literatur betreffend Beschränkungen der Amtszeit für Abgeordnete in der Legislative in den USA sowie eine Abbildung der Argumente, siehe Christopher Z. Mooney, Term Limits as a Boon to Legislative Scholarship: A Review, State Politics \& Policy Quarterly 9 (2009), 204-228, $206 \mathrm{ff}$. 92 Jüngst zB Evo Morales in Bolivien, vgl. Emily Achtenberg, Evo's Bolivia at a Political Crossroads, NACLA Report on the Americas 48 (2016), 372-380. 
führen, es steigt mit einer längeren Amtsdauer aber auch die Möglichkeit, korrupte Netzwerke aufzubauen.93

Mexiko war lange Zeit hindurch ein Musterbeispiel, wenn es um die Beschränkung der Möglichkeit der Wiederwahl ging. Mexikos Verfassung ging sogar so weit, nicht nur Beschränkungen der Amtszeit für die Exekutive (Art 83), sondern auch für die Legislative (Art 59, Art 115) vorzusehen. So war nicht nur der Präsident auf eine Wahlperiode beschränkt, sondern auch der Kongress sowie der Senat. ${ }^{94}$ Während der Präsident bereits seit 1917 nicht zur Wiederwahl antreten darf, wurden die Beschränkungen für die Abgeordneten und Senatoren erst 1933 eingeführt. Diese strengen Bestimmungen wurden mittlerweile, nach einigen erfolglosen Gesetzesvorschlägen ${ }^{95}$, gelockert: Für Kongressabgeordnete sowie Bürgermeister gilt nun, dass eine (einmalige) Wiederwahl möglich ist. ${ }^{6}$ Ob Beschränkungen der Amtszeit bzw des Mandates ein sinnvolles Mittel im Kampf gegen die Korruption sind, ist umstritten. ${ }^{97}$ Während eine einzige Periode es nicht erlauben mag, ein korruptes Netzwerk aufzubauen, kann bei nur einer Periode die Haltung aufkommen, dass in kurzer Zeit so viel wie möglich in die eigene Tasche gewirtschaftet werden muss, weil die zur Verfügung stehende Zeit kurz ist. ${ }^{98}$ Da kein Grund zum Wahlkampf besteht, kann auch keine potentielle Wählerschaft durch das Verhalten verschreckt werden. Mandatsbeschränkungen können schließlich aber auch dazu führen, dass Wissen verloren geht. ${ }^{99}$

Festzuhalten ist jedenfalls, dass Beschränkungen der Wiederwahl häufiger für die Exekutive (insbesondere den Präsidenten) als für die Legislative verfassungsrechtlich vorgesehen sind.

93 Für eine umfassende Diskussion der Vor- und Nachteile von Amtszeitbeschränkungen der Exekutive, siehe Ginsburg/Elkins/Melton (Fn. 77), $1816 \mathrm{ff}$.

94 Der Hintergrund dieser Bestimmungen war, dass die damals stärkste Kraft, der Partido Nacional Revolucionario, die nationale revolutionäre Partei, sich dadurch eine Schwächung der gegnerischen Parteien erhoffte, siehe dazu Jesús Tovar Mendoza, Condicionantes políticos que impiden la reelección de legisladores en México, Convergencia 52 (2010), 187-206, 189.

95 Tovar Mendoza (Fn. 93), 190 ff. Vgl. dazu auch jüngst Armando Soto Flores, Reflexiones en torno a la reelección de los senadores y diputados del Congreso de la Unión como consequencia de la reforma política: Compromiso del Congreso de la Unión 2012-2018, Revista Mexicana de Derecho Constitucional 31 (2014), 273-284.

96 Siehe Art 59 und Art 115 der mexikanischen Verfassung und die Novelle D. O. F 14.2.2014.

97 Vgl. hierzu auch die Untersuchungen zur Frage, ob korruptes Verhalten dazu führt, dass die Wähler einen bestimmten Politiker nicht mehr wählen, Brian F. Crisp / Santiago Olivella / Joshua d. Potter / William Mishler, Elections as instruments for punishing bad representatives and selecting good ones, Electoral Studies 34 (2014), 1-15, 11 f. Zur Problematik, dass die Wahl „sauberer Politiker" nicht unbedingt zu Reformen im Bereich der Korruptionsbekämpfung führt, siehe Haldun Evrenk, Why a clean politician supports dirty politics: A game-theoretical explanation for the persistence of political corruption, Journal of Economic Behavior \& Organization 80 (2011), 498-510.

98 Susan Rose-Ackerman, Political corruption and democracy, Connecticut Journal of International Law 14 (1999), $363-378,366$.

99 Ginsburg/Elkins/Melton (Fn. 77), $1816 \mathrm{ff}$. 
Für die Gesetzgebung scheint eine zumindest mehrfache Möglichkeit der Wiederwahl der Regelfall zu sein; Amtszeitbeschränkungen für Präsidenten sind, insbesondere in präsidentiellen Systemen, häufig. ${ }^{100}$

Wenngleich in Bezug auf korrupte Verhaltensweisen keinesfalls erwiesen ist, dass das Verbot der Wiederwahl die Wahrscheinlichkeit von Korruption senkt, so wird eines deutlich:

Anders als Mandatsbeschränkungen für Abgeordnete durch einzelne Abgeordnete kaum zu umgehen sind, versuchten und versuchen Präsidenten auf die eine oder andere Weise immer wieder, sich dem Verbot der Wiederwahl zu entziehen und so zu einer weiteren Amtszeit zu kommen. ${ }^{101}$ Dies geschieht durch Verfassungsänderungen, aber auch durch eine entsprechende Interpretation der Verfassung. ${ }^{102}$ Eine solche Interpretation kann vorbeugend durch das Parlament erfolgen, wie es Perus Ex-Präsident Alberto Fujimori ${ }^{103}$ vorgemacht hat. Sie kann aber auch durch ein Verfassungsgericht oder Wahlgerichte geschehen, wie es bis zum Rückzug von Evo Morales in Bolivien der Fall war. ${ }^{104}$

Auch wenn die Beschränkungen der Wiederwahl also umstritten bleiben, so kann damit zumindest eine zeitliche Gewaltenteilung erfolgen. ${ }^{105}$

Für Mexiko jedenfalls haben sich die strengen Verbote der Wiederwahl nicht als Allheilmittel erwiesen. Der Wahlsieg von AMLO zeigt zudem, dass auch der zumindest seiner Rhetorik nach populistische Politiker mit seiner Partei durch Beschränkungen der Wiederwahl nicht am Erfolg gehindert wurde. ${ }^{106}$

\footnotetext{
100 Ginsburg/Elkins/Melton (Fn. 77), 1813.

101 Ginsburg/Elkins/Melton (Fn. 77), $1811 \mathrm{ff}$.

102 Ley No. 26657, kundgemacht am 23. August 1996, mit dem Art 112 der Verfassung von Peru dahingehend interpretiert wurde, dass die Beschränkung der Wiederwahl des Präsidenten so verstanden werden muss, dass nur jene Amtszeiten zählen, die nach Inkrafttreten der Verfassung beginnen.

103 Für einen Überblick über Alberto Fujimoris Präsidentschaft siehe Jo-Marie Burt, An Era of Terror, NACLA Report on the Americas 50 (2018), 272-273; Luis Esteban González Manrique, La democracia ,ilibe$\mathrm{ral}^{\prime}$ de Fujimori: Golpe de Estado permanente, Política Exterior 14 (2000), 12-16; 19-20.

104 Plurinationales Verfassungsgericht Bolivien, 28.11.2017, 20960-2017-42-AIA und Bolivia aprueba postulación de Evo Morales por la reelección, Excelsior 4.12.2008, https://www.excelsior.com.mx/global/boliviaaprueba-postulacion-de-evo-morales-por-la-reeleccion/1282721, 10.6.2019.

105 Vgl. zur temporalen Gewaltenteilung Michael Anderheiden, Gemeinwohl in Republik und Union, 2006, 512.

106 Inwiefern die von AMLO angekündigten Reformen Mexiko zu einer stärkeren Demokratie verhelfen, ist zu diesem Zeitpunkt nicht klar.
} 

2. Fallbeispiel: Chile - Mandatsverlust bei illegaler Finanzierung
als Erfolgsmodell?

Regelungen zur Finanzierung von Parteien und Kampagnen sind deshalb entscheidend, weil Korruption in diesem Bereich den demokratischen Prozess verfälscht. ${ }^{107}$ Nicht nur populistische Führungspersönlichkeiten (aber eben auch diese) sind, insbesondere wenn es um die Wiedererlangung der Macht, oft versucht, mittels Korruption ihrer Beliebtheit oder dem Wahlergebnis nachzuhelfen. ${ }^{108}$

Chile beweist, dass durch den Verbund kluger verfassungsrechtlicher und einfachgesetzlicher Regelungen auch die illegale Wahlkampf- und Parteienfinanzierung eingedämmt werden kann. ${ }^{109}$ Auffällig ist jedenfalls, dass Chile in sozialwissenschaftlichen Untersuchungen über Korruption regelmäßig im lateinamerikanischen Spitzenfeld und gleichauf mit EU-Staaten gereiht wird. ${ }^{.10}$

In puncto Korruptionsbekämpfung kann in Chile - neben einem gelungenen System der Kampagnenfinanzierung ${ }^{111}$ in Kombination mit dem sogenannten binominalen Wahlsystem ${ }^{112}$ - insbesondere Art 60 der Verfassung genannt werden. Art 60 der chilenischen Verfassung bestraft im Fall von illegaler Finanzierung den Abgeordneten selbst und zwar mit dem Verlust seines Mandats. Die Gründe für den Amtsverlust sind relativ streng, sowohl betreffend Bevorzugung bestimmter Personen wie auch in Bezug auf die Beeinflussung der Verwaltung und der Judikative. Darüber hinaus wird auch die illegale Wahlkampffinanzierung mit der Beendigung des Mandats bestraft.

Ein eigenes Kapitel über die Wahlbehörde und die Wahlgerichtsbarkeit ergänzt die Bestimmungen. Art 94 ff legen die Grundzüge des chilenischen wahlbehördlichen und gerichtlichen Systems fest. Die weitere Ausführung erfolgt durch ein organisches Gesetz. Gemeinsam mit einem funktionierenden Justizsystem steht Chile damit im lateinamerikanischen Vergleich verhältnismäßig gut da. ${ }^{113}$

107 Justin Fisher / Todd A. Eisenstadt, Introduction: Comparative Party Finance, Party Politics 10 (2004), 619-626, $619 \mathrm{f}$.

108 Für Lateinamerika sei hier lediglich auf den sogenannten Odebrecht-Skandal verwiesen.

109 Joel W. Johnson, Incumbents without a Campaign Finance Advantage: Competition and Money in Chile's Congressional Elections, Journal of Politics in Latin America 3 (2011), 3-33.

110 Vgl. die Daten vom World Justice Project. http://data.worldjusticeproject.org/, 13.6.2019. Allerdings ist die Ungleichheit nach wie vor ein großes Problem in Lateinamerika, was auch auf Chile zutrifft, siehe zB De Ferranti ua., Inequality in Latin America: Breaking with History? World Bank Latin American and Caribbean Studies, 2004, https://openknowledge.worldbank.org/handle/10986/15009 (10.6.2019).

111 Johnson (Fn. 108), 5 f.

112 Daniel Pastor, Origins of the Chilean Binominal Election System, Rev. cienc. polit. (Santiago) 24 (2004), 38.

113 Vgl. die Freedomhouse Country Reports, Freedomhouse Country Reports. https://freedomhouse. org/report/freedom-world-2018-table-country-scores, 10.6.2019, wo Chile bezüglich Freiheit der Demokratie gleichauf mit Österreich, Deutschland und Spanien liegt. 
3. Fallbeispiel: Peru - Führt „Nichtvertrauen" aufgrund von Korruption zu mehr Populismus?

Ein schwaches Parteiensystem kann Korruption begünstigen. Ein Parteiensystem ist dann schwach, wenn zB Regelungen über Parteien ganz fehlen (dies führt zu Unsicherheit) oder Regelungen so ausgestaltet sind, dass Parteien Schwierigkeiten haben, sich langfristig zu etablieren. ${ }^{114}$ Wenn interne Kontrollmechanismen der Parteien fehlen und Parteien selbst sehr kurzlebig sind, dann kann dies opportunistisches Verhalten fördern bzw können Parteien von Individuen leichter "gekapert" werden. ${ }^{15}$ Umgekehrt kann eine strenge Parteidisziplin auch dazu führen, Bestechungsgelder in die Höhe zu treiben. ${ }^{116}$

Das schwache Parteiensystem Perus fördert nicht nur korrupte Taktiken, sondern auch Populismus. ${ }^{117}$ Resultat des schwachen Parteiensystems ist nämlich ein hoher Grad an Personalisierung, der wiederum Populismus begünstigt. ${ }^{118}$

Beide Probleme sind in Peru eng mit Ex-Präsident Alberto Fujimori verknüpft. ${ }^{119}$ Bald 20 Jahre nach Fujimoris Rücktritt hat Peru noch immer ein riesiges Korruptionsproblem und ist nach wie vor anfällig für populistische politische Taktiken. ${ }^{120}$

Das schwache Parteiensystem ist das Produkt eines entsprechenden Parteiengesetzes, welches das Entstehen einer konsolidierten Parteienstruktur ua dadurch verhinderte, dass auf regionaler Ebene überhaupt keine Parteien gegründet werden konnten. Dadurch konnte sich für die Parteien auf regionaler Ebene keine Basis bilden. Dies erklärt auch die großen Schwankungen bei Wahlerfolgen der Parteien sowie bei den Präsidentschaftswahlen. Das Parteiengesetz fügt sich in entsprechende Wahlgesetze ein, die ebenso zur Schwächung beitragen. ${ }^{121}$

Hinzu kommt, dass die Dezentralisierung, die an sich auch der Demokratisierung Perus hätte dienen sollte, auch zu einer Dezentralisierung der Korruption geführt hat. ${ }^{122}$

114 Petra Schleiter / Alisa M. Voznaya, Party system competitiveness and corruption, Party Politics 20 (2014), 675-686, 676.

115 Walter Little, Corruption and Democracy in Latin America, IDS Bulletin 27 (1996), 64-70, 67

116 Rose-Ackerman (Fn. 97), 366.

117 Steven Levitsky / James Loxton, Populism and competitive authoritarianism in the Andes, Democratization 20 (2013), 107-136, 112.

118 Christoph Heuser, New President, Old Problems: Corruption and Organised Crime Keep Peru in Crisis, GIGA Focus Lateinamerika (2018), 1-14, 5.

119 Heuser (Fn. 117), 2 f.

120 Dies zeigt nicht zuletzt das von Präsidenten Vizcarra erzwungene Referendum, vgl. Bertel (Fn. 70).

121 Martín Tanaka, Situación y perspectivas de lospartidos políticos en la Región Andina: el caso peruano, in: Partidos políticos en la Región Andina, hg. von Idea, 2004, 93-112, 96 f.; Fernando Tuesta Soldevilla, Un voto letal: el voto preferencial y los partidos políticos en el Perú, Politai: Revista de Ciencia Política 4 (2012), $107-118$.

122 Lucia Dammert / Katherine Sarmiento, Corruption, Organized Crime, and Regional Governments in Peru, in: Corruption in Latin America, hg. von Robert I. Rotberg, 2019, 179-204. 
Einzig der Partei von Keiko Fujimori, der Tochter des ehemaligen Präsidenten Alberto Fujimori, gelang es, dieses Vakuum zu füllen und eine gut organisierte Partei, Fuerza Popular, aufzustellen. ${ }^{123}$ Keiko Fujimori und ihre Fuerza Popular polarisieren jedoch. Fast die Hälfte aller Peruaner gab im Präsidentschaftswahlkampf 2016 an, den Antifujimorismo zu unterstützen und auf keinen Fall die Stimme Keiko Fujimori bzw Fuerza Popular zu geben. ${ }^{124}$ So wie alle Präsidenten seit 2001 stolperte nun auch Keiko Fujimori über den sog Odebrecht-Skandal. ${ }^{125}$ Auch sie hatte, so wie viele andere, Geld von der Firma Odebrecht illegalerweise für die Wahlkampffinanzierung angenommen. ${ }^{126}$

Neben dem Odebrecht-Skandal erschütterte im Juli 2018 ein weiterer Korruptionsskandal, dessen Protagonisten als „die weißen Krägen des Hafens “ ${ }^{{ }_{127}}$ eingingen, das Land. ${ }^{128}$ Dieser betraf höchste Justizkreise und führte zu tagelangen Massenprotesten. ${ }^{129}$ Die Korruption hat in Peru damit einen Höchststand erreicht und das Vertrauen, nicht nur in die Justiz und in die staatliche Verwaltung, sondern auch in das Parlament, muss als stark erschüttert bezeichnet werden.

In Verbindung mit dem Odebrecht-Skandal musste auch der Wahlsieger der Präsidentschaftswahl 2016 und der gewählte Präsident Perus, Pedro Pablo Kuczynski (PPK), im März 2018 zurücktreten. ${ }^{130}$ Damit gelangte sein Vizepräsident, Martín Vizcarra, an die Staatsspitze. Vizcarra steht (bislang) für tiefgreifende Reformen, über die er das Volk in einem Referendum im Dezember 2018 abstimmen ließ.131 Die Reformen betreffen ua das Parteiensystem sowie die Finanzierung der Parteien. ${ }^{132}$

Peru zeigt auch, wie sich ein bestimmtes Verfassungsdesign ungünstig auswirken kann. Zwar hat der peruanische Präsident eine relativ starke Stellung; das verfassungsrechtliche System erlaubt es jedoch, dass der Präsident ohne parlamentarische Mehrheit im Parlament regiert. Aufgrund der Möglichkeit des Parlaments, die Regierung 123 Alberto Vergara, Virtue, Fortune, and Failure in Peru, Journal of Democracy 29 (2018), 65-76, 66.
124 Ivan Lanegra, ¿El neoliberalismo sin fin?, Nueva Sociedad (2016), 19-27, 23.
125 Siehe dazu Francisco Durand, The Odebrecht Tsunami, NACLA Report on the Americas 51 (2019),
146-152; Nicolás Campos / Eduardo Engel / Ronald D. Fischer / Alexander Galetovic, Renegotiations and
Corruption in Infrastructure: The Odebrecht Case, https://www.economia.unipd.it/sites/economia.unipd.
it/files/20190230.pdf, April 2019, 10.6.2019.

126 Heuser (Fn. 117), 5 f.

127 „Los cuellos blancos del puerto“, vgl. hierzu Redacción EC, Los Cuellos Blancos del Puerto: el organigrama de la banda, El Comercio 13.8.2018, https://elcomercio.pe/politica/cuellos-blancos-puerto-orga nigrama-presunta-organizacion-criminal-incluye-antonio-camayo-noticia-541302, 10.6.2019.

$128 \mathrm{Zu}$ den Entwicklungen 2018 siehe Maria Bertel / César Landa Arroyo / Luis Angel López Zamora, Peru, in: 2018 Global Review of Constitutional Law, Peru, in: The I.CONnect-Clough Center 2018 Global Review of Constitutional Law, hg. von Richard Albert / David Landau / Pietro Faraguna / Simon Drugda, 2019, $229 \mathrm{ff}$. 129 César R. Nureña / Federico Helfgott, Rings of Corruption in Peru, NACLA Report on the Americas 51 (2019), 167-173, 168 .

130 Vergara (Fn. 123), 65 .

131 Bertel (Fn. 70).

132 Martín Tanaka, The Drive to Reform Peru's Judicial and Political System: Opportunistic and Incompatible? http://constitutionnet.org/news/drive-reform-perus-judicial-and-political-system-opportunistic -and-incompatible, 10.6.2019. 
des Präsidenten durch die Vertrauensfrage zu stürzen und in einem letzten Schritt dadurch Neuwahlen zu erzwingen, kann es zu Machtkämpfen zwischen dem Parlament und dem Präsidenten kommen. ${ }^{133}$ Präsident Vizcarra muss, macht er von seinem gemäß Art 107 der peruanischen Verfassung gewährleisteten Recht, Gesetze zu initiieren Gebrauch und möchte er, dass seine Initiative erfolgreich ist, entsprechende Mehrheiten im Parlament finden. Er hat nämlich keine Mehrheit im Kongress. Da dies wegen der Kräfteverhältnisse schwierig ist, sah sich Martin Vizcarra veranlasst, ein Referendum über die Reformen in seiner Rede an die Nation am 28. Juli 2018 anzukündigen. ${ }^{134}$ Dadurch ging Vizcarra in populistischer Manier ein Bündnis mit dem Volk ein. Das Parlament sah sich gezwungen, das Referendum nicht zu blockieren, sondern zuzulassen. ${ }^{135}$ Nicht ohne freilich die entsprechenden Vorschläge zu modifizieren, was dazu führte, dass Martin Vizcarra der Bevölkerung empfahl, nur für drei von vier Reformen zu stimmen, ${ }^{136}$ was sich im Ergebnis des Referendums widerspiegelte. ${ }^{137}$ Auch hier zeigt sich das Bündnis, das Vizcarra mit der Bevölkerung eingegangen ist. Diese Verbindung mit dem Volk, am Kongress vorbei, ist eine populistische Strategie. Zugutehalten muss man Präsident Vizcarra, dass durch diese Strategie und das daraus resultierende Referendum schon längst fällige Reformen angestoßen wurden.

Solange damit Änderungen erreicht werden, die die Demokratie stärken, kann sich dies positiv auf die Demokratie auswirken; dies wird aber aktuell teilweise angezweifelt. ${ }^{138}$

Kritisch ist sicherlich die Dimension des Machterhalts. Diese Unsicherheit hat sich darin ausgedrückt, dass angezweifelt wurde, ob Präsident Vizcarra nach Ablauf der Amtszeit aus dem Amt scheiden würde oder aber, ob er versuchen würde, bei den nächsten Wahlen anzutreten. Die Unsicherheit ergibt sich aus einer vagen Formulierung in der peruanischen Verfassung. Art 112 der peruanischen Verfassung sieht ein Verbot der unmittelbaren Wiederwahl (reelección) des Präsidenten vor. Weil Präsident Vizcarra nicht gewählt wurde (sondern als Ersatz für PPK eingesetzt wurde), wird nun in der peruanischen Diskussion teilweise vertreten, dass Vizcarra 2021 kandidieren könnte. ${ }^{139}$

133 Dan Collyns, Peru's president in high-stakes gamble to push through anti-corruption reforms, The Guardian 19.9.2018, https://www.theguardian.com/world/2018/sep/18/martin-vizcarra-peru-anti-corruption -measure-reform, 10.6.2019.

134 Tanaka (Fn. 131).

135 Es ist umstritten, ob Vizcarra aus verfassungsrechtlicher Sicht dazu befugt war, ein Referendum anzusetzen, vgl. Bertel (Fn. 70).

136 Dan Collyns, Scandal-plagued Peru to vote on reshaping political system, The Guardian 9.12.2018, https://www.theguardian.com/world/2018/dec/o9/peru-referendum-corruption-scandal-judiciary-poli tics, 10.6.2019.

137 Resolución $\mathrm{N}^{\circ}$ 0002-2019-JNE.

138 Tanaka (Fn. 131).

139 Maritza Espinoza, Patricia Donayre: Vizcarra podría postular a la presidencia el 2021, La República 22.4.2018, https://larepublica.pe/domingo/1231033-vizcarra-podria-postular-a-la-presidencia-el-2021, 
Der Machtkampf zwischen Legislative und Judikative gipfelte Ende September 2019 in der Auflösung des Parlaments und der Festsetzung von Neuwahlen für Januar 2020 durch Präsident Vizcarra. Das Parlament wiederum suspendierte daraufhin Vizcarra. Der Hintergrund der neuerlichen Krise ist die anstehende Besetzung von Richterstellen am Verfassungsgericht, welches in den nächsten Monaten die Freilassung von Keiko Fujimori verhandeln wird. ${ }^{140}$

Letztlich illustriert das peruanische Beispiel eines der größten Probleme von Korruption, nämlich das der apathischen Wähler. Durch den völligen Verlust des Vertrauens in das politische System im Allgemeinen („Nichtvertrauen“) und im Speziellen darauf, dass ein Wechsel der handelnden Personen in Ämtern eine Änderung herbeiführt, entsteht eine Demokratieverdrossenheit, die sich in sinkender Beteiligung äuBern kann. ${ }^{141}$

Der Ausblick in die Zukunft ist damit alles andere als rosig, denn die Kombination aus Korruption und schwachen Institutionen könnte dazu führen, dass ein populistischer Kandidat bei den kommenden Präsidentschaftswahlen 2021 das Rennen macht. $^{142}$

\section{Resümee}

Theorie und Praxis zeigen, dass die Verbindungen zwischen Demokratie, Korruption und Populismus vielschichtig und komplex sind. Speziell vor dem Hintergrund der veränderten Bedingungen für die Demokratie ${ }^{143}$ und dem vielfach beklagten demokratischen Rückbau scheint die Bekämpfung von Korruption wichtiger denn je. Dies zeigen auch die lateinamerikanischen Beispiele. Insbesondere Peru macht deutlich, dass das Nichtvertrauen der Bevölkerung gefährliche Ausmaße für die Demokratie erreicht hat.

Die Demokratie mag ein gewisses Maß an Korruption aushalten. Kommt zur Korruption Populismus hinzu, so kann Korruption dem Populismus zu noch mehr Auftrieb verhelfen. Glaubwürdige legislative Maßnahmen gegen die Korruption und eine entsprechende Durchsetzung helfen, das grundsätzliche Vertrauen des Wahlvolks in

\footnotetext{
10.6.2019; Pablo de Jesús Carranza, Vizcarra no puede postular en 2021, Expreso 28.1.2019, https://www. expreso.com.pe/politica/vizcarra-no-puede-postular-en-2021/, 10.6.2019.

140 Perus Präsident löst überraschend das Parlament auf, Zeit Online 1.10.2019, https://www.zeit.de/poli tik/ausland/2019-10/martin-vizcarra-peru-machtkampf-parlament-praesident-opposition, 8.10.2019 und Perus Präsident löst Kongress auf, Spiegel Online 1.10.2019, https://www.spiegel.de/politik/ausland/peru-prae sident-martin-vizcarra-loest-parlament-auf-a-1289429.html, 8.10.2019.

141 Tatiana Kostadinova, Abstain or Rebel: Corruption Perceptions and Voting in East European Elections, Politics \& Policy 37 (2009), 691-714, 696.

142 Heuser (Fn. 117), 10.

143 Vgl. hierzu den Beitrag von Schmid in dieser Ausgabe.
} 
die Demokratie herzustellen bzw zu verstärken. Nur auf einer solchen Basis kann die Bevölkerung den demokratischen Prozessen mit einem gesunden Misstrauen begegnen, die für eine Demokratie notwendig sind.

Montesquieus Diktum, dass die Republik Spaltung benötigt, scheint auch heute bestätigt. Nicht zuletzt das Misstrauen hilft, dass die Bevölkerung wachsam bleibt. Doch Montesquieu verweist auch schon darauf, dass neben der Bevölkerung auch der Gesetzgeber tätig werden muss. Denn, so Montesquieu: „Es gibt zwei Arten der Verderbniß; eine, wenn das Volk die Gesetze durchaus nicht beobachtet; die andre, wenn es durch die Gesetze verdorben ist: ein unheilbares Uebel, weil es im Heilmittel selbst steckt. ${ }^{\text {"144 }}$

144 Charles Louis de Secondat de Montesquieu (Fn. 12), Sechstes Buch, Zwölftes Kapitel. 

VII. Epilog 



\title{
Seid jetzt wachsam
}

\author{
HEINZ FISCHER
}

Herzlichen Dank für die Einladung bei der diesjährigen Tagung des Jungen Forums Rechtsphilosophie an der Universität Salzburg, die der Krise des demokratischen Rechtsstaates im 21. Jahrhundert gewidmet ist, den Festvortrag zu halten. ${ }^{1}$

Unter einem demokratischen Rechtsstaat verstehe ich einen Staat, der sich zu Menschenrechten und zur Menschenwürde bekennt und dessen Agieren auf Normen beruht, die von direkt oder indirekt demokratisch legitimierten Organen geschaffen wurden, wobei deren Einhaltung der Kontrolle durch eine unabhängige Gerichtsbarkeit unterliegt.

Haben wir einen solchen demokratischen Rechtsstaat?

Oder ist das ein Ideal, das an vielerlei Realitäten scheitert und auch in Zukunft nie umfassend verwirklicht werden kann?

Oder hatten wir in der 2. Hälfte des 20. Jahrhunderts einen demokratischen Rechtsstaat schon weitgehend verwirklicht, der aber zu Beginn des 21. Jahrhunderts in eine Krise zu geraten droht?

Das sind Fragen, mit denen ich mich beschäftigen möchte.

Wenn es um Recht, Macht, Demokratie oder Rechtsstaat geht, kann man leider - zum Unterschied von der Physik - nicht in Zentimeter, Gramm oder Sekunden messen und daher auch keine Aussagen mit mathematischer Präzision treffen.

Aber wir können Systeme beschreiben, Tendenzen analysieren und aus Fehlentscheidungen lernen.

1 Eine gekürzte Fassung der Festrede ist am 8. Mai 2019 im Falter erschienen. 
Und da sich dieser Sammelband in interdisziplinärer Weise auch mit der historischen Dimension dieses Themas beschäftigt, darf ich darauf verweisen, dass der demokratische Rechtsstaat ein spätes, ein relativ junges Produkt in der Menschheitsgeschichte ist.

Im Zusammenleben der Menschen spielt Macht - von allem Anfang an und bis heute - eine dominierende Rolle. Und die Verteilung der Macht war beeinflusst von physischer, intellektueller und ökonomischer Stärke, sowie von weiteren Faktoren, die sich daraus ableiten wie zum Beispiel Organisationstalent, militärische Stärke oder Lebenserfahrung.

Der Macht inhärent ist bekanntlich die Tendenz zur Akkumulation der Macht bis hin zu jenem Punkt, wo eine zu große Machtkonzentration in der Hand einer Person oder einer kleinen Gruppe existiert und wo entsprechend große Machtdefizite bei den Machtunterworfenen bestehen.

Überschreitet die dadurch geschaffene Situation die Grenzen des Erträglichen, dann kann es zum Machtkampf und zum Umsturz der Machtverhältnisse kommen.

Eine Veränderung der Machtverhältnisse kann aber auch das Ergebnis von Verhandlungen sein, also auf Vertrag und friedlicher Übereinkunft beruhen.

Mit solchen groben Pinselstrichen kann man die Entwicklung und die Veränderung bei der Verteilung der Macht durch Jahrhunderte hindurch beschreiben.

Es war vor allem die Aufklärung des 17. und 18. Jahrhunderts, die nach gravierenden Veränderungen des Weltbildes und des Menschenbildes den Grundgedanken entwickelte, dass alle Menschen gleich an Rechten und Würde geboren sind, wobei aber diese Einsicht in der Realität zunächst durch Klassenunterschiede, durch eine ständische Gesellschaft und durch ein von vielen als gottgegeben und unveränderlich betrachtetes hierarchisches System nach dem Motto Kaiser - König - Edelmann - Bürger Bauer - Bettelmann verschüttet und blockiert war.

Die Konsequenzen, die daraus in weiterer Folge gezogen wurden und die Texte, die gegen Ende des 18. Jahrhunderts im Laufe der französischen Revolution aber auch im Zusammenhang mit der amerikanischen Unabhängigkeitserklärung formuliert wurden, muss ich hier nicht im Einzelnen referieren.

Wichtige Schritte zur Umsetzung dieser Gedanken in die Realität erfolgten in den weiter fortgeschrittenen Teilen Europas im 19. Jahrhundert.

Zwischen 1848 und 1868 liegen nur 20 Jahre und doch wurde in diesen zwei Jahrzehnten in Österreich der weite Weg von der Niederschlagung der Revolution des Jahr 1848 und der anschließenden Restauration bis zu den Staatsgrundgesetzen vom Dezember 1867 mit ihrem dauerhaften Katalog an Grund und Freiheitsrechten zurückgelegt.

Und zwischen 1889 und 1919 liegen nur 30 Jahre und in diesen 30 Jahren wurde der ebenso weite Weg von der Gründung der Sozialdemokratischen Arbeiter Partei in Hainfeld bis zu ihrer Rolle als stärkste Parlamentspartei bei den Wahlen in die kons- 
tituierende Nationalversammlung der jungen Republik Deutsch-Österreich im Feber 1919 zurückgelegt.

Ähnliches galt für die Christlich-Sozialen, die im Jahr 1887 gegründet wurden und 33 Jahre nach ihrer Gründung, nämlich bei den Wahlen im Oktober 1920 die Rolle als stärkste Partei im österreichischen Nationalrat erlangten. Man sieht daraus, wie rasch sich politische Veränderungen und damit Veränderungen in der Machtverteilung beziehungsweise in der politischen Orientierung der Bevölkerung durchsetzen können und auch heute befinden wir uns in einer Phase rascher Veränderungen.

Jedenfalls war das Modell der rechtsstaatlichen Demokratie zum Zeitpunkt der Gründung der Republik Österreich, also vor 100 Jahren, im Wesentlichen akzeptiert und wurde auch im Verfassungstext von 1920 niedergeschrieben, aber die Demokratie war offenbar noch stark unterentwickelt und ungewohnt.

So viel zur Vorgeschichte.

Was die Gegenwart betrifft stelle ich zunächst die Frage, ob die Demokratie, wenn sie einmal etabliert ist als dauerhaft oder gar irreversibel betrachtet werden kann.

Dass sie nicht unzerstörbar ist, wurde uns in Österreich in der ersten Republik aber nicht nur in Österreich - drastisch vor Augen geführt. Schlagwortartige Erkenntnisse aus dieser Zeit lauten zum Beispiel: 1) Die Demokratie braucht auch eine Demokratiegesinnung, also Demokraten, die die Demokratie tatsächlich wollen und auch bereit sind, Kontrolle zu akzeptieren und Macht wieder abzugeben.

2) Sie braucht ein gewisses Mindestmaß an sozialer Stabilität und sozialer Gerechtigkeit, um allzu große ökonomische, soziale und damit auch politische Erschütterungen zu vermeiden.

3) Die Demokratie kann auch durch Ermüdungserscheinungen Schaden nehmen, wenn der berühmte Satz des französischen Staatsmannes Édouard Herriot nicht berücksichtigt wird, welcher lautet: „Wer die Demokratie stabil halten will, muss sie in Bewegung halten“.

Ich habe mir manchmal erlaubt ein Beispiel aus der Pflanzenwelt heranzuziehen und die Demokratie bzw. den demokratischen Rechtsstaat mit einem Baum zu vergleichen: Der Baum ist ein Symbol der Festigkeit in der Pflanzenwelt, der in der Regel auch Kälte, Wind und Wetter überdauert. Aber er ist nicht unzerstörbar: Wenn der Sturm zum Orkan wird, wenn der Borkenkäfer überhandnimmt, wenn sich ein Feuer ausbreitet etc. kann auch ein Baum mit festen Wurzeln in Gefahr geraten. Dessen müssen wir uns bewusst sein.

Was kann man also vor diesem Hintergrund zum Thema Krise der Demokratie und des demokratischen Rechtsstaats im 21. Jahrhundert sagen?

Mein Befund lautet, dass sich die Demokratie in den sieben Jahrzehnten nach 1945 in vielen Teilen Europas und auch über Europa hinaus gut entwickelt hat. Die Zahl der 
demokratisch regierten Staaten ist größer geworden, die Zahl der Diktaturen und Einparteiensysteme entsprechend kleiner.

1989 war diesbezüglich ein besonders markantes Jahr.

Und auch die Qualität der einzelnen Demokratien hat sich meines Erachtens über Jahrzehnte hinweg - obwohl das schwer zu messen ist - vielfach gut entwickelt, wobei sich die Demokratie meiner Meinung nach dem demokratischen Ideal immer nur annähern, dieses aber niemals vollkommen erreichen kann. Es wird nie eine perfekte Demokratie geben - um ein berühmtes Diktum von Winston Churchill etwas milder zu formulieren.

Dennoch muss man sich heute die Frage stellen, ob wir nicht seit der Jahrhundertwende und insbesondere in jüngster Zeit eine Tendenzwende in Bezug auf die Entwicklung unserer rechtsstaatlichen Demokratie erleben, wobei ich naheliegender Weise ein besonderes Augenmerk auf Österreich richte, aber hinzufügen muss, dass ähnliche Phänomene auch in anderen europäischen Staaten und in der Europäischen Union als Ganzes zu beobachten sind.

Lassen Sie mich einige Themen oder Fakten benennen, die bei der Erörterung des Gefährdungspotentials für den demokratischen Rechtsstaat nicht unbeachtet bleiben sollen.

1) Es ist ein unbestreitbares und nachweisbares Faktum, dass unsere junge und wiederaufgebaute Demokratie in den ersten Jahren nach dem Ende von Krieg und Diktatur, also in den ersten Jahren nach 1945, aus verschiedenen Gründen zwar noch schwach und unterentwickelt war, aber dennoch von der Bevölkerung sehr positiv gesehen und empfunden wurde; und zwar deshalb, weil in der ersten Phase der zweiten Republik auch eine noch im Aufbau befindliche Demokratie vor dem Hintergrund von Krieg, Terror und NS Diktatur als enormer Fortschritt und als riesiger Sprung in das Reich der Freiheit empfunden wurde. Diesen „Stimmungsbonus“ hat unsere Demokratie in der Zwischenzeit eingebüßt.

2) In der österreichischen Bundesverfassung ist zu Recht verankert, dass die Existenz und Vielfalt demokratischer, politischer Parteien ein unverzichtbarer Bestandteil unseres parlamentarisch-demokratischen Systems ist. Meines Erachtens kann aber kein Zweifel daran bestehen, dass die Bedeutung der politischen Parteien in Österreich und auch in anderen europäischen Staaten zuletzt deutlich zurückgegangen ist und wahrscheinlich weiter zurückgehen wird; angesichts der engen Vernetzung zwischen der Funktionsweise der parlamentarischen Demokratie und der Rolle der politischen Parteien bedeutet das, dass eine Schwächung beziehungsweise Zersplitterung der politischen Parteien auch an der Substanz der parlamentarischen Demokratie zehrt.

3) Zum Teil hängt das auch mit der Mediatisierung unserer Gesellschaft zusammen. Im 20. Jahrhundert hatten die Parteien und deren Repräsentanten einen entscheidenden Einfluss auf die Information und die politische Orientierung ihrer Mitglieder und Wähler. In dem Maße, in dem heute jede Bürgerin und jeder Bürger Zugang zu einer unendlichen Vielfalt an Informationen aus dem Netz hat und davon auch Gebrauch 
macht - was viele positiven Seiten hat - reduziert sich auf der anderen Seite die Bedeutung der politischen Parteien als Teil des Informationssystems. Sie können auch ihren verfassungsgesetzlichen Auftrag, nämlich eine Vielzahl von Meinungen und Standpunkten zu „abstimmbaren Alternativen“ zusammenzufassen, weniger wirksam erfüllen. Ihre programmatische Führungsrolle wird schwächer. In dieses Vakuum dringen neue politische Bewegungen ein.

Der Kampf um die politische Hegemonie findet somit teilweise auf neuen und vielfach noch wenig erprobten Spielfeldern statt.

4) Ein weiteres allerdings ganz anderes Problem, das eine Gefahr für unsere rechtsstaatliche Demokratie darstellt, ist das Anwachsen beziehungsweise Wiedererstarken von nationalistischen Tendenzen und Vorurteilen, was v. a. zu einer Spaltung innerhalb der Gesellschaft und auch zwischen den Staaten führt.

Ich habe schon eingangs erwähnt, dass unserer Demokratie ein auf Gleichwertigkeit und gleicher Menschenwürde beruhendes Menschenbild zu Grunde liegt. Ein Neo-Nationalismus, der in Widerspruch zu diesem Menschenbild die Menschen nach nationalen und ethnischen Kriterien in Wir und die Anderen aufteilt und spaltet, wobei die Anderen de facto und de jure als minderen Rechtes betrachtet werden (was Flüchtlinge und Asylsuchende hautnah zu spüren bekommen), ist eine Gefahr für Demokratie und Rechtsstaat.

5) Es würde noch etwas fehlen, wenn ich nicht auch versuche auf das Thema Populismus und direkte Demokratie einzugehen.

Demos auf Griechisch und Populus auf Lateinisch bedeuten - wie Sie wissen - im Wesentlichen das Gleiche. Rein sprachlich könnte man daher behaupten, dass die Herrschaft des Volkes (also Demokratie) und Populismus wesensgleich sind und bestens harmonieren.

Das ist aber nicht der Fall.

Das Wesen der Demokratie lässt sich eben nicht auf das Prinzip reduzieren, dass am besten alle über alles entscheiden sollen.

Sie wissen, wie viele Spielregeln, Kontrollmechanismen und Korrekturmöglichkeiten aus guten Gründen in das parlamentarische System eingebaut sein müssen und wie viele Minderheitsrechte notwendig sind, um eine schwarz-weiß Demokratie, die sich auch bei komplexen Sachverhalten auf ja/nein Entscheidungen reduziert, zu vermeiden.

In einem solchen differenzierten parlamentarischen System haben auch Elemente der direkten Demokratie als Ergänzung ihren Platz, etwa in der Weise, wie das die österreichische Bundesverfassung vorsieht:

1) z. B. in der Institution des Volksbegehrens,

2) bei obligatorischen Volksabstimmungen über grundlegende Verfassungsänderungen,

3) bei fakultativen Volksabstimmungen über Gesetzesbeschlüsse des Nationalrates 
4) oder bei Volksbefragungen über eine vom Nationalrat formulierte Fragestellung aus dem Kompetenzbereich der Bundesgesetzgebung.

Was ich hingegen nach sorgfältiger Überlegung ablehne ist, dass jede außerparlamentarische Gruppierung oder Lobby versuchen kann eine Volksabstimmung über den Kopf einer gewählten parlamentarischen Körperschaft hinweg zu erzwingen indem von einer solchen Gruppierung ein bestimmter Text oder eine bestimmte Fragestellung formuliert wird, dann Unterschriften für eine Abstimmung gesammelt werden und wenn eine Mindestzahl von Unterschriften erreicht wird (z.B. 10\% der Wahlberechtigten), dann muss eine Volksabstimmung über diese Fragestellung oder über diesen Gesetzestext stattfinden. Damit könnte einem medienunterstützten Populismus und Lobbyismus Tür und Tor geöffnet werden, schützenswerte Minderheiten könnten oft auf der Strecke bleiben und eine Berücksichtigung neuer Argumente oder Einwendungen ist bei dieser Prozedur ohne Zustimmung der Initiatoren nicht mehr möglich - selbst wenn das von einer Mehrheit des Nationalrates gewünscht wird.

Es fällt mir schwer in diesem Zusammenhang nicht auch das Stichwort Brexit in den Mund zu nehmen, wobei ich klarstellen möchte, dass der Beitritt eines Landes zur EU oder der Austritt aus der EU natürlich ein Thema für ein Referendum sein kann und sogar sein soll, aber eben auf der Basis einer vom Parlament ausgearbeiteten Fragestellung.

Das alles sind Themen, die bei der Analyse, ob es eine Krise des demokratischen Rechtsstaates gibt, primär das Segment „Demokratie“ betreffen.

Daher soll jetzt auch dem rechtsstaatlichen Aspekt noch zusätzliche Aufmerksamkeit gewidmet werden.

Und da gelange ich zum Ergebnis, dass sich auch der Rechtsstaat in Österreich und in vielen anderen Staaten Europas in den letzten Jahrzehnten gut entwickelt hat.

1) Der Stellenwert und das Selbstbewusstsein der Justiz ist stabil und sogar im Wachsen.

2) Die Öffentlichkeit ist gegenüber dem Versuch einer parteipolitischen Einflussnahme auf die Justiz sensibler geworden.

3) Das rechtsstaatliche Netz ist insgesamt dichter geworden, nicht zuletzt auch durch Instanzen der Gerichtsbarkeit auf europäischer Ebene.

4) Und der Vorwurf der Klassenjustiz, der in der Zwischenkriegszeit in manchen Staaten Europas eine große Rolle gespielt hat, hat in erfreulicher Weise an Relevanz verloren.

Dennoch dürfen wir nicht blind sein für die bekannten und gravierenden Rechtsstaatsprobleme in Ungarn, Polen, Rumänien und anderen EU-Staaten und müssen hellhörig sein für bestimmte Signale aus der jüngsten Vergangenheit, die auch in Österreich vor Gefahren für den Rechtsstaat warnen und sei es „nur“ eine finanzielle Unterdotierung des Rechtsstaates. 
Ich habe mich oft und intensiv mit der Frage beschäftigt, ob die Menschen in der Lage sind, aus der Geschichte zu lernen. Dazu gibt es bekanntlich sehr unterschiedliche Meinungen.

Wenn ich die jüngere Geschichte Europas analysiere, dann erscheint es mir eindeutig, dass jene Generationen, die den zweiten Weltkrieg und den Nationalsozialismus noch bewusst erlebt haben, für den Aufbau und Ausbau von Demokratie und Rechtsstaat im Nachkriegs-Europa enorm viel aus der Geschichte vor 1945 gelernt haben. Das ist unübersehbar.

Ich gewinne aber auch immer mehr den Eindruck, dass diese Lehren aus der Geschichte nicht zeitlich unbegrenzt anhalten.

Lehren aus der Geschichte hatten und haben zwar starken und nachhaltigen Einfluss, aber sie beginnen sich zu verflüchtigen, sobald jene Menschen und jene Generationen, die aus der Geschichte gelernt haben (und lernen müssten) aus unserem Kreis ausscheiden, bzw. ausgeschieden sind.

Das ist für mich ein wichtiger Teil zur Erklärung des vorhin erwähnten Phänomens, dass nationalistische Ideologien sowie rechtsextreme und rechtsstaats-feindliche Positionen wieder an Einfluss gewinnen; und es ist auch eine Erklärung dafür, wieso es eine wachsende Gefahr gibt, dass mit Errungenschaften des demokratischen Rechtsstaates neuerdings fahrlässig oder zumindest leichtfertig umgegangen wird:

1) Es gibt heute in Europa Staaten, wo der Begriff einer liberalen pluralistischen Demokratie, wie sie sich auch Karl Popper gewünscht hat, nicht mehr als positiv eingeschätzt wird, sondern bei der Staatsführung und deren Anhängern negativ besetzt ist und wo sich autoritäre Führungsmodelle immer mehr durchsetzen.

2) Es gibt auch in manchen Staaten plumpe oder weniger plumpe Versuche den jeweiligen Verfassungsgerichtshof politisch unter Kontrolle zu bringen. Der Europäische Gerichtshof hat dazu klare Feststellungen getroffen.

3) Alarmierend ist auch die These eines ehemaligen Mitgliedes der österreichischen Bundesregierung wonach „das Recht der Politik zu folgen hat und nicht die Politik dem Recht“.

Sehr wohl muss in einem Rechtsstaat die Politik - also die Gesamtheit aller politischen Handlungen - dem Recht folgen. Man kann es sogar noch schärfer formulieren: jeder Politiker, jede Politikerin und auch die Politik als Ganzes ist dem Recht unterworfen (!). Dem Recht nicht zu folgen bedeutet Rechtsbruch.

Gleichzeitig ist es ein Charakteristikum des demokratischen Rechtsstaates, dass es genau vorgeschriebene Prozeduren gibt, die eingehalten werden müssen, wenn man eine Veränderung der Rechtslage anstrebt.

Aber auch bei einer Änderung des Rechts und der Rechtslage ist die Politik nicht im rechtsfreien Raum unterwegs, sondern gleichfalls an rechtliche Normen gebunden. Darüber hinaus ist die gesamte staatliche Verwaltung und daher auch die Tätigkeit aller Regierungsmitglieder an das Recht gebunden. 
Die Antwort auf die Frage, ob die Politik dem Recht folgen muss oder das Recht der Politik, markiert daher nicht weniger als den Unterschied zwischen einem Rechtsstaat und einem autoritären politischen System.

In diesem Zusammenhang ist es auch bemerkenswert, dass es in Österreich Versuchsballone gibt, ob man nicht die richterliche Kontrolle über die Verhängung der Haft zurückdrängen könnte, indem bei Flüchtlingen - und nur bei Flüchtlingen - die Verhängung einer Sicherungshaft bei vermuteter Gefährlichkeit durch die Verwaltungsbehörde ermöglicht werden soll.

Mir erscheint die Idee, dass es beim Thema Haft einerseits für Flüchtlinge und andererseits für alle anderen Menschen zwei verschiedene Kategorien des Rechtsschutzes geben soll, ziemlich entlarvend. Dazu hat der Präsident der Wiener Rechtanwaltskammer Dr. Enzinger kürzlich dankenswerter Weise sehr klar und deutlich Stellung genommen.

Es ist unübersehbar, dass eine (ehemalige) österreichische Regierungspartei mit dem Satz „Alle Menschen sind gleich an Rechten und Würde geboren“ große Probleme hat.

Auch ein ganz anderes Faktum, nämlich die Tatsache, dass Österreich beim Ranking betreffend den Schutz der Pressefreiheit und der pluralistischen Unabhängigkeit in jüngster Zeit vom 11. auf den 16. Platz zurückgefallen ist, muss Besorgnis auslösen.

Lassen sie mich das Gesagte in folgender Weise zusammenfassen: In Österreich und in den meisten anderen Mitgliedstaaten der Europäischen Union ist das System der rechtsstaatlichen parlamentarischen Demokratie nach wie vor das vorherrschende und mit großer Mehrheit bejahte Regierungsmodell.

In der praktischen Durchführung gibt es aber doch beträchtliche Unterschiede im Rechtsstaats- und Demokratieverständnis.

Und was die jüngste Entwicklung in Österreich betrifft, wird jedenfalls eine stärkere politische Polarisierung und Spaltung in Kauf genommen. Die Dominanz der Regierung gegenüber dem Parlament und der Regierungseinfluss auf parlamentarische Prozeduren ist im Wachsen. Versuche, ein gründliches parlamentarisches Verfahren, das dem Austausch von Argumenten und Gegenargumenten dient, sowie der Einholung außerparlamentarischer Expertise, wie z. B. durch ein umfassendes Begutachtungsverfahren in bestimmten Fällen, auf ein Mindestmaß zu reduzieren, sind unübersehbar. Der schon als überwunden betrachtete und für eine gute und korrekte parlamentarische Arbeit schädliche Grundsatz „SPEED KILLS“ kommt wieder in Mode.

Es wird somit Aufgabe der Öffentlichkeit, kritischer Medien und der einschlägigen wissenschaftlichen Disziplinen sein, die weiteren Entwicklungen auf diesem Gebiet genau zu beobachten und entsprechend zu reagieren. 


\section{Herausgeber*innen und Autor*innen}

Dr. iur., Kristin Y. Albrecht

Kristin Y. Albrecht ist Senior Scientist an der Rechtswissenschaftlichen Fakultät der Paris Lodron Universität Salzburg. Nach dem Studium der Rechtswissenschaften an der Ruprecht-Karls-Universität Heidelberg wurde sie an der Universität Salzburg zum Thema „Fiktionen im Recht“ (Nomos 2020) promoviert. Ihre Forschungsschwerpunkte liegen in der Rechtsphilosophie und den Grundlagen des öffentlichen Rechts.

Fachbereichsteil Rechts- und Sozialphilosophie, Fachbereich Sozial- und Wirtschaftswissenschaften, Rechtswissenschaftliche Fakultät, Paris Lodron Universität Salzburg, Churfürststraße 1, 5020 Salzburg. Kontakt: kristin.albrecht@sbg.ac.at

Dr., Maria Bertel, BA.

Maria Bertel ist Elise-Richter-Stelleninhaberin (FWF) am Institut für Öffentliches Recht, Staats- und Verwaltungslehre der Universität Innsbruck. Ihre Forschungsschwerpunkte liegen im Verfassungs- und Verwaltungsrecht sowie in der Verfassungsvergleichung (insbes. Lateinamerika). In ihrem Habilitationsprojekt beschäftigt sie sich mit dem Effizienzprinzip der österreichischen Verfassung. Maria Bertel studierte Rechtswissenschaften (Dr.) in Innsbruck und Dijon sowie Philosophie in Innsbruck (bakk.phil.). Neben Forschungsaufenthalten in Lateinamerika war sie von Mai 2018 bis April 2019 als Research Fellow an der Central European University in Budapest tätig.

Institut für Öffentliches Recht, Staats- und Verwaltungslehre, Universität Innsbruck, Innrain 52d, 6020 Innsbruck. Kontakt: maria.bertel@uibk.ac.at

\section{Dr., Bruno Buonicore}

Bruno Tadeu Buonicore ist am Obersten Gerichtshof Brasiliens tätig. Parallel dazu ist er Professor für Strafrecht an der Katholischen Universität von Brasilia. Bruno Tadeu Buonicore hat 2019 an der Universität Frankfurt promoviert und arbeitet im Bereich Strafrecht und Rechtsphilosophie. Er ist Autor des Buches „Freiheit und Schuld als Anerkennung“ (Vittorio Klostermann 2020).Kontakt: bruno.buonicore@gmail.com 
Sebastian Enghofer, M. A.

Sebastian Enghofer arbeitet als wissenschaftlicher Mitarbeiter am Lehrstuhl für Vergleichende Politikwissenschaft (Schwerpunkt Westeuropa) der Universität Regensburg. Nach dem Studium der Kriminologie und Gewaltforschung sowie Demokratiewissenschaft promoviert er derzeit zu verhaltensbasierten Policy-Instrumenten (Nudging) als Mittel der Kriminalitätsprävention. In seiner Forschung beschäftigt er sich dabei vor allem mit der Transformation von Gewalt und der interdisziplinären Betrachtung von politischem Extremismus aus psychologischer, kriminologischer und politikwissenschaftlicher Perspektive.

Institut für Politikwissenschaft, Lehrstuhl für Vergleichende Regierungslehre, Schwerpunkt Westeuropa, Universität Regensburg, Universitätsstraße 31, 93053 Regensburg

Univ.-Prof. Dr., Heinz Fischer, Bundespräsident a. D.

Heinz Fischer wurde 1978 als Universitätsdozent für Politikwissenschaften an der Universität Innsbruck habilitiert, 1994 wurde er zum ordentlichen Universitätsprofessor ernannt. Von 2004 bis 2016 war er Bundespräsident der Republik Österreich. Davor war er Wissenschaftsminister und Nationalratsabgeordneter der SPÖ sowie Präsident beziehungsweise Zweiter Präsident des österreichischen Nationalrates. Heinz Fischer wurde bereits mit zahlreichen Ehren- und Verdienstzeichen im In- und Ausland ausgezeichnet. Ban Ki-moon Centre for Global Citizens, Veithgasse 9/6, 1030 Wien

Dr. iur., Nula Frei

Nula Frei ist Oberassistentin am Institut für Europarecht der Universität Freiburg i. Ue $(\mathrm{CH})$ und Lehrbeauftragte an der Universität Genf. Davor arbeitete sie als wissenschaftliche Assistentin am Zentrum für Migrationsrecht sowie am Schweizerischen Kompetenzzentrum für Menschenrechte der Universität Bern. Ihre Dissertation zur Umsetzung der völkerrechtlichen Verpflichtungen gegen Menschenhandel im Asylverfahren (Nomos/Stämpfli 2018) wurde 2019 mit dem Brigitte Schnegg Preis für Geschlechterforschung ausgezeichnet. Ihre Arbeitsgebiete sind das Verfassungs- und Verwaltungsrecht, Menschenrechtsschutz und Europarecht, mit einem Fokus auf Fragen der Demokratie, Migration, Gleichstellung sowie Datenschutz.

Institut für Europarecht, Universität Freiburg i. Ue., Avenue de Beauregard 11, 1700 Fribourg. Kontakt: nula.frei@unifr.ch

Dr. Dóra Frey, LL. M.

Dóra Frey ist wissenschaftliche Mitarbeiterin an der Andrássy Gyula Deutschsprachige Universität Budapest und Lehrbeauftragte an der Eeötvös Loránd Universität Budapest. Ihre Forschungsthemen umfassen den juristischen Hintergrund der Zwangsmigration nach dem Zweiten Weltkrieg in Ungarn, die Geschichte der Minderheiten- und Nationalitätenrechte in Ungarn sowie die ungarische Verfassungs- und Verwaltungsgeschichte. Andrássy Universität Budapest, Pollack Mihály tér 3, H-1088 Budapest. Kontakt: dora.frey@andrassyuni.hu 


\section{Prof. Dr. Francis Fukuyama}

Francis Fukuyama ist Olivier Nomellini Senior Fellow at the Freeman Spogli Institute for International Studies (FSI); Director of the Ford Dorsey Master's in International Policy; Research Affiliate at The Europe Center; Mosbacher Director of the Center on Democracy, Development, and the Rule of Law. He is also a professor by courtesy in the Department of Political Science. He was previously at the Paul H. Nitze School of Advanced International Studies (SAIS) of Johns Hopkins University, where he was the Bernard L. Schwartz Professor of International Political Economy and director of SAIS International Development program. Dr. Fukuyama has written widely on issues relating to questions concerning democratization and international political economy. Stanford University, Encina Hall, C140, 616 Jane Stanford Way, Stanford, CA 94305, USA

Mag., Jakob Gaigg, BA.

Jakob Gaigg ist Universitätsassistent/prae doc am Institut für Rechtsphilosophie der Universität Wien. Seine Forschungsschwerpunkte liegen im Bereich der Rechtsphilosophie sowie Rechtstheorie, der politischen Philosophie und politischen Theorie, insbesondere deutscher Idealismus. Die Arbeitsgebiete sind im Zusammenhang von Globalisierung, Recht und Demokratie angesiedelt. Zurzeit arbeitet er an der Fertigsstellung der Dissertation zum Thema „Demokratie, Grenzen und Betroffenheit“.

Institut für Rechtsphilosophie (Univ.-Prof.Dr.Alexander Somek), Rechtswissenschaftliche Fakultät, Universität Wien, Schenkenstraße 8-10, 1010 Wien. Kontakt: jakob.emanuel.gaigg@univie.ac.at

Ass. jur., Holger Grefrath, M.Jur. (Oxon.)

Holger Grefrath ist wissenschaftlicher Mitarbeiter am Lehrstuhl für Öffentliches Recht und Finanzrecht (Prof. Dr. Christian Waldhoff) an der Humboldt Universität Berlin. Seine Arbeitsgebiete sind Verfassungsrecht, Rechtstheorie, Verfassungs- und Rechtsgeschichte.

Lehrstuhl für Öffentliches Recht und Finanzrecht (Prof. Dr. Christian Waldhoff), Juristische Fakultät, Humboldt Universität zu Berlin, Unter den Linden 6, 10099 Berlin. Kontakt: holger.grefrath@rewi.hu-berlin.de

Dipl. sc. pol. Univ., Timo Greger, BA.

Timo Greger studierte Philosophie und Geschichte an der Ludwig-Maximilians-Universität München sowie Politikwissenschaft mit den Teilfächern Volkswirtschaftslehre und Verwaltungswissenschaften an der Hochschule für Politik in München. Gegenwärtig ist er wissenschaftlicher Mitarbeiter am Lehrstuhl für Philosophie und politische Theorie an der Philosophischen Fakultät der Ludwig-Maximilians-Universität München. Seine Arbeitsgebiete sind Politische Philosophie, insbesondere Liberalismus und Demokratie, Rechtsphilosophie, Bildungsphilosophie und Erziehungsethik sowie ausgewählte Fragestellungen der Moralphilosophie und Ethik. 
Lehrstuhl für Philosophie und politische Theorie (Prof. Dr. Dr. h. c. Julian Nida-Rümelin), Ludwig-Maximilians-Universität München, Geschwister-Scholl-Platz 1, 80539 München. Kontakt: timo.Greger@lrz.uni-muenchen.de

Prof., Mag. iur. rer. oec., Dr. iur., Lando Kirchmair

Lando Kirchmair vertritt die Professur für Nationales und Internationales Öffentliches Recht mit dem Schwerpunkt Kulturgüterschutz an der Universität der Bundeswehr München und ist Ko-Leiter des European Constitutional Court Network Projekts am Fachbereich Öffentliches Recht, Völker- und Europarecht an der Rechtswissenschaftlichen Fakultät der Universität Salzburg. Seine Arbeitsgebiete sind das Völker-, Europa-, und Öffentliche Recht sowie die Rechtsphilosophie und der Kulturgüterschutz. Institut für Öffentliches Recht und Völkerrecht sowie Institut für Kulturwissenschaften, Werner-Heisenberg-Weg 39, 85579 Neubiberg. Kontakt: lando.kirchmair@unibw.de

Dr.phil., Clara Maier, MA.

Clara Maier ist wissenschaftliche Mitarbeiterin am Lehrstuhl für Europäische Geschichte des 19. Jahrhunderts an der Humboldt-Universität zu Berlin. Ihre Forschungsinteressen sind Deutsche und spanische Verfassungsgeschichte im 19. und 20. Jahrhundert, Politische Theorie und Ideengeschichte, Geschichte von Demokratie und Staatlichkeit, und Historiographiegeschichte. Lehrstuhl für Europäische Geschichte des 19. Jahrhunderts, Humboldt-Universität zu Berlin, Friedrichstraße 191-193, 10117 Berlin, Kontakt: clara.maier@hu-berlin.de

\section{Melissa Muller}

Melissa Muller war US-amerikanische Fulbright Stipendiatin an der Universität Heidelberg. Sie studierte Philosophie, Politik und Wirtschaft am Claremont McKenna College. Während ihres Studiums absolvierte sie Praktika beim Office of the Counselor to the Chief Justice am U.S. Supreme Court und in verschiedenen Forschungsinstituten, wie dem Max-Planck-Institut für ausländisches öffentliches Recht und Völkerrecht, Bipartisan Policy Center und dem Global Public Policy Institute. Ihre Forschungsschwerpunkte liegen im Bereich des vergleichenden Verfassungsrechts, der Verfassungsidentität sowie des Verfassungspatriotismus.

Claremont McKenna College, California; 9140 Olson Ct. Pleasanton, CA 94588 USA

Dr. phil., Benjamin Schmid

Benjamin Schmid ist wissenschaftlicher Mitarbeiter an der Professur für Politische Theorie an der Universität der Bundeswehr München. Er promovierte zum Thema „Politisches Denken und Architektur im Mittelalter“ (Paderborn: Wilhelm Fink 2020). Schwerpunkte in Forschung und Lehre sind beispielsweise die Geschichte politischen Denkens, politische Ikonologie und das Verhältnis von Politik und Zeit. 
Professur für Politische Theorie (Prof. Dr. Dirk Lüddecke), Fakultät für Staats- und Sozialwissenschaften, Universität der Bundeswehr München, Werner-HeisenbergWeg 39, 85579 Neubiberg. Kontakt: benjamin.schmid@unibw.de

Dr. phil., Karsten Schubert, MA.

Karsten Schubert ist geschäftsführender Assistent/wissenschaftlicher Mitarbeiter an der Professur für Politische Theorie, Philosophie und Ideengeschichte der AlbertLudwigs-Universität Freiburg. Seine Arbeitsgebiete sind zeitgenössische kritische politische Theorie und Philosophie, Michel Foucault, Demokratietheorie, Rechtsphilosophie, queere und schwule Theorie und Anti-Rassismus. Zurzeit forscht er zur Schnittstelle von kritischer Rechtstheorie und intersektionaler gesellschaftskritischer Ethik. Zuvor promovierte er in Philosophie an der Universität Leipzig zum Thema „Freiheit als Kritik. Sozialphilosophie nach Foucault“ (Bielefeld: transcript 2018). Texte, Videos und aktuelle Infos auf www.karstenschubert.net.

Professur für Politische Philosophie, Theorie und Ideengeschichte, Universität Freiburg i. B., Rempartstr. 15, 79085 Freiburg. Kontakt: karsten.schubert@politik.uni-freiburg.de

Mag., Valerie Schwarzer, LL. B.

Valerie Schwarzer ist wissenschaftliche Mitarbeiterin an der Rechtswissenschaftlichen Fakultät der Paris Lodron Universität Salzburg, Fachbereich Öffentliches Recht, Völker- und Europarecht (Univ.-Prof. Dr. András Jakab, LL. M.). Zuvor hat sie an der Universität Wien und der Universität Salzburg Rechtswissenschaften und Recht und Wirtschaft studiert. Im Rahmen ihrer Dissertation forscht sie zum Thema des verfassungsrechtlichen Menschenbildes.

Fachbereich Öffentliches Recht, Völker- und Europarecht, Rechtswissenschaftliche Fakultät, Paris Lodron Universität Salzburg, Kapitelgasse 5-7, 5020 Salzburg. Kontakt: valerie.schwarzer@sbg.ac.at

Dr. jur., Berit Völzmann

Berit Völzmann ist Wissenschaftliche Mitarbeiterin und Habilitandin am Institut für Öffentliches Recht und Rechtsvergleichung bei Prof. Dr. Ute Sacksofsky M.P.A. (Harvard) an der Goethe-Universität Frankfurt am Main. Sie studierte Rechtswissenschaften in Greifswald und Köln. Sie promovierte zum Thema „Geschlechtsdiskriminierende Wirtschaftswerbung. Zur Rechtmäßigkeit eines Verbots geschlechtsdiskriminierender Werbung im UWG“ (Nomos 2014). Zu ihren Forschungsgebieten gehören vor allem das Verfassungsrecht, das Verwaltungsrecht und die Legal Gender Studies. Institut für Öffentliches Recht, Universität Frankfurt, Campus Westend, RuW o8, 60629 Frankfurt am Main. Kontakt: voelzmann@jur.uni-frankfurt.de 


\section{ARCHIV FÜR RECHTS- UND SOZIALPHILOSOPHIE - BEIHEFTE}

Herausgeben von der Internationalen Vereinigung für Rechts- und Sozialphilosophie (IVR). Die Bände 1-4 sind im Luchterhand-Fachverlag erschienen.

Franz Steiner Verlag

ISSN 0341-079x

83. Gralf-Peter Calliess /

Matthias Mahlmann (Hg.)

\section{Der Staat der Zukunft}

Vorträge der 9. Tagung des Jungen Forum Rechtsphilosophie in der Internationalen Vereinigung für Rechts- und Sozialphilosophie vom 27.-29. April 20or an der Freien Universität Berlin

2002. 226 S., kt.

ISBN 978-3-5I5-08048-4

84. Winfried Brugger / Görg Haverkate (Hg.)

Grenzen als Thema der Rechtsund Sozialphilosophie

Referate der Tagung der Deutschen Sektion der Internationalen Vereinigung für

Rechts- und Sozialphilosophie vom 22.-23. September 2000 in Heidelberg

2002. 2I8 S., kt.

ISBN 978-3-5I5-08042-2

85. Paricia Smith / Paolo Comanducci (Hg.)

Legal Philosophy: General Aspects

Theoretical Examinations and Practical Application. Proceedings of the $19^{\text {th }}$ World Congress of the International Association for Philosophy of Law and Social Philosophy in New York, $24^{\text {th }}-30^{\text {th }}$ June 1999

2002. I76 S., kt.

ISBN 978-3-5I5-08Ioo-9

86. Hirokazu Kawaguchi /

Kurt Seelmann (Hg.)

Rechtliche und ethische Fragen der Transplantationstechnologie in einem interkulturellen Vergleich 2003. I8o S., kt.

ISBN 978-3-5I5-08I32-0

87. Rolf Gröschner / Gerhard Haney (Hg.)

Die Bedeutung P. J. A. Feuerbachs (I755-I833) fürr die Gegenwart

Tagung der Deutschen Sektion der Internationalen Vereinigung für Rechts- und Sozialphilosophie vom I5.-I6. März 2002 in Jena

2003. 240 S., kt.

ISBN 978-3-5I5-08I93-I

88. Arend Soeteman (Hg.)

Pluralism and Law I
Justice. Proceedings of the $2 \mathrm{O}^{\text {th }}$ World Congress of the International Association for Philosophy of Law and Social Philosophy in Amsterdam, 200I 2003. 203 S., kt.

ISBN 978-3-5I5-08327-0

89. Arend Soeteman (Hg.)

Pluralism and Law II

State, Nation, Community, Civil Society.

Proceedings of the $2 \mathrm{O}^{\text {th }}$ World Congress of the International Association for Philosophy of Law and Social Philosophy in Amsterdam, 200I

2003. I93 S., kt.

ISBN 978-3-5I5-08362-I

90. Arend Soeteman (Hg.)

\section{Pluralism and Law III}

Global Problems. Proceedings of the $20^{\text {th }}$ World Congress of the International Association for Philosophy of Law and Social Philosophy in Amsterdam, 200I 2004. 2I7 S., kt.

ISBN 978-3-5I5-08446-8

9I. Arend Soeteman (Hg.)

\section{Pluralism and Law IV}

Legal Reasoning. Proceedings of the $20^{\text {th }}$ World Congress of the International Association for Philosophy of Law and Social Philosophy in Amsterdam, 200I 2004. I95 S., kt.

ISBN 978-3-5I5-08503-8

92. Christian Hiebaum / Peter Koller (Hg.)

Politische Ziele und juristische Argumentation

Symposium der Internationalen Vereinigung für Rechts- und Sozialphilosophie vom II.-I2. Oktober 2002 in Graz 2003. I42 S., kt.

ISBN 978-3-5I5-08284-6

93. Jan C. Joerden / Roland Wittmann (Hg.) Recht und Politik

Jahrestagung der Deutschen Sektion der Internationalen Vereinigung für Rechtsund Sozialphilosophie vom 26.-29. September 2002 in Frankfurt an der Oder 2004. I84 S., kt. ISBN 978-3-5I5-08458-I 
94. Philippe Mastronardi (Hg.)

Das Recht im Spannungsfeld

utilitaristischer und

deontologischer Ehtik

Vorträge der Tagung der Schweizer Sek-

tion der Internationalen Vereinigung für

Rechts- und Sozialphilosophie vom I5.-I6.

November 2002 in Luzern

2004. I70 S., kt.

ISBN 978-3-5I5-08366-9

95. Aleksander Peczenik (Hg.)

Justice

Proceedings of the $2 \mathrm{I}^{\text {st }}$ World Congress

of the International Association for Philoso-

phy of Law and Social Philosophy in Lund

(Sweden), $12^{\text {th }}-18^{\text {th }}$ August 2003

Volume I

2004. 2I8 S., kt.

ISBN 978-3-5I5-08483-3

96. Yasutomo Morigiwa / Fumihiko Ishiyama /

Tetsu Sakurai (Hg.)

Universal Minority Rights?

A Transnatioal Approach. Proceedings

of the $5^{\text {th }}$ Kobe Lectures. Tokyo and Kyoto,

December 1998

2004. I26 S., kt.

ISBN 978-3-5I5-08504-5

97. Svein Eng (Hg.)

Law and Practice

Proceedings of the $2 \mathrm{I}^{\text {st }}$ World Congress

of the International Association for Philoso-

phy of Law and Social Philosophy in Lund

(Sweden), $12^{\text {th }}-18^{\text {th }}$ August 2003

Volume 2

2005. 213 S., kt.

ISBN 978-3-5I5-08524-3

98. Kenneth Einar Himma (Hg.)

Law, Morality, and Legal Positivism

Proceedings of the $2 \mathrm{I}^{\mathrm{st}}$ World Congress of

the International Association for Philoso-

phy of Law and Social Philosophy in Lund

(Sweden), $12^{\text {th }}-18^{\text {th }}$ August 2003

Volume 3

2004. 183 S., kt.

ISBN 978-3-5I5-085I3-7

99. Günther Kreuzbauer /

Silvia Augeneder (Hg.)

Der Juristische Streit

Recht zwischen Rhetorik, Argumentation

und Dogmatik

2004. I66 S., kt.

ISBN 978-3-5I5-08480-2

Ioo. Ulfrid Neumann / Winfried Hassemer /

Ulrich Schroth (Hg.)

Verantwortetes Recht
Die Rechtsphilosophie Arthur Kaufmanns.

Tagung vom Io.-II. Mai 2003 in München

2005. I88 S., kt.

ISBN 978-3-5I5-08580-9

IoI. Kurt Seelmann (Hg.)

Menschenwürde als Rechtsbegriff

Tagung der Schweizer Sektion der

Internationalen Vereinigung für Rechts-

und Sozialphilosophie vom 25.-28. Juni

2003 in Basel

2004. 175 S., kt.

ISBN 978-3-5I5-0859I-5

I02. Zenon Bankowski (Hg.)

\section{Epistemology and Ontology}

Proceedings of the $2 \mathrm{I}^{\text {st }}$ World Congress

of the International Association for Philoso-

phy of Law and Social Philosophy in Lund

(Sweden), $12^{\text {th }}-18^{\text {th }}$ August 2003

Volume 4

2005. 195 S., kt.

ISBN 978-3-5I5-08707-0

I03. Carsten Bäcker / Stefan Baufeld (Hg.)

Objektivität und Flexibilität

im Recht

Tagungen des Jungen Forums Rechts-

philosophie in der Internationalen Vereini-

gung für Rechts- und Sozialphilosophie im

September 2004 in Kiel und im April 2005

in Hagen

2005. 213 S., kt.

ISBN 978-3-5I5-08743-8

I04. Robert Alexy (Hg.)

Juristische Grundlagenforschung

Tagung der Deutschen Sektion der Internationalen Vereinigung für Rechts- und Sozialphilosophie vom 23.-25. September 2004 in Kiel

2005. 25I S., kt.

ISBN 978-3-515-08640-0

I05. Philippe Mastronardi / Denis Taubert (Hg.)

Staats- und Verfassungstheorie im Spannungsfeld der Disziplinen

Tagung der Schweizerischen Vereinigung

für Rechts- und Sozialphilosophie vom

I2.-I3. November 2004 an der Universität

St. Gallen

2006. 255 S., kt.

ISBN 978-3-5I5-0885I-O

I06. José Juan Moreso (Hg.)

Legal Theory / Teoría del derecho

Legal Positivism and Conceptual Analysis /

Positivismo juridico y análisis conceptual.

Proceedings of the $22^{\text {nd }}$ World Congress

of the International Association for

Philosophy of Law and Social Philosophy 
in Granada, 2005

Volume I

2007. 263 S., kt.

ISBN 978-3-5I5-089I0-4

I07. José Rubio Carrecedo (Hg.)

Political Philosophy /

Filosofía política

New Proposals for New Questions / Nuevas propuestas para nuevas cuestiones. Proceedings of the $22^{\text {nd }}$ World Congress of the International Association for Philosophy of Law and Social Philosophy in Granada, 2005

Volume 2

2007. 239 S., kt.

ISBN 978-3-5I5-089II-I

I08. Andrés Ollero (Hg.)

Human Rights and Ethics /

Derechos humanos y Ética

Proceedings of the $22^{\text {nd }}$ World Congress

of the International Association for

Philosophy of Law and Social Philosophy

in Granada, 2005

Volume 3

2007. 323 S., kt.

ISBN 978-3-5I5-089I2-8

I09. Nicolás López Calera (Hg.)

Globalization, Law and Economy /

Globalización, Derecho y Economía

Proceedings of the $22^{\text {nd }}$ World Congress

of the International Association for

Philosophy of Law and Social Philosophy

in Granada, 2005

Volume 4

2007. 32I S., kt

ISBN 978-3-5I5-089I3-5

IIo. Josep Aguiló-Regla (Hg.)

Logic, Argumentation and

Interpretation / Lógica,

Argumentación e Interpretación

Proceedings of the $22^{\text {nd }}$ World Congress of the International Association for

Philosophy of Law and Social Philosophy

in Granada, 2005

Volume 5

2007. 206 S., kt.

ISBN 978-3-5I5-089I4-2

III. Marcel Senn / Dániel Puskás (Hg.)

Gehirnforschung und rechtliche Verantwortung

Fachtagung der Scheizerischen Vereinigung für Rechts- und Sozialphilosophie vom 19.-20. Mai 2006 an der Universität Bern 2006. I7I S., kt.

ISBN 978-3-5I5-08963-0
II2. Annette Brockmöller (Hg.)

Hundert Jahre Archiv für Rechtsund Sozialphilosophie (I907-2007)

Auswahl I4 bedeutender Aufsätze

von Kelsen, Radbruch, Luhmann u. a.

2007. 330 S., kt.

ISBN 978-3-5I5-09I00-8

II3. Horst Dreier / Eric Hilgendorf (Hg.)

Kulturelle Identität als Grund

und Grenze des Rechts

Akten der Tagung der Internationalen Vereinigung für Rechts- und Sozialphilosophie vom 28.-30. September 2006 in Würzburg 2008. 374 S., geb.

ISBN 978-3-5I5-09I0I-5

II4. Jochen Bung / Brian Valerius /

Sascha Ziemann (Hg.)

Normativität und Rechtskritik

Tagungen des Jungen Forums Rechts-

philosophie in der Internationalen Vereinigung für Rechts- und Sozialphilosophie im September 2006 in Würzburg und im März 2007 in Frankfurt am Main

2007. 269 S., kt.

ISBN 978-3-5I5-09I30-5

II5. Marcel Senn / Dániel Puskás (Hg.)

Rechtswissenschaft

als Kulturwissenschaft?

Kongress der Schweizerischen Vereinigung für Rechts- und Sozialphilosophie vom I5.-I6. Juni 2007 an der Universität Zürich 2007. $220 \mathrm{~S}$., kt.

ISBN 978-3-5I5-09I49-7

II6. Annette Brockmöller /

Eric Hilgendorf (Hg.)

Rechtsphilosophie

im 2o. Jahrhundert

Ioo Jahre Archiv für Rechts-

und Sozialphilosophie

2009. 207 S., kt.

ISBN 978-3-515-09285-2

II7. Marcel Senn / Barbara Fritschi (Hg.)

Rechtswissenschaft

und Hermeneutik

Kongress der Schweizerischen Vereinigung für Rechts- und Sozialphilosophie vom I6.-I7. Mai 2008 an der Universität Zürich 2009. 258 S., kt. ISBN 978-3-5I5-09I55-8

II8. Bart C. Labuschagne / Ari M. Solon (Hg.)

Religion and State

From separation to cooperation?

Proceedings of the Special Workshop

"Legal-philosophical reflections for a

de-secularized world" held at the $23^{\text {rd }}$ 
World Congress of the International Association for Philosophy of Law and Social Philosophy in Kraków, 2007

2009. 209 S., kt.

ISBN 978-3-5I5-09368-2

II9. Martin Borowski (Hg.)

On the Nature of Legal Principles

Proceedings of the Special Workshop

"The Principles Theory" held at the $23^{\text {rd }}$

World Congress of the International

Association for Philosophy of Law and

Social Philosophy in Kraków, 2007

20I0. I82 S., kt.

ISBN 978-3-5I5-09608-9

I20. Friedrich Toepel (Hg.)

Free Will in Criminal Law

and Procedure

Proceedings of the $23^{\text {rd }}$ and $24^{\text {th }}$ World

Congress of the International Association

for Philosophy of Law and Social Philoso-

phy in Kraków, 2007, and in Beijing, 2009

20IO. I22 S., kt.

ISBN 978-3-5I5-09320-o

I2I. Marcel Senn / Bénédict Winiger /

Barbara Fritschi / Philippe Avramov (Hg.)

Recht und Globalisierung /

Droit et Mondialisation

Kongress der Schweizerischen Vereinigung für Rechts- und Sozialphilosophie, I5.-I6.

Mai 2009, Universität Genf / Congrès de

l'Association Suisse de Philosophie du Droit et de Philosophie Sociale, I5-I6 mai 2009, Université de Genève

20I0. I96 S., kt.

ISBN 978-3-5I5-09673-7

I22. Imer B. Flores / Uygur Gülriz (Hg.)

Alternative Methods in the

Education of Philosophy of Law and

the Importance of Legal Philosophy in the Legal Education

Proceedings of the $23^{\text {rd }}$ World Congress of the International Associaction for Philosophy of Law and Social Philosophy "Law and Legal Cultures in the 2Ist Century: Diversity and Unity" in Kraków, 2007

20I0. II4 S., kt.

ISBN 978-3-515-09695-9

I23. Sascha Ziemann

Archiv für Rechts- und

Sozialphilosophie:

Bibliographie und Dokumentation

(1907-2009)

20Io. 434 S., kt.

ISBN 978-3-5I5-097I9-2
I24. Jan-Reinard Sieckmann (Hg.)

Legal Reasoning:

The Methods of Balancing

Proceedings of the Special Workshop

"Legal Reasoning: The Methods of

Balancing" held at the $24^{\text {th }}$ World Congress

of the International Association for

Philosophy of Law and Social Philosophy

(IVR), Beijing, 2009

20I0. 205 S., kt.

ISBN 978-3-5I5-09723-9

I25. Edward Schramm / Wibke Frey / Lorenz

Kähler / Sabine Müller-Mall / Friederike

Wapler (Hg.)

\section{Konflikte im Recht -}

Recht der Konflikte

Tagungen des Jungen Forums Rechtsphilosophie in der Internationalen Ver-

einigung für Rechts- und Sozialphilosophie in Tübingen und Göttingen

20I0. 308 S., kt.

ISBN 978-3-5I5-09729-I

I26. Kristian Kühl (Hg.)

Zur Kompetenz der Rechts-

philosophie in Rechtsfragen

Tagung der Deutschen Sektion der

Internationalen Vereinigung für

Rechts- und Sozialphilosophie

vom 24.-26. September 2008 in Tübingen

20II. I40 S., kt.

ISBN 978-3-5I5-098I6-8

I27. Stephan Kirste / Anne van Aaken / Michael

Anderheiden / Pasquale Policastro (Hg.)

Interdisciplinary Research in Jurisprudence and Constitutionalism

20I2. 267 S. mit 2 Abb. und 2 Tab., kt.

ISBN 978-3-5I5-0994I-7

I28. Stephan Ast / Julia Hänni / Klaus Mathis /

Benno Zabel (Hg.)

Gleichheit und Universalität

Tagungen des Jungen Forums Rechtsphilosophie (JFR) in der Internationalen Vereinigung für Rechts- und Sozialphilosophie (IVR) im September 2oro in Halle (Saale) und im Februar 20II in Luzern

20I2. 3I5 S., kt.

ISBN 978-3-515-I0067-0

I29. Bénédict Winiger / Matthias Mahlmann / Philippe Avramov / Peter Gailhofer (Hg.)

Recht und Verantwortung /

\section{Droit et responsabilité}

Kongress der Schweizerischen Vereinigung

für Rechts- und Sozialphilosophie,

II.-I2. Juni 20Io, Universität Zürich /

Congrès de l'Association Suisse de Philoso- 
phie du Droit et de Philosophie Sociale, II-I2 juin 20Io, Université de Zurich

20I2. $206 \mathrm{~S}$. mit $6 \mathrm{Abb}$., kt.

ISBN 978-3-5I5-I0o66-3

I30. Thomas Bustamante / Oche Onazi (Hg.)

Global Harmony

and the Rule of Law

Proceedings of the $24^{\text {th }}$ World Congress of the International Association for Philosophy of Law and Social Philosophy, Beijing, 2009. Vol. I

20I2. I33 S., kt.

ISBN 978-3-5I5-I0o8I-6

I3I. Thomas Bustamante / Oche Onazi (Hg.)

Human Rights, Language and Law

Proceedings of the $24^{\text {th }}$ World Congress of the International Association for Philosophy of Law and Social Philosophy, Beijing, 2009. Vol. 2

20I2. I92 S., kt.

ISBN 978-3-5I5-I0o82-3

I32. Yasutomo Morigiwa / Hirohide Takikawa

(Hg.)

Judicial Minimalism -

For and Against

Proceedings of the $9^{\text {th }}$ Kobe Lectures.

Tokyo, Nagoya, and Kyoto, June 2008

20I2. 99 S., kt.

ISBN 978-3-5I5-IOI36-3

I33. Thomas Bustamante / Carlos Bernal Pulido (Hg.)

On the Philosophy of Precedent

Proceedings of the $24^{\text {th }}$ World Congress of the International Association for Philosophy of Law and Social Philosophy, Beijing, 2009

Volume 3

20I2. I44 S., kt.

ISBN 978-3-5I5-IOI50-9

I34. Matthias Kaufmann / Joachim

Renzikowski (Hg.)

Zurechnung und Verantwortung

Tagung der Deutschen Sektion der Internationalen Vereinigung für Rechts- und

Sozialphilosophie vom 22.-24. September 2oro in Halle (Saale)

20I2. I84 S., kt.

ISBN 978-3-5I5-IOI80-6

I35. Carsten Bäcker / Sascha Ziemann (Hg.)

Junge Rechtsphilosophie

20I2. 2 I4 S., kt.

ISBN 978-3-5I5-IO268-I

I36. Ulfrid Neumann / Klaus Günther /

Lorenz Schulz (Hg.)

\section{Law, Science, Technology}

Plenary lectures presented at the $25^{\text {th }}$ World Congress of the International Association for Philosophy of Law and Social Philosophy, Frankfurt am Main, 20II

20I2. I73 S., kt.

ISBN 978-3-5I5-IO328-2

I37. Winfried Brugger / Stephan Kirste (Hg.)

\section{Human Dignity}

as a Foundation of Law

Proceedings of the Special Workshop held at the $24^{\text {th }}$ World Congress of the International Association for Philosophy of Law and Social Philosophy in Beijing, 2009

20I3. 267 S., kt.

ISBN 978-3-5I5-IO440-I

I38. Philippe Avramov / Mike Bacher / Paolo Becchi / Bénédict Winiger (Hg.)

Ethik und Recht in der Bioethik / Ethique et Droit en matière de Bioéthique

Kongress der Schweizerischen Vereinigung für Rechts- und Sozialphilosophie, II.-I2. Mai 20I2, Universität Luzern / Congrès de l'Association Suisse de Philosophie du Droit et de Philosophie Sociale, II-I2 mai 20I2, Université de Lucerne

20I3. 226 S., kt.

ISBN 978-3-5I5-I0436-4

I39. Tetsu Sakurai / Makoto Usami (Hg.)

Human Rights and Global Justice

The Io $^{\text {th }}$ Kobe Lectures, July 20 II

20I4. I67 S., kt.

ISBN 978-3-5I5-I0489-O

I40. Bernhard Jakl / Beatrice Brunhöber / Ariane Grieser / Juliane Ottmann /

Tim Wihl (Hg.)

Recht und Frieden - Wozu Recht?

Tagungen des Jungen Forums Rechtsphilosophie (JFR) in der Internationalen Vereinigung für Rechts- und Sozialphilosophie (IVR) im September 2012 in Münster und im April 2013 in Berlin 2014. 206 S. mit 3 Abb., kt. ISBN 978-3-5I5-I0806-5

I4I. Axel Tschentscher / Caroline Lehner / Matthias Mahlmann / Anne Kühler (Hg.)

Soziale Gerechtigkeit heute Kongress der Schweizerischen Vereinigung für Rechts- und Sozialphilosophie, 7. Juni 20I3, Universität Bern

2015. I39 S., kt.

ISBN 978-3-5I5-I0907-9 
142. Daniela Demko / Kurt Seelmann /

Paolo Becchi (Hg.)

Würde und Autonomie

Fachtagung der Schweizerischen Vereinigung für Rechts- und Sozialphilosophie, 24.-25. April 20I3, Landgut Castelen, Augst 20I5. 2I6 S., kt.

ISBN 978-3-5I5-I0949-9

I43. Jean-Christophe Merle / Alexandre T. G.

Trivisonno (Hg.)

\section{Kant's Theory of Law}

Proceedings of the Special Workshop

"Kant's Concept of Law" held at the $26^{\text {th }}$

World Congress of the International

Association for Philosophy of Law and

Social Philosophy in Belo Horizonte, 2013

20I5. I38 S., kt.

ISBN 978-3-5I5-IIO37-2

I44. Júlio Aguiar de Oliveira / Stanley L. Paulson / Alexandre T. G. Trivisonno (Hg.)

\section{Alexy's Theory of Law}

Proceedings of the Special Workshop

"Alexy's Theory of Law" held at the $26^{\text {th }}$

World Congress of the International

Association for Philosophy of Law and

Social Philosophy in Belo Horizonte, 2013

20I5. I87 S., kt.

ISBN 978-3-5I5-IIO43-3

I45. Annette Brockmöller / Stephan Kirste /

Ulfrid Neumann (Hg.)

Wert und Wahrheit

in der Rechtswissenschaft

20I5. II3 S., kt.

ISBN 978-3-5I5-IIO53-2

I46. Marcelo Campos Galuppo / Mônica Sette Lopes / Karine Salgado / Thomas Bustamante / Lucas Gontijo (Hg.)

Human Rights, Rule of Law and the Contemporary Social Challenges in Complex Societies

Proceedings of the $26^{\text {th }}$ World Congress of the International Association for Philosophy of Law and Social Philosophy in Belo Horizonte, 2013

20I5. I55 S. mit 2 Abb., kt.

ISBN 978-3-5I5-III30-o

I47. Paul Tiedemann (Hg.)

\section{Right to Identity}

Proceedings of the Special Workshop "Right to Identity" held at the $27^{\text {th }}$ World Congress of the International Association for Philosophy of Law and Social Philosophy in Washington DC, 2015

20I6. I85 S., kt.

ISBN 978-3-5I5-II244-4
I48. Hajime Yoshino / Andrés Santacoloma Santacoloma / Gonzalo Villa Rosas (Hg.) Truth and Objectivity in Law and Morals

Proceedings of the Special Workshop Held at the 26th World Congress of the International Association for Philosophy of Law and Social Philosophy in Belo Horizonte, 2013 20I6. I58 S., kt.

ISBN 978-3-5I5-II26o-4

I49. Alain Papaux / Simone Zurbuchen (Hg.)

Philosophy, Law and Environmental Crisis / Philosophie, droit et crise environnementale

Workshop of the Swiss Society for Philosophy of Law and Social Philosophy, September I2-I3, 20I4, Swiss Institute of Comparative Law, Lausanne / Congrès de l'Association Suisse de Philosophie du Droit et de Philosophie Sociale, I2-I3 septembre 2014

20I6. I53 S. mit 2 Tab., kt.

ISBN 978-3-5I5-II387-8

I50. Markus Abraham / Till Zimmermann /

Sabrina Zucca-Soest (Hg.)

Vorbedingungen des Rechts

Tagungen des Jungen Forums Rechtsphilosophie (JFR) in der Internationalen Vereinigung für Rechts- und Sozialphilosophie (IVR) im September 20I4 in Passau und im April 2015 in Hamburg 2016. 23I S., kt. ISBN 978-3-5I5-II389-2

I5I. André Ferreira Leite de Paula / Andrés Santacoloma Santacoloma / Gonzalo Villa Rosas (Hg.)

Truth and Objectivity in Law and Morals II

Proceedings of the Second Special Workshop held at the $27^{\text {th }}$ World Congress of the International Association for Philosophy of Law and Social Philosophy in Washington D.C., 2015 20I6. 2Io S. mit 4 Abb., kt. ISBN 978-3-5I5-II484-4

I52. Kosuke Nasu (Hg.)

Insights about the Nature of Law from History

The $\mathrm{II}^{\text {th }}$ Kobe Lecture, 2014

20I7. I46 S., kt.

ISBN 978-3-5I5-II570-4

I53. Jochen Bung / Armin Engländer (Hg.)

Souveränität, Transstaatlichkeit und Weltverfassung

Tagung der Internationalen Vereinigung 
für Rechts- und Sozialphilosophie (IVR)

im September 2014 in Passau

20I7. I33 S., kt.

ISBN 978-3-5I5-II620-6

I54. Bénédict Winiger / Matthias Mahlmann /

Sophie Clément / Anne Kühler (Hg.)

La propriété et ses limites /

Das Eigentum und seine Grenzen

Congrès de l'Association Suisse de Philosophie du Droit et de Philosophie Sociale, 26 septembre 2015, Université de Genève / Kongress der Schweizerischen Vereinigung für Rechts- und Sozialphilosophie, 26. September 20I5, Universität Genf 20I7. 274 S., kt.

ISBN 978-3-5I5-II688-6

I55. Gralf-Peter Calliess / Lorenz Kähler (Hg.) Theorien im Recht - Theorien über das Recht

Tagung der Internationalen Vereinigung für Rechts- und Sozialphilosophie (IVR) im September 2016 in Bremen

20I8. 224 S., kt.

ISBN 978-3-5I5-I2IO2-6

I56. Dennis-Kenji Kipker / Matthias Kopp /

Peter Wiersbinski / Jan-Christoph

Marschelke / Falk Hamann / Martin

Weichold (Hg.)

Der normative Druck des

Faktischen: Technologische Heraus-

forderungen des Rechts und seine

Fundierung in sozialer Praxis

Tagungen des Jungen Forums Rechtsphilosophie (JFR) in der Internationalen Vereinigung für Rechts- und Sozialphilosophie (IVR) im September 2016 in Bremen und im September 2017 in Regensburg 20I9. 26I S., geb.

ISBN 978-3-5I5-I2I96-5

I57. Miguel Nogueira de Brito / Rachel Herdy / Giovanni Damele / Pedro Moniz Lopes / Jorge Silva Sampaio (Hg.)

The Role of Legal Argumentation and Human Dignity in Constitutional Courts

Proceedings of the Special Workshops Held at the $28^{\text {th }}$ World Congress of the International Association for Philosophy of Law and Social Philosophy in Lisbon, 2017 20I9. 239 S. mit 3 Abb., kt.

ISBN 978-3-5I5-I2235-I

I58. André Ferreira Leite de Paula /

Andrés Santacoloma Santacoloma

Law and Morals

Proceedings of the Special Workshop held at the $28^{\text {th }}$ World Congress of the International Association for Philosophy of Law and Social Philosophy in Lisbon, Portugal, 2017

20I9. 377 S., geb.

ISBN 978-3-5I5-I2278-8

I59. Daniel Kipfer / Anne Kühler (Hg.)

Justizberichterstattung in der direkten Demokratie

Kongress der Schweizerischen Vereinigung für Rechts- und Sozialphilosophie vom 22.-23. Juni 2017 in Bellinzona 20I9. I70S., geb.

ISBN 978-3-5I5-I2368-6

I6o. Joshua Kassner /Colin Starger (Hg.)

The Value and Purpose of Law

Essays in Honor of M. N. S. Sellers

20I9. $262 \mathrm{~S}$. mit I Abb., geb.

ISBN 978-3-5I5-I2460-7

I6I. Hirohide Takikawa (Hg.)

The Rule of Law and Democracy

The $12^{\text {th }}$ Kobe Lecture and the Ist IVR Japan International Conference, Kyoto, July 2018 2020. 229 S. mit 3 Abb., geb.

ISBN 978-3-5I5-I2482-9

162. Ruwen Fritsche / Philipp Gisbertz / Philipp-Alexander Hirsch / Franziska Bantlin / Rodrigo Cadore / David Freudenberg / Sabine Klostermann / Laura Wallenfels (Hg.)

Unsicherheiten des Rechts.

Von den sicherheitspolitischen

Herausforderungen für die

freiheitliche Gesellschaft bis zu den Fehlern und Irrtiimern in Recht und Rechtswissenschaft

Tagungen des Jungen Forums Rechtsphilosophie (JFR) in der Internationalen Vereinigung für Rechts- und Sozialphilosophie (IVR) im April 2018 in Göttingen und im September 2018 in Freiburg 2020. 338 S., geb.

ISBN 978-3-5I5-I256I-I

I63. Matthias Jestaedt / Ralf Poscher / Jörg Kammerhofer (Hg.)

Die Reine Rechtslehre auf dem Prüfstand / Hans Kelsen's Pure Theory of Law: Conceptions and Misconceptions

Tagung der Deutschen Sektion der Internationalen Vereinigung für Rechts- und Sozialphilosophie vom 27.-29. September 2018 in Freiburg im Breisgau 2020. 427 S. mit 8 Abb., geb. ISBN 978-3-5I5-I2568-O 
Der demokratische Rechtsstaat ist im 21. Jahrhundert ins Wanken geraten keineswegs nur in Europa. Entwicklungen wie beispielsweise in den USA und in Brasilien zeugen von der globalen Tragweite dieses Phänomens. Auf Grund der Vielzahl besorgniserregender Ereignisse ist es von eminenter Bedeutung, diese Krise zu analysieren. Wie kann den Angriffen auf die Demokratie begegnet werden? Stehen uns internationale oder supranationale Mittel zur Bewältigung zur Verfügung? Wie können Antworten aussehen, wenn der freiheitliche Rechtsstaat von Voraussetzungen lebt, die er um seiner Freiheitlichkeit willen nicht (mehr) selbst garantieren kann?

Die Autorinnen und Autoren setzen sich mit der historischen Dimension der Thematik auseinander und nehmen Gegenwartsanalysen vor, die auf konkrete Auswirkungen und zeitnah drohende Konsequenzen des Phänomens eingehen. Insbesondere wird die Verbindung von Rechtsstaat und Demokratie beleuchtet: Kann es eine Demokratie ohne Rechtsstaat oder den Rechtsstaat ohne Demokratie geben? 